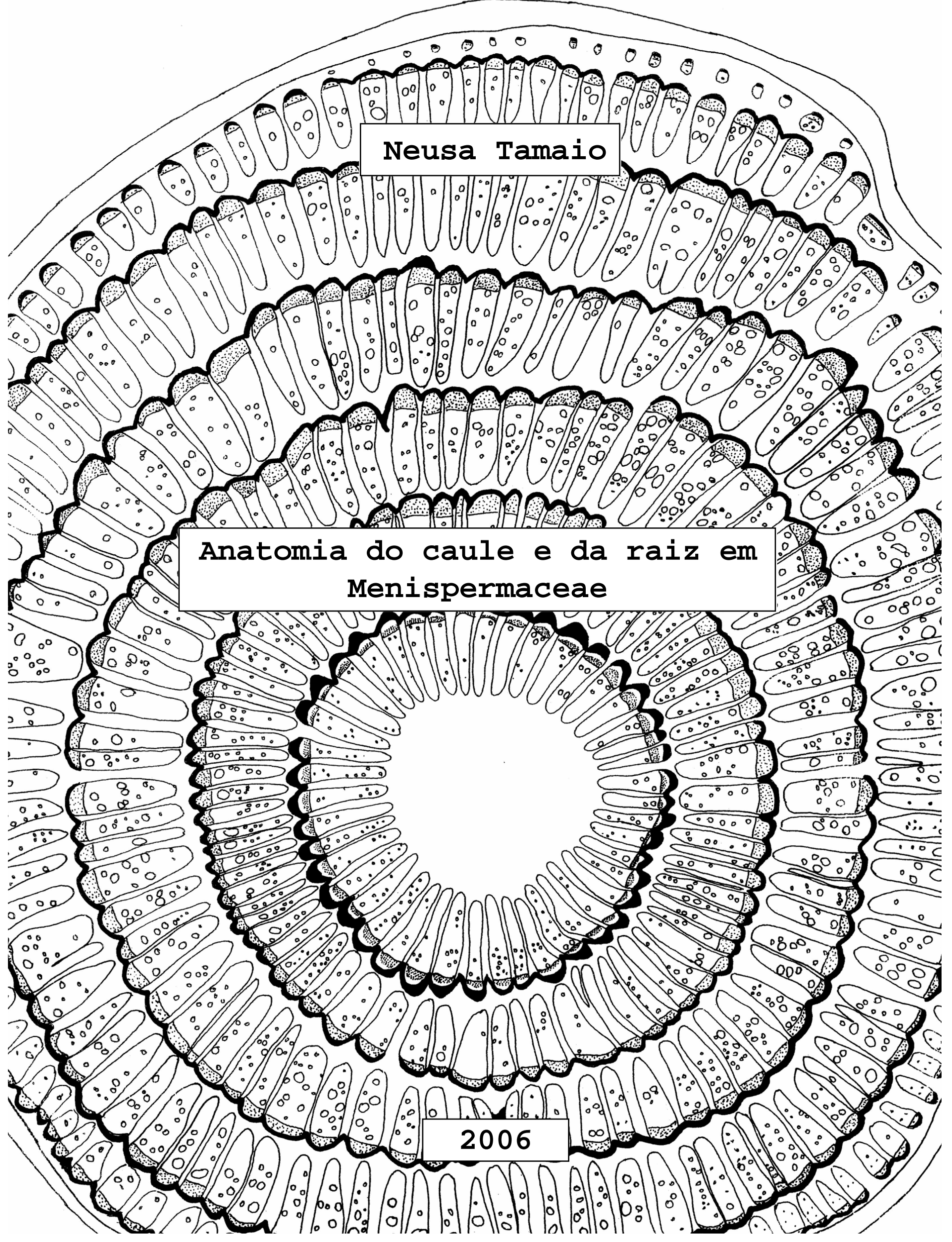


Neusa Tamaio

\section{Anatomia do caule e da raiz em Menispermaceae}

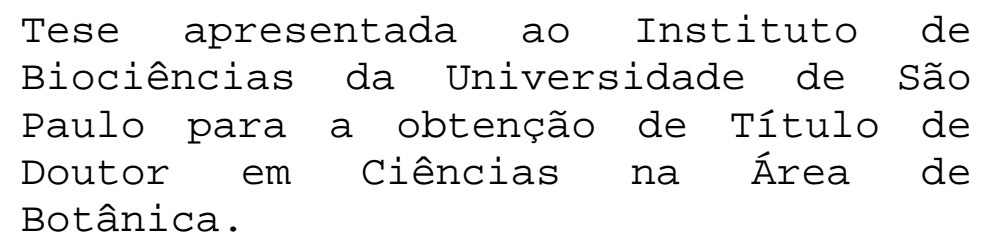

Orientadora: Dra. Veronica Angyalossy

São Paulo

2006 
Tamaio, N.

Anatomia do caule e da raiz em

Menispermaceae

Número de páginas: 165

Tese (Doutorado) - Instituto de Biociências da Universidade de São Paulo. Departamento de Botânica.

1. Menispermaceae. 2. Trepadeira herbácea. 3. Liana. 4. Arbusto. 5. Anatomia do caule. 6. Anatomia da raiz. 7. Câmbios sucessivos. Universidade de São Paulo. Instituto de Biociências. Departamento de Botânica.

Comissão julgadora

Prof(a). Dr(a).

Prof(a). Dr(a).

Prof(a). Dr(a).

Prof(a). Dr(a).

Prof. Dra. Veronica Angyalossy 


\section{The trees}

There is unrest in the forest, There is trouble with the trees, For the maples want more sunlight And the oaks ignore their pleas.

The trouble with the maples,

(And they're quite convinced the 're right)

They say the oaks are just too lofty

And they grab up all the light.

But the oaks can't help their feelings

If they like the way they're made.

And they wonder why the maples

Can't be happy in their shade.

There is trouble in the forest,

And the creatures all have fled,

As the maples scream 'Oppression'

And the oaks, just shake their heads

So the maples formed a union

And demanded equal rights.

"The oaks are just too greedy;

We will make them give us light."

Now there's no more oak oppression,

For they passed a noble law,

And the trees are all kept equal

By hatchet, axe, and saw.

Neil Peart - Rush

\section{Ensinamento}

Minha mãe achava estudo

A coisa mais fina do mundo.

Não é.

A coisa mais fina do mundo é o sentimento. Aquele dia de noite, o pai fazendo serão, Ela falou comigo:

"Coitado, até essa hora no serviço pesado".

Arrumou pão e café, deixou tacho no fogo com água quente. Não me falou em amor. Essa palavra de luxo.

Adélia Prado

E uma mulher que carregava o filho nos braços disse: "Fala-nos dos filhos". E ele disse: "Vossos filhos não são vossos filhos. São os filhos e as filhas

da ânsia da vida por si mesma. Vêm através de vós, mas não de vós. Embora vivem convosco, não vos pertencem... Vós sois os arcos dos quais vossos filhos são arremessados como flechas vivas. O Arqueiro mira o alvo na senda do infinito e vos estica com toda a Sua força para que Suas flechas se projetem, rápidas e para longe. Que vosso encurvamento na mão do Arqueiro seja vossa alegria: pois assim como Ele ama a flecha que voa, ama também o arco que permanece estável". 


\section{AGRADECIMENTOS}

Uma tese de doutorado depende de uma série de fatores, e principalmente de pessoas - acadêmicas ou não - que conspirem a seu favor. Portanto, os meus agradecimentos são destinados às pessoas envolvidas em todas as etapas da minha vida durante o período de estudo e desenvolvimento desta tese. Então, agradeço:

- À minha amiga e orientadora, Veronica, por TUDo, especialmente pela confiança nas potencialidades de sua aluna.

- Ao Departamento de Botânica (IB), USP, pelo oferecimento do curso.

- Ao Instituto de Pesquisas Jardim Botânico do Rio de Janeiro por meio do Laboratório de Botânica Estrutural, onde a parte técnica desta tese foi desenvolvida.

- Ao Pablo, atual coordenador do Programa Mata Atlântica, e à coordenadora anterior, Rejan, pelo apoio.

- Aos colegas do Programa Mata Atlântica, no qual me insiro.

- A toda equipe do Laboratório de Botânica Estrutural do Jardim Botânico do Rio de Janeiro, e à equipe de pesquisadores: André, Cecília, Claudia, Conceição, Karen e Osnir. Aos técnicos: Elaine, Rogério, Monique e Rachel. Aos ex-técnicos: Paulo Rogério e Tatiane.

- Ao Laboratório de Anatomia do Departamento de Botânica da USP por meio da Gisele, a técnica responsável, pela simpatia e ajuda em alguns momentos.

- Ao taxonomista João Marcelo Alvarenga Braga por sua ajuda fundamental, fornecendo bibliografias, identificando e principalmente coletando material de Menispermaceae.

- À ADERE (Associação para o Desenvolvimento e Recuperação do Excepcional) pela acolhida, pelo fornecimento de material e pela disposição em ajudar da diretora Soeni e a todos os "aprendizes" que confeccionam os lindos objetos com os caules de "cipós".

- À Monique, no começo, minha estagiária, agora também minha amiga. Colaborou em vários momentos de forma voluntária a esta tese. 
- À minha co-orientanda Elaine Zózimo pelo seu entusiasmo com os estudos em Combretaceae, pela alegria e disposição em ajudar.

- Ao amigão Antonio pela amizade singular e por ter atendido ao meu pedido de socorro no finalzinho. Com sua habilidade, ele processou o material mais difícil.

- À Olivia, estagiária voluntária, pelos dois anos e meio de trabalho, simpatia e ajuda também nesta tese.

- Ao Robson, aluno voluntário de iniciação científica, por me dar a chance de sua orientação e pela convivência calma e prazerosa.

- Aos professores Gregório, Nanuza e Edenise pelas boas sugestões no meu exame de qualificação.

- À Adriana, Érika, Marli, Marina e ao Marcelo por dividirem o tempo da Veronica comigo.

- Ao professor Ricardo Vieira pelo incentivo, pela confiança e por sua alegria italiana.

- À Genise pela amizade e pelas parcerias com as Sapindaceae.

- Ao Rubens por ter socorrido com muita paciência a sua "obsessora" na parte estatística.

- À Dulce pela imensa ajuda nos assuntos de estatística.

- Ao Ricardo, (laboratório de sementes - JBRJ) que com boa vontade me acompanhou em algumas excursões, conseguindo acessar ramos altos.

- Ao Paulo Ormindo pelas ilustrações e pelo bom humor.

- Ao Leandro Cardoso pela solicitude em coletar algumas espécies de Menispermaceae.

- Ao Marcelo Pace, pelo auxílio, sempre tão gentil.

- Aos funcionários do departamento de botânica da USP, em especial ao "brother" Norberto, pela pronta disposição em ajudar.

- Aos funcionários da secretaria de pós-graduação do IB-USP, em especial, ao Helder, pela ajuda em vários momentos.

- Ao Rosemberg e Renato pelo suporte técnico em assuntos de computação .

- Às secretárias Ana Marmelo, Ana Mathias e Thania pelo suporte técnico e pela boa vontade. 
- Aos funcionários da Biblioteca do Instituto de Pesquisas Jardim Botânico do Rio de Janeiro, em especial ao Miltom, pelas inúmeras ajudas na busca de bibliografia.

- À Kátia pela simpatia e ajuda com as xerocópias.

- À Vera Ayres pela revisão profissional desta tese.

- Às mães da lista "Mães Empoderadas" e seus filhos, com as quais aprendi a refletir e a buscar o melhor para o meu filho; agradeço em especial à Ana Paula (Laura); Ana Paula (Pedro); Ana Claudia (Ana Cecília); Anacris (Cecília e André); dinda Daniela Brito; Diana (Artur e Natália); Eleonora (Letícia); Elizabeth (Ila); Fernanda (Gabriel), Flavia Oliveira (Luiza); Jacqueline (Daniella e Davi); Malu (Rafael); Mônica (Pablo e Hugo); Michelle (Renan); Renata (Maiara); Renata Rose (Téo); Silvia (Carina e Geovanna); Socorro (Mário e Juliano); Thania (Léo); Tricia (Thaís).

- Ao Jardim Michaelis do Rio de Janeiro por oferecer um serviço diferenciado ao meu filho (pedagogia Waldorf). Agradeço à coordenadora e professora Nina e às professoras Ana Carina, Tereza, Luciene e ao "seu" Ademar.

- À "Dona" Ligia pelo incentivo à amamentação prolongada e por perguntar, diariamente, qual era a "nova" do Iuri.

- À Silvia Schiros pelas ajudas.

- À Rosani Arruda pela amizade e disposição em ajudar.

- Ao Arno pelas parcerias em cursos que ministramos juntos. É muito bom ter "lianólogos" por perto!

- À família Melo-de-Pinna - Gladys Flávia, Mário e Júlia - pela hospitalidade e pelas boas risadas.

- À Patrícia Soffiatti pela amizade, por trazer as amostras de madeira da Holanda e por ter fotografado algumas pranchas de uma obra rara.

- À Claudia Luizon, que está distante, mas perto.

- À Rafaela pela idéia da "tese pretinho básico" e pela amizade.

- À Ivonne pelas "trocas" sobre maternidade e pela nova amizade.

- Ao casal Miriam e Lúcio pelos momentos de alegria e descontração.

- ̀̀ Beatriz Maia pela amizade e pelo carinho.

- À Adriana pela companhia desde a graduação e pelo carinho. 
- Ao Geraldo Zenid pelas mensagens eletrônicas enviadas, pelo bom humor e por ter me atendido sempre que precisei.

- À minha eterna "irmã" Majô, ao seu marido Marcelo e à filhinha Lívia, que de forma tão carinhosa nos receberam nas visitas esporádicas.

- À minha eterna "irmã" Lucília, que está distante, mas perto.

- À amiga "número um" da Lucília, Bia, pela boa companhia.

- À Karen por partilhar o seu tempo comigo, dividir alguns anseios e firmar uma nova amizade.

- Aos amigos Eduardo e Júlio, tão distantes e tão perto.

- Ao Oscar Lira pela amizade e humor refinado. É sempre bom ter alguém para conversar sobre espiritismo.

- Ao Geddy Lee, Alex Lifenson e Neil Peart, da banda Rush, por terem me proporcionado um dos melhores momentos durante esta tese (eles finalmente vieram ao Brasil!)

- Aos fiéis companheiros Susie e oddie (vulgo Didi).

- À Renata, minha ajudante em casa. A sua presença me ajudou muito no final desta tese.

- À minha sogra, Regina, que de forma tão carinhosa e solícita cuidou do Iuri nos momentos que mais precisei. Suas vibrações, rezas e promessas foram muito valiosas.

- Ao meu sogro, Elizeu, pela amizade e apoio, por ser sempre tão carinhoso com o Iuri.

- ̀̀ minha sobrinha Flavia por ser "baby sitter" do Iuri todas as vezes que precisei ficar em São Paulo.

- À família Tamaio de Suzano - irmão Levi, cunhada Silvana e as sobrinhas Mariane e Natália - pela hospitalidade e simpatia.

- À família Tamaio de Brasília - irmão Irineu e cunhada Maria Clara - pelo carinho e pela torcida.

- À família Tamaio de São Paulo - irmã Diva, sobrinha Flavia e minha mãe - pela solicitude com relação ao Iuri, sempre que precisei ficar em São Paulo.

- À família Tamaio da Colômbia: cunhada Monica e sobrinha Thaís. As fotos da Thaís tornaram os meus dias mais alegres.

- À minha mãe, pelo seu ímpeto de coragem. Ela se mudou do interior de são Paulo para a capital em 1979, trazendo os cinco filhos menores de idade. Sem seu esforço, sem sua vontade de mudança, eu não estaria onde estou. 
- À minha "célula companheira", meu marido Marcelo, por apoiar minhas escolhas, pelo nosso amor profundo, grande e definitivo, e que por ser assim multiplica a minha alegria.

- Ao meu filho Iuri, por ser meu sonho tão acalentado que virou realidade. Seu espírito colaborador e amigo, sua facilidade em se adaptar a novas situações (está na terceira escola!), sua ótima saúde e esperteza máxima muito me ajudaram! Você é o melhor resultado que já tive. Finalizo os meus agradecimentos citando uma frase da atriz e mãe Glória Pires: "Nada na vida se compara ao olhar de um bebê para a mãe, enquanto mama". 


\section{ÍNDICE}

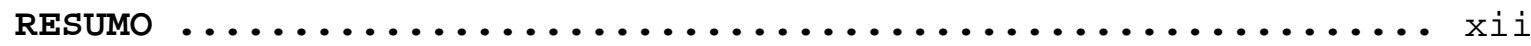

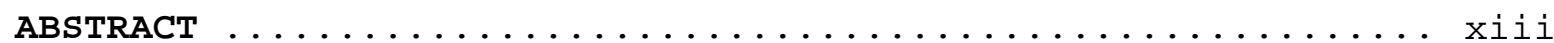

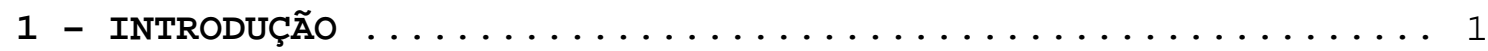

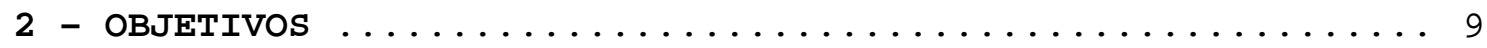

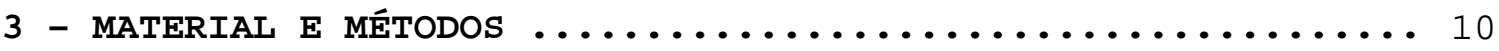

3.1. Aquisição, coleta e seleção dos espécimes............ 10

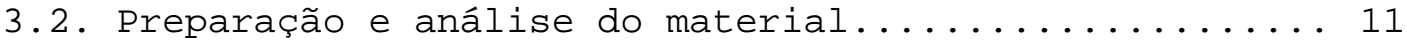

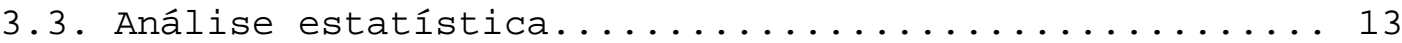

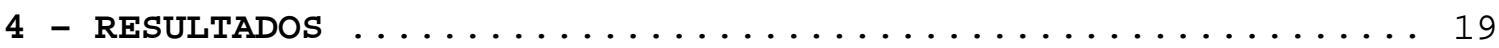

4.1 Desenvolvimento do caule em trepadeiras herbáceas e lianas ............................ 19

4.2. Origem do tecido conjuntivo e dos câmbios sucessivos na liana Abuta imene .................... 24

4.3. O caule nos diferentes hábitos ............... 26

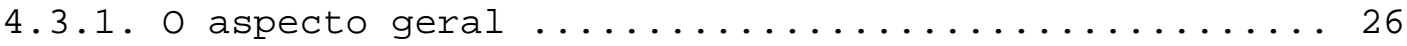

4.3.2. O sistema de revestimento e o córtex ........... 26

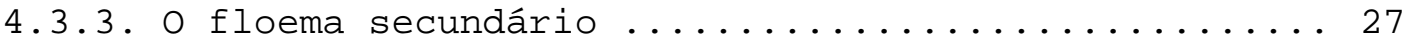

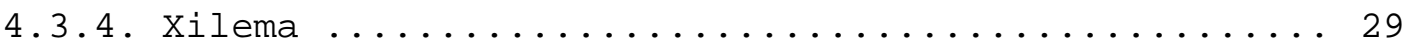

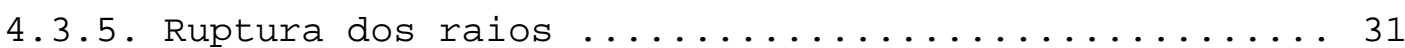

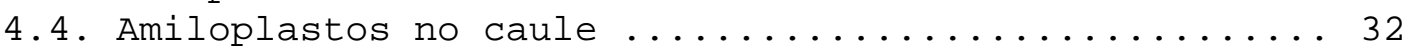

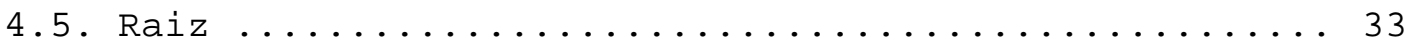

4.5.1. Desenvolvimento em trepadeiras herbáceas ........ 33

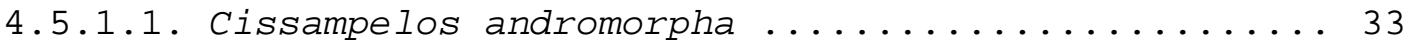

4.5.1.2. Disciphania hernandia ................ 33

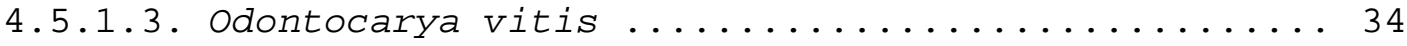

4.5.1.4. Ungulipetalum filipendulum ............. 35

4.5.2. Aspectos anatômicos do tecido vascular da raiz em trepadeiras herbáceas ................ 36

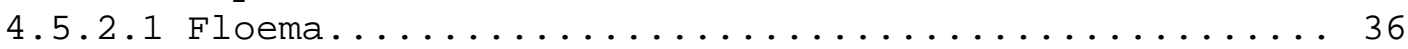

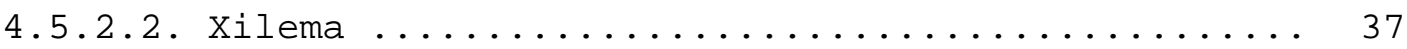

4.5.3. Estrutura secundária da raiz do arbusto Cissampelos ovalifolia....................... 38

4.5.4. Estrutura secundária da raiz da liana

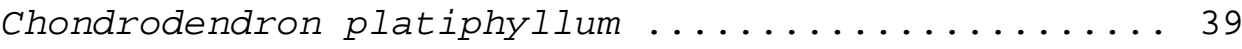

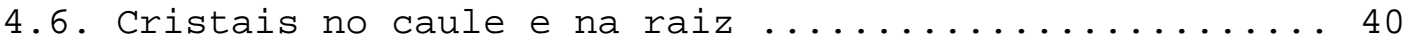

4.7. Identificação do caule em objetos comercializados ... 41

4.8. Análise estatística das características quantitativas

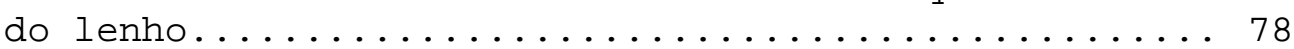

4.8.1. Anéis sucessivos................... 78

4.8.2. Hábito arbustivo e liana de Abuta grandifolia..... 86

4.8.3. Trepadeiras herbáceas, lianas e a espécie herbácea 89

4.8.4. Fibras e fibrotraqueídes em um mesmo indivíduo..... 94

4.8.5. Comprimento de elementos de vasos de diâmetro grande e pequeno em todos os hábitos............ 96

4.8.6. Caule X Raiz ........................ 97 


\section{DISCUSSÃO}

5.1. Trepadeiras herbáceas X lianas: o problema da

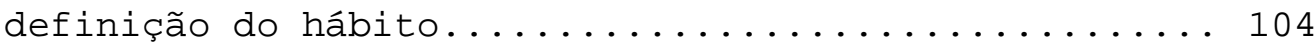

5.2. Caule. Desenvolvimento: raio medular............. 106

5.3. Caule. Desenvolvimento: Câmbios sucessivos,

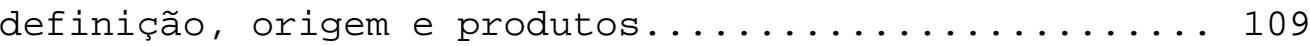

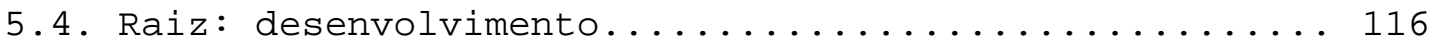

5.5. Qual anel sucessivo utilizar em estudos anatômicos? Uma abordagem com base em dados morfométricos

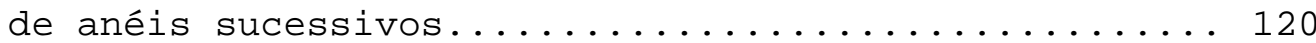

5.6. Xilema. Considerações gerais para o caule e a raiz 125

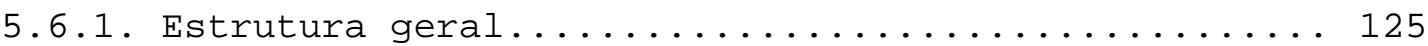

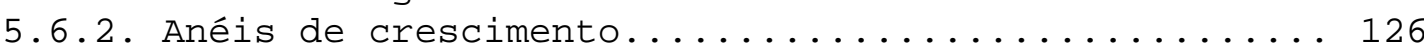

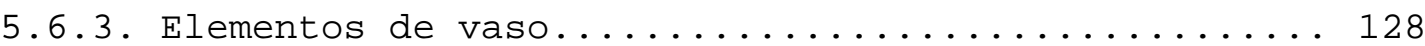

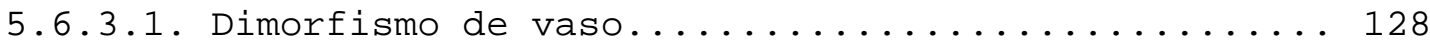

5.6.3.2. O diâmetro do elemento de vaso em espécies de

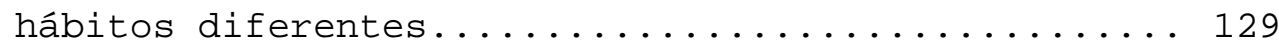

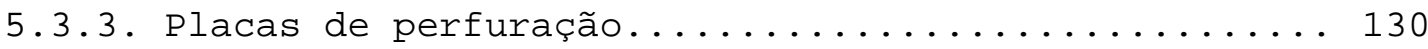

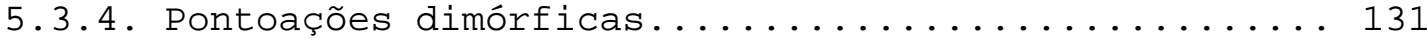

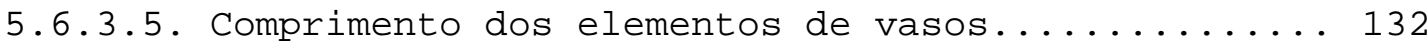

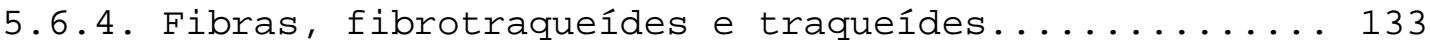

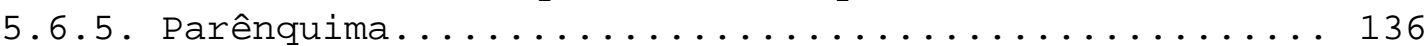

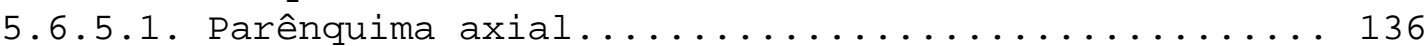

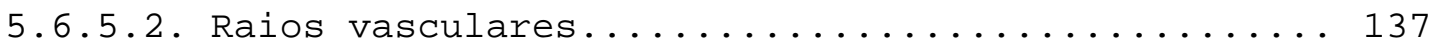

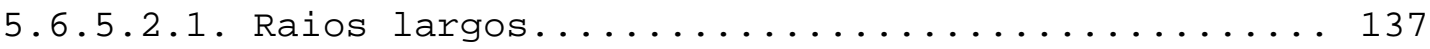

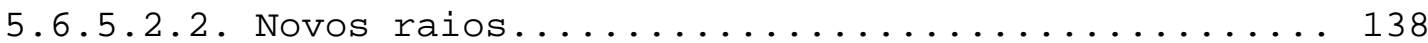

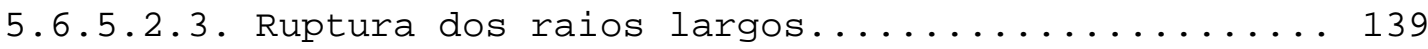

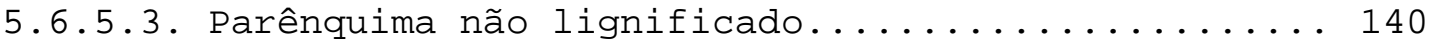

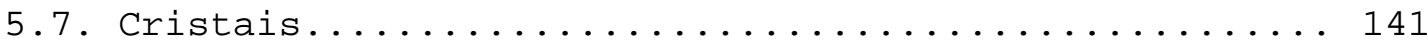

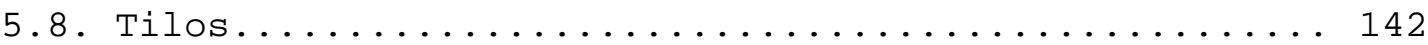

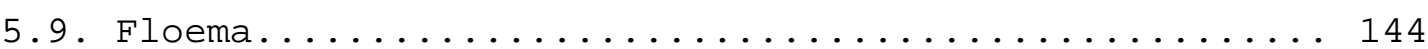

5.10. Análise morfométrica em lenho do caule e da raiz.... 145

5.11. Identificação do lenho em objetos comercializados... 146 


\section{RESUMO}

Menispermaceae é uma família de distribuição pantropical que compreende diversos hábitos, em sua maioria, trepadeiras herbáceas e lianas, além de ervas, arbustos e árvores e onde se faz presente a variação cambial do tipo câmbios sucessivos. Este trabalho apresenta um estudo anatômico do caule e da raiz com ênfase nas lianas e trepadeiras herbáceas. Estudou-se 10 gêneros, 14 espécies e 31 espécimes. Cinco espécies são trepadeiras herbáceas, uma é herbácea (Cissampelos ovalifolia), uma é arbustiva (Abuta grandifolia), e o restante são lianas. As lianas e o arbusto apresentam em seus caules, a variação cambial do tipo câmbios sucessivos, enquanto as trepadeiras herbáceas e a erva não apresentam essa variação estrutural. Demonstra-se na liana Abuta imene, de maneira inédita para a família, que o periciclo origina o tecido conjuntivo, e esse, por sua vez, os câmbios sucessivos. Na análise comparativa do xilema secundário em diversos anéis sucessivos contidos no mesmo caule, destaca-se que o lenho produzido pelos novos anéis vasculares, normalmente, não difere qualitativamente do anel vascular original, no entanto há diferenças quando aos caracteres quantitativos: os diâmetros dos elementos de vasos sofreram aumento estatisticamente significativo no sentido centro-periferia. A análise do caule entre dois hábitos de Abuta grandifolia (liana $X$ arbusto) mostrou que ambos possuem o mesmo padrão anatômico, porém, destaca-se que os diâmetros de elementos de vasos são menores no arbusto. Variações quantitativas ocorrem entre o lenho de caule e a raiz de trepaderias herbáceas e estão relacionadas ao diâmetro e comprimento dos elementos de vasos que são maiores nos caules. Alguns dados são relatados, pela primeira vez, para essa família: (1) Classifica-se o sistema subterrâneo de Disciphania hernandia como raiz tuberosa; (2) Ruptura do raio vascular através da transformação de iniciais radiais em iniciais fusiformes no xilema e floema; (3) A constatação de câmbios sucessivos na raiz da liana Chondrodendron platiphyllum. Apesar da similaridade quanto à estrutura anatômica geral do caule, existem caracteres que separam as trepadeiras herbáceas das lianas, tais como: o tipo de parênquima, morfologia dos cristais, o diâmetro e a distribuição dos elementos de tubos crivados e a transformação das iniciais, tanto fusiformes quanto radiais nas trepadeiras herbáceas. Fornece-se, ainda, alguns aspectos anatômicos do floema secundário no caule. Recomenda-se a padronização de estudos do lenho na família através do primeiro anel. Discute-se a presença de raio medular na família. Conclui-se que os caules das lianas são muito similares, portanto, a identificação das porções do lenho utilizadas em objetos comercializados somente é possível ao nível de família. 


\section{ABSTRACT}

The pantropical family Menispermaceae includes several habits, like herbaceous vines, herbs, shrubs, and trees, showing cambial variant of successive type. The present study is an anatomical approach of stem and root of woody and herbaceous vine habits. In the present study, 31 specimens were investigated, sampling 10 genera and 14 species. Of those species, five are herbaceous vines, one is herb (Cissampelos ovalifolia) and one is shrub (Abuta grandifolia), and the rest are woody vines. Stems of woody vines and shrubs show successive cambia, not assigned to herbs and herbaceous vines. For the first time in the family, it is observed in the woody vine Abuta imene that the conjunctive tissue originates from the pericycle, and that the successive cambia, on its turn, originates from the conjunctive tissue. In the comparative analysis of secondary xylem in its several successive rings in the same stem, the wood produced by new vascular rings does not differ qualitatively from the original vascular ring, while there are differences in quantitative characters: diameter of vessel elements show significant increase in centreperiphery direction. The stem analysis between two habits of Abuta grandifolia (woody vine $\mathrm{X}$ shrub) shows that both have the same anatomical pattern. However, diameter of vessel elements is smaller in shrubs. Quantitative variation occurs between stem and root in herbaceous vine wood, and are related to diameter and length of vessel elements, which are larger in stems. Some data are described for the family for the first time: (1) The subterranean system of Disciphania hernandia is assigned as root tuber; (2) Splitting of ray by transformation of ray initials to fusiform initials in xylem and phloem; (3) Presence of successive cambia in woody vine root of Chondrodendron platiphyllum. Despite the anatomical general resemblance of stem, there are characters that distinguish herbaceous from woody vines, like: the kind of parenchyma, crystal morphology, diameter and distribution of sieve tube elements, and transformation of fusiform and ray initials in herbaceous vines. Additionally, some anatomical aspects of secondary phloem in stem are shown. The standardization of woody studies in the family considering the first ring is recommended. Discussions are made about the presence of medullary ray in the family. It is concluded that the stem of woody vines are very similar to each other, and thus, identification of woody portions used in commercialized objects is possible only at familial level. 


\section{INTRODUÇÃO}

As trepadeiras são plantas cujo crescimento em altura depende da sustentação mecânica fornecida por outras plantas (Putz \& Windsor, 1987). Esses organismos podem ser de natureza herbácea ou lenhosa (Engel et al., 1998).

Gentry (1991) classifica como lianas aquelas trepadeiras que geralmente desenvolvem caules de maior diâmetro, começam o seu ciclo de vida como plântulas terrestres e são capazes de crescer em florestas maduras. Já as que apresentam caules mais finos, e cuja distribuição se restringe mais às áreas abertas, clareiras e bordas de mata, são classificadas como trepadeiras herbáceas.

A família Menispermaceae apresenta uma grande diversidade de hábitos, sendo constituída, em sua maioria, por trepadeiras - mas também abrange ervas, arbustos, subarbustos e árvores (Carlquist, 1996). Essa é uma família essencialmente pantropical, com apenas três espécies registradas para a região temperada da América do Norte (Ott, 1997).

Várias classificações são conhecidas para a família, e de acordo com qual é seguida, pode estar composta por 350 espécies em 65 gêneros (Thorne, 1992), ou por 450 espécies em 71 gêneros (Kessler, 1993), ou ainda, 520 espécies em 75 gêneros (Watson \& Dallwitz, 1992). Os gêneros estão distribuídos em cinco tribos, segundo Krukoff \& Barneby (1970): Triclisieae, Hyperbaeneae, Anomospermeae, Tinosporeae e Menispermeae.

Algumas trepadeiras dessa família têm seus princípios ativos ou compostos químicos utilizados para alguns fins, como armas químicas (curare), antipiréticos, diuréticos, edemas, cólicas e diarréias, regulação do ciclo menstrual e doenças venéreas (Bennett, 1995). Além dessas aplicações farmacológicas, também é comum o uso de fragmentos do 
caule, em seções transversais, na criação de objetos feitos artesanalmente, que são comercializados principalmente pela Associação para o Desenvolvimento, Educação e Recuperação do Excepcional (Adere), na cidade de São Paulo.

Segundo Mennega (1982), anatomicamente, o caule de Menispermaceae é muito similar, tornando difícil a separação dos gêneros pelo lenho, mas há caracteres que podem ser inferidos para as tribos, tais como o diâmetro dos elementos de vasos e a morfologia dos cristais. Já Gentry-Ortiz (2000) afirma que o lenho do caule contribui para a identificação de espécies no gênero Curarea.

O lenho apresenta características anatômicas peculiares: raios medulares, presença de raios vasculares largos e variação cambial do tipo câmbios sucessivos em alguns gêneros (Schenck, 1893; Solereder, 1899; Pfeiffer, 1926; Chalk \& Chattaway, 1937; Metcalfe \& Chalk, 1950; Obaton, 1960; Mennega, 1982; Détienne, 1983; Fahn et al., 1986; Carlquist, 1996; Wet et al. 2002).

O termo raio medular foi adotado por inúmeros botânicos renomados dos séculos XVIII e XIX (Chandurkar, 1989). Ele corresponde à região interfascicular, sendo um tecido primário, originado a partir do meristema fundamental, que é caracterizado por células alongadas radialmente. O limite interno do raio medular é a própria medula (Eames \& MacDaniels, 1947); já o seu limite externo é o periciclo (Boureau, 1958) ou o córtex (Fahn, 1990).

Segundo Eames \& MacDaniels (1947), o raio medular é geralmente encontrado em trepadeiras e herbáceas. Naquela época, esses autores já chamavam a atenção para o uso indevido do termo raio medular como sinônimo de raio vascular, simplesmente porque eles não são homólogos.

Segundo Metcalfe (1950), além de Menispermaceae, os raios medulares estão presentes nas seguintes famílias: Berberidaceae, Lardizabalaceae, Sterculiaceae, 
Zygophylaceae, Rutaceae, Ampelidaceae, Rhizophoraceae e Aristolochiaceae, que é o exemplo clássico na maioria das citações.

Em razão da inexistência de trabalhos detalhados do desenvolvimento em Menispermaceae, questiona-se a presença do raio medular em caules dessa família, sendo que essa é uma das questões abordadas nesta tese.

Dentre todas as variações cambiais, os câmbios sucessivos e o floema incluso são os mais enfocados em trabalhos investigativos de anatomia. Há polêmicas em relação à definição dessas variações. Para Carlquist (2001), o termo floema incluso só deverá ser utilizado quando apenas um câmbio estiver envolvido no processo.

As informações sobre origens, localizações e ocorrências dos câmbios sucessivos são mais freqüentes para Amaranthaceae, Chenopodiaceae, Nyctaginaceae e Phytollacaceae. Essas famílias possuem atividade cambial limitada, formando xilema e floema secundários que resultam na formação de vários anéis concêntricos ou segmentos fasciculares ${ }^{1}$. Os tecidos vasculares secundários formados ficam imersos em um tecido parenquimático, denominado de tecido conjuntivo (Carlquist, 2004).

A variação cambial do tipo câmbios sucessivos (Pfeiffer, 1926) ou câmbios acessórios (Eames \& MacDaniels, 1947) é caracterizada por anéis consecutivos de elementos axiais separados por raios xilemáticos largos e tangencialmente por camadas de tecido conjuntivo. Essa estrutura é interpretada como floema incluso por Chalk \& Chattaway (1937); Metcalfe \& Chalk (1983) e Wheeler et al. (1989), idéia que é rebatida por Carlquist (1996), pelo mesmo motivo supracitado, ou seja, no floema incluso somente um câmbio deverá estar envolvido, e também porque o

\footnotetext{
1 Tecido vascular (xilema e floema secundários) geralmente destituído de raio vascular. É chamado de "feixe vascular" por diversos autores.
} 
floema não está localizado dentro do xilema², mas, sim, no tecido conjuntivo.

As observações em relação à origem dessa estrutura, independentemente da família à qual ela pertence, são controversas. No geral, os câmbios sucessivos podem ter origem pericíclica, floemática ou cortical (e.g. Pfeiffer, 1926; Chalk \& Chattaway, 1937; Joshi, 1937; Wheat, 1977; Fahn \& Zimmermann, 1982; Carlquist, 1999).

Uma idéia bastante polêmica é a origem dos câmbios sucessivos através do meristema de espessamento primário (MEP) em caules de dicotiledôneas. Essa idéia foi introduzida por Stevenson \& Popham (1973) e foi usada seqüencialmente por Mikesell \& Popham (1976); Mikesell (1979) e Yarrow \& Popham (1981), para designar a camada geradora da variação cambial em membros de Centrospermae (Aizoaceae, Amaranthaceae, Caryophyllaceae, Chenopodiaceae, Nyctaginaceae e Portulacaceae).

Carlquist (1996) traz algumas referências relacionadas à origem e ao desenvolvimento dos câmbios sucessivos em caules Menispermaceae fundamentadas apenas na estrutura secundária, ou seja, não verificou etapas seqüenciais nos diversos estágios de desenvolvimento. Segundo o autor, a camada cortical mais interna, próxima a um cordão de esclereídes, é o tecido gerador dos câmbios sucessivos. Esse tecido gerador é denominado por ele de "meristema lateral", que forma o tecido conjuntivo e os câmbios sucessivos.

Uma segunda referência sobre a origem dos câmbios sucessivos em Menispermaceae é fornecida por Rajput \& Rao (2003), mas nos mesmos padrões de Carlquist (1996), com resultados fundamentados apenas em estrutura secundária. Esses autores são adeptos da observação de Carlquist (1996), ou seja, que a camada geradora dos câmbios

\footnotetext{
2 Grifo do autor.
} 
sucessivos, é aquela mais interna do córtex junto ao cordão de esclerênquima, com a diferença de que consideram a natureza desse cordão como pericíclica.

Recentemente, alguns pesquisadores estão se interessando e realizando estudos do tecido conjuntivo em diferentes famílias. Rajput (2002), estudando o caule de vários gêneros de Amaranthaceae, constatou que, em alguns gêneros, o raio vascular está ausente durante os primeiros estágios do desenvolvimento secundário. Os segmentos fasciculares ficam, então, imersos no tecido conjuntivo.

Carlquist (2004) fez uma "reinterpretação" da origem e dos produtos do meristema lateral em Nyctaginaceae. Segundo esse autor, o meristema lateral forma o tecido conjuntivo, os câmbios sucessivos e os raios. O tecido conjuntivo diferenciado em "raios" é denominado pelo autor de "raylike radial sheets of conjunctive parenchyma"; isto é, "faixas radiais de parênquima conjuntivo semelhante a raios".

A ausência de estudos que envolvam o desenvolvimento primário em caules, assim como o início do crescimento secundário em Menispermaceae, motivou parte da criação deste trabalho.

Foram constatados apenas dois trabalhos gerais abordando a anatomia do caule na família Menispermaceae: o de Mennega (1982) e de Carlquist (1996).

Mennega (1982) trabalhou com espécies do Novo Mundo, principalmente do Neotrópico, e fez uma análise do xilema nas cinco tribos, englobando 13 gêneros, sendo três trepadeiras herbáceas, uma árvore, um arbusto e o restante lianas. A autora conclui que o lenho de Menispermaceae não tem valor diagnóstico ao nível de espécie ou gênero. No entanto, pode-se levantar características diagnósticas ao nível de tribos, como a presença e distribuição de cristais e o diâmetro de vasos. Mennega não especifica a 
padronização utilizada na escolha do anel vascular selecionado.

o único trabalho que aborda a morfometria dos elementos celulares nos diferentes anéis sucessivos na família é o de Rajput \& Rao (2003) com o arbusto Cocculus hirsutus. Esses autores detectaram que o diâmetro do vaso aumenta de acordo com o anel sucessivo mais externo. Com base nessa informação, as questões a seguir nortearam parte deste trabalho: (1) Qual anel sucessivo deve ser utilizado em análises anatômicas em caule de Menispermaceae?

Seria necessário padronizar?

O segundo trabalho que aborda a anatomia do lenho em Menispermaceae é o de Carlquist (1996). O autor trabalhou com 14 gêneros, um arbusto, um subarbusto e o restante lianas - ele não enfocou as trepadeiras herbáceas. Carlquist constatou que algumas característica do lenho, como a histologia dos raios e distribuição de cristais, são promissores em subsidiar estudos taxonômicos. Ele sugere também que estudos entre hábitos poderão mostrar interessantes correlações entre o lenho, e afirma não ter idéia se a produção dos câmbios sucessivos, tanto qualitativa quanto quantitativamente, é similar ou não entre caules grossos e finos de Menispermaceae.

Diante dos questionamentos e comentários de Carlquist (1996), propõe-se, portanto, a anatomia comparada de caules de trepadeiras herbáceas (caules finos) e lianas (caules grossos), assim como a análise morfométrica e merística entre os anéis sucessivos de algumas espécies.

Alguns trabalhos apontam tendências comparativas para - caule de lianas com outros hábitos. As lianas apresentam vasos mais longos (Zimmermann, 1983; Ewers, 1985; Ewers et al., 1990); maior diâmetro e freqüência de elementos de vasos (Mennega, 1982; Baas \& Schweingruber, 1987; Ewers et al., 1990; Bamber \& Ter Welle, 1994; Carlquist, 1996; 
Schweingruber \& Poschlod, 2005); placa de perfuração simples (Carlquist, 1991); dimorfismo de vasos (Baas \& Schweingruber, 1987; Carlquist, 2001); maior quantidade de parênquima axial (Gasson \& Dobbins, 1991; Bamber \& Ter Welle, 1994; Dias-Leme, 1999); raios mais altos (Putz, 1980; Bamber \& Ter Welle, 1994; Fisher \& Ewers; 1995 Carlquist, 1996) e fibrotraqueídes mais curtas (Carlquist, 1975; Mennega, 1982).

Para Menispermaceae, há somente o trabalho de Mennega (1982), em que ela aborda a anatomia de Abuta grandifolia como árvore, arbusto e liana. A autora obteve, conforme abordado anteriormente, elementos de vasos de maior diâmetro para o hábito escalador, médias similares para o comprimento dos elementos de vasos e as menores médias para - comprimento de fibrotraqueídes das lianas, e não verificou diferenças entre o hábito arbustivo e as lianas. É importante ressaltar que a autora não tratou os dados estatisticamente e não padronizou a porção (anel vascular) do lenho que foi utilizada.

Alguns trabalhos com enfoque comparativo entre o lenho de caule e a raiz com câmbios sucessivos foram desenvolvidos por Joshi (1937); Mikessel (1979); Bailey (1980); Carlquist (2004) e Nunes \& Tamaio (2005); para Amaranthaceae e Chenopodiaceae; Phytolaccaceae, Buxaceae; Nyctaginaceae e Leguminosae, respectivamente.

Joshi (1937) ressalta que em Amaranthaceae e Chenopodiaceae os câmbios sucessivos podem estar presentes na raiz ou na base do caule e ausente no restante do caule. Schweingruber \& Poschlod (2005) analisaram órgãos que correspondem à zona de transição entre caule e raiz em duas espécies de Amaranthaceae e quatro de Chenopodiaceae, e eles não constataram a presença de câmbios sucessivos nessa região. 
Carlquist (1996) afirma que a anatomia das raízes de Menispermaceae nunca foi estudada. O que se pode encontrar são apenas aspectos gerais da raiz, sem câmbios sucessivos, de Jateorhiza palmata, feitos por Metcalfe \& Chalk (1950).

Solereder (1908) acredita que o lenho caulinar que que apresenta câmbios sucessivos pode também apresentar a mesma variação na raiz. Isso se constata para Abuta rufescens; Chondrodendron tomentosum; Cocculus laurifolius e Clypea burmani (Blotièrre, 1886); Abuta rufescens (Blottière apud Solereder, 1908) e Cissampelos pareira (Wigand apud Solereder, 1908).

Metcalfe \& Chalk (1950) fornecem uma relação de 15 gêneros com caules providos com câmbios sucessivos e sete gêneros destituídos dessa variação. Mennega (1982) e Carlquist (1996) acrescentaram sete gêneros cada um na relação de caules com câmbios sucessivos. Mennega (1982) acrescentou dois gêneros na lista sem variação. Considerando que a família está constituída por 75 gêneros, constata-se que, para mais da metade dos gêneros, a presença ou não de variação cambial em seus caules sequer é conhecida.

O objetivo desta tese é abordar a anatomia do caule de 10 gêneros incluindo 15 espécies. O lenho do caule e a raiz das seis espécies citadas a seguir são estudados pela primeira vez: Cissampelos andromorpha, Cissampelos ovalifolia, Disciphania hernandia, Odontocarya tamoides, Odontocarya vitis e Ungulipetalum filipendulum.

Dessa forma, a função deste estudo é contribuir para a ampliação do conhecimento da anatomia do lenho em Menispermaceae. 


\section{OBJETIVOS}

\subsection{Objetivos gerais}

Comparar a anatomia do caule e da raiz de espécies de Menispermaceae, de diferentes hábitos - trepadeiras herbáceas, lianas, erva e arbusto, visando verificar se apresentam diferenças quanto ao hábito.

\subsection{Objetivos específicos:}

- Estudo do desenvolvimento do caule com o objetivo de detectar a origem dos câmbios sucessivos e do tecido conjuntivo;

- Análise morfométrica do xilema, entre o primeiro, segundo, quinto e décimo anel, em três lianas e um arbusto, visando verificar se há variação entre esses anéis e se o primeiro anel pode ser padronizado para futuros estudos comparativos;

- Anatomia do lenho entre o hábito arbustivo e liana de Abuta grandifolia;

- Anatomia comparada do caule e da raiz de trepadeiras herbáceas, lianas e erva, principalmente quanto ao sistema vascular; e

- Verificar se é possível a identificação de porções do caule de lianas em objetos comercializados. 


\section{MATERIAL E MÉTODOS}

\subsection{Aquisição, coleta e seleção dos espécimes}

Foram selecionados 10 gêneros, 15 espécies e 34 espécimes, entre lianas, trepadeiras herbáceas, uma erva e um arbusto (Tabela 1). Nessa tabela é apresentado o enfoque dado a cada táxon que variou em (1) desenvolvimento; análise morfométrica entre os anéis sucessivos; (3) estudo do lenho secundário do caule; e (4) estudo do lenho da raiz. O hábito de algumas espécies estão representados nas Figuras 1-4.

Procurou-se obter, no mínimo, dois gêneros de cada tribo, exceto Hyperbaeneae, que é monotípica. É importante ressaltar que a posição de Ungulipetalum filipendulum ainda não está definida. Barneby \& Krukoff (1971) afirmam que o fruto ainda não era conhecido até essa data e, portanto, inferem uma provável posição na tribo Tricliseae.

No entanto, para estudos de desenvolvimento, é necessário que a planta possua diversas etapas de crescimento (ápice, caule jovem, intermediário e adulto), o que nem sempre é possível. Dessa forma, a escolha das espécies para o desenvolvimento do caule, assim como para os estudos da raiz, foi baseada na adequação das espécies a essa necessidade de coleta.

Nos caules de Menispermaceae é possível a constatação ou não, a olho nu, dos câmbios sucessivos. As lianas e a espécie arbustiva possuem câmbios sucessivos em seus caules. Já as trepadeiras herbáceas e a espécie herbácea estão destituídas desta variação. A macroscopia de alguns caules consta nas Figuras 5-8.

Foram coletadas amostras em diversas regiões do Brasil (Tabela 1). As espécies de Menispermaceae apresentaram-se muito ramificadas. Procurou-se coletar ramos que 
possuíssem, no mesmo fragmento, segmentos apicais, intermediários, e, no caso de lianas, com pelo menos o segundo anel sucessivo formado. Para as trepadeiras herbáceas, procurou-se ramos que tivessem parte apical, intermediária e adulta, com o maior diâmetro possível. A erva Cissampelos ovalifolia foi coletada inteira, juntamente com sua raiz.

Em Odontocarya tamoides, foi observado um rebroto a partir do caule coletado para análise (Figura 9).

Procurou-se obter raízes em diversos estágios de desenvolvimento, o que, na maioria das vezes, não foi possível. A presença de sistemas subterrâneos espessados foi notada nos seguintes gêneros: Cissampelos andromorpha; Cissampelos ovalifolia; Disciphania hernandia e Ungulipetalum filipendulum. No entanto, apenas o órgão de Disciphania hernandia foi analisado.

O material botânico foi identificado pelo especialista João Marcelo Alvarenga Braga, do Instituto de Pesquisas Jardim Botânico do Rio de Janeiro. As exsicatas e porções do lenho foram depositadas no Instituto de Pesquisas Jardim Botânico do Rio de Janeiro, no herbário e na xiloteca, respectivamente.

Também foram obtidas amostras de madeiras provenientes da Xiloteca de Utrecht (Uw) e da Xiloteca do Instituto de Pesquisas Jardim Botânico do Rio de Janeiro (Rbw). Além de amostras de xilotecas, obteve-se também amostras diretamente de exsicatas provenientes do Herbário do Instituto de Pesquisas Jardim Botânico do Rio de Janeiro $(\mathrm{Rb})$.

\subsection{Preparação e análise do material}

As plantas coletadas foram fixadas em FAA (Johansen, 1940) ou glutaraldeído 2,5\%, em solução tampão-fosfato 
0,1M, pH 7,2 (Gabriel, 1982), desidratadas em série etílica e processadas segundo os métodos usuais para emblocamento em parafina (Sass, 1951) ou em hidroxietilmetacrilato (Gerrits \& Smid, 1983), para obtenção de seções transversais e longitudinais.

O estudo foi realizado a partir de cortes histológicos obtidos à mão livre, ou seccionados em micrótomo rotativo ou de deslize.

As seções em série, obtidas em micrótomo rotativo, foram feitas a partir de material incluso em parafina, ou em hidroxietilmetacrilato (Gerrits \& Smid, 1983). o material incluso em parafina foi secionado na espessura de 8-12 $\mu \mathrm{m}$.

No material incluso em hidroxietilmetacrilato, foram feitas seções com espessura de 3-7 $\mu \mathrm{m}$, que posteriormente foram coradas com azul de toluidina 0,05\% (O'Brien \& McCully, 1981).

Para o estudo do lenho, as amostras foram amolecidas por aquecimento em água e seccionadas em micrótomo de deslize, com a espessura de 15-30 $\mu$ m.

Todas as seções obtidas, exceto o material incluso em hidroetilmetacrilato, foram coradas com safranina e azul de astra, segundo Bukatsch (1972), modificado em Kraus \& Arduin 1997, e montadas com Permount.

Para os testes citoquímicos, foram utilizados os seguintes reagentes: reagente de Lugol (Johansen, 1940, modificado) e floroglucinol acidificado (Johansen, l.c.), para amido e lignina, respectivamente. O teste para amido foi realizado em seções obtidas em micrótomo rotativo de material emblocado em historesina. O reagente de Lugol foi colocado em seções sem corar ou coradas com azul de toluidina. Em paralelo, para algumas espécies, procedeu-se a montagem tradicional, obtida à mão livre, para fins de comparação com o método experimentado nesta tese. 
Para a caracterização dos elementos celulares, foi realizada a dissociação do órgão, separando o tecido floemático do xilema, e utilizou-se o método de Franklin modificado, segundo Berlyn \& Miksche (1976).

Foram realizadas as seguintes mensurações: do diâmetro e comprimento dos elementos de vasos; comprimento e largura das fibras. No macerado e no mesmo elemento de vaso, obteve-se o diâmetro e o comprimento.

O número de medições foi fixado em $\mathrm{n}=25$ e foram realizadas em um microscópio acoplado a um computador, por meio do programa KS-100 da Zeiss.

Esse trabalho foi documentado pelas fotos feitas no microscópio BH-2 acoplado à câmara digital.

A descrição anatômica do lenho segue as orientações propostas pela IAWA Committee (1989).

\subsection{Análise estatística}

Os dados foram analisados estatisticamente por meio do software STATISTICA 5.5 (StatSoft, 1995).

Observou vasos de calibres grandes e pequenos no lenho tanto do caule quanto da raiz. Para agrupá-los em categorias, utilizou-se um teste de freqüência.

Foram feitas análises de variância (ANOVA) e teste de Tuckey-Kramer para comparar as variáveis nas análises entre anéis sucessivos, hábitos e órgãos. Para as variáveis do elemento de vaso, que envolveram todas as categorias de diâmetro, constatou-se a não aderência dos dados à distribuição normal e à heterogeneidade na variância dos fatores, por meio dos testes de Shapiro-Wilks e de Levene, respectivamente; utilizou-se, portanto, o teste de análise de variância não paramétrico de Kruskal-Wallis (para três ou mais categorias) e Mann-Whitney (comparando apenas duas 
categorias). Valores de $p$ inferiores a 0,05 foram considerados significantes.

A apresentação da distribuição de alguns dados quantitativos é fornecida por diagramas esquemáticos (boxplot), em que se apresenta o menor valor (mínimo), o primeiro quartil, a mediana, o terceiro quartil e o maior valor (máximo). 
Tabela 1. Espécies estudadas. Enfoque dado a cada espécie: D (desenvolvimento) - Cs (câmbios sucessivos) - C (lenho do caule) - R (lenho da raiz). T.herbácea (trepadeira herbácea). Tricliaseae? (ainda existem dúvidas, na literatura, quanto ao posicionamento de Ungulipetalum filipendulum ao nível de tribo). Todas as espécies de Abuta grandifolia foram analisadas quanto ao hábito (arbusto X liana).

\begin{tabular}{|c|c|c|c|c|c|c|}
\hline Espécie & Coleção & Coletor & Origem & Hábito & Tribo & Enfoque \\
\hline Abuta convexa (Vell.) Diels & $\begin{array}{l}\text { Rbw } 8696 \\
\text { Rbw } 8697\end{array}$ & $\begin{array}{l}\text { NT30 } \\
\text { JMA7290 }\end{array}$ & $\begin{array}{ll}\text { Brasil, } & R J \\
\text { Brasil, } & R J\end{array}$ & $\begin{array}{l}\text { Liana } \\
\text { Liana }\end{array}$ & Anomospermeae & $\begin{array}{l}\mathrm{D}-\mathrm{Cs}-\mathrm{C} \\
\mathrm{C}\end{array}$ \\
\hline Abuta imene (Mart.) Eichler & $\begin{array}{l}\text { Uw } 18691 \\
\text { Rbw } 8698\end{array}$ & $\begin{array}{l}\text { Krukoff } 8605 \\
\text { NT97 }\end{array}$ & $\begin{array}{l}\text { Brasil } \\
\text { Brasil, RJ }\end{array}$ & $\begin{array}{l}\text { Liana } \\
\text { Liana }\end{array}$ & Anomospermeae & $\begin{array}{l}\mathrm{C} \\
\mathrm{D}-\mathrm{C}\end{array}$ \\
\hline $\begin{array}{l}\text { Abuta grandifolia (Mart.) } \\
\text { Sandwith }\end{array}$ & $\begin{array}{lr}\text { Uw } & 3441 \\
\text { Rbw } & 8699 \\
\text { Uw } & 18757 \\
\text { Uw } & 22804 \\
\text { Uw } & 23258 \\
\text { Uw } & 22771 \\
\end{array}$ & $\begin{array}{l}\text { Lindeman } 5076 \\
\text { JMA } 8015 \\
\text { Krukoff } 10954 \\
\text { Lindeman \& Heyde } 193 \\
\text { Heyde651 } \\
\text { Lindeman\&Heyde1 } 39 \\
\end{array}$ & $\begin{array}{l}\text { Suriname } \\
\text { Brasil, AM } \\
\text { Bolívia } \\
\text { Suriname } \\
\text { Suriname } \\
\text { Suriname } \\
\end{array}$ & $\begin{array}{l}\text { Arbusto } \\
\text { Arbusto } \\
\text { Arbusto } \\
\text { Liana } \\
\text { Liana } \\
\text { Liana } \\
\end{array}$ & Anomospermeae & $\begin{array}{l}\mathrm{C} \\
\mathrm{C}-\mathrm{Cs} \\
\mathrm{C} \\
\mathrm{C} \\
\mathrm{C} \\
\mathrm{C} \\
\end{array}$ \\
\hline Abuta selloana Eichler & $\begin{array}{l}\text { Rbw } 8235 \\
\text { Rb384571 }\end{array}$ & $\begin{array}{l}\text { Reitz e Klein } 3773 \\
\text { Kulmann } 4786\end{array}$ & $\begin{array}{ll}\text { Brasil, } & \mathrm{AM} \\
\text { Brasil, } & \mathrm{AM}\end{array}$ & $\begin{array}{l}\text { Liana } \\
\text { Liana }\end{array}$ & Anomospermeae & $\begin{array}{l}\mathrm{C} \\
\mathrm{C}\end{array}$ \\
\hline Anomospermum sp. Miers & Uw 36804 & Krukoff 7565 & Brasil & Liana & Anomospermeae & $\mathrm{C}$ \\
\hline $\begin{array}{l}\text { Chondrodendron platiphyllum } \\
\text { (A. St.-Hil.) Miers }\end{array}$ & $\begin{array}{l}\text { Rbw } 8700 \\
\text { Rbw } 8720 \\
\end{array}$ & $\begin{array}{l}\text { NT } 44 \\
\text { JMA } 7729\end{array}$ & $\begin{array}{l}\text { Brasil, RJ } \\
\text { Brasil, RJ }\end{array}$ & $\begin{array}{l}\text { Liana } \\
\text { Liana }\end{array}$ & Tricliseae & $\begin{array}{l}\mathrm{D}-\mathrm{C} \\
\mathrm{C}-\mathrm{R} \\
\end{array}$ \\
\hline Cissampelos andromorpha DC. & $\begin{array}{ll}\text { Rbw } & 8701 \\
\text { SPF } & 149075 \\
\text { Rb } & 148534\end{array}$ & $\begin{array}{l}\text { NT98 } \\
\text { M. Groppo Jr. } 706 \\
\text { Kulmann s/n }\end{array}$ & $\begin{array}{ll}\text { Brasil, } & \text { RJ } \\
\text { Brasil, } & \text { PP } \\
\text { Brasil } & \end{array}$ & $\begin{array}{l}\text { T.herbácea } \\
\text { T.herbácea } \\
\text { T.herbácea }\end{array}$ & Menispermeae & $\begin{array}{l}\text { D-C-R } \\
C \\
C\end{array}$ \\
\hline Cissampelos ovalifolia DC. & $\begin{array}{l}\text { Rbw } 8702 \\
\text { Rbw } 8703\end{array}$ & $\begin{array}{l}\text { JMA } 8500 \\
\text { JMA } 8700\end{array}$ & $\begin{array}{l}\text { Brasil, MG } \\
\text { Brasil, } M T\end{array}$ & $\begin{array}{l}\text { Erva } \\
\text { Erva }\end{array}$ & & $\begin{array}{l}C-R \\
C-R\end{array}$ \\
\hline $\begin{array}{l}\text { Disciphania hernandia } \\
\text { (Vell.) Barneby }\end{array}$ & $\begin{array}{l}\text { Rbw } 8704 \\
\mathrm{Rb} \quad 179452\end{array}$ & $\begin{array}{l}\text { JMA } 7913 \\
\text { L. Mautone } 195\end{array}$ & $\begin{array}{l}\text { Brasil, } \mathrm{RJ} \\
\text { Brasil, } \mathrm{RJ} \\
\end{array}$ & $\begin{array}{l}\text { T.herbácea } \\
\text { T.herbácea }\end{array}$ & Tinosporeae & $\begin{array}{l}D-C-R \\
D-C-R\end{array}$ \\
\hline $\begin{array}{l}\text { Hyperbaena domingensis } \\
\text { (DC.) Benth. }\end{array}$ & $\begin{array}{l}\text { Rbw } 4144 \\
\text { Rb } 355385\end{array}$ & D. & $\begin{array}{l}\text { Brasil } \\
\text { Brasil, RJ }\end{array}$ & $\begin{array}{l}\text { Liana } \\
\text { Liana }\end{array}$ & Hyperbaeneae & $\begin{array}{l}\mathrm{C}-\mathrm{Cs} \\
\mathrm{C}\end{array}$ \\
\hline $\begin{array}{l}\text { Odontocarya tamoides (DC.) } \\
\text { Miers }\end{array}$ & $\begin{array}{l}\text { Rbw } 8705 \\
\text { Rb } 405664\end{array}$ & $\begin{array}{l}\text { JMA } 8700 \\
\text { A.Pott, } 1819\end{array}$ & $\begin{array}{l}\text { Brasil, MS } \\
\text { Brasil, MS }\end{array}$ & $\begin{array}{l}\text { T.herbácea } \\
\text { T.herbácea }\end{array}$ & Tinosporeae & $\begin{array}{l}\mathrm{C} \\
\mathrm{C}\end{array}$ \\
\hline $\begin{array}{l}\text { Odontocarya vitis (Vell.) } \\
\text { J.M.A. Braga }\end{array}$ & $\begin{array}{l}\text { Rbw } 8706 \\
\text { Rbw } 8707 \\
\end{array}$ & $\begin{array}{lll}\text { NT et al. } 92 \\
\text { NT et al. } & 93 \\
\end{array}$ & $\begin{array}{ll}\text { Brasil, } & R J \\
\text { Brasil, } & R J \\
\end{array}$ & $\begin{array}{l}\text { T.herbácea } \\
\text { T.herbácea }\end{array}$ & Tinosporeae & $\begin{array}{l}\mathrm{D}-\mathrm{C}-\mathrm{R} \\
\mathrm{D}-\mathrm{C}-\mathrm{R} \\
\end{array}$ \\
\hline $\begin{array}{l}\text { Sciadotenia eichleriana } \\
\text { Moldenke }\end{array}$ & $\begin{array}{ll}\text { Uw } & 18656 \\
\text { Uw } & 18677\end{array}$ & $\begin{array}{l}\text { Krukoff } 8279 \\
-\end{array}$ & Brasil & $\begin{array}{l}\text { Liana } \\
\text { Liana }\end{array}$ & Tricliseae & $\begin{array}{l}\mathrm{C}-\mathrm{Cs} \\
\mathrm{C}\end{array}$ \\
\hline $\begin{array}{l}\text { Telitoxicum minutiflorum } \\
\text { (Diels) Moldenke }\end{array}$ & $\begin{array}{ll}\text { Uw } & 18677 \\
\text { Rb } & 194886\end{array}$ & $\begin{array}{l}\text { Krukoff } 7566 \\
\text { N.A. Rosa } 876\end{array}$ & $\begin{array}{l}\text { Brasil } \\
\text { Brasil, RO }\end{array}$ & $\begin{array}{l}\text { Liana } \\
\text { Liana }\end{array}$ & Anomospermeae & $\begin{array}{l}\mathrm{C} \\
\mathrm{C}\end{array}$ \\
\hline $\begin{array}{l}\text { Ungulipetalum filipendulum } \\
\text { (Mart.) Moldenke }\end{array}$ & $\begin{array}{l}\text { Rbw } 8708 \\
\text { Rbw } 8709\end{array}$ & $\begin{array}{l}\text { JMA } 7649 \\
\text { JMA } 7585\end{array}$ & $\begin{array}{l}\text { Brasil, RJ } \\
\text { Brasil, RJ }\end{array}$ & $\begin{array}{l}\text { T.herbácea } \\
\text { T.herbácea }\end{array}$ & Tricliaseae? & $\begin{array}{l}D-C-R \\
D-C-R\end{array}$ \\
\hline
\end{tabular}



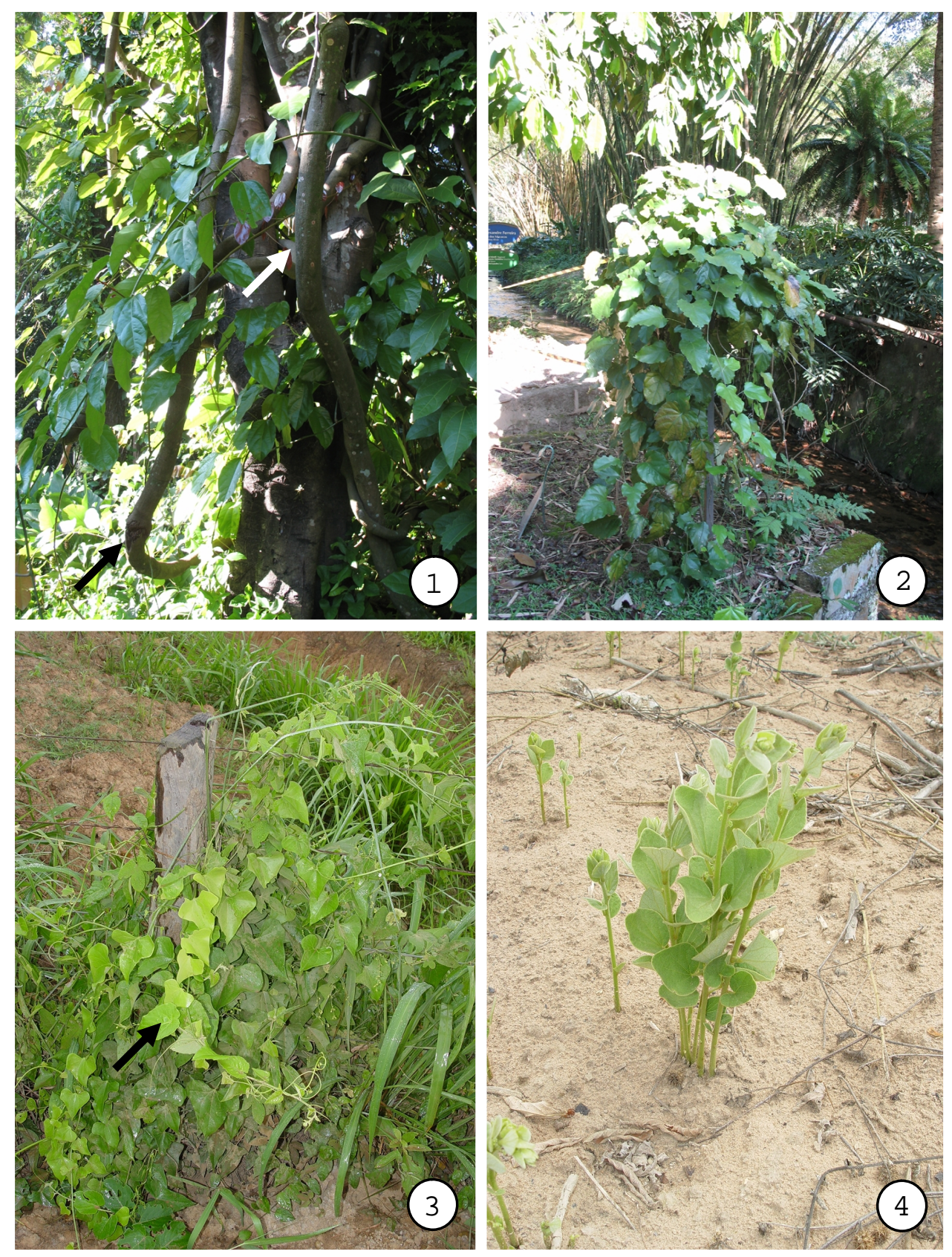

Figuras 1-4. Hábitos. 1. Abuta imene, liana. 2. Chondrodendron platiphyllum, trepadeira herbácea. $\mathbf{3}$. odontocarya tamoides, trepadeira herbácea. 4. Cissampelos ovalifolia, arbusto. 

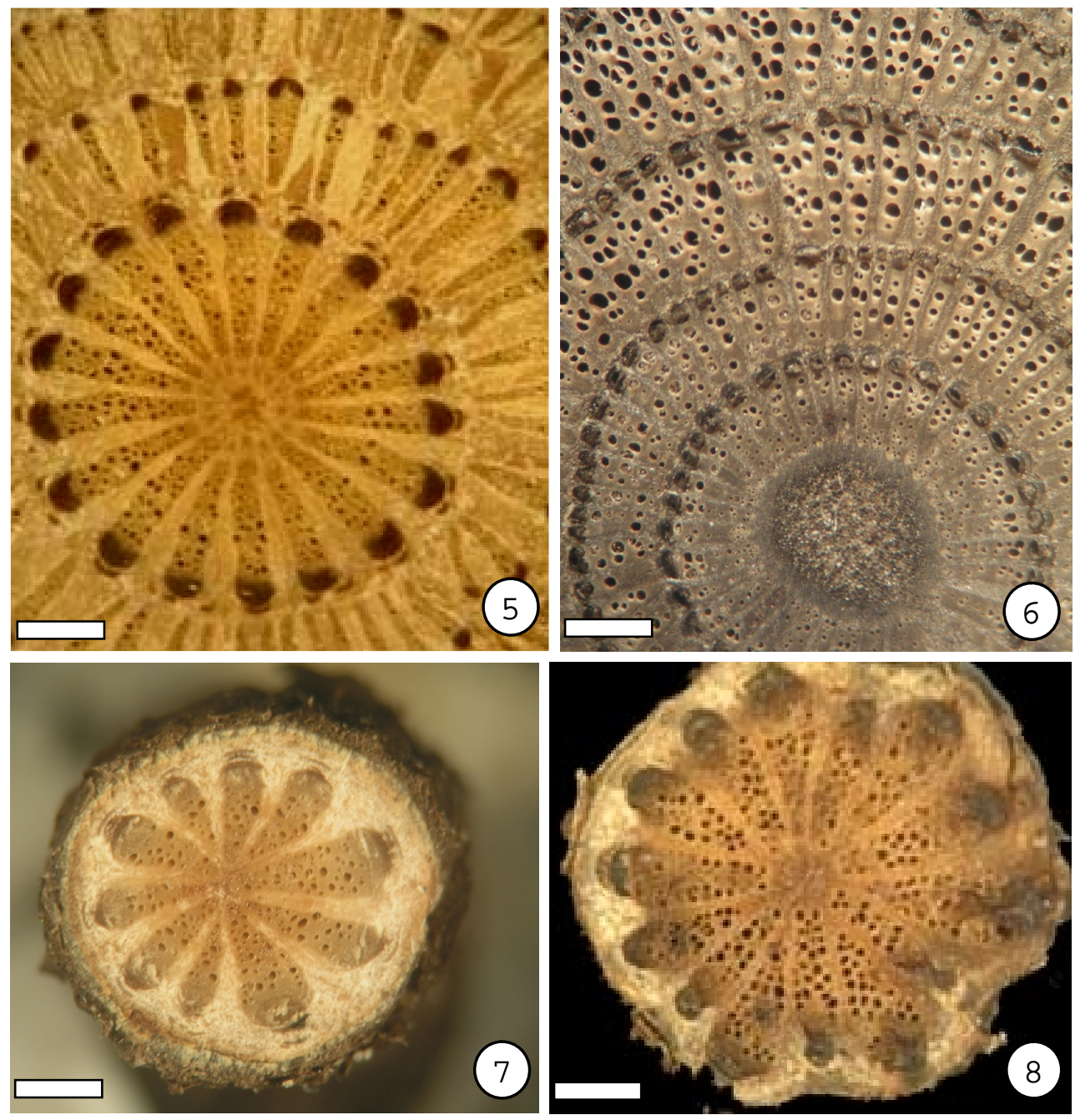

Figuras 5-8. Observação macroscópica do caule de trepadeiras. Seção transversal. 5-6. Lianas, com variação cambial do tipo câmbios sucessivos. 5. Chondrodendron platiphyllum. 6. Abuta convexa. 7-8. Trepadeiras herbáceas, sem câmbios sucessivos. 7. Disciphania hernandia. 8. Ungulipetalum filipendulum. Barra $=1 \mathrm{~mm}$. 


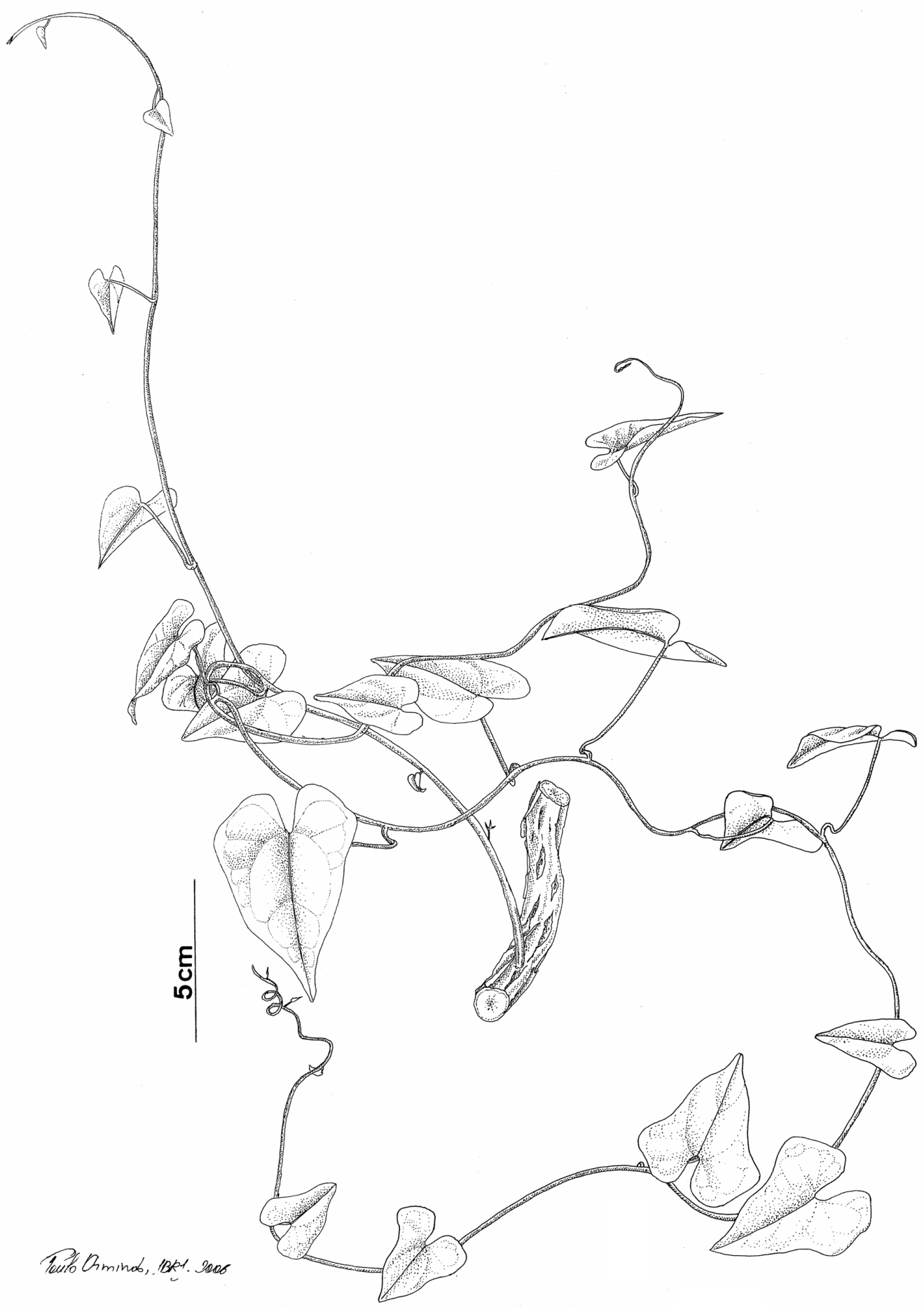

Figura 9. Rebroto de Odontocarya tamoides em um fragmento do caule após coleta. 


\section{RESULTADOS}

\subsection{Desenvolvimento do caule em trepadeiras herbáceas} lianas

Foram analisadas três espécies de lianas e quatro de trepadeiras herbáceas, relacionadas a seguir: Abuta convexa (Rbw 8696 - liana), Abuta imene (Rbw 8698 - liana), Chondrodendron platiphyllum (Rbw 8700 - liana), Cissampelos andromorpha (Rbw 8701; SPF 149.075 - trepadeira herbácea), Odontocarya vitis (Rbw 8706; Rbw 8707 - trepadeira herbácea), Ungulipetalum filipendulum (Rbw 8708; Rbw 8709 trepadeira herbácea) .

Tanto as trepadeiras herbáceas quanto as lianas apresentam padrões de desenvolvimento muito similares. Por esse motivo, será apresentada a seguir uma descrição que envolve todas as espécies mencionadas acima.

Em seções transversais próximas ao ápice caulinar, observa-se a epiderme com tricomas tectores e glandulares (Figuras 10, 11, 13 e 14), com exceção de Disciphania hernandia (Figura 12). As células epidérmicas são maiores no sentido anticlinal, caracterizando o formato retangular (Figuras 12 a 15).

O córtex está constituído por células arredondadas e ovaladas, com muitas células de núcleos proeminentes (Figura 12), sendo que a camada mais interna, nos trechos contíguos às regiões interfasciculares, se destaca pela presença de células com amiloplastos (Figura 15). Essas células constituem a endoderme, que se apresenta nítida nesses trechos (Figura 15). Na porção restante, a endoderme não possui amiloplastos, apresentando células de diâmetro variado, tornando-se, muitas vezes, de difícil distinção entre as células pericíclicas - menores - e as demais células corticais - maiores (Figuras 11 e 14). 
o periciclo plurisseriado está caracterizado como camadas mais externas de células precursoras de fibras e internamente por células parenquimáticas de maior calibre, caracterizando "calotas" que recobrem o tecido floemático. Esses dois tipos de células pericíclicas são visíveis nas Figuras 10, 12 e 13. Entre essas calotas ocorrem células parenquimáticas pericíclicas em todas as espécies, com exceção de Disciphania hernandia (Figura 12). Nessa espécie, o periciclo está constituído inteiramente por células precursoras de fibras, configurando um cordão contínuo (Figura 12). Em Cissampelos andromorpha (Figura 13) é possível observar os três tipos de células pericíclicas: células precursoras de fibras de menor calibre, que envolvem as células parenquimáticas de calibre maior. Esse conjunto de células forma calotas que são entremeadas por células parenquimáticas.

Observa-se a diferenciação do protofloema e protoxilema nas Figuras 12 e 13. A disposição do sistema vascular, isto é, dos feixes vasculares, juntamente com o tecido pericíclico, é diferenciada entre as trepadeiras herbáceas e as lianas. Os sistemas vasculares se dispõem no mesmo nível nas lianas, como em Abuta convexa (Figura 11), enquanto nas trepadeiras herbáceas eles se dispõem de forma desnivelada, isto é, assumindo a forma ondulada, como em Cissampelos andromorpha (Figura 10).

o protoxilema está constituído por elementos traqueais e parênquima nas trepadeiras herbáceas (Figura 13). Por outro lado, nas lianas, além de algumas células parenquimáticas, observa-se uma grande quantidade de células que assumem a posição abaxial ao protoxilema (Figura 16). Em seção longitudinal, essas células evidenciam-se como precursoras de fibras (Figura 17).

No final da diferenciação primária, os raios medulares tornam-se evidentes. Nas Figuras 16 e 17, observam-se os 
raios medulares como células de origem do tecido fundamental alongadas no sentido axial e longitudinal. Na Figura 17, pode-se ver, também, células medulares, as quais são mais curtas e de maior calibre que as do raio medular. Ressalta-se que a disposição ondulada dos sistemas vasculares nas trepadeiras herbáceas (Figura 10) favorece a presença de raios medulares.

Conforme o desenvolvimento caulinar progride, há uma mudança no formato das células epidérmicas quando são observadas em seção transversal, passando de retangulares a tabulares, ou levemente quadrangulares, sendo, no geral, maiores no sentido periclinal (Figura 18), com exceção de Disciphania hernandia, cujas células epidérmicas se apresentam de arredondadas a quadradas (Figura 19). A cutícula se apresenta espessa em todas as espécies (Figuras 18 e 20 a 23), com exceção de Disciphania hernandia, onde ela é imperceptível (Figura 19). Em microscopia de fluorescência evidencia-se que nas lianas a cutícula recobre totalmente algumas células (Figura 23). O teste para lignina apresentou resultado negativo.

As camadas corticais mais externas de ambos os hábitos possuem formato de arredondado a ovalado, enquanto as mais internas - de 2 a 3 - são aproximadamente retangulares e com contorno sinuoso (Figuras 24 e 25 ).

É possível perceber a instalação do crescimento secundário na Figura 26 por meio da formação, ainda sem diferenciação, do xilema secundário. Ainda na Figura 26, percebe-se a diferenciação das fibras do protoxilema.

Com o desenvolvimento em progresso, ocorre a diferenciação das camadas mais externas do periciclo pela deposição de parede secundária e lignificação, isto é, ocorre a diferenciação das fibras pericíclicas (Figuras 24 e 26). 
Ressalta-se, principalmente nas lianas, que algumas células pericíclicas da camada mais externa, ou seja, adjacente à endoderme, não se lignificam (Figuras 26 e 27). Houve dificuldades na diagnose dessas células - se endodérmicas ou pericíclicas, os seguintes eventos foram primordiais: (1) ocorrência dessas células entre células pericíclicas lignificadas (Figura 27); (2) células endodérmicas com amido (Figura 28) ou não (Figura 29) externamente a essas células.

Concomitante com o processo de instalação do crescimento secundário, ocorrem divisões nas células pericíclicas não lignificadas (Figuras 30 a 34 ). Essas células assumem o formato irregular e de contorno sinuoso (Figura 35), constituindo uma camada de duas a três células de largura (Figura 36), caracterizando a sua condição meristemática.

Em todas as espécies, as camadas mais externas do periciclo diferenciam-se em fibras e as camadas mais internas do periciclo, adjacentes ao floema, permanecem parenquimáticas (Figuras 37 a 39 e 41). Na Figura 39, é possível observar o periciclo parenquimático em divisão, produzindo novas células parenquimáticas.

Em todas as espécies, com exceção de Disciphania hernandia, que já apresenta o periciclo em cordão contínuo de fibras desde o início do desenvolvimento (Figuras 12, 37 e 38), em algumas células pericíclicas da região interfascicular deposita-se a parede secundária, com posterior lignificação (Figuras 40 a 42). Esses grupos de células interfasciculares ligam-se às calotas de fibras pericíclicas, resultando em um cordão pericíclico sinuoso (Figura 44), e essa sinuosidade caracteriza a presença de sulcos. Esse grupo de células foi diagnosticado como sendo de natureza pericíclica pela posição que ocupa, isto é, 
logo abaixo da endoderme. A endoderme foi detectada pela presença de amiloplastos (Figura 43).

o câmbio de origem procambial origina os tecidos axiais (Figura 45). Já o câmbio de origem pericíclica origina somente raios vasculares, o que pode ser detectado, na sua condição inicial, nas Figuras 46 e 50 .

O câmbio interfascicular é de difícil constatação. Na maioria das vezes, ele se apresenta como na Figura 47, ou seja inativo. Ainda nesta figura, foi observado que o câmbio de origem procambial também se apresenta inativo, pois não se verificou diferenciação de células.

Os raios floemáticos são constituídos por poucas células - de duas a três (Figura 50) -, nas quais, muitas vezes, há deposição de parede secundária e lignificação, assemelhando-se às células pericíclicas, que também passam por esse processo de deposição de parede secundária (Figura 49). O resultado desse evento é a conexão dos raios floemáticos ao periciclo, ambos lignificados (Figuras 48 e 49). As células radiais das trepadeiras herbáceas permanecem com parede primária (Figura 52). Já nas lianas ocorre lignificação (Figura 52), exceto em Chondrodendron platiphyllum.

Por outro lado, as células radiais permanecem com parede primária, como pode ser observado nas Figuras 49, 51 a 52 .

As Figuras 51 e 52 ilustram o caule em estrutura secundária, onde são observadas as células axiais do xilema e do floema produzidas pelo câmbio de origem procambial e as células radiais floemáticas e xilemáticas, produzidas pelo câmbio de origem pericíclica. Dessa maneira, forma-se uma configuração em que os elementos axiais ficam separados entre si por raios largos. Nas trepadeiras herbáceas, esse é o único padrão (Figura 52). Já nas lianas esse anel tem crescimento limitado e posteriormente novos câmbios serão 
adicionados centripetamente, formando-se, assim, os anéis sucessivos, como evidenciados na Figura 53. Ainda nas Figuras 51 e 52, é possível observar diferenças quanto à medula, que é mais ampla nas lianas.

\subsection{Origem do tecido conjuntivo e dos câmbios sucessivos na liana Abuta imene}

Verifica-se a presença de câmbios sucessivos nos caules de todas as lianas listadas no item Material e Métodos (Tabela 1). O estudo sobre a origem dos câmbios sucessivos foi realizado em Abuta imene.

Depois de uma considerável atividade secundária (Figura 53), foram observadas divisões celulares em células pericíclicas parenquimáticas que tangenciam externamente o periciclo lignificado (Figuras 54 a 56). As divisões ocorrem em toda a circunferência do caule, tangenciando externamente o periciclo, tanto na região das fibras pericíclicas quanto na região dos sulcos, onde ocorrem as células parenquimáticas pericíclicas lignificadas (Figuras 54 e 56).

Nota-se que essas células em divisão se localizam internamente na endoderme, como mostram as Figuras 55 e 56, reforçando ainda mais a origem pericíclica das mesmas.

Neste trabalho, o tecido neoformado é denominado de tecido conjuntivo. Inicialmente, esse tecido é formado por aproximadamente dez camadas de células, com formato retangular, que se dispõem em pilhas, sendo que cada pilha teve origem a partir de uma única célula pericíclica meristemática, como se pode observar nas Figuras 57 e 58.

Separando essas camadas, há uma linha de esclereídes do tecido conjuntivo, subdividindo-o em duas partes. A parte mais interna dará origem a várias porções cambiais, 
que, por sua vez, originarão vários novos cordões vasculares secundários, que serão responsáveis pela formação do segundo anel vascular do caule. Por outro lado, a parte mais externa do tecido conjuntivo permanecerá parenquimática durante a instalação do segundo anel (Figura $57)$.

Essas primeiras porções cambiais surgem, a princípio, nas regiões dos sulcos (Figura 57), formando no floema, inicialmente, elemento de tubo crivado e parênquima axial, e no xilema, fibras e parênquima axial (Figuras 58 e 59).

Entre os cordões neoformados diferenciam-se novos câmbios que formarão somente raios (Figura 58, 60 e 62). Note na Figura 63 que os raios floemáticos são produzidos em menor quantidade quando comparados com os raios do xilema.

Mesmo após a instalação do novo anel, o tecido conjuntivo externo continua a se dividir (Figuras 61 e 63). Ele está caracterizado por células com formato arredondado e sem o empilhamento característico do tecido conjuntivo interno.

Externamente à linha de esclereídes pericíclicas, foi possível observar, além de células do tecido conjuntivo, células da endoderme com amiloplastos (Figura 64).

Cristais prismáticos também estavam presentes em células do tecido conjuntivo (Figura 64) e em células da linha de esclereídes (Figuras 62 e 63).

o padrão descrito se repetirá inúmeras vezes, isto é, - tecido conjuntivo externo sofrerá mais divisões, e uma porção desse tecido se diferenciará no segundo cordão de esclereídes, subdividindo o tecido conjuntivo em externo e interno - o tecido conjuntivo interno formará novos câmbios que darão origem aos novos cordões vasculares e novos raios entre os mesmos, originando, portanto, o terceiro anel vascular, e assim sucessivamente, à medida que ocorre o 
crescimento em espessura do caule. Essas etapas sucessivas podem ser observadas em Chondrodendron platiphyllum na Figura 65.

\subsection{O caule nos diferentes hábitos}

\subsubsection{O aspecto geral}

Os aspectos gerais dos caules estudados, estão representados, em seção transversal, nas Figuras 65 e 68 a 79. Nas lianas e no arbusto, observam-se os anéis vasculares sucessivos (Figuras 65, 74 a 79 e 111), que estão ausentes nas trepadeiras herbáceas (Figuras 68-73).

\subsubsection{O sistema de revestimento e o córtex}

A periderme está presente em todos os hábitos, exemplificada na Figura 66 pela liana Chondrodendron platiphyllum, e na Figura 67, pela trepadeira herbácea Cissampelos andromorpha. O felogênio instala-se nas camadas corticais mais externas, muitas vezes, em posição subepidérmica (Figura 67), permanecendo uma considerável porção cortical nos espécimes analisados. A periderme é composta pela feloderme, que é constituída de uma a seis camadas de células retangulares, de paredes primárias, e pelo súber, com dez ou mais camadas de células suberizadas, e, em muitos espécimes, esclerificados.

O córtex, conforme supracitado, permanece nos estágios mais desenvolvidos. Nas lianas, algumas células formam parede secundária, que se distribuem de maneira difusa nessa região (Figura 66).

o córtex nas trepadeiras herbáceas é variável em tamanho e composição celular, apresentando células de 
grandes calibres (Figura 68), de médios (Figura 70) e de pequenos (Figura 69).

Em Odontocarya vitis (Figura 70), observa-se uma faixa de esclereídes corticais circundando completamente o caule.

\subsubsection{O floema secundário}

O floema secundário nos cordões vasculares, exemplificado na Figura 75, está composto por elementos de tubos crivados, células companheiras, parênquima axial (Figuras 80 e 81) e, mais raramente, por raios unisseriados e curtos (Figura 85).

Os elementos de tubos crivados são de pequeno calibre nas trepadeiras herbáceas e no arbusto analisado, (Figuras 68 a 70) e, geralmente, de grande calibre nas lianas analisadas (Figuras 77 e 79) - exceto em Chondrodendron platiphyllum, que apresenta elementos de tubos crivados de pequeno calibre (Figuras 65 e 75). Os elementos de tubos crivados apresentam uma distribuição difusa nas lianas (Figura 80) e uma tendência à distribuição radial nas trepadeiras herbáceas (Figura 81), e possuem placa crivada simples ou composta (Figura 84), podendo ocorrer os dois tipos no mesmo caule. As células companheiras são bem evidentes, ocorrendo uma por elemento de tubo crivado (Figuras 80 e 81), podendo ser solitárias ou em série de duas a três células (Figura 83). Os elementos de tubo crivados podem conter amiloplastos (Figura 82). As células parenquimáticas axiais podem apresentar diâmetro semelhante aos elementos de tubos crivados (Figura 83), dificultando a separação entre esses tipos de células em seção transversal (Figura 80), e com possibilidade de terem maior diâmetro em outras espécies (Figura 81).

Nas trepadeiras herbáceas, é comum a instalação de novos raios, ao lado dos raios unicelulares, na porção dos 
cordões vasculares (Figura 86). Tal evento ocorre em razão da modificação das iniciais cambiais fusiformes em iniciais radiais ao lado de um raio unicelular. Assim, instalam-se, raios largos tanto floemáticos quanto xilemáticos (Figuras 86 a 88). Nessas figuras, pode-se observar que o novo raio floemático é dilatado. Os raios neoformados surgem entre os elementos axiais do floema condutor e não condutor, conectando-se ao tecido pericíclico proliferado. Ainda nas Figuras 86 a 88 , nota-se que algumas células radiais se lignificam.

Os raios floemáticos entre os cordões vasculares de elementos axiais do xilema e floema são largos, como os raios xilemáticos dessa mesma região, porém, são constituídos por poucas células durante o início do desenvolvimento (Figura 50). À medida que o caule cresce em espessura, há uma maior produção de células radiais floemáticas, como pode ser observado na Figura 87.

No floema condutor, os elementos de tubos crivados estão íntegros, percebendo-se nitidamente suas células companheiras, com citoplasma denso (Figura 83). Uma das primeiras características observadas no floema não condutor é o início do colapso dos elementos de tubos crivados (Figuras 80 e 81). Posteriormente, todos os elementos de tubos crivados sofrem colapso, formando faixas escuras geradas pela sobreposição das várias paredes primárias dos elementos de tubos crivados colapsados. Essa situação é exemplificada, em detalhes, nas Figuras 75 e 79 e nas Figuras 80 e 81. No primeiro anel vascular, ocorre o colapso não só dos elementos de tubos crivados do floema secundário, como também do floema primário, juntamente com algumas células do periciclo parenquimático (Figuras 80 e 81 ). 


\subsubsection{Xilema}

Os aspectos gerais dos diferentes caules analisados quanto ao xilema secundário, em seção transversal, estão representados nas Figuras 65, 68 a 79. Nessas figuras, observa-se porosidade difusa, vasos solitários em sua maioria e eventuais múltiplos de dois a três.

Os vasos apresentam apêndices (Figuras 89 a 90) ou não (Figura 91). Os apêndices podem estar presentes apenas em uma extremidade do vaso (Figura 89) ou em ambas (Figura $90)$.

Foram observados vasos de maior e menor diâmetros, cujo teste de freqüência apontou quatro categorias: grandes $(>150 \mu \mathrm{m})$; médios $(101-150 \mu \mathrm{m})$; pequenos $(50-100 \mu \mathrm{m})$ e muito pequenos $(<50 \mu \mathrm{m})$. Os elementos de vasos apresentam placas de perfuração simples, com posição transversal (Figura 91) ou oblíqua (Figuras 89 a 90).

As pontoações radiovasculares são areoladas (Figura 92), semelhantes às pontoações dos vasos (Figuras 93 e 94). Destacam-se que as pontoações localizadas nas extremidades dos elementos de vasos são de simples a semi-areoladas, de arredondadas a ovais e maiores que as demais (Figuras 93 e 94). Constatou-se que essas pontoações correspondem às parênquimo-vasculares (Figura 94).

Os tilos foram observados em todas as espécies, e apresentam paredes finas, isto é, primárias (Figuras 95, 79 e 97), ou paredes secundárias e lignificadas (Figuras 77 e 96). É interessante observar que um tilo pode apresentar mais de uma célula, tornando-se seriado (Figura 95).

Com relação ao parênquima axial, observamos tendências quanto ao hábito. Nas trepadeiras herbáceas, é escasso e ausente (Figuras 98 e 99). As lianas têm parênquima difuso e difuso em agregados, com tendência a formar linhas e paratraqueal escasso (Figuras 100 a 103). 
Os raios de origem pericíclica são muito largos (Figuras 68 a 79, 104 e 105). Podem ocorrer células axiais, denominadas de células envolventes, que tangenciam algumas regiões do raio, porém nunca completamente. Essa condição está exemplificada nas Figuras 104 a 107.

As lianas possuem raios com células lignificadas, com exceção de Chondrodendron platiphyllum (Figura 75), e as trepadeiras herbáceas têm raios não lignificados (Figuras 68 a 73). Os raios não lignificados podem apresentar, principalmente em caules bem amadurecidos, porções lignificadas cuja distribuição é variada. Em Ungulipetalum filipendulum, apenas as células radiais que estão na margem são lignificadas (Figura 107), enquanto em Odontocarya tamoides (Figura 72) e Cissampelos andromorpha (Figura 71) a parte interna do raio, ou seja o corpo, pode conter células lignificadas, sendo que em $O$. tamoides as células têm um maior grau de lignificação (Figuras 72 e 108).

Esses raios largos são extremamente longos (acima de 5 cm) e constituídos por células procumbentes e quadradas (Figuras 112 e 113). Na Figura 112, observe que o raio não lignificado possui células de tamanhos variados.

Raios de origem procambial são raros, e, quando presentes, são estreitos (de uma a três células de largura) e curtos (até oito células de altura), como mostram as Figuras 109 e 110 .

Nas lianas e na espécie arbustiva, os raios formados a partir do câmbio de origem do tecido conjuntivo possuem configuração similar ao do primeiro anel. Ressalta-se que são raras as conexões entre os raios vasculares nos diferentes anéis sucessivos (Figura 111).

As traqueídes estão presentes, sendo mais bem observadas em material dissociado. Elas apresentam pontoações areoladas geralmente dispostas em duas fileiras (Figuras 114 e 115). São vasicêntricas, como pode ser 
observado na Figura 120 em seção tangencial, com terminações arredondadas (Figuras 120 e 121), podendo assumir formas variadas (Figuras 121 e 122).

As fibrotraqueídes são comuns e diferem das traqueídes por apresentarem terminações mais afiladas, além de serem mais longas e terem uma fileira de pontoações areoladas (Figuras 117, 118 e 119).

As fibras libriformes, geralmente, não são septadas (Figuras 114, 115 e 119), sendo septadas apenas no primeiro anel do arbusto Abuta grandifolia (Figura 116). Elas podem apresentar amido como em Chondrodendron platiphyllum, estando ausente nas fibrotraqueídes do mesmo caule (Figura 119) .

Todas as lianas apresentam camadas de crescimento, exemplificadas aqui por Anomospermum sp. e Hyperbaena domigensis (Figuras 123 a 127). Nessas espécies, podem ser vistos 0 espessamento e o achatamento radial das fibras e das células radiais correspondentes (Figura 124), além da dilatação dos raios (Figura 125). Ressalta-se que a camada de crescimento envolve poucos cordões vasculares secundários, normalmente de três a seis.

Ainda em Anomospermum sp. é comum, no início do anel vascular sucessivo, a presença de camadas de crescimento demarcadas por cordões vasculares destituídos de vasos e constituídos essencialmente por fibras apenas em poucas células parenquimáticas axiais (Figuras 126 e 127). A análise de material dissociado dessa região mostrou que são fibras libriformes, enquanto o restante do cordão vascular está constituído por fibrotraqueídes.

\subsubsection{Ruptura de raios}

A ruptura de raios foi observada em todas os hábitos estudados. Os raios, conforme mencionado anteriormente, são 
muito longos (Figura 128). As Figuras 129-133 ilustram a sequiência de eventos na ruptura dos raios para Cissampelos andromorpha. No processo de ruptura, algumas células iniciais radiais se diferenciam em iniciais fusiformes, que darão origem a células do sistema axial, tanto xilemático quanto floemático, que interrompem o raio. Essas células são inicialmente parenquimáticas, constituídas de parede primária, como as células radiais (Figuras 129 e 130), havendo posterior diferenciação em fibras (Figura 128) e elementos de vasos (Figuras 131 e 132). O mesmo processo ocorre nos raios floemáticos, onde se observa raio interrompido por elementos de tubos crivados e células companheiras (Figura 133).

\subsection{Amiloplastos no caule}

Nos caules de todas as espécies estudadas, inclusive a espécie arbustiva e a herbácea, foi constatada uma abundância de amiloplastos.

Em caules mais jovens, foram observados amiloplastos presentes na medula, raios medulares, raios vasculares, floema, periciclo parenquimático, esclereídes e córtex (Figura 134). Em estágios mais avançados, os amiloplastos continuam presentes em abundância nos mesmos tecidos de quando o caule estava no início do crescimento (Figura 135). Nas lianas, observa-se amiloplastos no tecido conjuntivo e nos raios formados pelo câmbio de origem pericíclica (Figura 136). Destaca-se a presença de amiloplastos em esclereídes de origem do periciclo e do tecido conjuntivo (Figuras 137 e 138), e em tilos, no interior de elementos de vasos (Figura 139). Amiloplastos em tilos foram observados apenas em Cissampelos andromorpha. 


\subsection{Raiz}

\subsubsection{Desenvolvimento em trepadeiras herbáceas}

\subsubsection{Cissampelos andromorpha}

A raiz de C. andromorpha em crescimento secundário avançado é ilustrada na Figura 140.

O sistema de revestimento é uma periderme, onde se observa o súber, o felogênio e a feloderme (Figuras 141 e 142). Em porções mais jovens da raiz, nota-se que o felogênio se originou a partir de células pericíclicas, visto que esclereídes pericíclicas estão tangenciando a periderme, como se pode ver na Figura 140. O súber está composto de cinco a oito camadas de células com paredes delgadas e suberizadas. A feloderme apresenta de duas a três camadas de células com paredes delgadas. Tangenciando a feloderme, observam-se células pericíclicas parenquimáticas e esclereídes pericíclicas (Figura 142).

Com o aumento da circunferência da raiz, surgem novos raios, em razão do aparecimento de iniciais radiais em locais do câmbio onde só havia iniciais fusiformes (Figura 140). Outra reorientação das iniciais cambiais ocorre com as radiais que se transformam em iniciais fusiformes, formando novos cordões vasculares onde só havia raios largos (Figura 140).

A raiz não apresenta medula (Figura 140) .

\subsubsection{Disciphania hernandia}

As porções terminais das raízes laterais de Disciphania hernandia, próximas à extremidade, apresentamse espessadas (Figura 143). 
Após essa porção espessada, a raiz volta a assumir um menor calibre (Figura 143) e as seções transversais dessa porção são mostradas nas Figuras 144 e 145 .

Constata-se que se trata de uma raiz diarca, observando-se os dois raios largos formados em frente aos dois pólos de protoxilema.

O sistema de revestimento é uma periderme (Figuras 144 e 145), onde se observa o súber, o felogênio e a feloderme (Figura 145). O súber é composto por várias camadas de células delgadas e suberizadas, e pela feloderme, que apresenta paredes muito delgadas, compostas por duas a três camadas de células (Figura 145).

Seções transversais do aspecto geral da raiz espessada podem ser vistas nas Figuras 146-147. Observa-se um processo de parenquimatização em razão da intensa divisão, do tipo anticlinal, oblíqua e periclinal, das células parenquimáticas do sistema vascular, isto é, células do periciclo, floema e xilema (Figuras 146 e 147). Por causa da parenquimatização do tecido, os elementos condutores do xilema e floema estão em número reduzido (Figuras 146 e 147). Em teste específico, percebe-se a grande quantidade de amiloplastos nas células parenquimáticas, caracterizando, assim, como tecido de reserva (Figuras 148 e 149).

\subsubsection{Odontocarya vitis}

A raiz de Odontocarya vitis pode ser triarca em estágio inicial de crescimento secundário (Figura 150) ou diarca em estágio secundário mais avançado (Figura 153), sem medula.

o sistema de revestimento no início do crescimento secundário (Figura 150) é uma epiderme representada como células pequenas em relação às demais células corticais 
(Figura 151). Abaixo da epiderme ocorre uma camada de células levemente maiores que as demais, constituindo a exoderme (Figuras 150 e 151).

Observa-se a instalação do felogênio a partir de células corticais (Figuras 150 e 151). A epiderme e exoderme são eliminadas e o súber está caracterizado por aproximadamente dez camadas de células suberizadas e pela feloderme, com cerca de duas camadas de células de paredes primárias (Figura 152).

A endoderme pode ser detectada pelo formato retangular (Figura 152), e logo abaixo constata-se o periciclo com uma a duas camadas de células (Figura 152).

\subsubsection{Ungulipetalum filipendulum}

A raiz de $U$. filipendulum em início de crescimento secundário pode ser observada na Figura 154 .

Observa-se epiderme com células de contorno irregular e tricomas tectores (Figura 155). Abaixo da epiderme, observa-se a exoderme composta por células um pouco maiores que as outras células corticais (Figuras 154 e 155). O restante do córtex está constituído por 5-6 camadas de células de formato circular a irregular, e pela endoderme, cujas células têm formato retangular e estão justapostas (Figura 155).

O periciclo está representando por uma a duas camadas de células (Figura 155).

Essa raiz não apresenta medula nesse estágio de desenvolvimento (Figuras 154, 156 e 157), e está representada por células já lignificadas. Em teste específico, essas células lignificadas se apresentam com amiloplastos (Figura 157).

Com a instalação do câmbio de origem procambial, é possível perceber que se trata de uma raiz diarca, 
observando-se os dois pólos de protoxilemas (Figuras 154, 156 e 157).

Em fase mais avançada do desenvolvimento da raiz, observa-se a instalação de uma medula, constituída por células de parede primária (Figuras 158 e 159). Nesse estágio, os raios produzidos pelo câmbio de origem procambial, formados em frente aos pólos de protoxilema, são evidentes, e estão compostos por células parenquimáticas de paredes primárias (Figuras 158 e 160). Por outro lado, também podem ser observados dois raios com células parenquimáticas de paredes primárias, formados pelo câmbio de origem procambial, que se localizam um oposto ao outro (Figuras 158 e 159). Esses dois raios cruzam as células axiais do xilema secundário e se conectam à medula, como se observa nas Figuras 158 e 159. Após várias divisões celulares, tanto desses dois raios quanto da medula, a raiz apresenta uma faixa parenquimática, de origem medular e vascular, que cruza o cilindro vascular, separando-o em duas metades (Figura 160). Nesse estágio de desenvolvimento, novos raios são formados, em razão da diferenciação de iniciais radiais na porção cambial em que só havia iniciais fusiformes (Figura 160).

\subsubsection{Aspectos anatômicos do tecido vascular da raiz em trepadeiras herbáceas}

\subsubsection{Floema}

O floema condutor está composto por elementos de tubos crivados, células companheiras, parênquima e raios (Figuras 161 e 162). Os elementos de tubos crivados têm uma forma aproximadamente retangular, e possuem calibre variável, podendo ser mais largos, como em Cissampelos andromorpha (Figura 161) e Disciphania hernandia (Figura 162), ou 
estreitos, como em Odontocarya vitis (Figura 163) e Ungulipetalum filipendulum (Figura 164). Eles apresentam distribuição radial (Figuras 161, 162 e 164) ou difusa entre as células parenquimáticas (Figura 163). Entre os elementos axiais ocorrem raios, geralmente, unisseriados, tornando difícil, em um primeiro momento, a separação entre eles e as células axiais (Figura 164). Novos raios são formados por causa do aparecimento de iniciais radiais em locais do câmbio em que só havia iniciais fusiformes (Figura 163), e estes são multisseriados, apresentando grande quantidade de amiloplastos (Figuras 161 e 164).

No floema não condutor, foi constatado o colapso dos elementos de tubos crivados, observando-se a justaposição das paredes deles (Figuras 161, 162 e 164). Percebe-se, também, que pode ocorrer o colapso de células parenquimáticas do periciclo (Figuras 161 e 164).

\subsubsection{Xilema}

Os vasos apresentam porosidade difusa, são solitários em sua maioria (Figuras 161 e 164) ou múltiplos de dois (Figuras 162 e 163), e mais raramente múltiplos de três. Eles apresentam vasos de maior e menor calibre, como se observa nas Figuras 161 a 164.

Os elementos de vasos apresentam placas de perfuração simples, com posição transversal ou oblíqua (Figuras 166, 167, 168 e 169). Os apêndices podem estar presentes ou ausentes (Figura 166). Se presentes, eles podem estar apenas em uma extremidade do elemento de vaso (Figuras 167 e 168) ou em ambas as extremidades (Figura 169), e podem ser curtos (Figura 167) ou longos (Figuras 168 e 169).

Os tilos foram observados nos vasos de Cissampelos andromorpha (Figura 165). 
o parênquima é inexistente e escasso (Figuras 161 a $164)$.

Entre os elementos axiais (Figura 164) ocorrem raios, geralmente unisseriados. Novos raios são formados em razão do aparecimento de iniciais radiais em locais do câmbio em que só havia iniciais fusiformes, e estes são multisseriados, apresentando grande quantidade de amiloplastos (Figuras 161 e 164).

Somente fibrotraqueídes foram observadas (Figuras 170 a 172). Traqueídes também estão presentes.

\subsubsection{Estrutura secundária da raiz do arbusto Cissampelos ovalifolia}

Em estrutura secundária jovem, a raiz apresenta-se como diarca e destituída de medula (Figuras 173 e 174). A epiderme está representando as células pequenas e de formato irregular (Figura 173). Abaixo da epiderme localiza-se a exoderme, cujas células são mais espessas e maiores que as epidérmicas (Figura 173). O córtex está constituído por cinco a oito camadas de células (Figura 173) .

o sistema de revestimento em estrutura secundária avançada é uma periderme, que tangencia as células parenquimáticas pericíclicas, indicando que a diferenciação do felogênio se dá no periciclo (Figuras 175 e 176). A periderme está constituída por algumas camadas de súber e pela feloderme, com duas a três camadas de células de paredes delgadas (Figuras 175 e 176). Com a instalação da periderme, o córtex será eliminado (Figura 175).

o periciclo está composto por uma a duas camadas de células parenquimáticas e duas a quatro camadas de esclereídes, que formam um cordão ao redor do cilindro vascular (Figuras 174 a 177). 
O floema primário encontra-se parcialmente colapsado e - floema secundário é inteiramente condutor, apresentando elementos de tubos crivados com suas células companheiras e células parenquimáticas em distribuição aleatória. (Figura 176). O xilema secundário está composto por elementos de vasos de dois calibres: maiores e menores, em sua maioria, solitários. Os vasos apresentam placa de perfuração simples. O parênquima axial está ausente (Figuras 174 e 175). Novos raios são formados, por causa da diferenciação de iniciais radiais em locais do câmbio em que só havia iniciais fusiformes, e estes são multisseriados (Figura $174)$.

\subsubsection{Estrutura secundária da raiz da liana de Chondrodendron platiphyllum}

A raiz em crescimento secundário pode ser observada na Figura 178. Trata-se de uma raiz excêntrica e sem medula. O cilindro vascular está envolvido por um cordão de esclereídes pericíclicas (Figura 178). Como no caule, células pericíclicas parenquimáticas se dividem, formando pilhas de células, caracterizando o tecido conjuntivo (Figuras 179 e 180). Algumas células localizadas no meio desse tecido se lignificam, formando assim o segundo cordão de esclereídes (Figuras 179 e 180). As células mais externas darão origem ao terceiro anel sucessivo, e assim por diante (Figura 182).

Diferentemente do caule, no início, há uma grande produção de tecido conjuntivo e surgem poucos câmbios. Na Figura 181, pode-se observar apenas um novo cordão vascular, resultando da atividade de um novo câmbio, mas também se observa o tecido conjuntivo se dividindo, dando origem a novas células cambiais, dispostas lado a lado (Figura 181). Também de forma distinta do caule, apenas a 
primeira faixa de esclereídes de origem pericíclica circunda totalmente o cilindro vascular, como se vê na Figura 182. As faixas formadas posteriormente pela atividade do tecido conjuntivo não envolvem totalmente os novos anéis vasculares, apenas parcialmente, em forma de meia lua, concentrando-se em um lado do órgão, o que mantém a excentricidade do caule, como se observa na Figura 182.

Como no caule, os diferentes tipos de raios los formados em frente aos pólos de protoxilema, os novos e os formados nos anéis sucessivos) possuem células somente com paredes primárias (Figuras 182 e 183). Também como no caule, há o colapso do floema não condutor secundário, juntamente com células do floema primário e periciclo nos cordões vasculares do primeiro anel, e juntamente com células parenquimáticas do tecido conjuntivo dos cordões vasculares dos anéis formados posteriormente (Figuras 182 e 183). O xilema apresenta elementos de vasos solitários e parênquima axial difuso, tendendo a formar linhas (Figura 182). O floema condutor apresenta elementos de tubos crivados com suas células companheiras em disposição radial (Figuras 183 e 184).

\subsection{Cristais no caule e na raiz}

A distribuição e a morfologia dos cristais, presentes em caules e raízes, constam na Tabela 2 .

Os cristais podem estar presentes em diversos tecidos, tanto do caule quanto da raiz. Os raios constituem o tecido de maior ocorrência, podendo estar nas células do corpo do raio (Figura 185) ou restritos na margem (Figuras 186 e 187). Conforme já abordado, constata-se cristais em esclereídes de origem do tecido conjuntivo (Figuras 62, 63 e 64), no parênquima conjuntivo, em células corticais 
(Figura 190) e em células parenquimáticas axiais do floema (Figura 187) e do xilema.

Há uma diversidade de cristais que podem ser prismáticos grandes ou pequenos (Figuras 185, 188 e 189), cúbicos (Figura 190) ou estilóides (Figura 191).

$\mathrm{Na}$ Tabela 2, pode-se observar que ocorre uma tendência quanto à morfologia do cristal para os hábitos liana e trepadeira herbácea. Os grandes cristais ocorrem mais freqüentemente nas lianas.

\subsection{Identificação do caule em objetos comercializados}

Vários objetos confeccionados com caules de lianas e trepadeiras herbáceas foram analisados (Figura 191) com o intuito de se identificar as espécies de Menispermaceae utilizadas. Verificou-se, dentre as diferentes amostras de caule que compõem os objetos, a presença de três caules pertencentes à essa família, macroscopicamente diferentes, que foram identificados como espécies (sp): sp1, sp2 e sp3 (Figura 192).

A olho nu ou com o uso de uma lupa de 10 vezes de aumento, constata-se que a espécie 1 (sp1) possui coloração mais clara que as demais, apresentando-se esbranquiçada a amarelada. Já as outras espécies, sp2 e sp3, possuem coloração acastanhada. A espécie 2 (sp2) se apresenta fistulosa, excêntrica e com casca mais espessa que as demais (Figura 192).

Confirma-se, através de análises microscópicas, que trata-se de três espécies diferentes. A espécie 1 (sp1) possui raios não lignificados, raios medulares conspícuos e lignificados e parênquima difuso escasso (Figura 193). Já a espécie 2 (sp2) possui raios lignificados, não apresenta raio medular e possui diâmetro de vasos maiores que as outras duas espécies e parênquima difuso escasso (Figura 
194). Enquanto que a espécie 3 (sp3), assim como a sp2 não apresenta raio medular e também possui raios lignificados, no entanto possui grande quantidade de parênquima do protoxilema lignificado (Figura 195) e parênquima difuso em abundância tendendo a formar linhas, além do apotraqueal escasso (Figura 195).

Além dessas características diagnósticas do xilema, nota-se que o diâmetro das células do floema são menores na espécie 1 (sp1). A espécie 3 (sp3) não pode ser avaliada com relação a este caráter, visto que, foi totalmente fragmentado durante o preparo técnico.

As características descritas para a espécie 1 (sp1) se assemelham a espécie estudada nesta tese, a liana Chondrodendron platiphyllum (Figura 75). Não foi possível inferir identificações para as outras espécies (sp2 e sp3). 
Tabela 2. Ocorrência de cristais no caule e raiz. Tipo e localização.

\begin{tabular}{|c|c|c|c|c|c|}
\hline Tribo & Táxon & $\begin{array}{l}\text { Prismáticos, } \\
\text { grandes }\end{array}$ & Prismáticos pequenos & Cúbicos & Aciculares \\
\hline \multirow[t]{4}{*}{ Tricliseae } & Chondrodendron platiphyllum & & & & \\
\hline & (caule) & $++(4,5)$ & $+(1,3,4,5,6,8,9)$ & $+++(1,3,5,6,8,9)$ & \\
\hline & (raiz) & & $++++(2,3,4,5,6,7)$ & & \\
\hline & Sciadotenia eichleriana & $+++(2,4,5)$ & $+++(2,4,5)$ & $+(2,4,5)$ & \\
\hline Hyperbaenae & Hyperbaena domingensis & $+++++(2,4,5)$ & $++(2,4,5)$ & $++(2,4,5)$ & \\
\hline \multirow{8}{*}{ Anomospermae } & Telitoxicum minutiflorum & - & - & - & - \\
\hline & Abuta convexa & $++(2)+(4,5)$ & & $+(2,4,5)$ & \\
\hline & Abuta imene & $++(2)++(4)$ & $+++(4)$ & & \\
\hline & Abuta grandifolia - liana & ++++ & $++(2)+,++++(6)$ & $++(2)+++++(6)$ & + \\
\hline & Abuta grandifolia - arbusto & - & - & - & - \\
\hline & Abuta grandifolia - árvore & - & - & - & - \\
\hline & Abuta selloana & $+(2)+++(5)$ & $++(4)$ & $++(8)$, & $++(8)$ \\
\hline & Anomospermum sp & $+(4,5)$ & & & \\
\hline \multirow[t]{7}{*}{ Tinosporae } & Odontocarya vitis & & & & \\
\hline & caule & & $++(1)$ & $++2,6,7,8$ & $++2,6,7,8$ \\
\hline & raiz & & & $++(1,2,6,7)$ & $++(1,2,6,7)$ \\
\hline & Odontocarya tamoides & & & $++1,7,8$ & \\
\hline & Disciphania hernandia & & & & \\
\hline & caule & & & $+++(1,6,7,8)$ & \\
\hline & raiz & & $+++(1)$ & $+(2,6,7)$ & \\
\hline \multirow[t]{8}{*}{ Menispermae } & $\begin{array}{l}\text { Cissampelos andromorpha } \\
\text { caule }\end{array}$ & - & - & - & - \\
\hline & raiz & & & $++(1,2,6)$ & \\
\hline & Cissampelos ovalifolia & & & & \\
\hline & caule & - & - & - & - \\
\hline & raiz & & & $+++(2)$ & $++++(2)$ \\
\hline & Ungulipetalum filipendulum & & & & \\
\hline & caule & & & $++(2,6,7)$ & \\
\hline & raiz & & & $+(6)$ & \\
\hline
\end{tabular}

$(-)$ ausência de cristais; $(+,++, \quad+++,+++)$ quantidade relativa de cristais. Tecidos nos quais os cristais ocorrem: (1) raio xilemático, principalmente nas células marginais (1); (2) raio, principalmente nas células do corpo; (3) parênquima axial xilemático; (4) tecido conjuntivo; (5) esclerênquima de origem do tecido conjuntivo; (6) córtex; (7) células parenquimáticas do floema; (8) medula; (9) raio medular. 

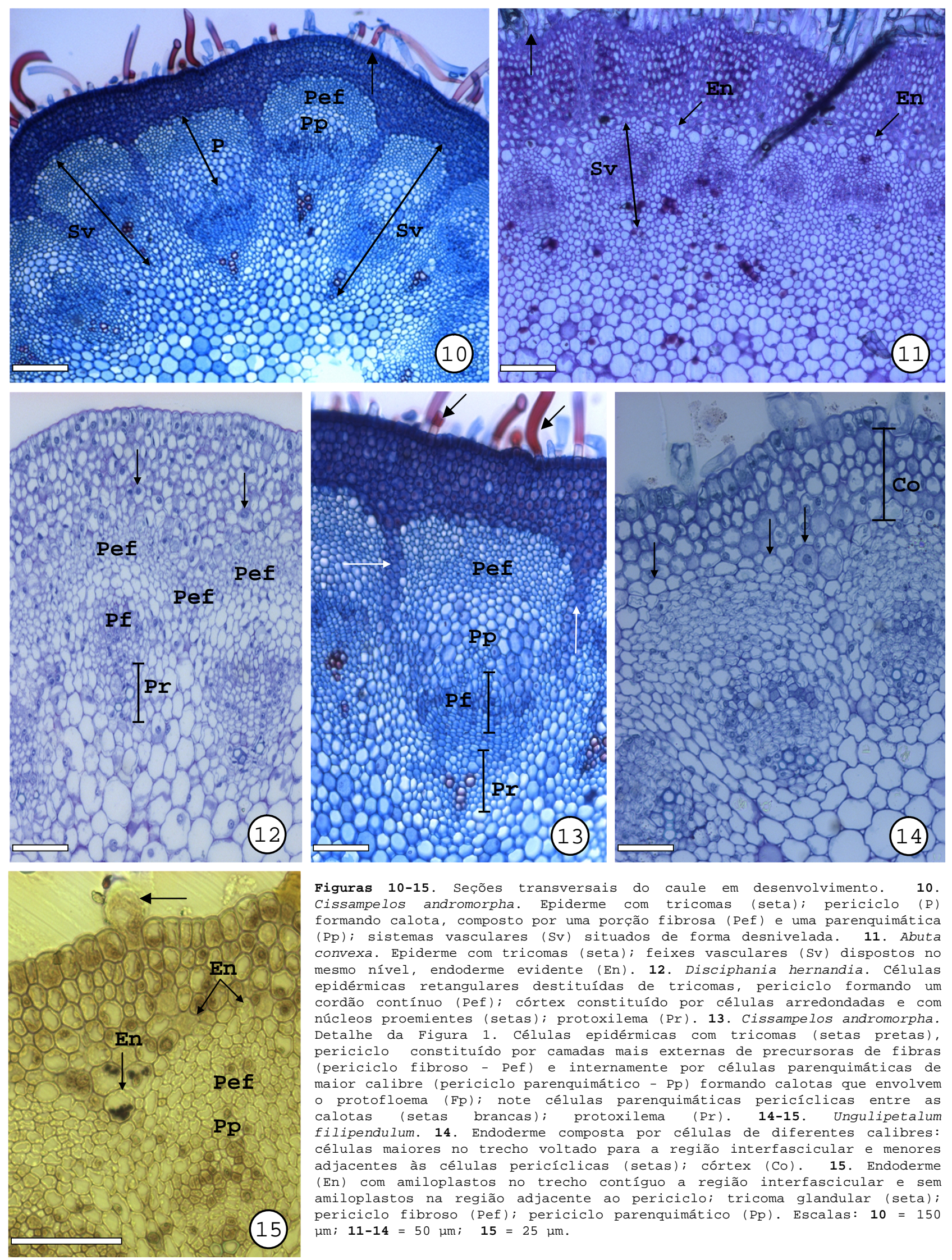

Figuras 10-15. Seções transversais do caule em desenvolvimento. 10 Cissampelos andromorpha. Epiderme com tricomas (seta); periciclo (P) formando calota, composto por uma porção fibrosa (Pef) e uma parenquimática (Pp); sistemas vasculares (Sv) situados de forma desnivelada. 11. Abuta convexa. Epiderme com tricomas (seta); feixes vasculares (Sv) dispostos no mesmo nível, endoderme evidente (En). 12. Disciphania hernandia. Células epidérmicas retangulares destituídas de tricomas, periciclo formando um cordão contínuo (Pef); córtex constituído por células arredondadas e com núcleos proemientes (setas); protoxilema $(\mathrm{Pr})$. 13. Cissampelos andromorpha. Detalhe da Figura 1. Células epidérmicas com tricomas (setas pretas), periciclo constituído por camadas mais externas de precursoras de fibras (periciclo fibroso - Pef) e internamente por células parenquimáticas de maior calibre (periciclo parenquimático - Pp) formando calotas que envolvem - protofloema (FP); note células parenquimáticas pericíclicas entre as calotas (setas brancas); protoxilema (Pr). 14-15. Ungulipetalum filipendulum. 14. Endoderme composta por células de diferentes calibres: células maiores no trecho voltado para a região interfascicular e menores adjacentes às células pericíclicas (setas); córtex (Co). 15. Endoderme (En) com amiloplastos no trecho contíguo a região interfascicular e sem amiloplastos na região adjacente ao periciclo; tricoma glandular (seta); periciclo fibroso (Pef); periciclo parenquimático (Pp). Escalas: $10=150$ $\mu \mathrm{m} ; 11-14=50 \mu \mathrm{m} ; 15=25 \mu \mathrm{m}$. 

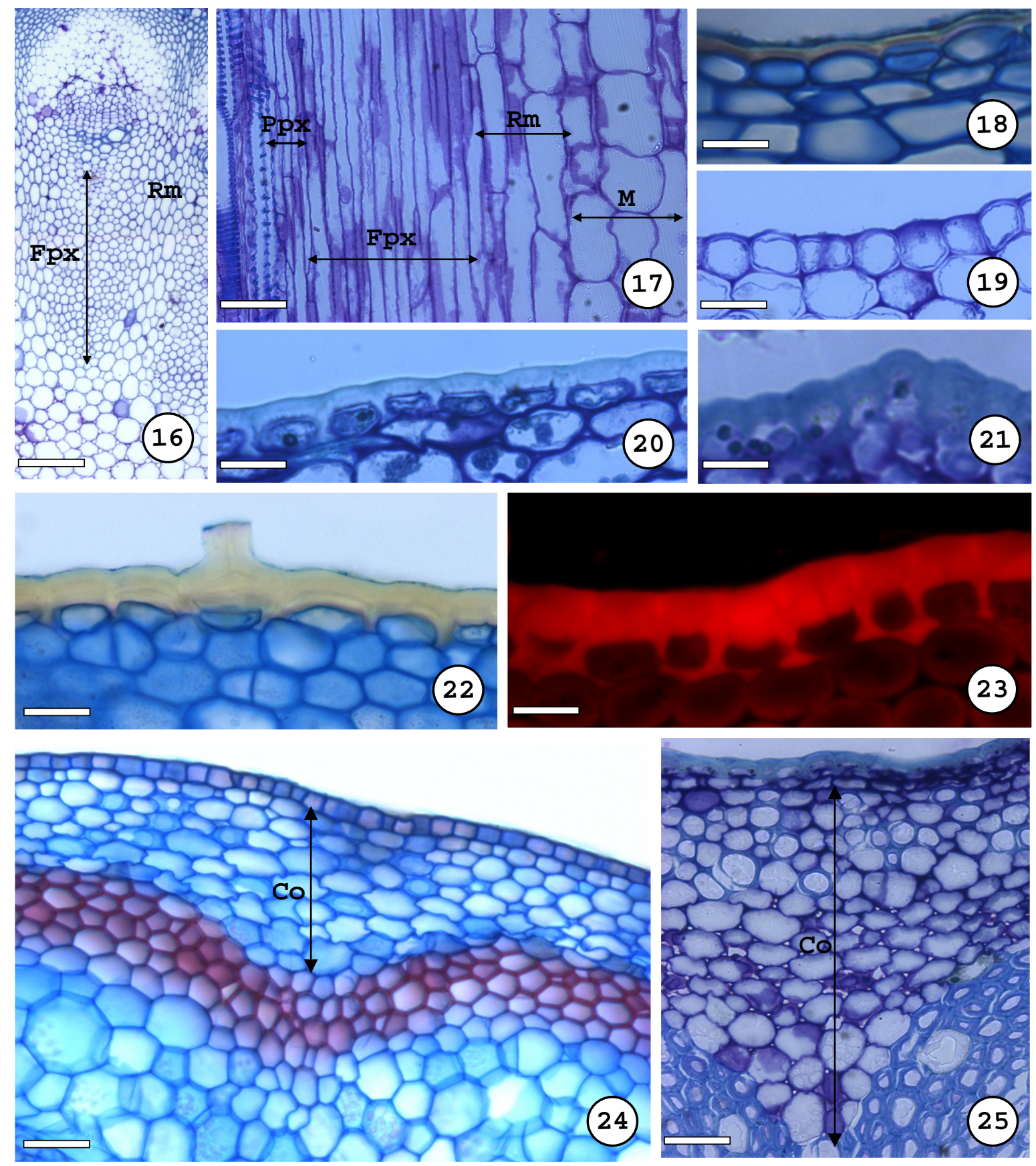

Figuras 16-17. Abuta grandifolia. 16. Seção transversal. Observe os cordões de células precursoras de fibras do protoxilema (Fpx); note o raio medular (Rm), que se forma entre dois sistemas vasculares. 17. Seção longitudinal. Detalhe das células precursoras de fibras (FPx), das células parenquimáticas do protoxilema (Ppx); note que os raios medulares (Rm) se constituem de células mais estreitas e alongadas que as medulares (M). Escalas: $\mathbf{1 6}=125 \mu \mathrm{m} ; \mathbf{1 7}=100 \mu \mathrm{m}$.

Figuras 18-23. Epiderme; seção transversal. 18. Cissampelos andromorpha. Note cutícula espessa. 19. Disciphania hernandia. Cutícula imperceptível. 20-23. Cutícula espessa. 20. Abuta convexa. 21. Ungulipetalum filipendulum. 22. Odontocarya vitis. 23. Chondrodendron platiphyllum. Microscopia de fluorescência. Observe que a cutícula envolve completamente algumas células epidérmicas. Escalas: $\mathbf{1 8 - 2 3}=15 \mu \mathrm{m}$.

Figuras 24-25. Diferenciação cortical. Seção transversal. Camadas mais externas corticais com formato arredondado, enquanto as demais têm contorno sinuoso e aproximadamente retangulares. 24. Odontocarya vitis. 25. Abuta convexa. Escalas: 24-25 = $30 \mu \mathrm{m}$. 
Figuras 26-36. Diferenciação da endoderme e periciclo. Abuta convexa. Seções transversais. 26. Aspecto geral. Instalação do crescimento secundário, perceptível pelo surgimento dos primeiros vasos (*) ainda em diferenciação. Percebe-se, também a diferenciação das fibras pericíclicas (Pef) e das fibras do protoxilema (Fpx). As setas indicam que algumas células da camada mais externa do periciclo, adjacente à endoderme, permanecem parenquimáticas enquanto há a diferenciação das demais. 27. Detalhe da região pericíclica fibrosa (Pef) e parenquimática (Pp). As setas indicam algumas células, da camada mais externa do periciclo adjacente à endoderme que permanecem parenquimáticas enquanto há a diferenciação das demais. Observe uma célula não lignificada entre as demais lignificadas (seta vermelha). 28. Endoderme $(*)$ caracterizada por amiloplastos; periciclo fibroso (Pef). 29. Observe algumas células pericíclicas não lignificadas (setas) para o interior da endoderme (*). 31-36. Divisões nas células não lignificadas do periciclo. 30. Note célula pericíclica recém dividida (seta). 31. Detalhe da Figura 30. Periciclo fibroso $(P e f)$. 32-34. Células recém divididas (setas). 35. Células recém formadas, que assumem uma formato retangular, com contorno sinuoso (setas). 36. Camada de células de origem do periciclo (Cp). Note que as células têm contorno sinuoso irregular. As setas indicam células que permanecem não lignificadas após a formação da camada; periciclo fibroso (Pef). Escalas: $26=130 \mu \mathrm{m} ; \mathbf{2 7}, 30$ e $36=40$ $\mu \mathrm{m} ; \mathbf{2 8 - 2 9}=30 \mu \mathrm{m} ; \mathbf{3 1}, \mathbf{3 3}, \mathbf{3 4}$ e $\mathbf{3 5}=25 \mu \mathrm{m} ; \mathbf{3 2}=12 \mu \mathrm{m}$. 


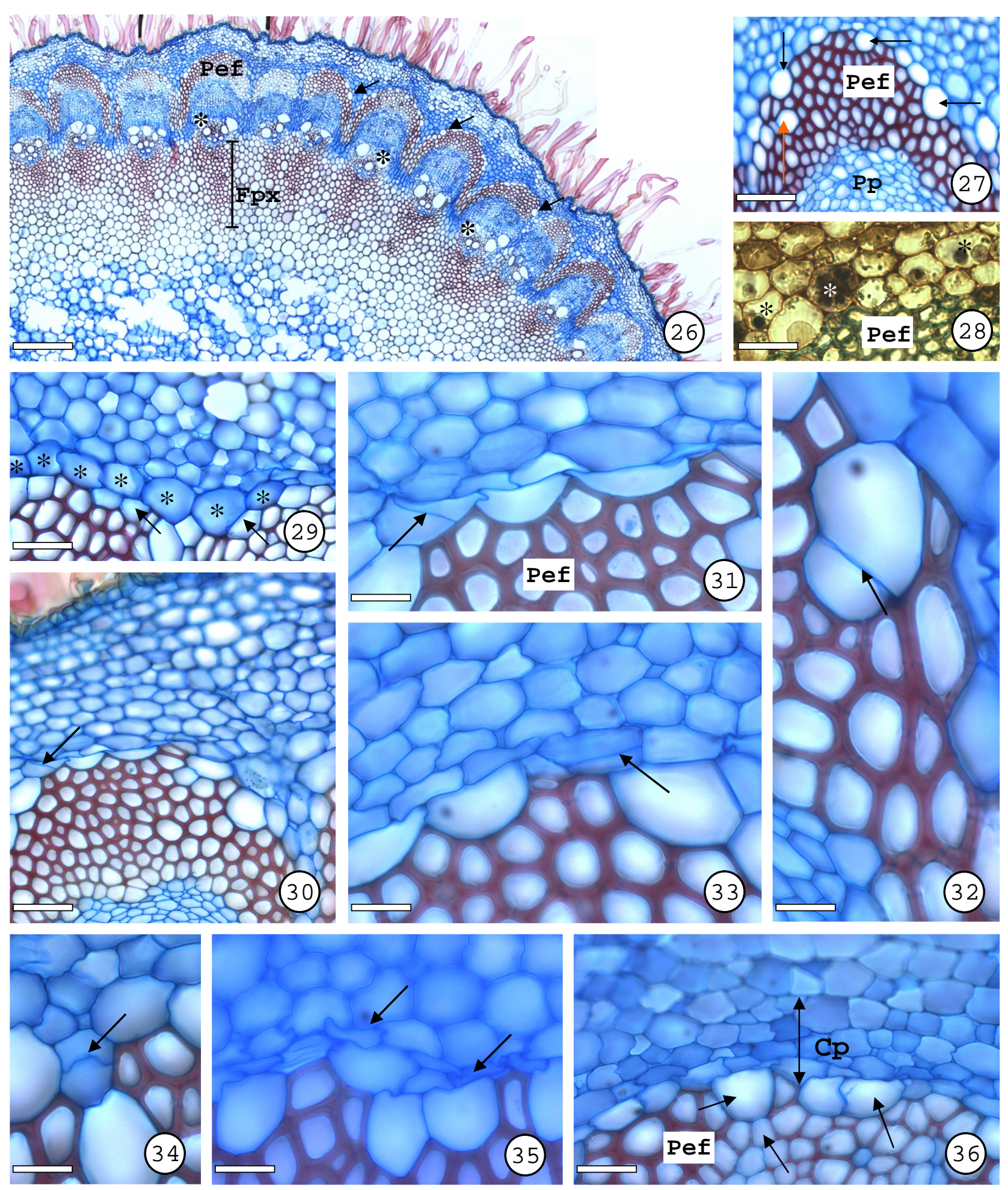



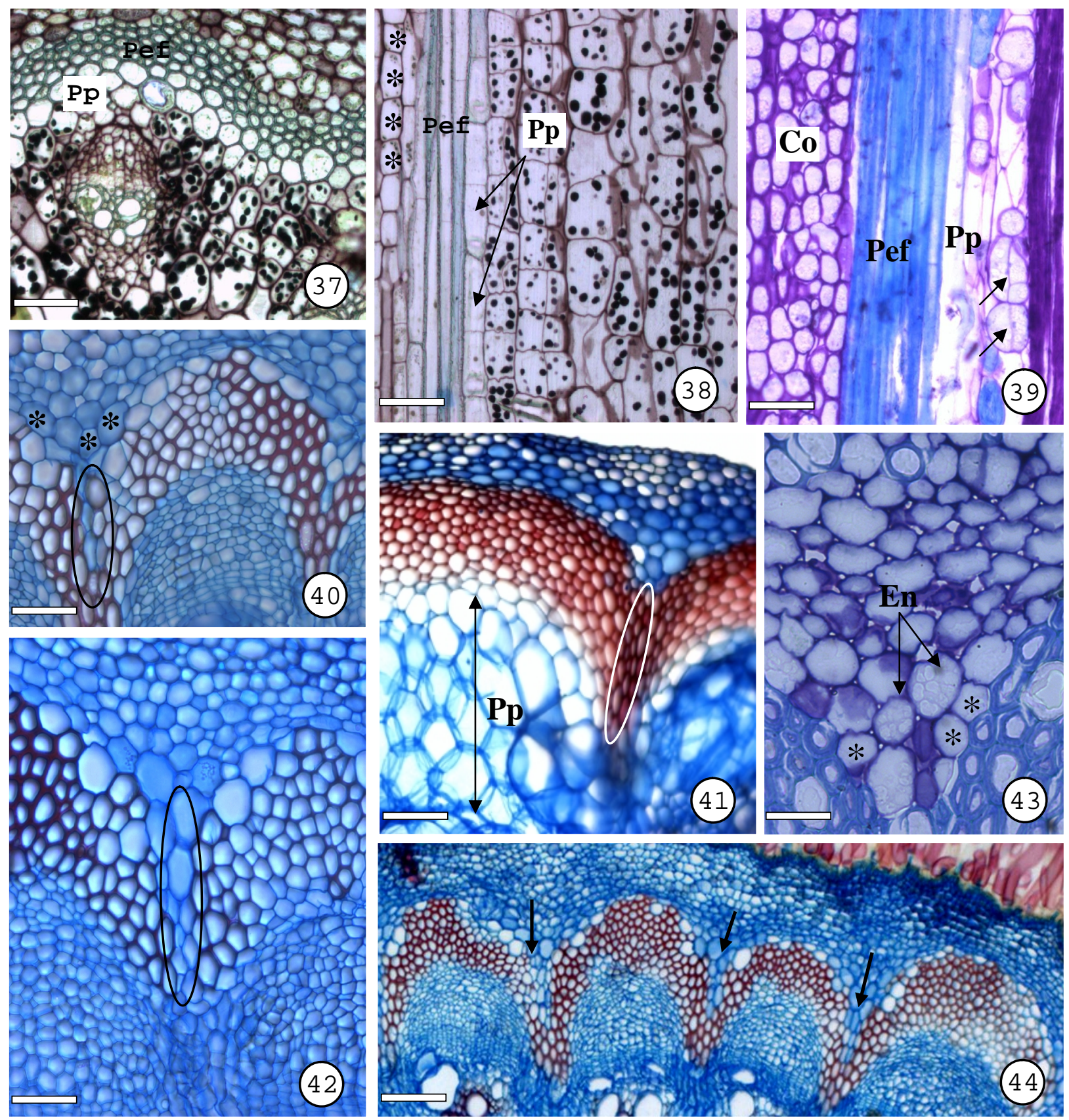

Figuras 37-44. Diferenciação do periciclo. 37-38. Disciphania hernandia. Observe amiloplastos em células da medula e no periciclo parenquimático $(\mathrm{Pp})$. 37. Seção transversal. Diferenciação das fibras nas camadas mais externas do periciclo (Pef), enquanto as demais permanecem parenquimáticas (Pp). 38. Seção longitudinal. Observe endoderme $(*)$, periciclo fibroso (Pef) e periciclo parenquimático (Pp). 39. Chondrodendron platiphyllum. Seção longitudinal. Note divisões nas células do periciclo parenquimático (setas); Co (córtex); Pef (periciclo fibroso); Pp (periciclo parenquimático). 40-44. Seção transversal. Fusão das calotas pericíclicas fibrosas. 40-41 e 43-44. Abuta convexa. 41. Cissampelos andromorpha. 40-42. Processo de diferenciação e lignificação de células da região interfascicular (região assinalada); endoderme (*); periciclo parenquimático (Pp). 43. Células da endoderme (En) com amiloplastos e células parenquimáticas $\left(^{*}\right)$ pericíclicas na região do sulco. 44. Detalhe da Figura 26. Observe cordão periciclo sinuoso, caracterizando a presença de sulcos (setas). Escalas: $37=$ $60 \mu \mathrm{m} ; \mathbf{3 8 - 3 9}=100 \mu \mathrm{m} ; \mathbf{4 0 - 4 3}-60 \mu \mathrm{m} ; 44-150 \mu \mathrm{m}$. 

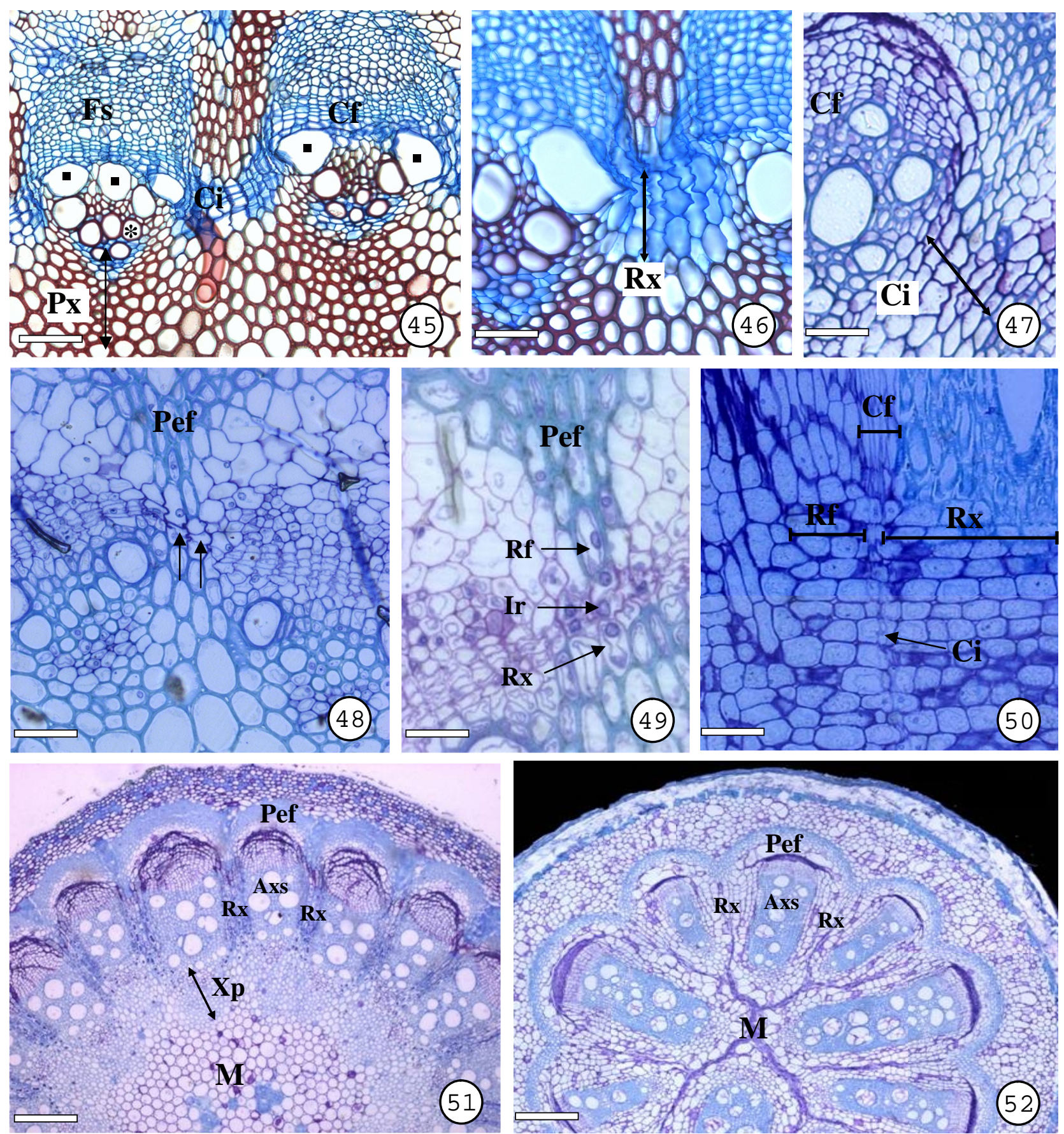

Figuras 45-50. Instalação do crescimento secundário. 45-49. Seção transversal. 45. Abuta convexa. Protoxilema (Px); metaxilema (*); câmbio fascicular ativo (Cf); câmbio interfascicular instalado (Ci); elementos de vasos do xilema secundário em diferenciação (Ш); floema secundário (Fs). 46. Disciphania hernandia. Câmbio interfascicular ativo, observam-se as primeiras células dos raios vasculares xilemáticos $(\mathrm{Rx})$. 47. Ungulipetalum filipendulum; câmbio inativo, tanto na porção interfascicular ( $\mathrm{C}$ ) quanto fascicular (Cf). 48-49. U. filipendulum. 48. As iniciais radiais estão destacadas através de setas; periciclo fibroso (Pef). 49. Primeiras células radiais formadas no floema (Rf) e xilema secundário (Rx); periciclo fibroso (Pef); inicial radial (Ir). Note a célula radial floemática lignificada (Rf), que se une ao periciclo, também lignificado (Pef). $50 . \quad U$. filipendulum. Seção longitudinal. Observe que o câmbio de origem pericíclica (Ci) forma somente raios xilemáticos ( $R x)$ e floemáticos (Rf) e que o câmbio de origem procambial (Cf) forma as células axiais do floema e xilema; observe que o raio floemático está representado por poucas células. 51. Abuta convexa - liana. 52. Odontocarya vitis - trepadeira herbácea. 51-52. Configuração final do caule em crescimento secundário em seção transversal: grupos de células axiais (Axs) separados por raios vasculares largos ( $\mathrm{Rx}$ ). Observe periciclo fibroso (Pef) e a medula (M) mais pronunciada em $A$. Convexa. Escalas: $\mathbf{4 5}=100 \mu \mathrm{m} ; \mathbf{4 6 - 4 8}$ e $\mathbf{5 0}=80 \mu \mathrm{m} ; \mathbf{4 9}=50 \mu \mathrm{m} ; \mathbf{5 1 - 5 2}=150 \mu \mathrm{m}$. 

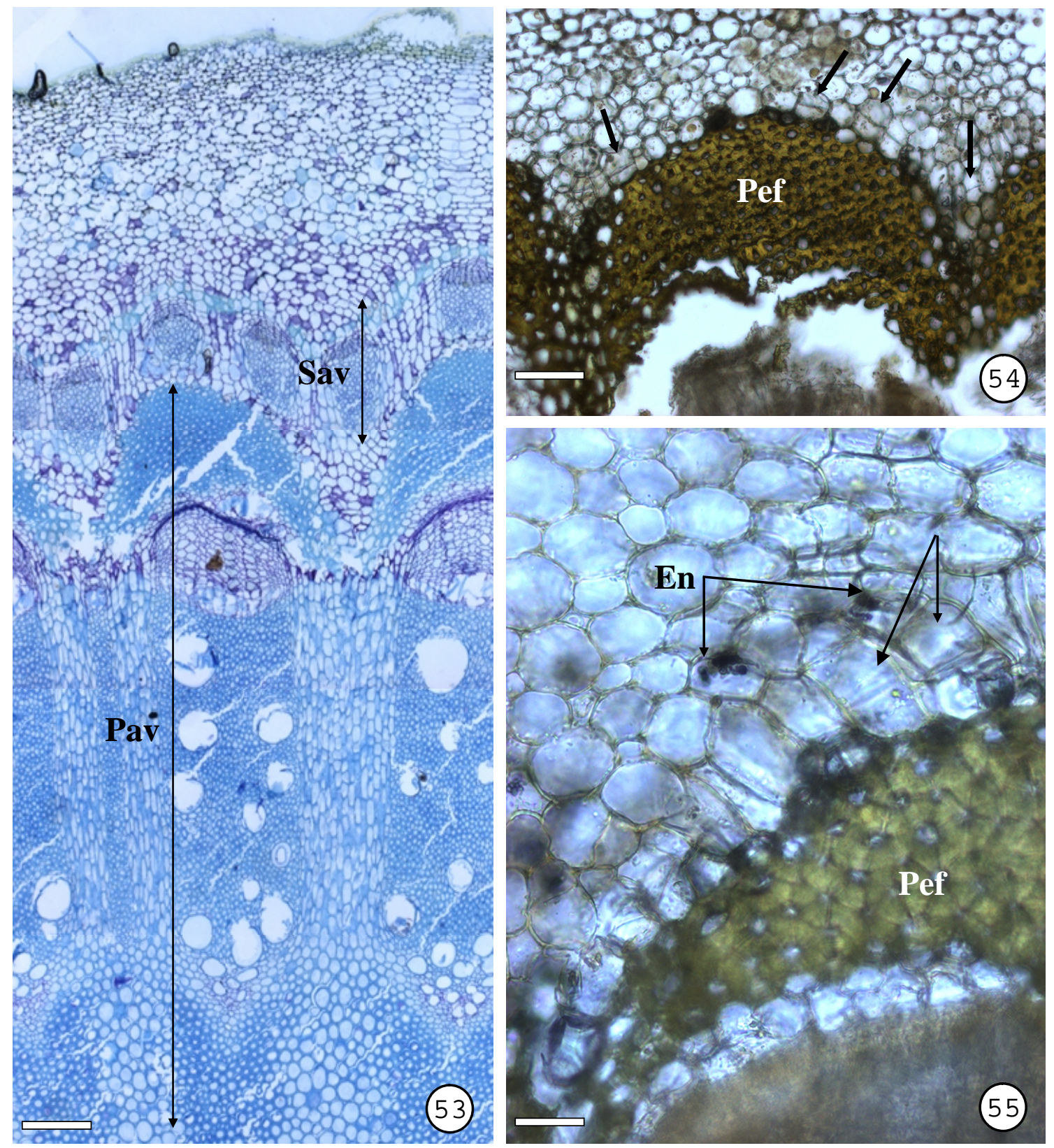

Figuras 53-55. Abuta imene. Seções transversais. Instalação do tecido conjuntivo. 53. O segundo anel vascular (Sav) somente se instala após o crescimento secundário bem estabelecido do primeiro anel (Pav). 54. As setas indicam células parenquimáticas pericíclicas, externas ao periciclo lignificado, em divisão celular. 55. Observe células em divisão (setas) localizadas internamente à endoderme com amiloplastos $(\mathrm{En})$. Escalas: $\mathbf{5 3}=120 \mu \mathrm{m} ; \mathbf{5 4}=70 \mu \mathrm{m} ; \mathbf{5 5}=30 \mu \mathrm{m}$. 
Figuras 56-59. Abuta imene. Seções transversais. Instalação do tecido conjuntivo. 56. Observe as divisões (setas) que ocorrem nas células pericíclicas parenquimáticas externas ao periciclo fibroso (Pef); note a endoderme (En) com amiloplastos. 57. Tecido conjuntivo (TC) constituído por pilhas de células; a linha de esclereídes pericíclicas (setas) subdivide o tecido conjuntivo em duas partes: tecido conjuntivo externo (TCe) e tecido conjuntivo interno (TCi); os novos cordões vasculares (região assinalada) se instalam primeiro nas regiões dos sulcos, entre as porções do periciclo fibroso (Pef), e posteriormente nas regiões adjacentes. 58. Dois cordões vasculares com floema (F) e xilema (X) em instalação. Células parenquimáticas (seta branca) e fibras (seta amarela) no xilema; note o câmbio se instalado entre os dois cordões vasculares, constituído por inicial radial (Ir); as células do raio são alongadas e lignificadas (R); observe as células do tecido conjuntivo formando pilhas de células (Tci); linha de esclereídes (setas). 59. Cordão vascular neoformado com floema e xilema (X) em instalação, note a inicial cambial (IC); elementos de tubos crivados (Etc) e células parenquimáticas (seta branca). Escalas: $\mathbf{5 6}=45 \mu \mathrm{m} ; \mathbf{5 7}=60 \mu \mathrm{m} ; \mathbf{5 8}=65 \mu \mathrm{m} ; \mathbf{5 9}=20 \mu \mathrm{m}$. 

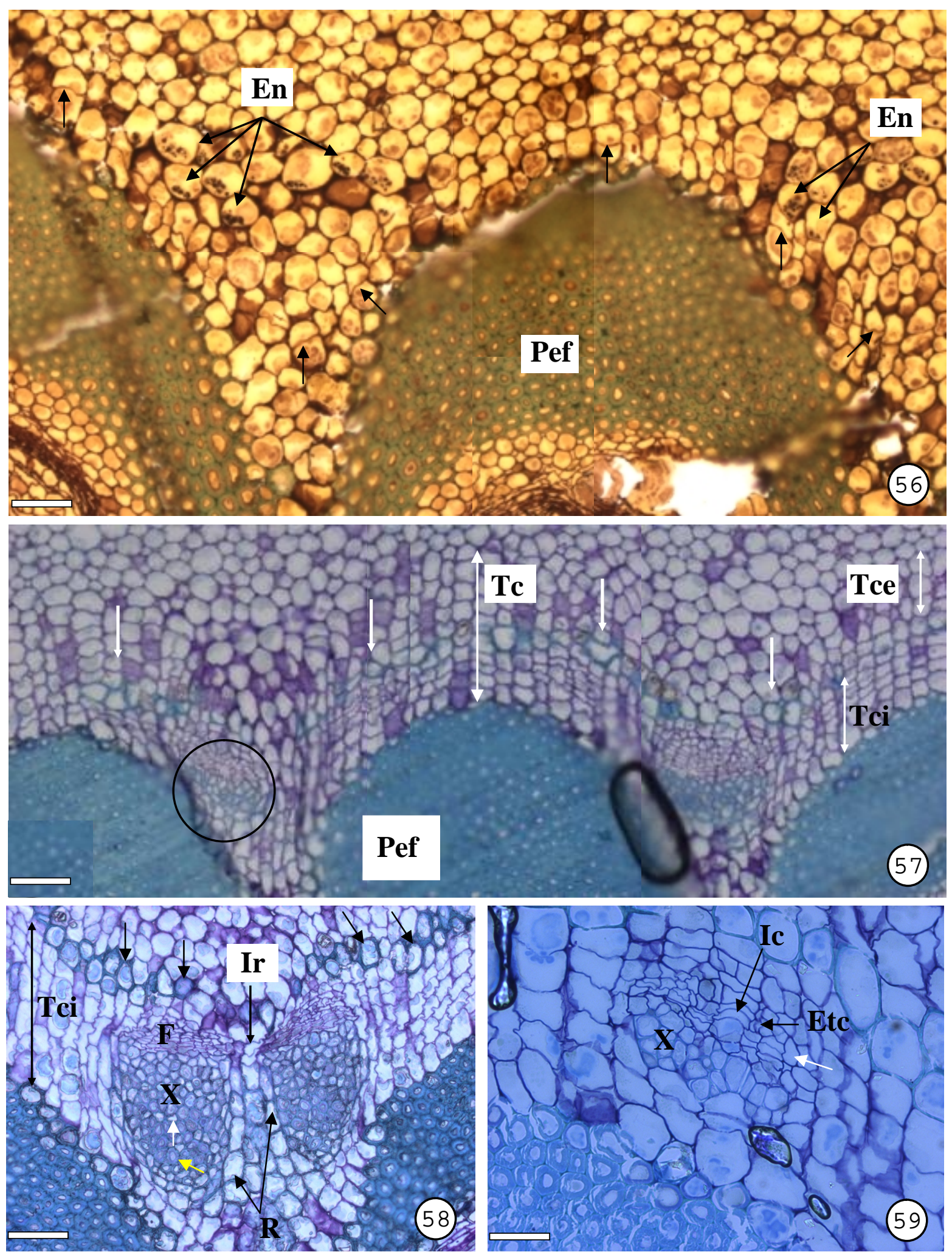
Figuras 60-64. Abuta imene. Seções transversais. Instalação do tecido conjuntivo. 60. Os novos câmbios formam apenas raios. Observe tecido conjuntivo (Tce) com células empilhadas o que permite a distinção entre as células corticais, note que após diferenciação completa do tecido conjuntivo externo, suas células são bastante similares às corticais (Tce + Co). As setas indicam a linha de esclereídes pericíclicas. Periciclo fibroso (Pef). $\mathbf{6 1}$. observe divisões celulares no tecido conjuntivo externo (Tce); córtex (Co); novo cordão vascular de tecidos secundários (Ncv); periciclo fibroso (Pef). 62. Córtex (Co); as setas pretas indicam divisões no tecido conjuntivo externo (TCe); linha de esclereídes pericíclicas $(*) ;$ as setas amarelas indicam cristais em esclereídes. 63. Observe a inicial radial (*); a célula derivada do floema (Df) e a derivada do xilema (Dx). Note que esta porção do câmbio forma somente raios (R). Tecido conjuntivo interno (TCi). A seta amarela indica cristal em esclereíde. 64. Externamente à linha de esclereídes (Le) observam-se células da endoderme com amiloplastos (En). Tecido conjuntivo interno (TCi). Novo cordão vascular de tecidos secundários (NCv). Periciclo fibroso (Pef). As setas amarelas indicam cristais em células do tecido conjuntivo. Escalas: $60=120 \mu \mathrm{m} ; \quad 61=80 \mu \mathrm{m} ; \mathbf{6 2}$ e $\mathbf{6 4}=70$ $\mu \mathrm{m} ; 63=60 \mu \mathrm{m}$. 


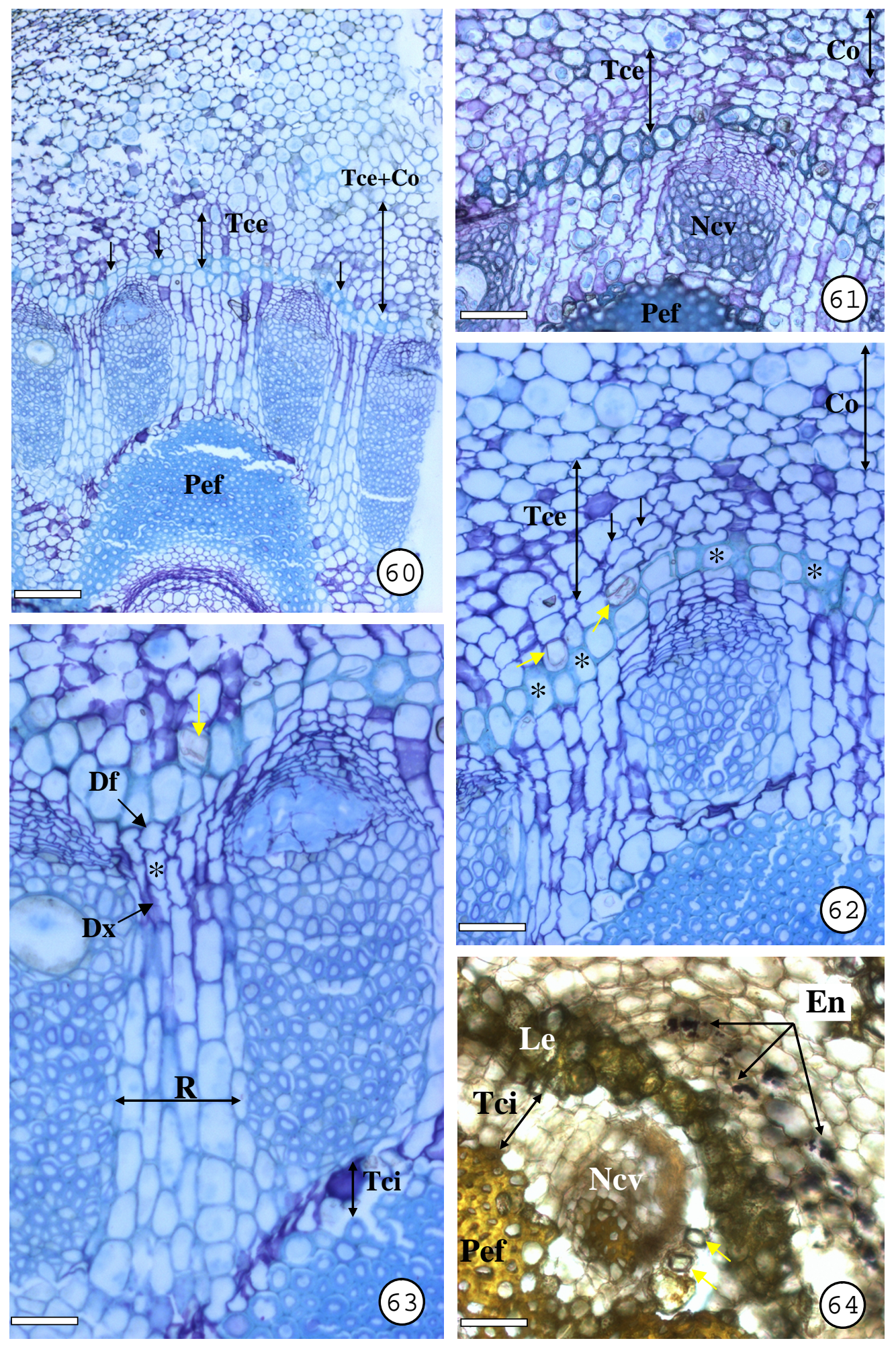


Figura 65. Chondrodendron platiphyllum, seção transversal. Caule com três anéis sucessivos. Periciclo fibroso (Pef); primeira linha de esclereídes (Ple); segunda linha de esclereídes (Sle). Nesta liana, o tecido conjuntivo (TC) e os raios (R) não se lignificam. Escala: $100 \mu \mathrm{m}$.

Figuras 66-67. Córtex, seção transversal. 66. Chondrodendron platiphyllum - liana. Detalhe da porção mais externa da Figura 65. Observe periderme composta por felogênio (seta amarela), súber (S) e feloderme (F). Córtex (Co) constituído por células parenquimáticas e esclereídes (setas brancas). Observe tecido conjuntivo (TC) em divisão dando continuidade ao processo de instalação de novos cordões vasculares. Escala: 50 um. $\mathbf{6 7}$. Cissampelos andromorpha, trepadeira herbácea. As setas indicam a epiderme, evidenciando a origem subepidérmica do felogênio. Súber $(\mathrm{S})$; feloderme (F), Córtex (Co). Escala: $50 \mu \mathrm{m}$. 


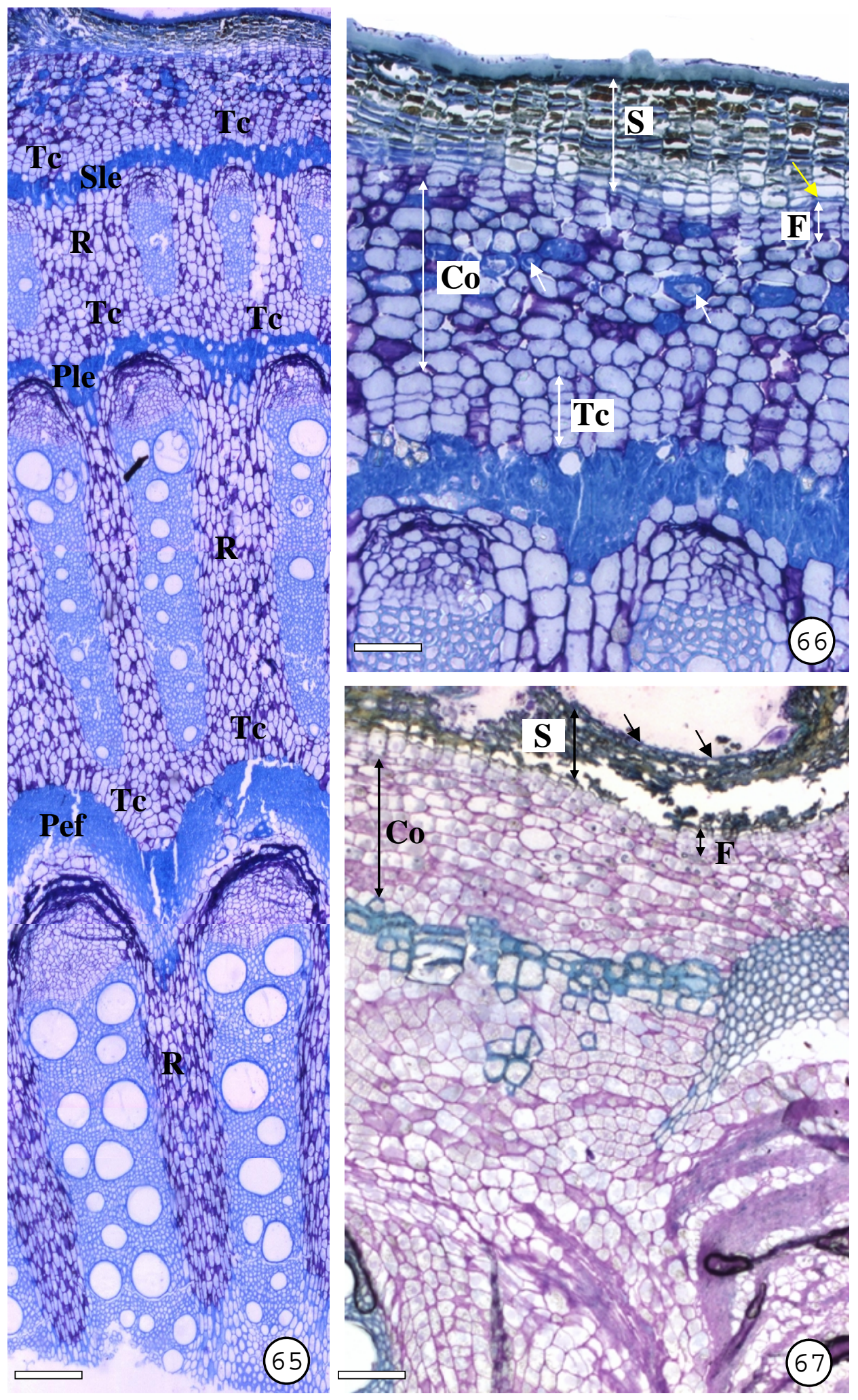



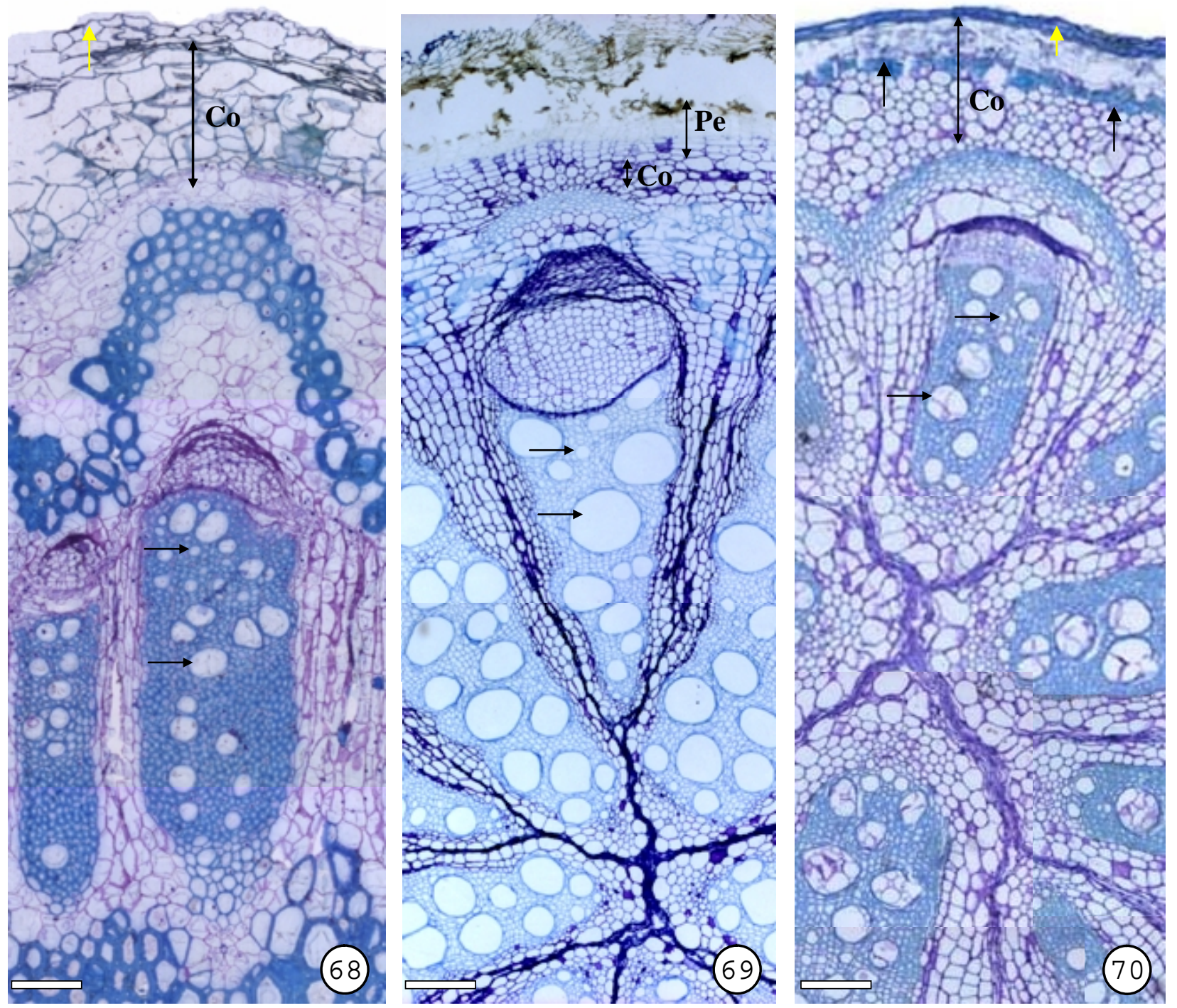

Figuras 68-70. Aspecto geral do caule adulto. Seção transversal. 68. Cissampelos ovalifolia. Córtex constituído por células de grandes diâmetros; Epiderme (seta amarela). Vasos dimórficos (setas). 69. Disciphania hernandia. Córtex (Co) estreito e células de pequenos calibres. Periderme (Pe). Vasos dimórficos (setas). 70. Odontocarya vitis. Córtex (Co) com células de diâmetros médios; periderme (seta amarela). Observe um cordão de esclereídes corticais (setas) que circunda o caule. Vasos dimórficos (setas). Escalas $=60 \mu \mathrm{m}$. 

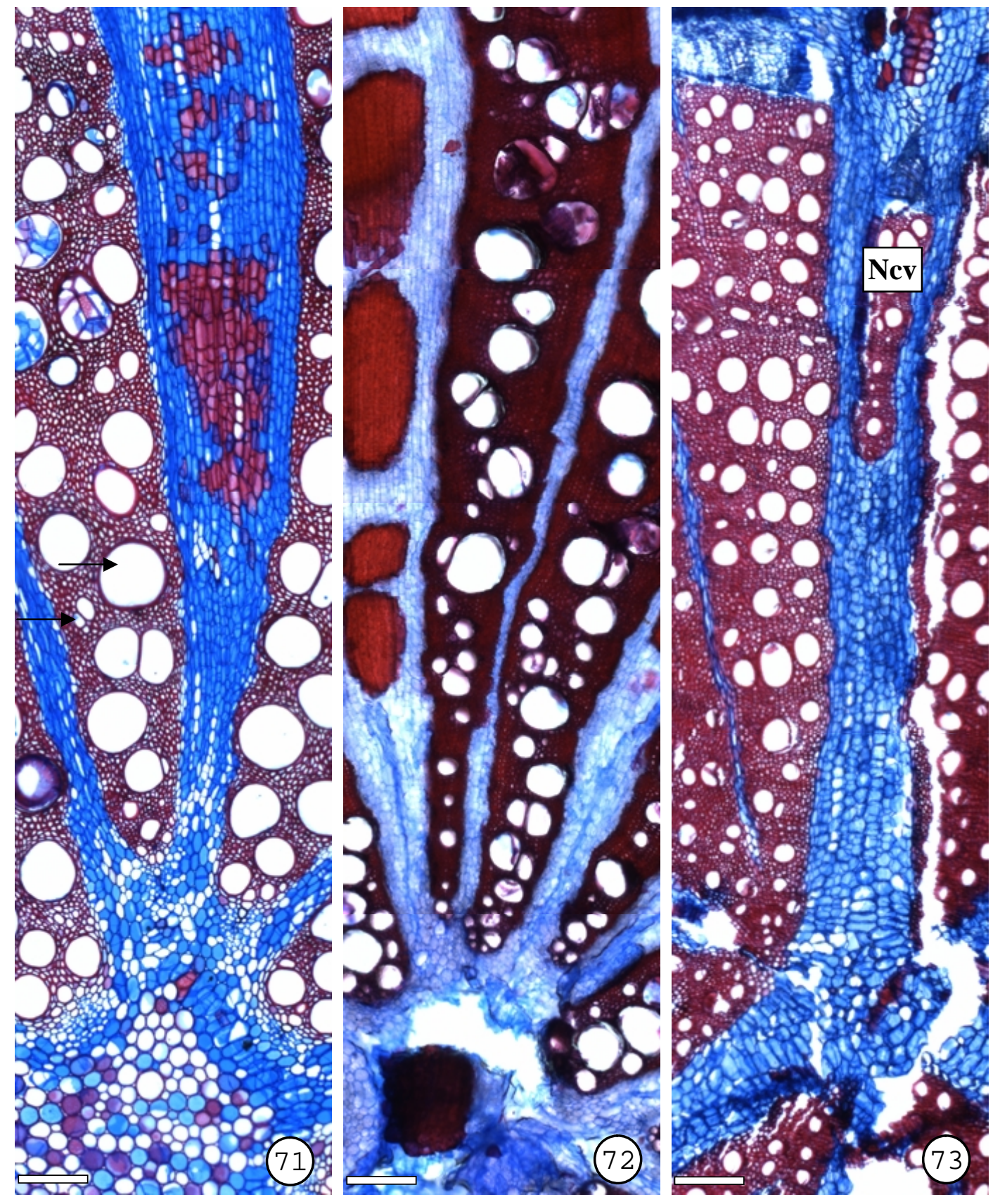

Figuras 71-73. Aspecto geral do caule adulto. 71. Cissampelos andromorpha. Observe células lignificadas no raio. Vasos dimórficos (setas) 72. Odontocarya tamoides. Células lignificadas no raio. 73. Ungulipetalum filipendulum. Observe um novo cordão vascular (Ncv) constituído por floema e xilema secundários, produzido por iniciais fusiformes resultantes da transformação de iniciais radiais. Escalas $=60 \mu \mathrm{m}$. 

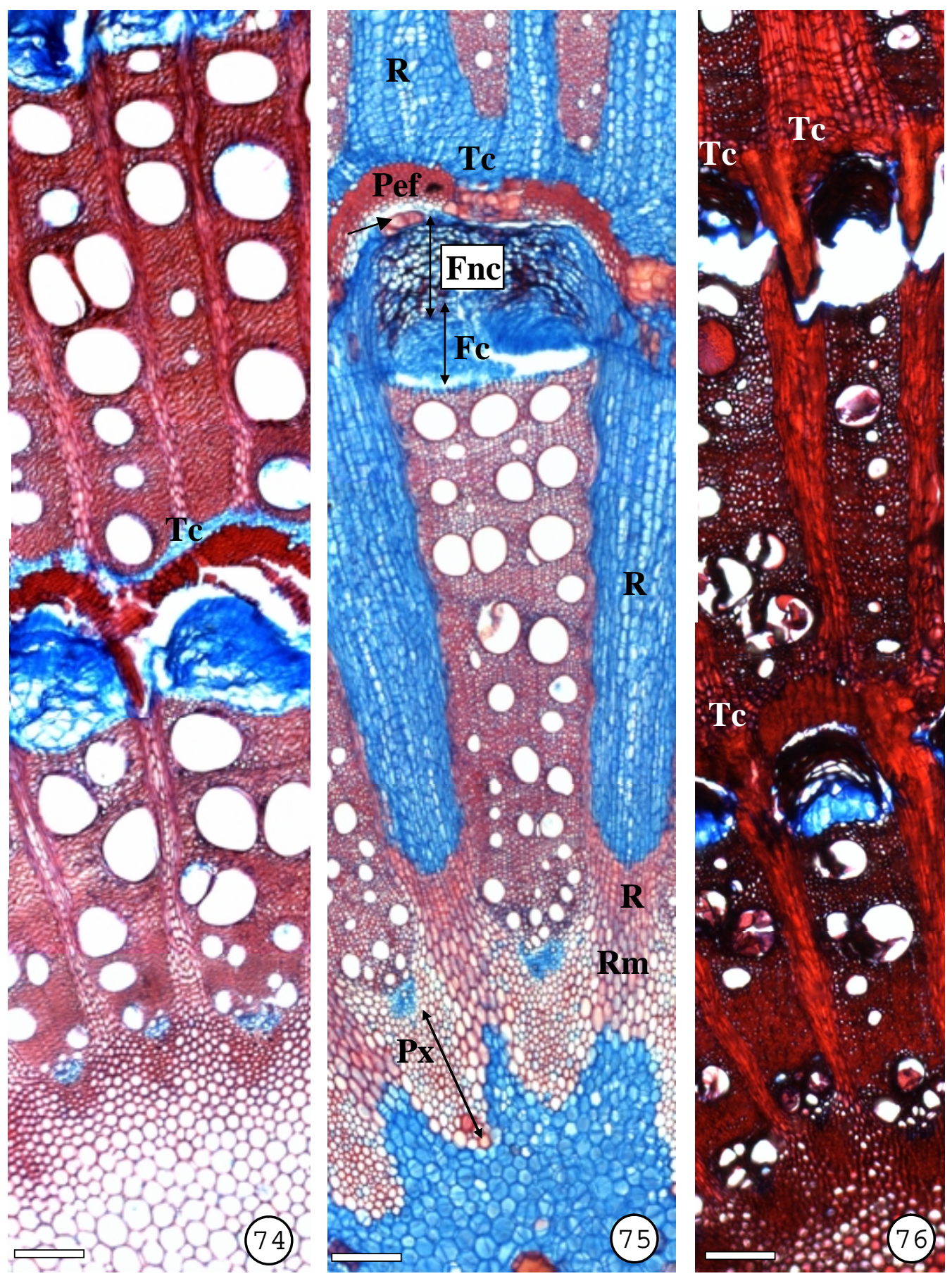

Figuras 74-76. Aspecto geral do caule adulto. 74. Anomospermum sp. Observe tecido conjuntivo não lignificado (TC) 75. Chondrodendron platiphyllum. Observe protoxilema lignificado (Px), Floema secundário condutor (FC); Floema não condutor (Fnc); Raio medular (Rm); Raio vascular (R), periciclo fibroso (Pef). A seta indica esclereídes de origem do periciclo parenquimático próxima ao floema não condutor. 76. Telitoxicum minutiflorum. Observe tecido conjuntivo (TC) lignificado. Escalas: $60 \mu \mathrm{m}$. 

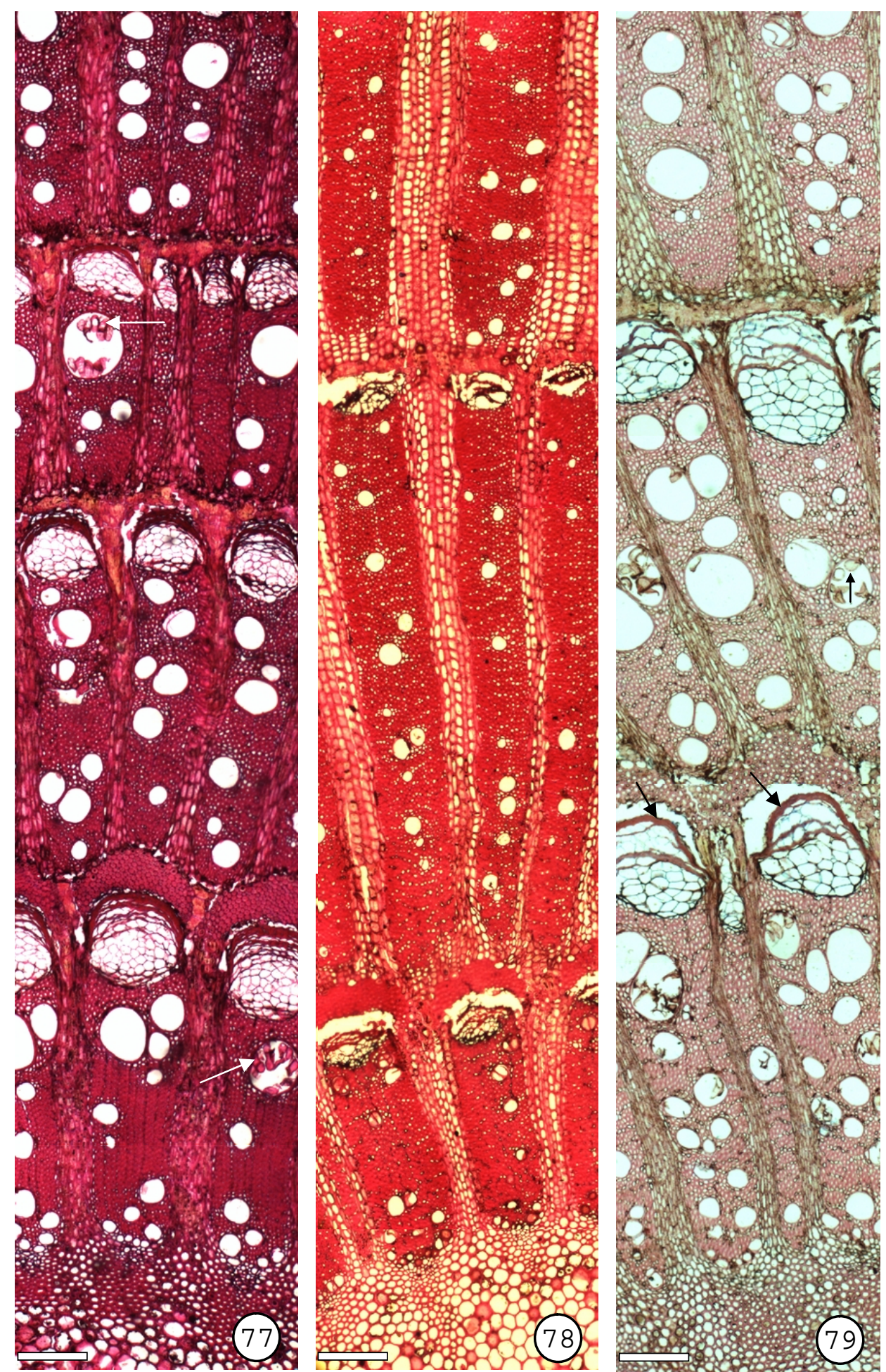

Figuras 77-79.

77. Abuta grandifolia, liana. Observe

vasos maiores em comparação com a espécie arbustiva da figura seguinte. Note elementos de tubos crivados de grande calibre. As setas indicam tilos. 78. Abuta grandifolia, arbusto. 79. Abuta selloana. As setas maiores indicam faixa escura gerada pela sobreposição de várias paredes primárias dos elementos de tubos colapsados; a seta menor indica tilos. Note elementos de tubos crivados de grande calibre. Escala $=78 \mu \mathrm{m}$. 

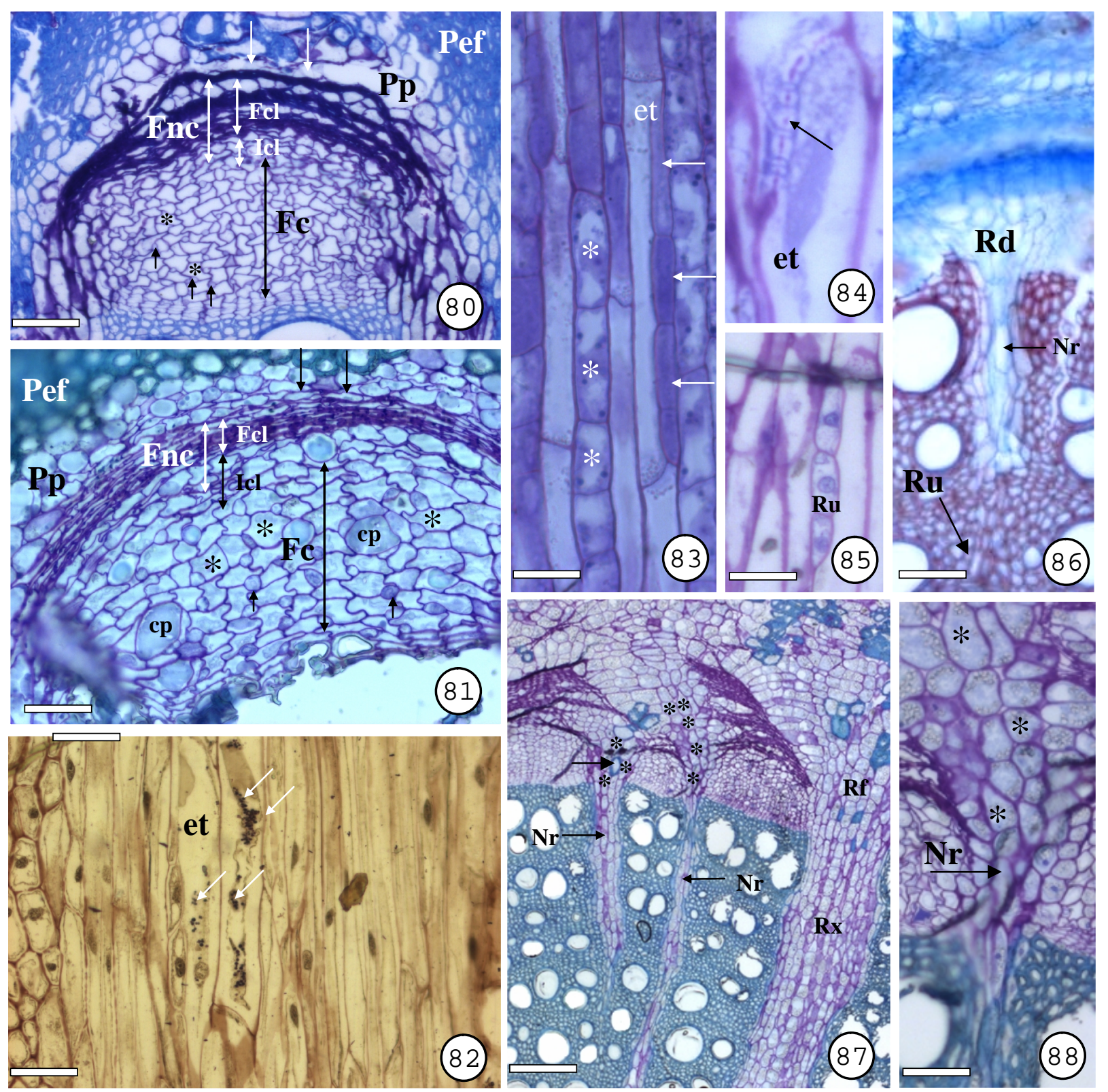

Figuras 80-88. Floema. 80. Chondrodendron platiphyllum. 81. Disciphania hernandia. 80-81. Seção transversal. Floema condutor (FC) e floema não condutor (Fnc), este último formado pela porção inicial não condutora (Icl) e pela porção colapsada (FCl); note que os elementos de tubos crivados (*) têm distribuição irregular em $C$. platiphyllum e radial em $D$. hernandia; as setas pretas indicam as células companheiras; células do parenquima axial (cp); note o periciclo fibroso (Pef) e parenquimático ( $\mathrm{Pp})$; as setas brancas indicam células pericíclicas colapsadas. 82. Ungulipetalum filipendulum. Seção tangencial. Grãos de amido (setas brancas) nos elementos de tubos crivados (et). 83. Cissampelos andromorpha. Seção tangencial. Elemento de tubo crivado (et) com célula companheira seriada (setas); parênquima axial (*). 84. Ungulipetalum filipendulum. Seção tangencial. Placa crivada composta (seta); elemento de tubo crivado (et). 85. Raio unisseriado composto de três células de altura. 86. Ungulipetalum filipendulum. Novo raio (Nr), que sofre dilatação no floema $(\mathrm{Rd})$; raio unisseriado $(\mathrm{Ru})$. 86-88. Ungulipetalum filipendulum. Seção transversal. Observe raios xilemáticos (Rx) e floemáticos (Rf) largos. Note novos raios (Nr) no xilema e floema. Observe dois novos raios floemáticos (*) que dividem - tecido floemático. 87. Observe que algumas células radiais floemáticas se lignificam (seta). 88. Detalhe da figura anterior. Novo raio (Nr); raio floemático dilatado $\left(^{*}\right)$. Escalas: $\mathbf{8 0 - 8 1 = 5 5 \mu m ; ~} \mathbf{8 2}=55 \mu \mathrm{m} ; \mathbf{8 3}=30 \mu \mathrm{m} ; \mathbf{8 4}=12 \mu \mathrm{m} ; \mathbf{8 5}=20 \mu \mathrm{m} ; \mathbf{8 6}=25$ $\mu \mathrm{m} ; \mathbf{8 7}=95 \mu \mathrm{m} ; \mathbf{8 8}=25 \mu \mathrm{m}$. 

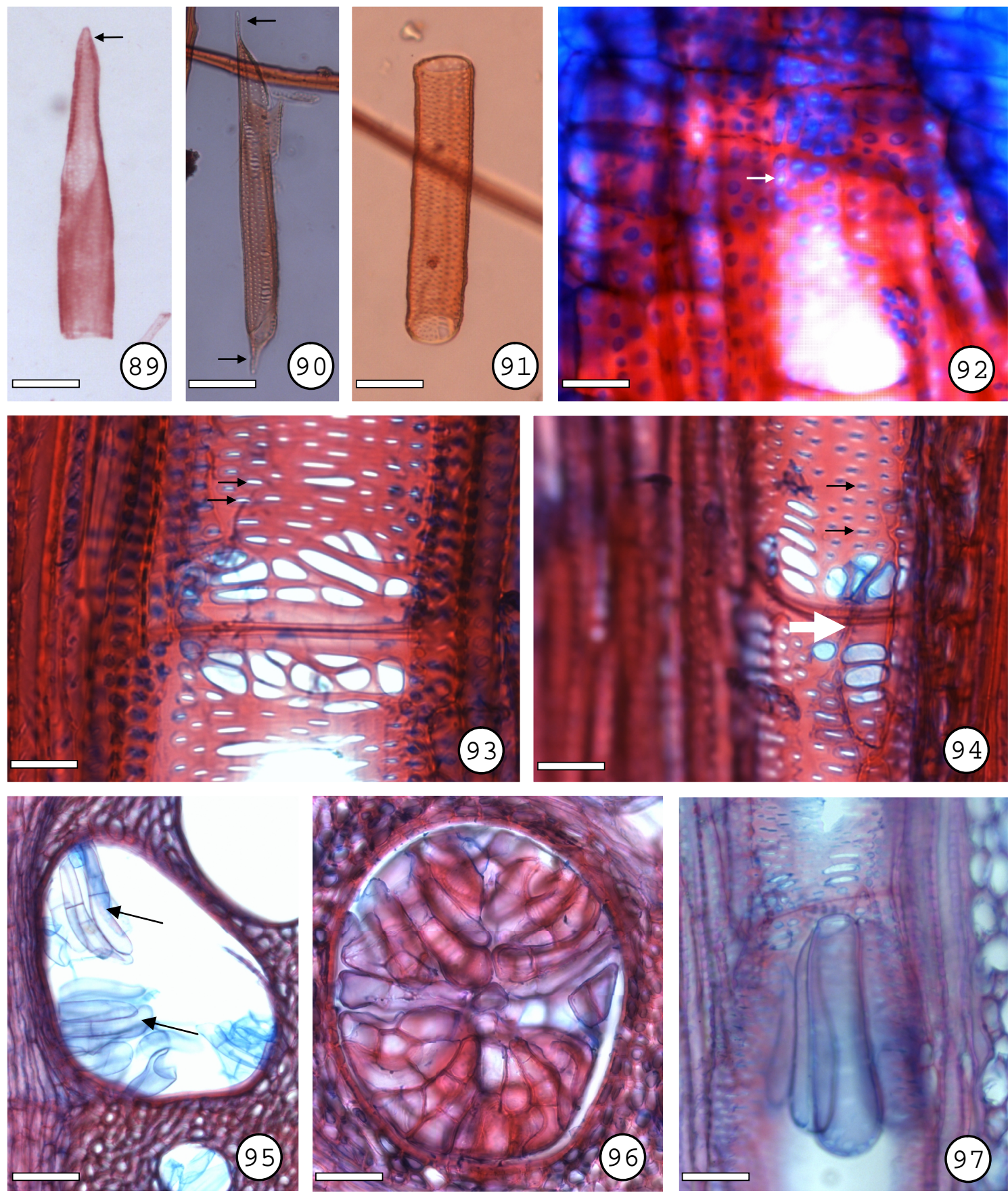

Figuras 89-91. Macerado (elementos de vaso). 89. Cissampelos ovalifolia. Apêndice somente em uma extremidade (seta); placa de perfuração transversal e oblíqua. 90. Abuta grandifolia. Apêndice em ambas as extremidades (setas). 91. Abuta grandifolia. Elemento de vaso sem apêndice.

Figura 92. Ungulipetalum filipendulum. Seção radial. Pontoações radiovasculares areoladas (seta) semelhantes às pontoações dos vasos (Figura 94).

Figuras 93-94. Abuta grandifolia. Seção tangencial. 93. Pontoações do vaso (setas). As pontoações nas extremidades dos elementos de vaso são simples e semi areoladas, arredondadas a ovais e maiores que as demais. 94. Observe que são pontoações parênquimovasculares. A seta branca indica o molde de uma célula parenquimática. Pontoações do vaso (setas pretas).

Figuras 95-97. Presença de tilos nos vasos. 95-96. Seção transversal. 95. Anomospermum sp. Tilos com paredes primárias. As setas indicam duas células parenquimáticas, constituindo um tilo. 96. Abuta convexa. Tilos com paredes secundárias e lignificadas. 97. Seção tangencial. Tilos com paredes primárias.

Escalas: 89-91 $=50 \mu \mathrm{m} ; \mathbf{9 2}=20 \mu \mathrm{m} ; \mathbf{9 3 - 9 7}=10 \mu \mathrm{m}$. 

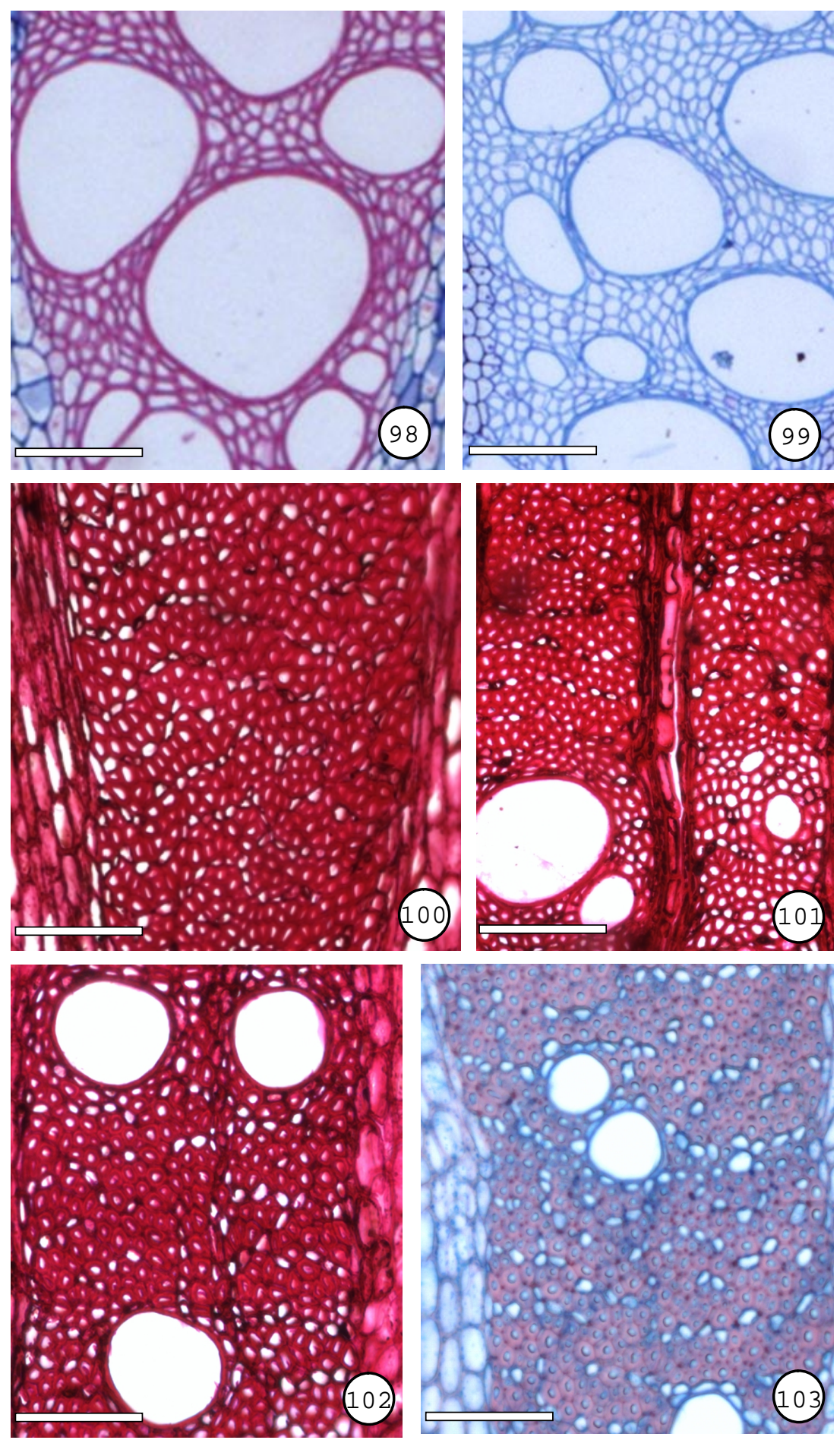

Figuras 98-103. Tipos de parênquima axial. Seção transversal. 98-99. Trepadeiras herbáceas. Parênquima ausente. 98. Cissampelos andromorpha. 99. Disciphania hernandia. 100-103. Parênquima difuso e difuso com tendência a formar linhas. 100. Hyperbaena domingensis, liana. 101. Telitoxicum minutiflorum, liana. 102-103. Abuta grandifolia. 102. Liana. 103. Arbusto. Além dos tipos de parênquimas já citados, nota-se o paratraqueal escasso. Escalas = 98-99 = $40 \mu \mathrm{m}$; 100-103 $=50 \mu \mathrm{m}$. 

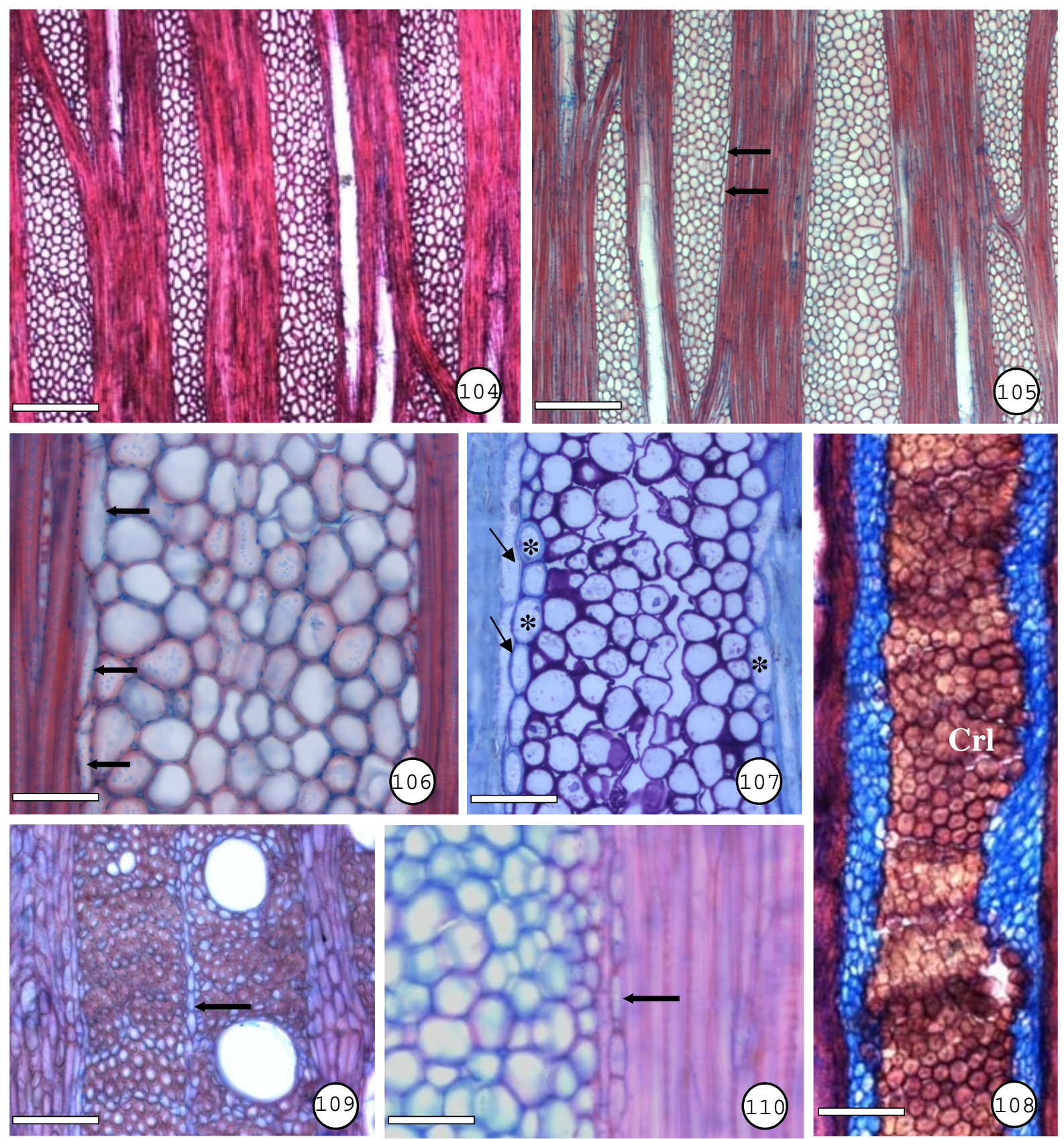

Figuras 104-108. Raios xilemáticos largos e longos do câmbio de origem do periciclo. Seção tangencial. 104. Hyperbaena domingensis. 105. Abuta grandifolia. As setas indicam as células envolventes tangenciando somente uma porção do raio. 106. Abuta grandifolia. Observe células axiais envolventes (setas) que margeiam 0 raio. 107. Ungulipetalum filipendulum. Células envolventes (setas); observe que somente as células radiais marginais têm paredes secundárias lignificadas (*). 108. odontocarya tamoides. Observe o corpo do raio com células lignificadas (Crl), onde - lume é observado apenas como um ponto.

Figuras 109-110. Abuta convexa. Raios unisseriados do câmbio de origem procambial (setas). 109. Seção transversal. 110. Seção longitudinal. Escalas: 104, 105 e $109=$ $90 \mu \mathrm{m} ; \mathbf{1 0 6 - 1 0 7}$ e $110=50 \mu \mathrm{m} ; 108=40 \mu \mathrm{m}$. 


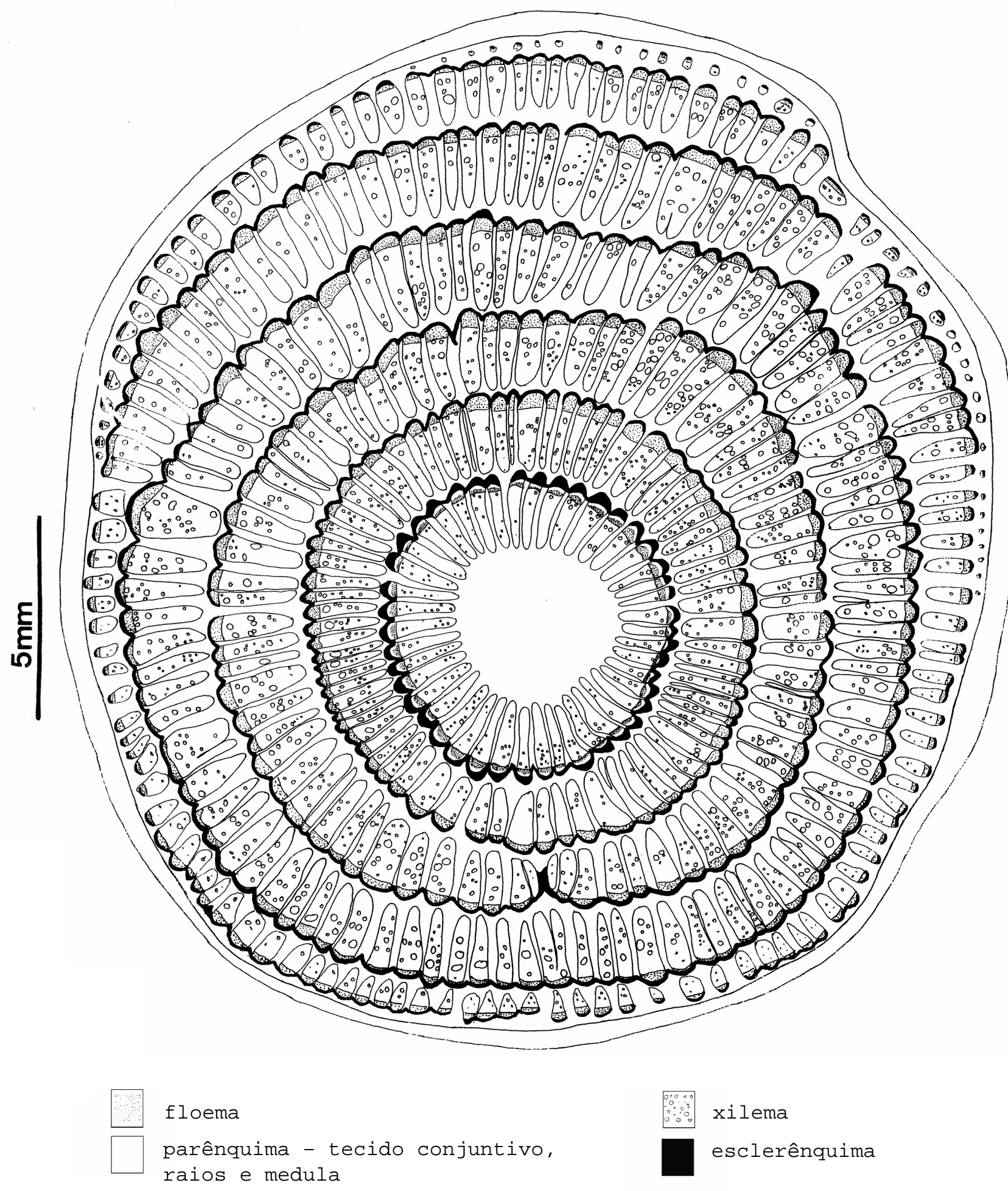

Figura 111. Desenho esquemático do caule de Abuta convexa. Seção transversal. Observe que os raios vasculares raramente se conectam entre si através dos anéis vasculares sucessivos. 

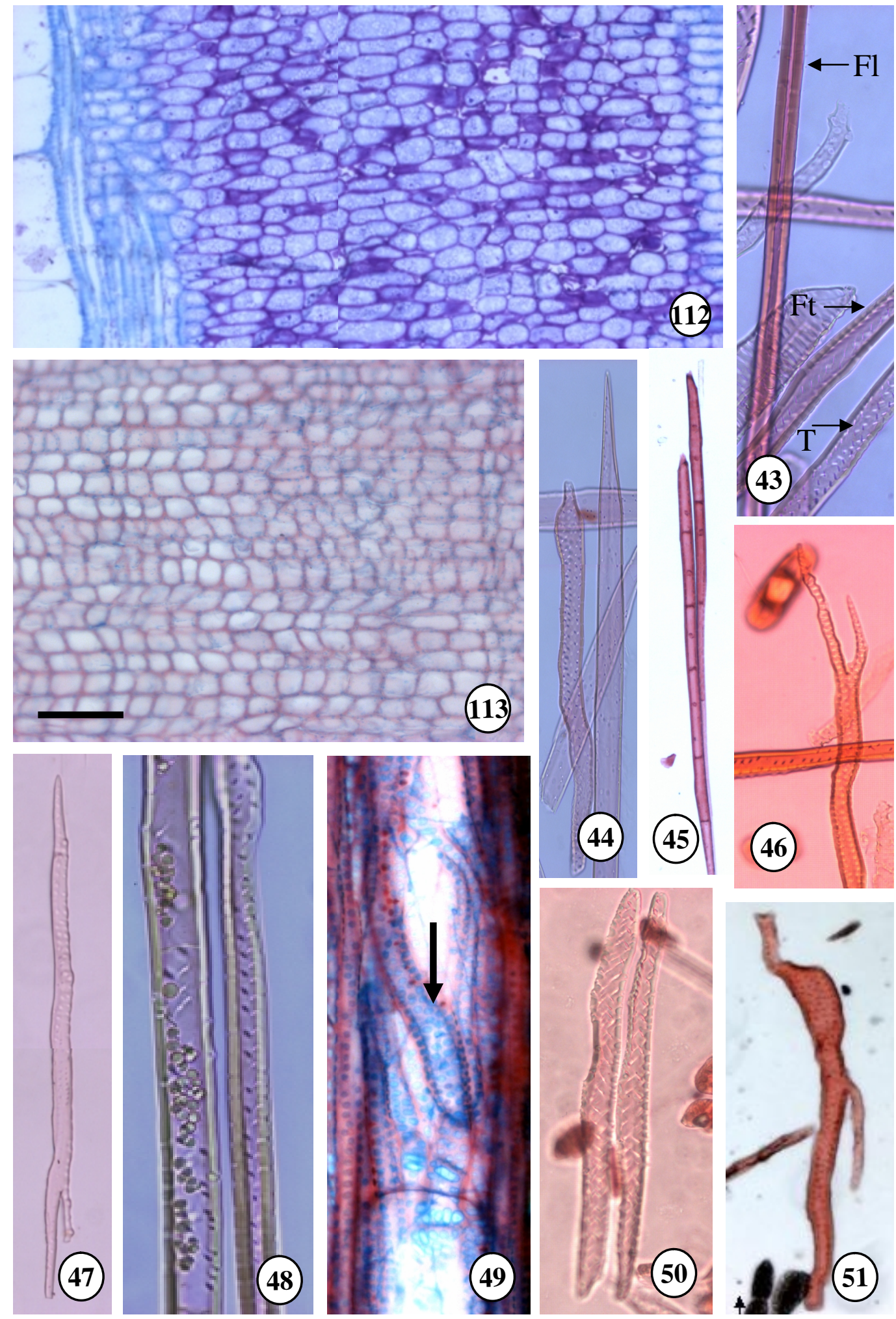

Figuras 41-42. Raio. Secção radial. 41. Ungulipetalum filipendulum. 42. Abuta grandifolia.

Figuras 43-48. Material dissociado do xilema. 43. Elementos imperfurados. Fibra libriforme (Fl), fibrotraqueídes (Ft) e traqueídes (T). 44. Cissampelos ovalifolia. Fibra libriforme (esquerda). Traqueíde (direita). 45. Abuta grandifolia. Fibras septadas. 46-47. Fibrotraqueides com terminação não afiladas. 46. Telitoxicum minutiflorum. 47. Sciadotenia eichelerana. 48. Chondrodendron platiphyllum Observe amido na fibra libriforme (elemento da esquerda), enquanto que a fibrotraqueíde (elemento da direita) não possui.

Figura 49. Hyperbaena domingensis. Secção tangencial. Traqueídes perivasculares (seta).

Figuras 50-51. Material dissociado do xilema. Traqueídes. 50. Telitoxicum minutiflorum. 51. Abuta imene. 

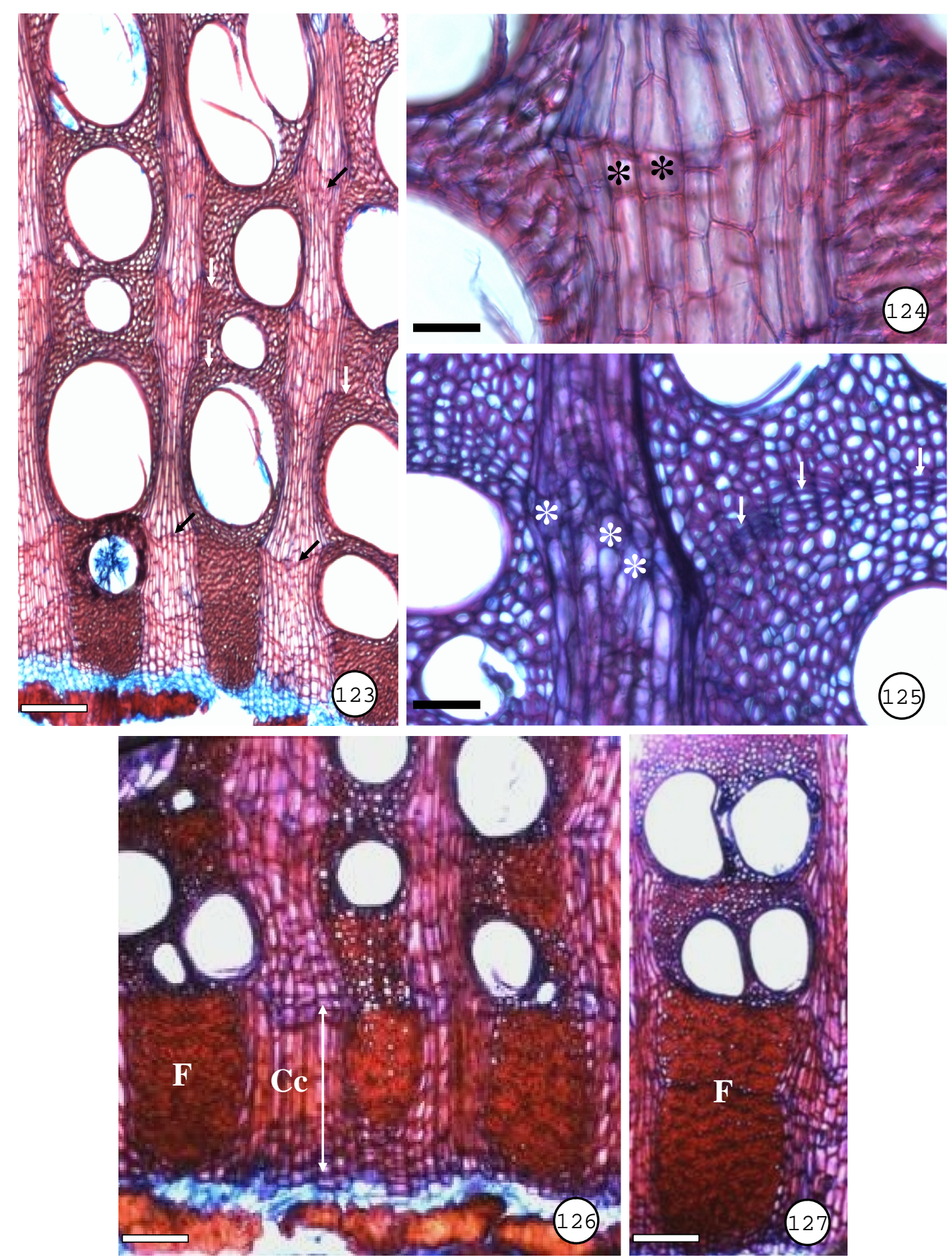

Figuras 123-127. Camadas de crescimento. Seção transversal. 123-124. Anomospermum sp. 123. Demarcação pelo achatamento e espessamento das fibras (setas brancas) e dilatação dos raios (setas pretas). 124. Detalhe da figura anterior, porção correspondente à camada de crescimento, evidencia 0 achatamento e dilatação das células do raio (*). 125 . Hyperbaena domingensis. Demarcação por achatamento das fibras (setas) e dilatação de células do raio (*). 126-127. Anomospermum sp. 126. Observe camada de crescimento (CC) demarcada por fibras espessas (F), ausência de vasos e pouco parênquima, além do achatamento das células radiais correspondentes. 127. Detalhe da figura anterior. Escalas $\mathbf{1 2 3}=90 \mu \mathrm{m} ; \mathbf{1 2 4}=40 \mu \mathrm{m} ; \mathbf{1 2 5}=60$ $\mu \mathrm{m} ; \mathbf{1 2 6}=80 \mu \mathrm{m} ; \mathbf{1 2 7}=55 \mu \mathrm{m}$. 

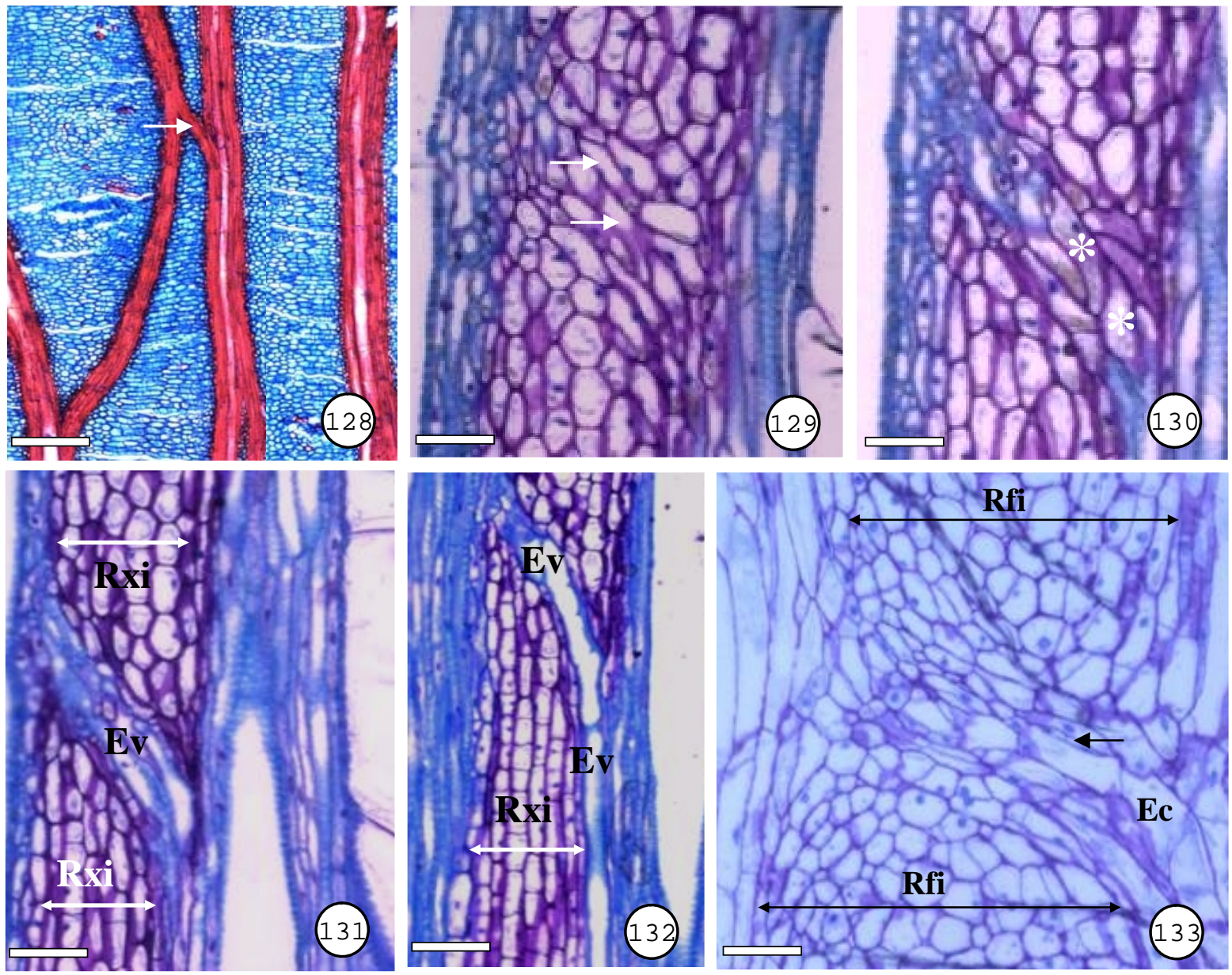

Figuras 128-133. Ruptura dos raios. Seção tangencial. Cissampelos andromorpha. 128-132. Xilema. 128. Observe raio interrompido por fibras (seta). 129-130. Células parenquimáticas axiais, com parede primária, iniciando a ruptura do raio, indicadas por setas brancas na figura 129 e por asteriscos na figura 130. 131-132. Raio xilemático (Rxi) interrompido por elementos de vaso (Ev). 133. Observe elemento de tubo crivado (Ec) com célula companheira (seta), interrompendo o raio floemático (Rfi). Escalas: $128=250 \mu \mathrm{m} ; \mathbf{1 2 9}=24 \mu \mathrm{m} ; \mathbf{1 3 0}=20 \mu \mathrm{m} ; \mathbf{1 3 1}=30 \mu \mathrm{m} ; \mathbf{1 3 2}=42$ $\mu \mathrm{m} ; \mathbf{1 3 3}=25 \mu \mathrm{m}$. 

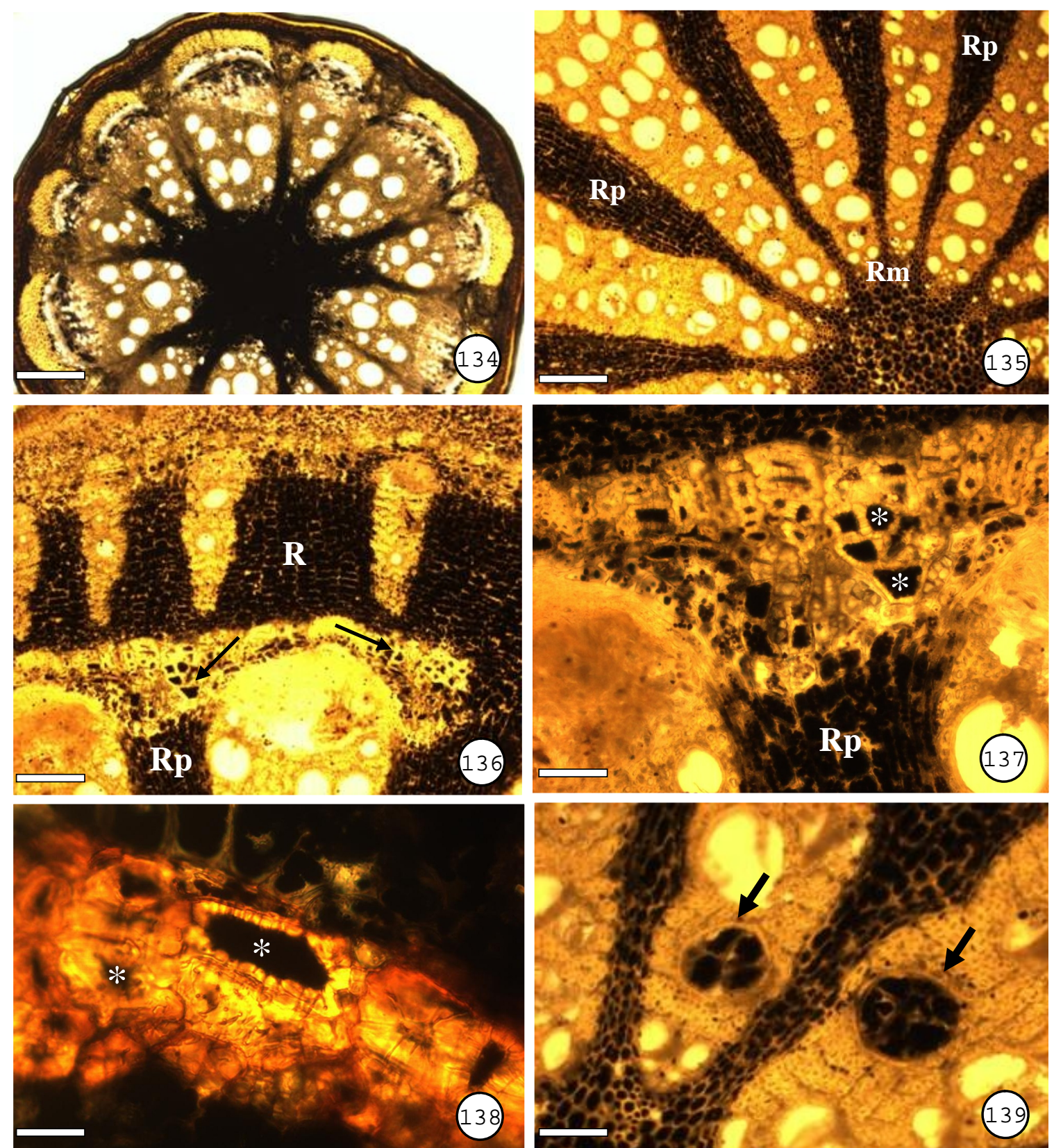

Figuras 134-139. Presença de amiloplastos no caule de lianas e trepadeiras herbáceas. Seção transversal. 134. Ungulipetalum filipendulum. Observe amiloplastos na região medular, nos raios, no floema, no córtex e na periderme. 135. Cissampelos andromorpha. Observe amiloplastos na medula; raios medulares ( $\mathrm{Rm}$ ) e raios formados pelo Câmbio de origem do periciclo (Rp). 136. Chondrodendron platiphyllum. observe amiloplastos em esclereídes pericíclicas (setas), em raios (R) de origem do câmbio formado pelo tecido conjuntivo e em raios formados pelo câmbio de origem do periciclo (Rp). 137-138. Detalhes da figura anterior. Amiloplastos em esclereídes (*). Raio formado pelo câmbio de origem do periciclo (Rp). 139. Cissampelos andromorpha. Note amiloplastos em tilos no elemento de vaso (setas). Escalas: $134=200$ $\mu \mathrm{m} ; \mathbf{1 3 5}=120 \mu \mathrm{m} ; \mathbf{1 3 6}=90 \mu \mathrm{m} ; \mathbf{1 3 7}=30 \mu \mathrm{m} ; \mathbf{1 3 8}=20 \mu \mathrm{m} ; 139=50 \mu \mathrm{m}$. 

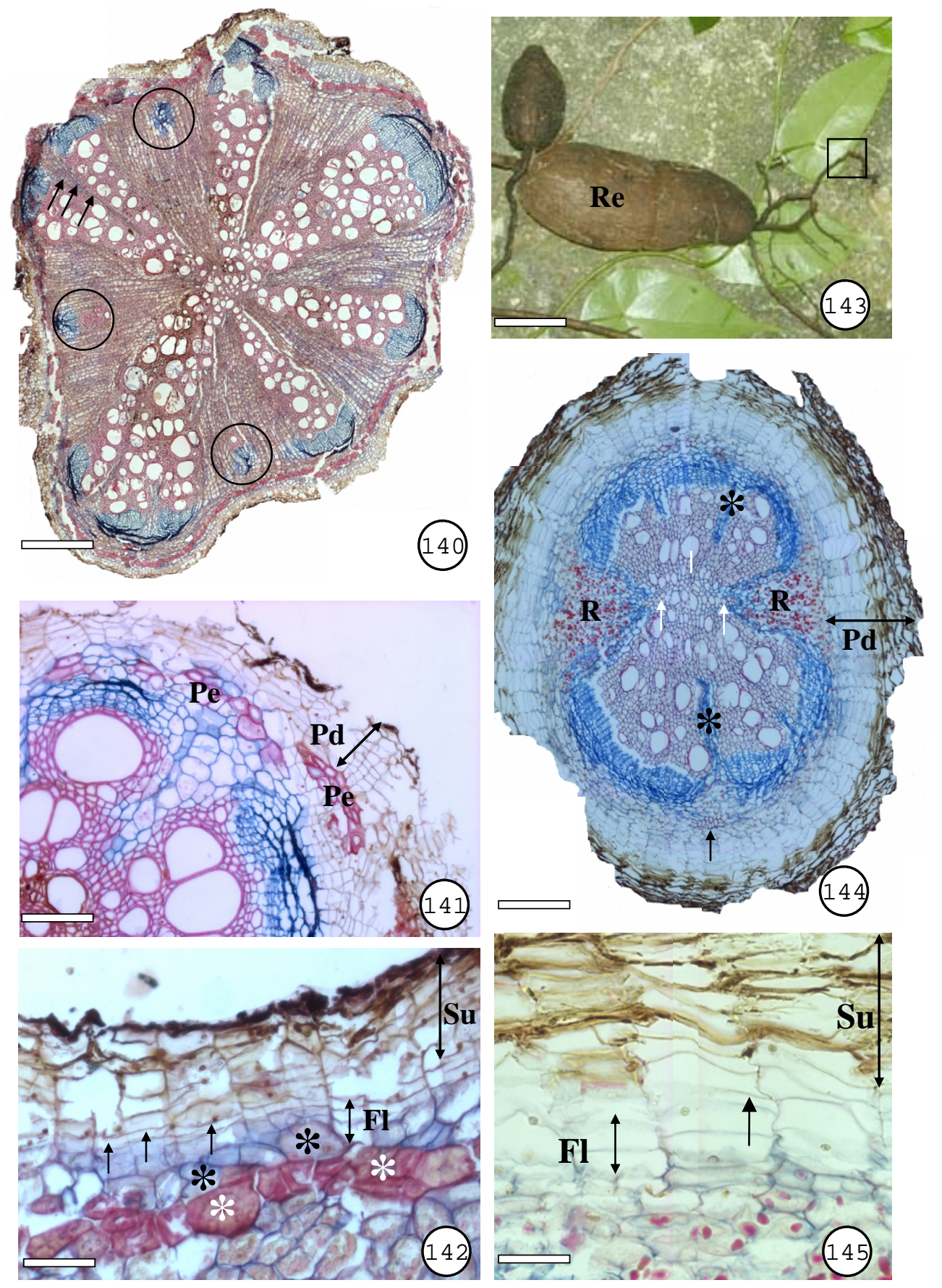

Figuras 140-142. Raiz de Cissampelos andromorpha, seção transversal. 140. Aspecto geral da raiz adulta. Observe novos sistemas vasculares formados onde só havia raios largos (circunferência) e novos raios (setas). 141. Observe a periderme ( $\mathrm{Pd})$, justaposta às esclereídes pericíclicas ( $\mathrm{Pe})$. 142. Detalhe da periderme, composta por súber (Su), felogênio (setas) e feloderme (Fl). Note - periciclo composto por células parenquimáticas (* preto) e esclereídes (* branco). Escalas: $\mathbf{1 4 0}=350 \mu \mathrm{m} ; \mathbf{1 4 1}=80 \mu \mathrm{m} ; \mathbf{1 4 2}=40 \mu \mathrm{m}$.

Figuras 143-145. Raiz de Disciphania hernandia. 143. Observe a porção espessada da raiz ( $R e$ ) e a porção terminal de pequeno calibre (assinalada). 144. Seção transversal da região não espessada assinalada na figura 132. A raiz é diarca, observe os raios ( $R$ ) em frente aos dois pólos de protoxilema (setas brancas). Periderme (Pd). Note os novos raios (*) e as esclereídes pericíclicas tangenciando a periderme (seta preta). 145. Súber (Su), felogênio (seta) e feloderme (Fl). Escalas: $143=4,5 \mathrm{~cm} ; \mathbf{1 4 4}=280 \mu \mathrm{m} ; \mathbf{1 4 5}=$ $30 \mu \mathrm{m}$. 

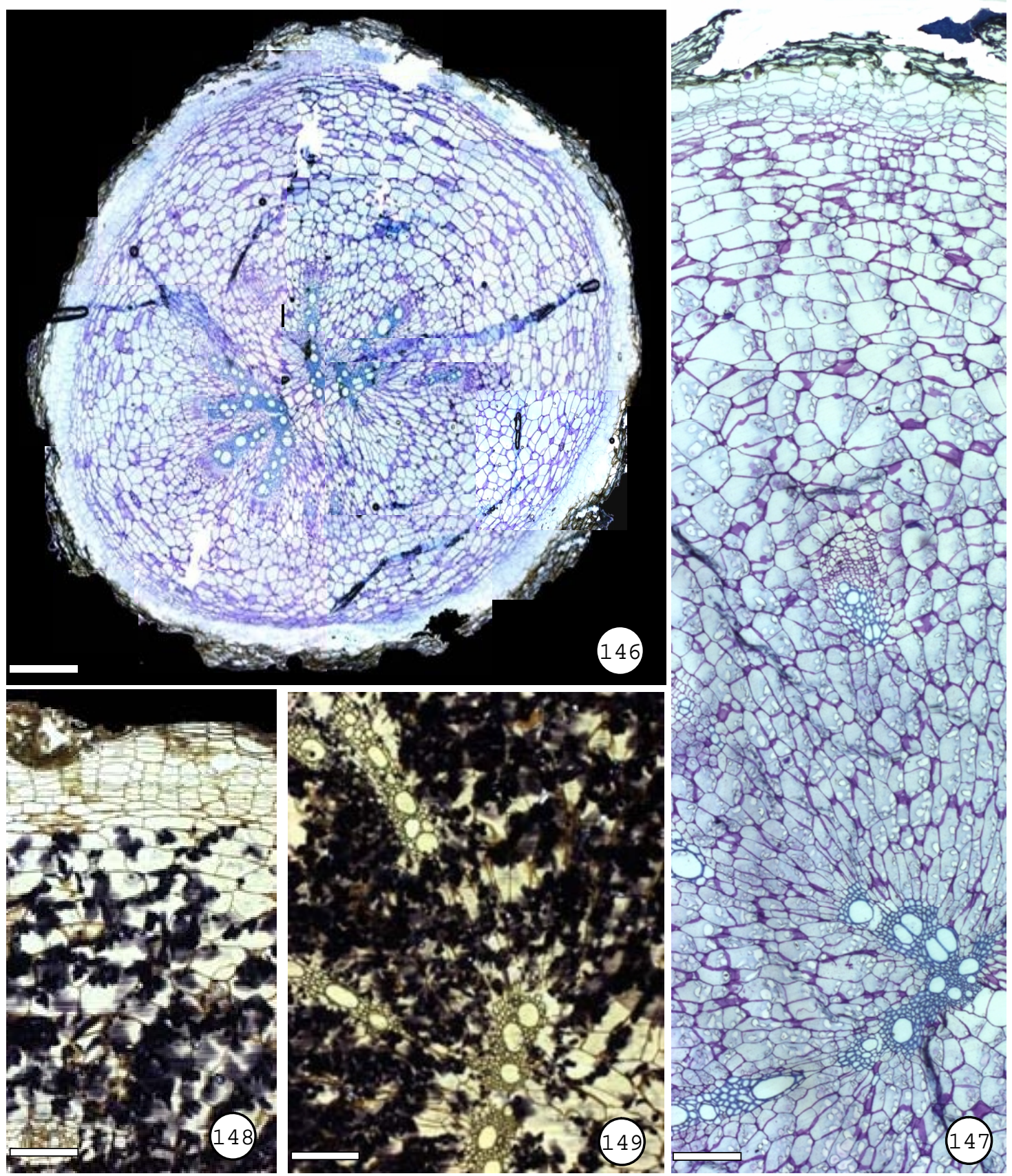

Figuras 146-149. Raiz espessada de Disciphania hernandia; seção transversal. 146. Aspecto geral. 147. Observe o intenso processo de parenquimatização, através de divisões anticlinais, oblíquas e periclinais das células do periciclo, floema e xilema. Note número reduzido de elementos condutores do xilema e do floema. 148-149. Amiloplastos em grande quantidade nas células parenquimáticas. Escalas: $\mathbf{1 4 6}=500 \mu \mathrm{m} ; \mathbf{1 4 7}=50 \mu \mathrm{m} ; \mathbf{1 4 8 - 1 4 9}=45 \mu \mathrm{m}$. 

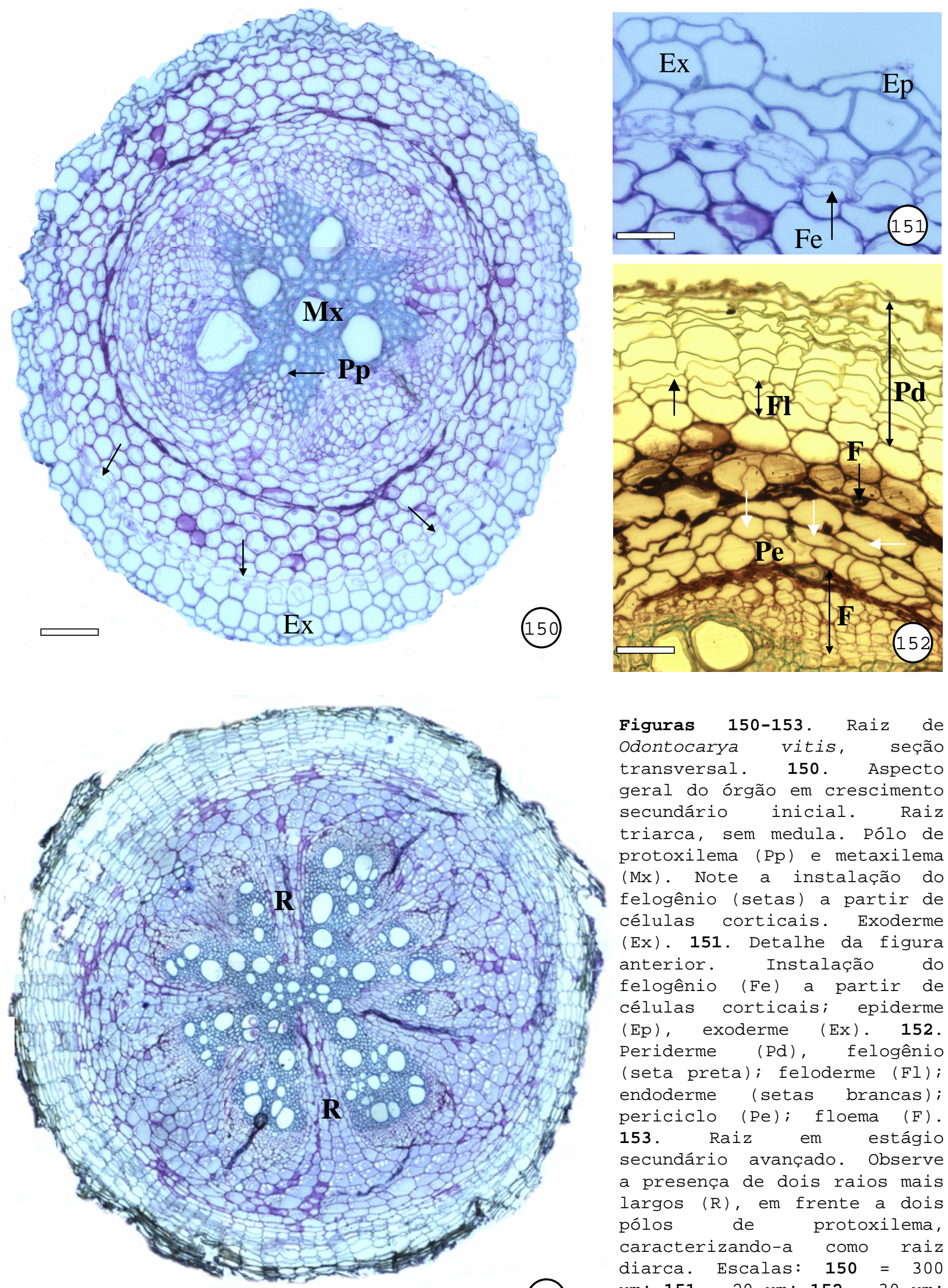

Figuras 150-153. Raiz de Odontocarya vitis, seção transversal. 150. Aspecto geral do órgão em crescimento secundário inicial. Raiz triarca, sem medula. Pólo de protoxilema (Pp) e metaxilema $(\mathrm{Mx})$. Note a instalação do felogênio (setas) a partir de células corticais. Exoderme (Ex). 151. Detalhe da figura anterior. Instalação do felogênio ( $\mathrm{Fe})$ a partir de células corticais; epiderme (Ep), exoderme (Ex). 152. Periderme (Pd), felogênio (seta preta); feloderme (Fl); endoderme (setas brancas); periciclo (Pe); floema (F). 153. Raiz em estágio secundário avançado. Observe a presença de dois raios mais largos ( $R$ ), em frente a dois pólos de protoxilema, caracterizando-a como raiz diarca. Escalas: $\mathbf{1 5 0}=300$ $\mu \mathrm{m} ; \mathbf{1 5 1}=20 \mu \mathrm{m} ; \mathbf{1 5 2}=30 \mu \mathrm{m}$; (153) $\begin{aligned} & \mu \mathrm{m} ; 151=20 \\ & 153=200 \mu \mathrm{m} .\end{aligned}$ 

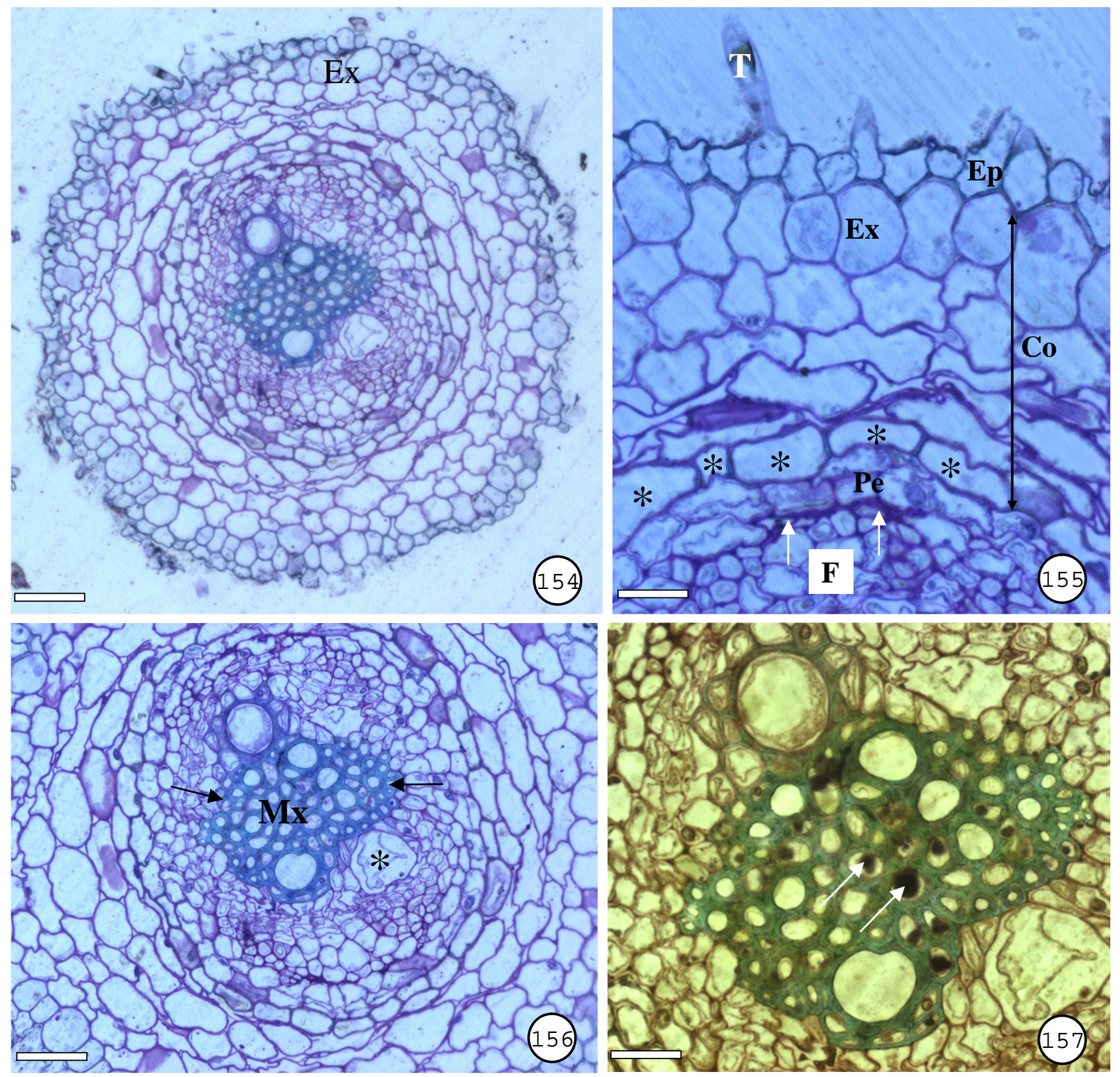

Figuras 154-157. Raiz de Ungulipetalum filipendulum. Seção transversal. 154. Aspecto geral do órgão em início do crescimento secundário. Observase epiderme, exoderme (Ex), células corticais circulares a irregulares. 155. Epiderme (Ep) com células menores com formato irregular e presença de tricomas tectores ( $\mathrm{T})$; exoderme (Ex); córtex (Co); endoderme (*); periciclo (Pe); floema primário colapsado (setas brancas); floema secundário (F). 156-157. Sistema vascular. Início do crescimento secundário. 156. Metaxilema (Mx). Dois pólos de protoxilema (setas). Vaso do xilema secundário em diferenciação (*). 157. Presença de amido nas células lignificadas do metaxilema (setas). Escalas: $154=150 \mu m ; 155=$ $25 \mu \mathrm{m} ; \mathbf{1 5 6}=100 \mu \mathrm{m} ; \mathbf{1 5 7}=18 \mu \mathrm{m}$. 

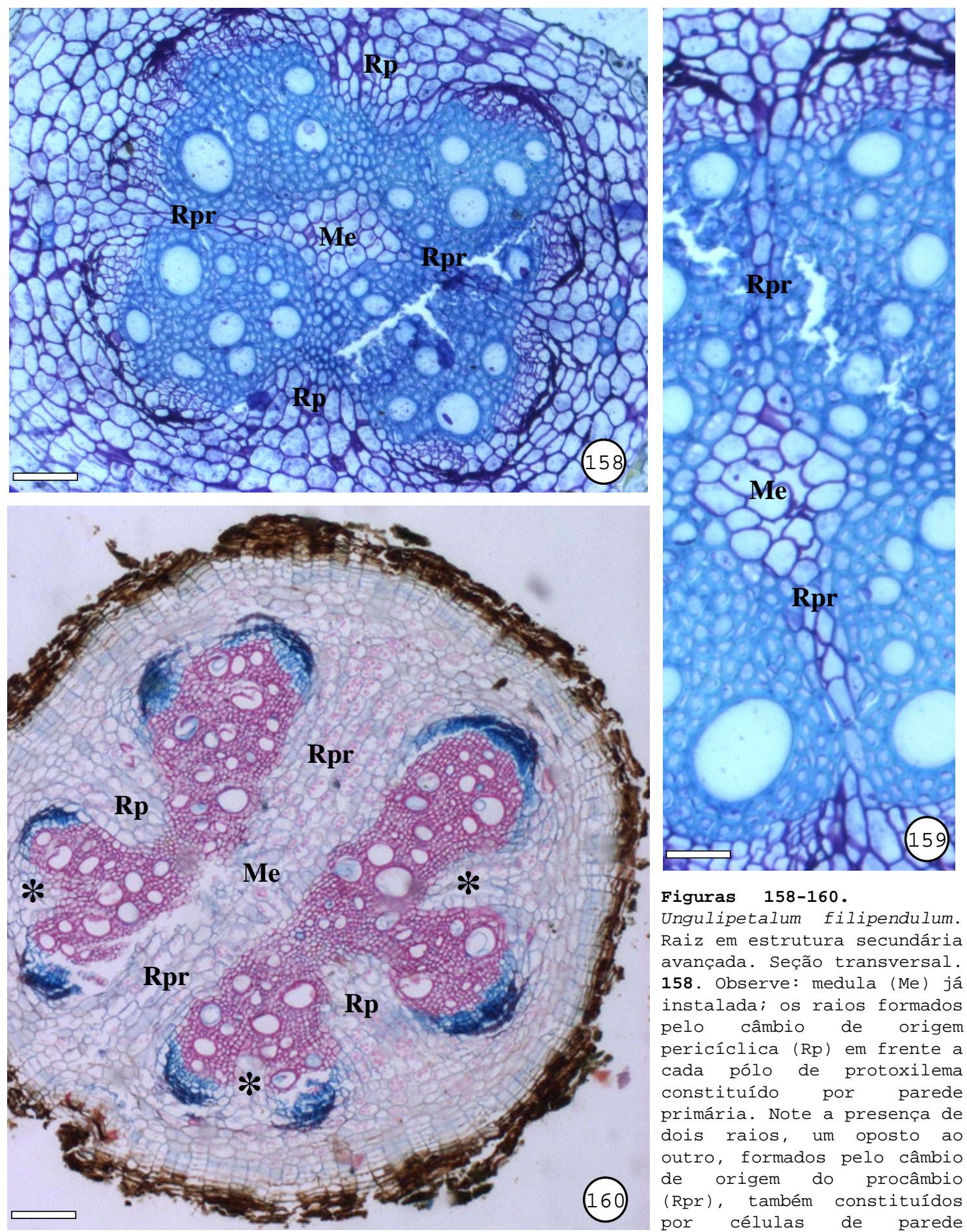

\section{Figuras 158-160.}

Ungulipetalum filipendulum. Raiz em estrutura secundária avançada. Seção transversal. 158. Observe: medula (Me) já instalada; os raios formados pelo câmbio de origem pericíclica (Rp) em frente a cada pólo de protoxilema constituído por parede primária. Note a presença de dois raios, um oposto ao outro, formados pelo câmbio de origem do procâmbio (Rpr), também constituídos
por células de parede

primária. 159. Detalhe dos raios xilemáticos, formados pelo câmbio de origem procambial (Rpr), compostos por células de parede primária, cruzando as células axiais lignificadas do xilema secundário. 160. Após várias divisões celulares tanto dos raios formados pelo câmbio de origem procambial (Rpr) quanto da medula (Me), a raiz apresenta uma faixa parenquimática, de origem medular e vascular, que cruza o cilindro vascular. Observe a formação de novos raios (*) e os raios formados pelo câmbio de origem pericíclica (Rp). Escalas: $\mathbf{1 5 8}=100 \mu \mathrm{m} ; \mathbf{1 5 9}=35 \mu \mathrm{m} ; \mathbf{1 6 0}=180 \mu \mathrm{m}$. 

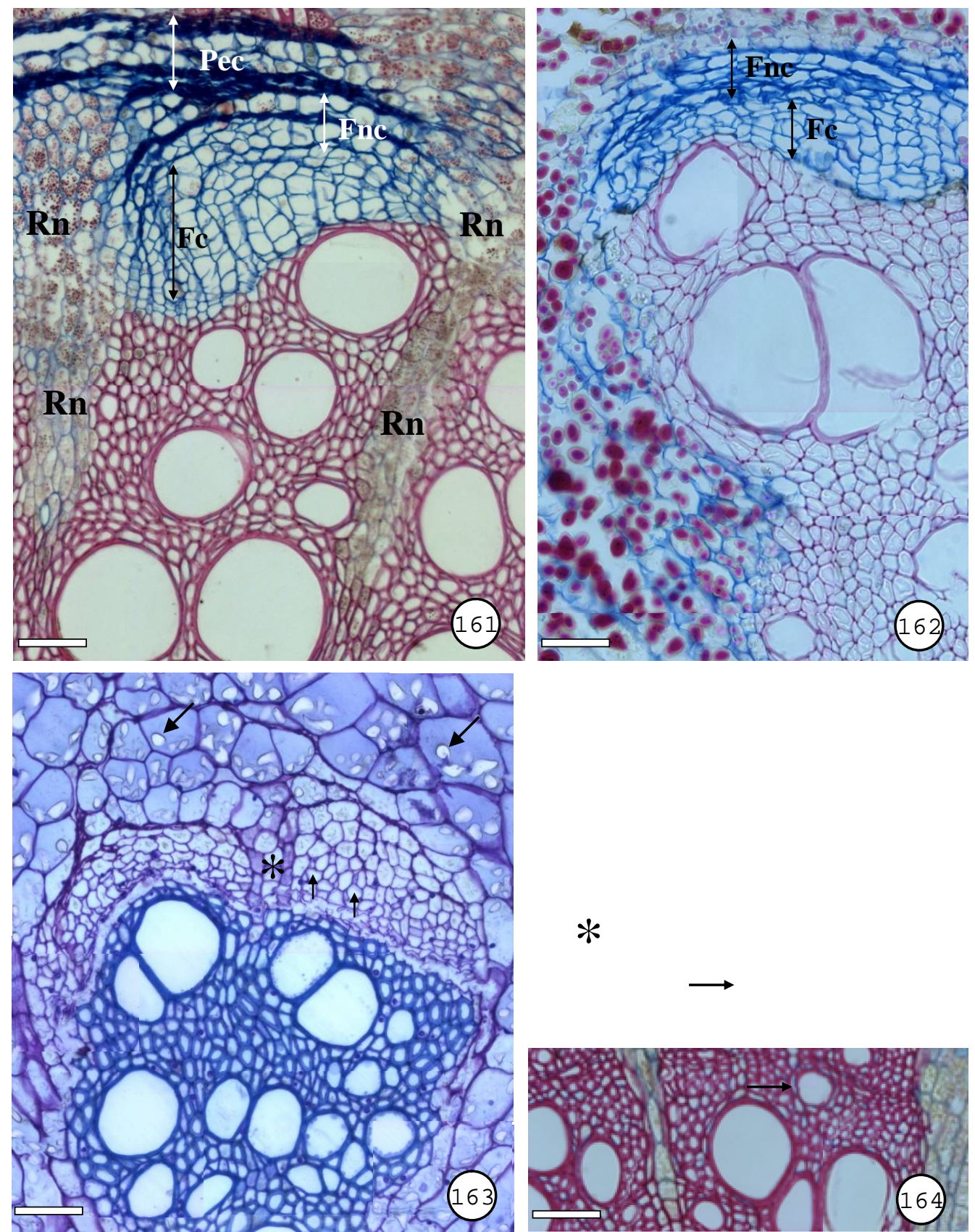

\section{$*$}

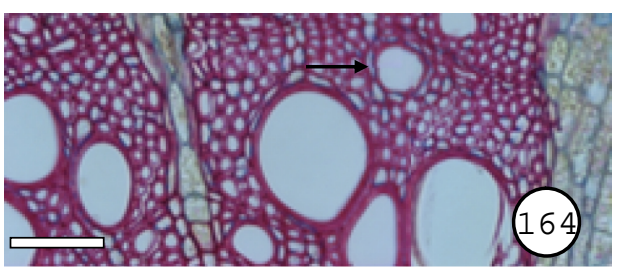

Figuras 161-164. Sistema vascular da raiz em crescimento secundário avançado. Seção transversal. 161. Cissampelos andromorpha. Observe a disposição radial dos elementos de tubos crivados no floema condutor (FC); note o maior calibre desses elementos condutores. Floema não condutor (Fnc). Periciclo parenquimático colapsado (Pec). Novo raio $(\mathrm{Rn})$ xilemático e floemático com amiloplastos. Vasos solitários. 162. Disciphania hernandia. Note no floema condutor (FC); à direita da figura, a disposição radial dos elementos de tubos crivados que apresentam maiores calibres. Vasos múltiplo de dois e solitários. 163. Odontocarya vitis. Amiloplastos nas células pericíclicas parenquimáticas (setas grandes). Elementos de tubos crivados de pequeno calibre e disposição difusa (setas pequenas). Novo raio (*). 164. Ungulipetalum filipendulum. Novo raio xilemático inicialmente unisseriado (seta preta), tornando-se multisseriado (*). Raio unisseriado xilemático e floemático (seta branca). Floema não condutor (Fnc) e periciclo colapsado (Pec). Escalas: 161-163 = $60 \mu \mathrm{m} ; \mathbf{1 6 4}=65 \mu \mathrm{m}$. 


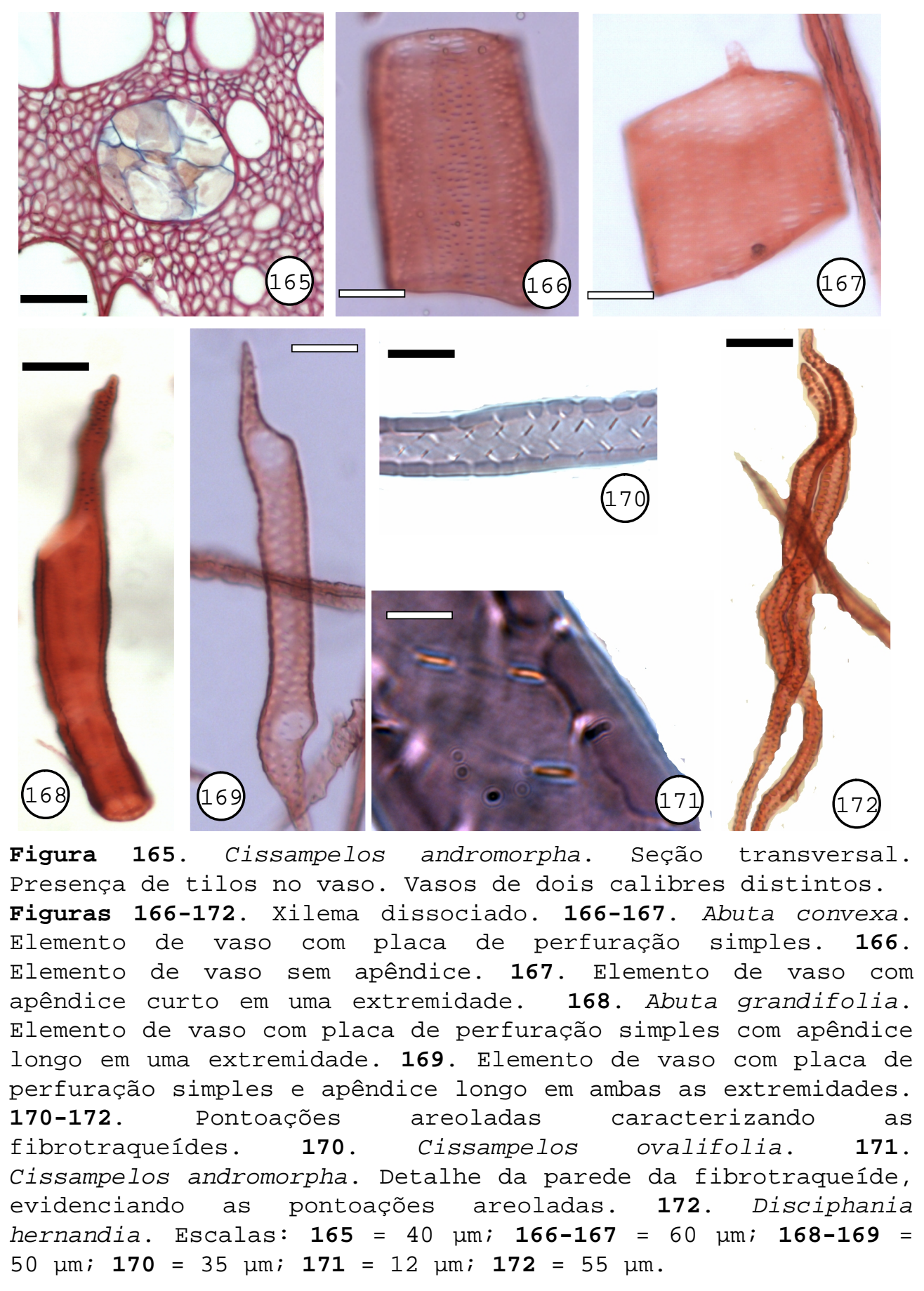



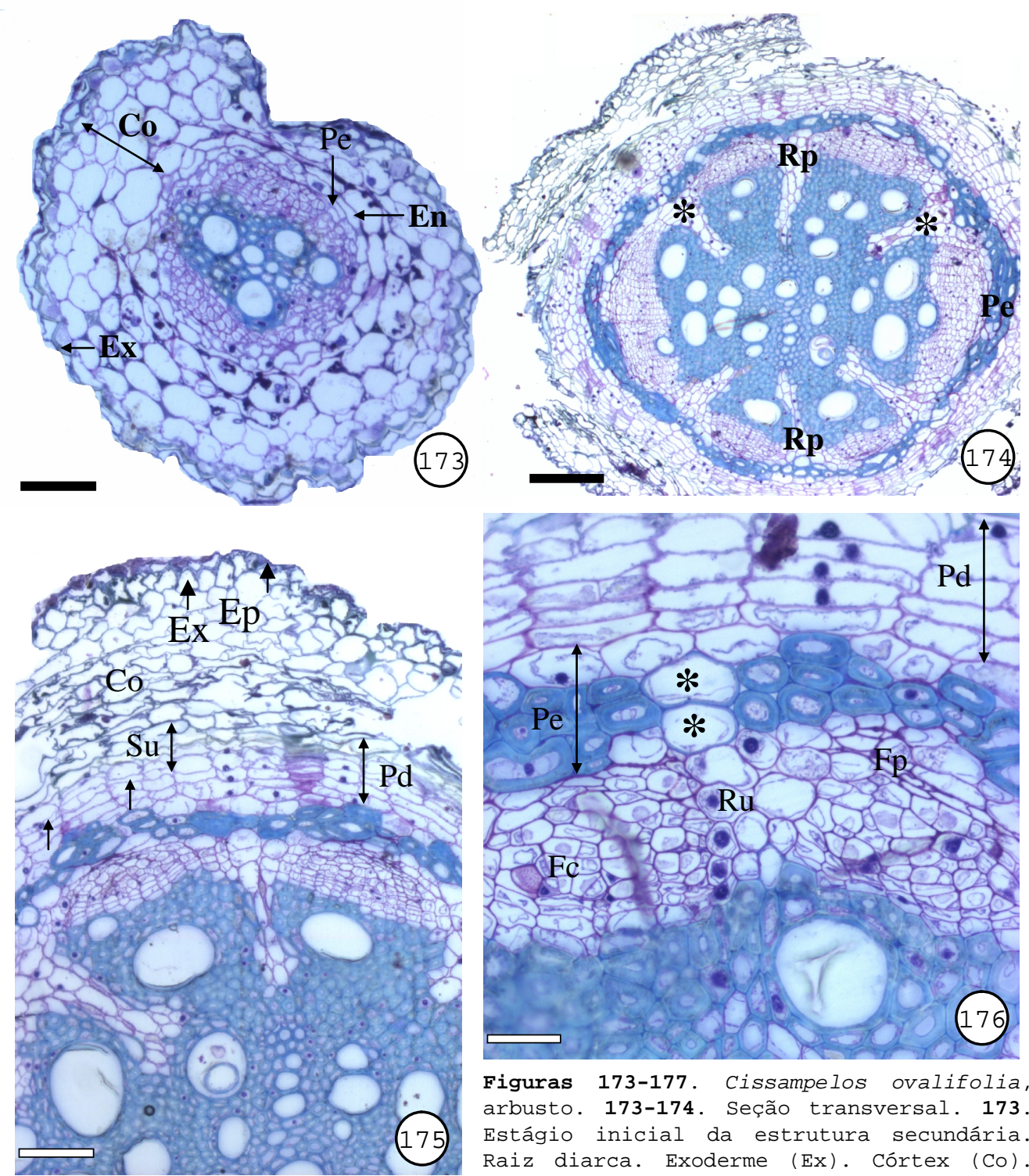

Figuras 173-177. Cissampelos ovalifolia, arbusto. 173-174. Seção transversal. 173. Estágio inicial da estrutura secundária. Raiz diarca. Exoderme (Ex). Córtex (Co). Endoderme (En). Periciclo (Pe). 174. Dois

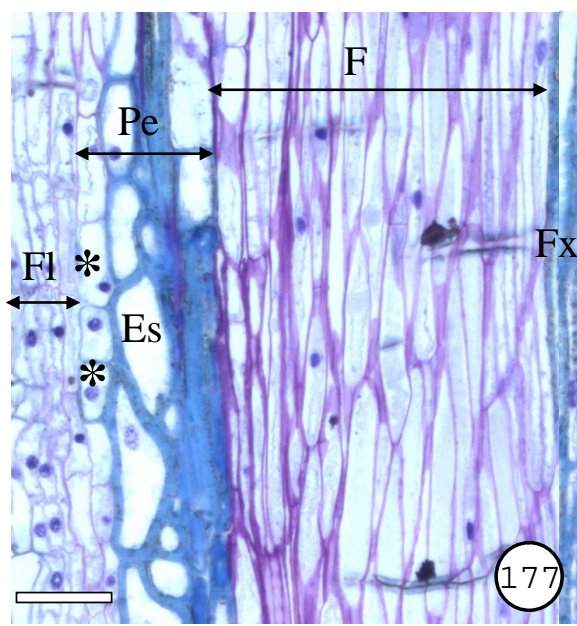

raios (Rp) em frente aos pólos de protoxilema, formados pelo câmbio de origem pericíclica. Novos raios (*). 175 . Epiderme (Ep). Exoderme (Ex). Córtex (Co). Periderme (Pd). Súber (Su). Felogênio (setas). 176. Detalhe da figura anterior. Periderme (Pd). Periciclo (Pe) composto por células parenquimáticas e esclereídes. Células parenquimáticas pericíclicas iniciando a deposição de parede secundária (*). Floema primário (Fp). Floema condutor $(F C)$. Raio unisseriado (Ru). 177. Seção longitudinal tangencial. Fibras do xilema $(F x)$. Floema (F). Periciclo (Pe), composto por células parenquimáticas (*) e esclereídes (ES). Feloderme (Fl). Escalas: $\mathbf{1 7 3}=350 \mu \mathrm{m} ; \mathbf{1 7 4}=250 \mu \mathrm{m} ; \mathbf{1 7 5}=80 \mu \mathrm{m}$; $176=30 \mu \mathrm{m} ; \mathbf{1 7 7}=50 \mu \mathrm{m}$. 

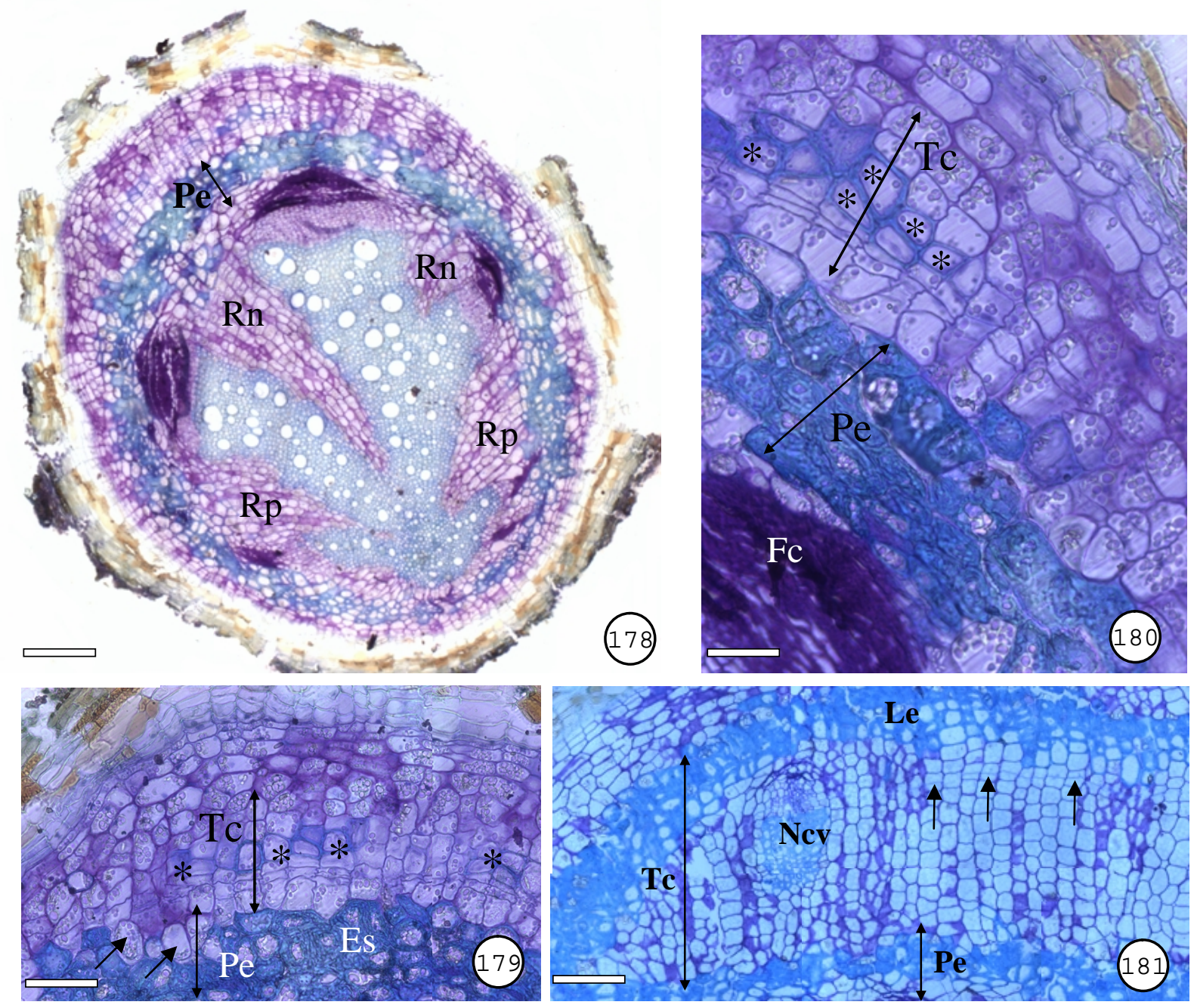

Figuras 178-181. Raiz de Chondrodendron platiphyllum (liana). Seção transversal. 178. Aspecto geral da raiz excêntrica e diarca. Periciclo $(\mathrm{Pe})$. Raios formados pelo câmbio de origem pericíclica (Rp). Raios novos $(\mathrm{Rn})$. 179. Periciclo (Pe), constituído por células parenquimáticas (setas) e esclereídes (Es). Tecido conjuntivo (TC) originado a partir de divisões das células parenquimáticas pericíclicas. Note novas células lignificadas formadas na porção mediana do tecido conjuntivo (*), que formarão novo anel de esclereídes. 180. Detalhe da figura anterior. Periciclo $(\mathrm{Pe})$. Tecido conjuntivo $(\mathrm{TC})$. Futuras esclereídes do tecido conjuntivo (*). 181. Segundo anel de esclereídes já formado (Le). Porção do primeiro cordão neoformado. As setas indicam um câmbio se diferenciando. Linha de esclereídes (Le). Tecido conjuntivo (TC). Periciclo $(\mathrm{Pe})$. Novo cordão vascular secundário ( $\mathrm{NcV})$. Escalas: $178=$ $250 \mu \mathrm{m} ; \mathbf{1 7 9}=35 \mu \mathrm{m} ; \mathbf{1 8 0}=18 \mu \mathrm{m} ; \mathbf{1 8 1}=65 \mu \mathrm{m}$. 

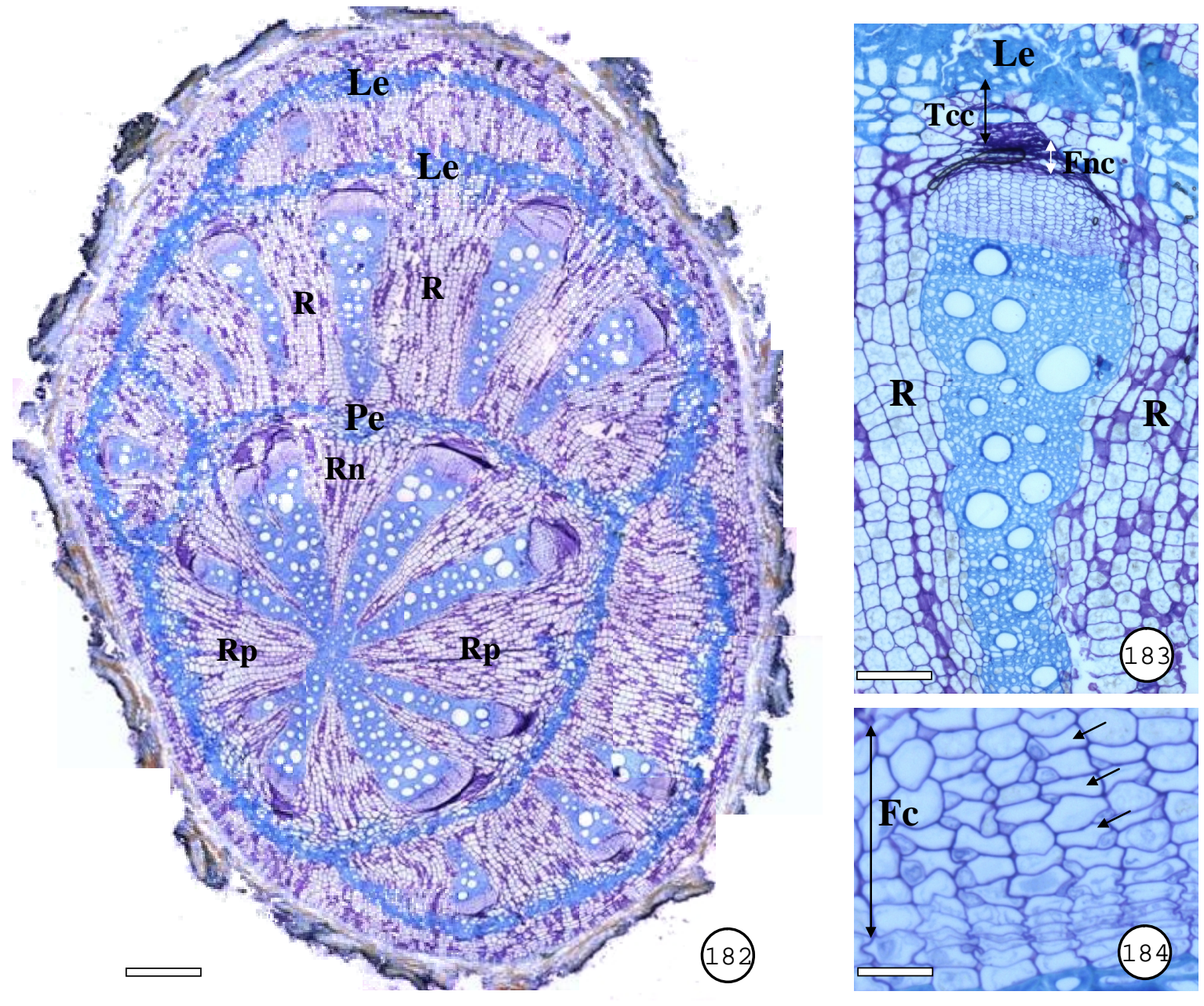

Figuras 182-184. Chondrodendron platiphyllum. Raiz. 182. Seção transversal. Aspecto geral da raiz excêntrica. Observe que apenas a primeira linha de esclereídes (Pe), de origem do periciclo, circunda totalmente o caule. As restantes (Le), de origem do tecido conjuntivo, assumem a forma de meia lua, de forma excêntrica. Diferentes tipos de raios não lignificados: raios formados pelo câmbio de origem do periciclo (Rp); raios neoformados ( $R$ n) e raios formados pelo câmbio de origem do tecido conjuntivo (R). 183. Linha de esclereíde (Le) de origem do tecido conjuntivo. Floema não condutor (Fnc) caracterizado pelo colapso do floema secundário, juntamente com células parenquimáticas do tecido conjuntivo (TCC). O xilema apresenta elementos de vasos solitários e parênquima axial difuso tendendo a formar linhas. Raios formados pelo câmbio de origem do tecido conjuntivo (R). 184. Detalhe do floema. O floema condutor (FC) apresenta elementos de tubos crivados com suas células companheiras em disposição radial (setas). Escalas: $182=200 \mu \mathrm{m} ; \mathbf{1 8 3}=60 \mu \mathrm{m}$; $184=20 \mu \mathrm{m}$. 

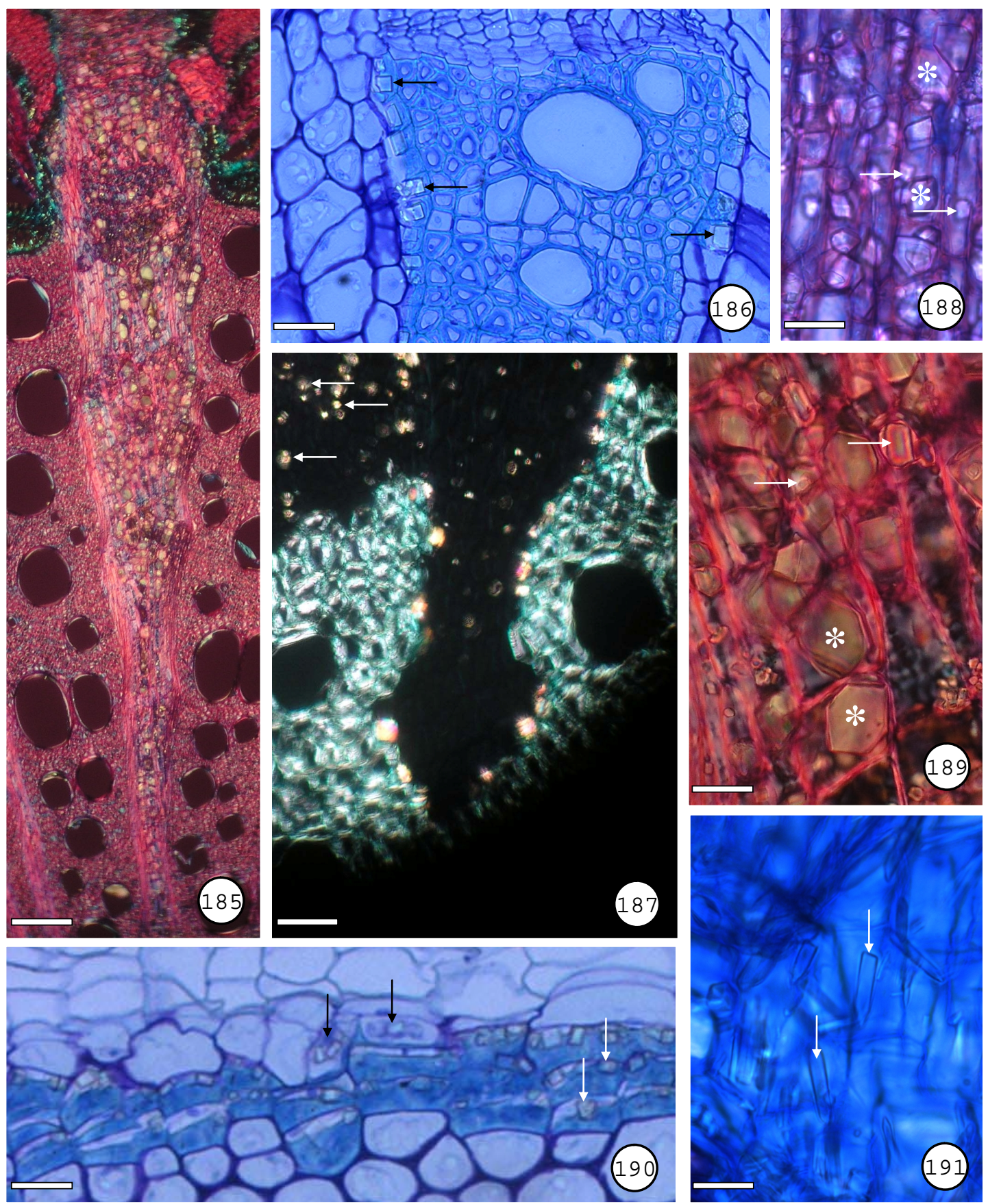

Figuras 185-191. Cristais. 185-189. Cristais no raio. 185, 187, 188, 189. Observação em luz polarizada. 185. Abuta convexa. Caule. Presença em todas as células do raio (corpo e margem). 186-187. Odontocarya vitis. Cristais prismáticos. 186. Caule. Presença nas células marginais do raio (setas). 187. Raiz. Presença em células marginais do raio e células parenquimáticas do floema (setas). 188-189. Cristais prismáticos grandes (*) e pequenos (setas). Caule. 188. Hyperbaena domingensis. 189. Abuta convexa. 190. Odontocarya vitis. Caule. Cristais cúbicos nas esclereídes corticais (setas brancas) e em células parenquimáticas corticais (setas pretas). 191. Odontocarya vitis. Raiz. Cristais estilóides (setas) em células parenquimáticas do floema. Escalas: $185=100 \mu \mathrm{m} ; \mathbf{1 8 6}=70 \mu \mathrm{m} ; \mathbf{1 8 7}=80 \mu \mathrm{m}$; $188=20 \mu \mathrm{m} ; \mathbf{1 8 9}=15 \mu \mathrm{m} ; \mathbf{1 9 0}=18 \mu \mathrm{m} ; \mathbf{1 9 1}=15 \mu \mathrm{m}$. 

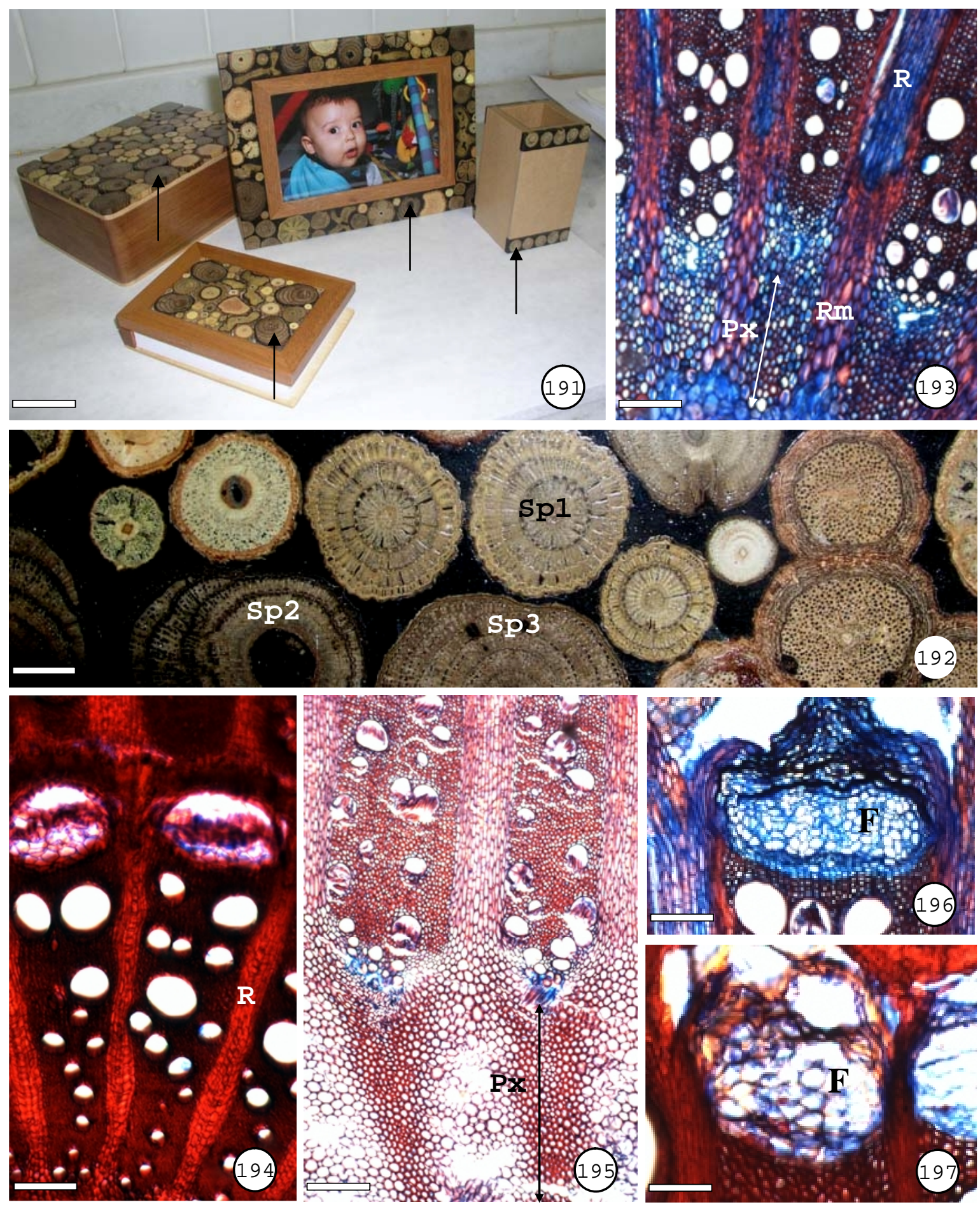

Figuras 191 e 192. Caules de Menispermaceae utilizados em objetos comercializados. 191. As setas indicam porções transversais do caule. 192. É possível detectar três espécies distintas (sp1, sp2 e sp3). 193. Espécie 1 (sp1). Seção transversal. Observe protoxilema lignificado (Px); raio medular lignificado (Rm) e raios do xilema não lignificados (R). Essa espécie é semelhante a liana Chondrodendron platiphyllum. 194-195. Espécies não identificadas. Seção transversal. 194. Espécie 2 (sp2). Raios lignificados (R); ausência de raio medular. 195. Espécie 3 (sp3). Observe parênquima do protoxilema lignificado (Px) e ausência de raio medular. 196197. Seção transversal. Note que as células floemáticas possuem calibre menor na Figura 196 quando comparadas a Figura 197. 196. Espécie 1(sp1). 197. Espécie 2 (sp2). Escalas: $191=6 \mathrm{~cm} ; 192=1 \mathrm{~cm} ; 193$ e 194-195 = $70 \mu \mathrm{m} ;$ 196-197. $70 \mu \mathrm{m}$. 


\section{8 - Análise estatística das características quantitativas do lenho}

\subsection{1 - Anéis sucessivos}

Para o estudo dos anéis sucessivos foram selecionadas três lianas (Abuta convexa, Abuta selloana e Hyperbaena domingensis) e um arbusto (Abuta grandifolia). Na Figura 111 é apresentado o desenho esquemático do caule de Abuta convexa. De cada espécie foram analisados quatro anéis sucessivos: primeiro, segundo, quinto e o décimo. Com relação ao diâmetro e comprimento de vasos foram realizados dois tipos de testes: (1) utilizando, separadamente, cada categoria de diâmetro do elemento de vaso; (2) utilizando, conjuntamente, todas as categorias de diâmetro do elemento de vaso. Os dados morfométricos das variáveis diâmetro e comprimento dos elementos de vasos e diâmetro e comprimento das fibras encontram-se na Tabela 3. As Tabelas 4, 5, 6 e 7 apresentam os resultados da análise de variância (ANOVA) e o teste de Tuckey-Kramer. Os Gráficos 1 a 8 apresentam os resultados da análise de Kruskall-Wallis e Mann-Whitney.

Tabela 4. Análise de variância (ANOVA) e teste Tuckey-Kramer para as variáveis dos anéis sucessivos de Abuta convexa. Médias com a mesma letra não diferem significativamente; médias com letras diferentes diferem significativamente a 5\%; medida $=$ micrômetros $(\mu \mathrm{m}), \quad \mathrm{X}=$ média. Categoria de diâmetro do elemento do vaso: grande (>150 $\mu \mathrm{m})$; médio $(101-150 \mu \mathrm{m})$; pequeno $(51-100 \mu \mathrm{m})$; muito pequeno $(\leq 50 \mu \mathrm{m})$.

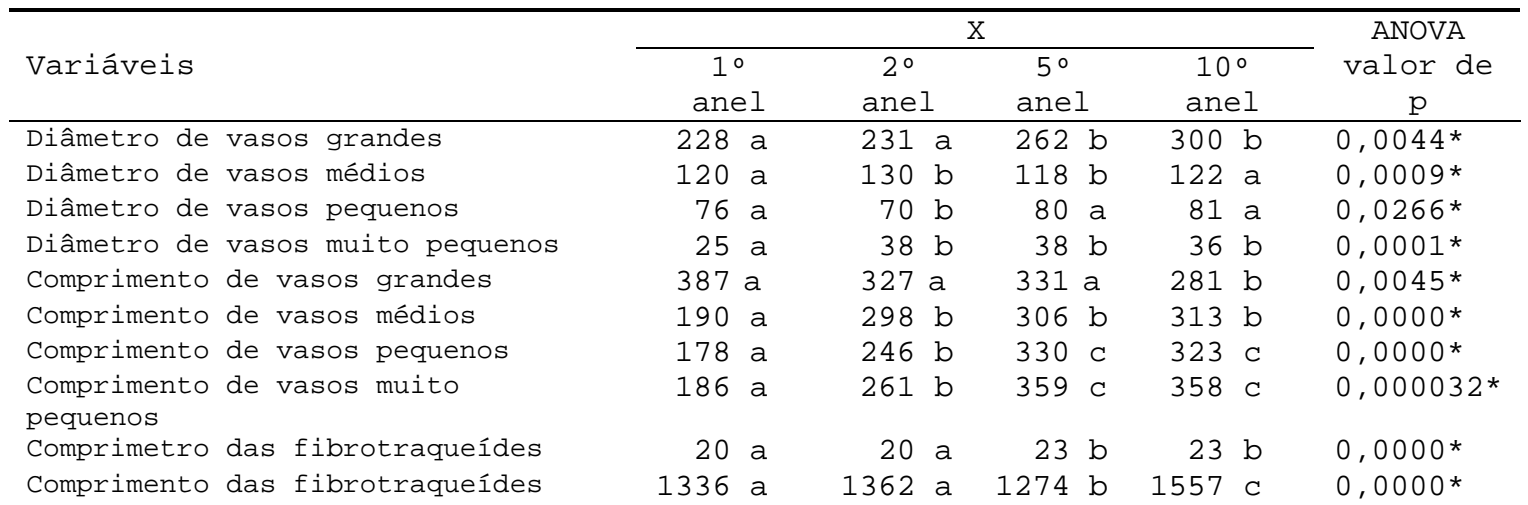




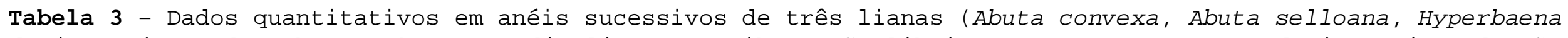

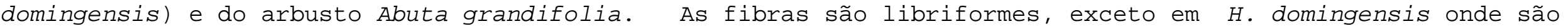
fibrotraqueídes. Unidade de medida = micrômetros ( $\mu m)$. Dados fornecidos em mínimo-média-máximo.

\begin{tabular}{|c|c|c|c|c|c|c|c|c|c|c|c|}
\hline \multicolumn{10}{|c|}{ Elemento de vaso } & \multirow{3}{*}{\multicolumn{2}{|c|}{ Fibras }} \\
\hline & & \multirow{2}{*}{\multicolumn{4}{|c|}{$\frac{\text { Diâmetro }}{\text { Categoria }}$}} & \multirow{2}{*}{\multicolumn{4}{|c|}{$\begin{array}{l}\text { Comprimento } \\
\text { Categoria }\end{array}$}} & & \\
\hline \multirow[t]{2}{*}{ Espécie } & \multirow[t]{2}{*}{ Anel } & & & & & & & & & & \\
\hline & & grande & médio & pequeno & $\begin{array}{l}\text { muito } \\
\text { pequeno }\end{array}$ & grande & médio & pequeno & $\begin{array}{l}\text { muito } \\
\text { pequeno }\end{array}$ & diâmetro & comprimento \\
\hline Abuta & 1 & $161-\mathbf{2 0 3}-266$ & $101-\mathbf{1 2 0}-143$ & $51-76-88$ & $12-25-50$ & $195-\mathbf{3 8 7}-590$ & $116-\mathbf{1 9 0 - 2 5 8}$ & $93-\mathbf{1 7 8}-259$ & $113-\mathbf{1 8 6}-269$ & $12-18-28$ & $975-1336-1880$ \\
\hline \multirow[t]{3}{*}{ convexa } & 2 & $151-\mathbf{2 0 0}-293$ & $103-130-148$ & $51-70-96$ & $19-38-51$ & $152-327-474$ & $206-298-408$ & $121-\mathbf{2 4 6 - 4 1 5}$ & $112-\mathbf{2 6 1 - 3 5 2}$ & $10-15-20$ & 949-1362-1707 \\
\hline & 5 & $154-\mathbf{2 1 1}-325$ & $101-118-150$ & $52-80-100$ & $17-38-50$ & $177-337-463$ & $131-299-457$ & $106-330-516$ & $112-359-515$ & $13-\mathbf{2 3}-32$ & $848-\mathbf{1 2 7 4}-1770$ \\
\hline & 10 & $162-\mathbf{2 2 5}-420$ & $102-\mathbf{1 2 2}-142$ & $60-81-97$ & $13-36-51$ & $198-281-344$ & $165-313-527$ & $102-323-468$ & $162-358-532$ & $13-\mathbf{2 3}-32$ & $848-1274-1170$ \\
\hline Abuta & 1 & - & - & $55-64-84$ & $24-40-50$ & - & - & $153-\mathbf{3 0 7}-412$ & $158-272-403$ & $14-21-34$ & 823-1119-1511 \\
\hline \multirow[t]{3}{*}{ grandifolia } & 2 & - & $101-115-148$ & $54-67-96$ & $25-\mathbf{4 1}-51$ & - & $283-\mathbf{3 8 0}-519$ & $166-\mathbf{2 8 3}-456$ & $257-\mathbf{3 9 2}-565$ & $16-22-31$ & $1146-\mathbf{1 5 4 1 - 1 8 8 1}$ \\
\hline & 5 & - & 101-109-129 & $52-68-94$ & $37-\mathbf{4 5}-51$ & - & $280-\mathbf{4 1 4}-509$ & $360-393-616$ & $339-\mathbf{4 0 4}-790$ & $16-\mathbf{2 2}-27$ & $1251-\mathbf{1 4 7 5}-1665$ \\
\hline & 9 & - & 101-110-131 & $53-63-78$ & $32-\mathbf{4 3}-51$ & - & $241-318-437$ & $167-305-516$ & $97-\mathbf{2 6 9}-472$ & $16-22-27$ & $1376-1617-1942$ \\
\hline Abuta & 1 & $151-\mathbf{2 0 4}-298$ & $102-\mathbf{1 2 8}-213$ & $64-80-99$ & $15-\mathbf{3 4}-49$ & $229-\mathbf{3 1 8}-428$ & $159-\mathbf{3 0 8}-464$ & $125-\mathbf{3 0 8}-531$ & $243-357-498$ & $17-\mathbf{2 2}-27$ & $1116-\mathbf{1 2 7 9 - 1 6 7 9}$ \\
\hline \multirow[t]{3}{*}{ convexa } & 2 & $158-216-321$ & $101-\mathbf{1 2 4 - 1 5 1}$ & $53-70-97$ & $17-\mathbf{3 4}-51$ & $240-\mathbf{3 4 4}-545$ & $259-\mathbf{3 6 2}-454$ & $114-316-501$ & $227-391-571$ & $14-23-36$ & $1074-1360-1807$ \\
\hline & 5 & $153-\mathbf{2 3 6}-340$ & $101-114-143$ & $53-73-98$ & $18-35-51$ & $271-369-456$ & $268-\mathbf{4 0 8}-575$ & $228-408-609$ & $279-437-715$ & $19-\mathbf{2 6}-42$ & $1049-\mathbf{1 3 4 8}-1820$ \\
\hline & 10 & $153-\mathbf{2 4 2}-396$ & $104-\mathbf{1 2 1}-149$ & $38-82-99$ & $12-33-48$ & $263-\mathbf{3 7 4}-475$ & $161-349-503$ & $193-\mathbf{3 5 9}-596$ & $130-355-552$ & $17-24-36$ & $1158-\mathbf{1 2 9 7}-1474$ \\
\hline Hyperbaena & 1 & 151-172-205 & 102-120-149 & $51-83-100$ & $12-\mathbf{3 7}-50$ & $277-\mathbf{3 7 6 - 4 7 5}$ & $242-\mathbf{3 9 7}-563$ & $125-\mathbf{4 0 2 - 5 8 6}$ & $276-604-73$ & $17-21-26$ & 975-1141-1322 \\
\hline \multirow[t]{3}{*}{ domingensis } & 2 & $153-181-244$ & $102-122-145$ & $52-66-99$ & $22-40-49$ & $232-\mathbf{3 1 4}-407$ & $136-311-428$ & $112-\mathbf{2 9 5}-421$ & $165-\mathbf{2 8 4}-439$ & $16-\mathbf{2 3}-35$ & $1035-1197-1555$ \\
\hline & 5 & $162-\mathbf{1 8 4}-214$ & $101-\mathbf{1 1 2}-143$ & $66-90-101$ & $26-40-51$ & $162-226-312$ & $150-\mathbf{2 4 3}-451$ & $165-266-400$ & $148-\mathbf{2 8 1}-82$ & $16-\mathbf{2 2}-28$ & $1022-\mathbf{1 2 1 0}-1571$ \\
\hline & 10 & $153-\mathbf{3 5 2}-467$ & - & $54-80-101$ & $8-28-43$ & $103-\mathbf{1 5 4}-233$ & - & $108-249-591$ & $130-314-507$ & $15-23-31$ & 998-1136-1395 \\
\hline
\end{tabular}


Tabela 5. Análise de variância (ANOVA) e teste Tuckey-Kramer para as variáveis dos anéis sucessivos de Abuta selloana. Médias com a mesma letra não diferem significativamente; médias com letras diferentes diferem significativamente a 5\%; medida = micrômetros $(\mu \mathrm{m}), \quad \mathrm{X}=$ média. Categoria de diâmetro do elemento do vaso: grande $(>150 \mu \mathrm{m})$; médio $(101-150 \mu \mathrm{m})$; pequeno (51-100 $\mu \mathrm{m})$; muito pequeno $(\leq 50 \mu \mathrm{m})$.

\begin{tabular}{|c|c|c|c|c|c|}
\hline \multirow{3}{*}{ Variáveis } & \multicolumn{4}{|c|}{$\mathrm{X}$} & ANOVA \\
\hline & $1^{\circ}$ & $2^{\circ}$ & $5^{\circ}$ & $10^{\circ}$ & valor de $p$ \\
\hline & anel & anel & anel & anel & \\
\hline Diâmetro de vasos grandes & $204 a$ & 216 a & $229 \mathrm{a}, \mathrm{b}$ & $257 \mathrm{~b}$ & $\mathrm{p}=0,0207 \star$ \\
\hline Diâmetro de vasos médios & $128 \mathrm{a}$ & $124 \mathrm{a}$ & $114 \mathrm{~b}$ & $121 \mathrm{a}$ & $\mathrm{p}=0,0070 *$ \\
\hline Diâmetro de vasos pequenos & $80 \mathrm{a}$ & $70 \mathrm{~b}$ & $73 \mathrm{~b}$ & $82 \mathrm{a}$ & $\mathrm{p}=0,0020 *$ \\
\hline Diâmetro de vasos muito pequenos & $34 a$ & 34 a & 35 a & $33 a$ & $\mathrm{p}=0,08440 *$ \\
\hline Comprimento de vasos grandes & $318 \mathrm{a}$ & 344 a, c & $369 \mathrm{~b}, \mathrm{c}$ & $374 \mathrm{~b}$ & $\mathrm{p}=0,0033 \star$ \\
\hline Comprimento de vasos médios & $308 \mathrm{a}$ & $362 \mathrm{~b}$ & $408 \mathrm{C}$ & $349 \mathrm{~b}$ & $\mathrm{p}=0,0018 *$ \\
\hline Comprimento de vasos pequenos & 308 a & 316 a & $408 \mathrm{~b}$ & $359 \mathrm{~b}$ & $\mathrm{p}=0,0067 \star$ \\
\hline Comprimento de vasos muito pequenos & $357 \mathrm{a}$ & 391 a & 437 a & 355 a & $\mathrm{P}=0,487 \mathrm{~ns}$ \\
\hline Diâmetro das fibras & $22 \mathrm{a}$ & 23 a & $26 \mathrm{~b}$ & $24 a$ & $\mathrm{p}=0,006 *$ \\
\hline Comprimento das fibras & $1279 \mathrm{a}$ & $1360 \mathrm{a}$ & 1348 a & 1297 a & $\mathrm{p}=0,1173 \mathrm{~ns}$ \\
\hline
\end{tabular}

Tabela 6. Análise de variância (ANOVA) e teste Tuckey-Kramer para as variáveis dos anéis sucessivos de Hyperbaena domingensis. Médias com a mesma letra não diferem significativamente; médias com letras diferentes diferem significativamente a 5\%; medida $=$ micrômetros $(\mu \mathrm{m}), \quad \mathrm{X}=$ média. Categoria de diâmetro do elemento do vaso: grande ( $>150 \mu m)$; médio (101-150 $\mu \mathrm{m})$; pequeno $(51-100 \mu \mathrm{m})$; muito pequeno ( $\leq 50 \mu \mathrm{m})$.

\begin{tabular}{|c|c|c|c|c|c|}
\hline \multirow[b]{2}{*}{ Variáveis } & \multicolumn{4}{|c|}{$\mathrm{X}$} & \multirow{2}{*}{$\begin{array}{l}\text { ANOVA } \\
\text { lor de p }\end{array}$} \\
\hline & $\begin{array}{c}1^{\circ} \\
\text { anel }\end{array}$ & $\begin{array}{l}2^{\circ} \\
\text { anel }\end{array}$ & $\begin{array}{c}5^{\circ} \\
\text { anel }\end{array}$ & $\begin{array}{c}10^{\circ} \\
\text { anel }\end{array}$ & \\
\hline Diâmetro de vasos grandes & $172 \mathrm{a}$ & $181 \mathrm{a}$ & $184 \mathrm{a}$ & $253 \mathrm{~b}$ & $\mathrm{p}=0,0000 *$ \\
\hline Diâmetro de vasos médios & $120 \mathrm{a}$ & $122 \mathrm{a}$ & $112 \mathrm{a}$ & - & $\mathrm{p}=0,5348 \mathrm{~ns}$ \\
\hline Diâmetro de vasos pequenos & $83 \mathrm{a}, \mathrm{c}$ & $66 \mathrm{~b}$ & $90 \mathrm{a}$ & $80 \mathrm{c}$ & $\mathrm{p}=0,0000 *$ \\
\hline & & & & & $0,7527 \mathrm{~ns}$ \\
\hline Comprimento de vasos grandes & 376 a & $314 \mathrm{~b}$ & $316 \mathrm{a}, \mathrm{b}$ & $154 \mathrm{C}$ & $p=0,0000 *$ \\
\hline Comprimento de vasos médios & 397 a & $311 \mathrm{~b}$ & $275 \mathrm{~b}$ & - & $P=0,0006 *$ \\
\hline Comprimento de vasos pequenos & $402 \mathrm{a}$ & $295 \mathrm{~b}$ & $266 \mathrm{~b}$ & $249 \mathrm{~b}$ & $\mathrm{P}=0,0000 *$ \\
\hline $\begin{array}{l}\text { Comprimento de vasos muito } \\
\text { pequenos }\end{array}$ & 392 a & $284 \mathrm{~b}$ & $281 \mathrm{~b}$ & $314 \mathrm{~b}$ & $\mathrm{p}=0,00001$ * \\
\hline
\end{tabular}

Tabela 7. Análise de variância (ANOVA) e teste Tuckey-Kramer para as variáveis dos anéis sucessivos de Abuta grandifolia. Médias com a mesma letra não diferem significativamente; médias 
com letras diferentes diferem significativamente a 5\%; medida = micrômetros $(\mu \mathrm{m}), \quad \mathrm{X}=$ média. Categoria de diâmetro do elemento do

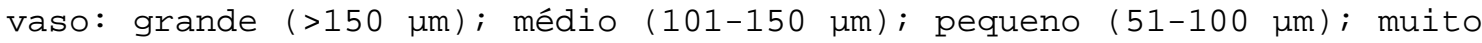
pequeno $(\leq 50 \mu \mathrm{m})$.

\begin{tabular}{|c|c|c|c|c|c|c|c|c|c|}
\hline \multirow[b]{2}{*}{ Variáveis } & \multicolumn{8}{|c|}{$\mathrm{X}$} & ANOVA \\
\hline & \multicolumn{2}{|c|}{$\begin{array}{c}1^{\circ} \\
\text { anel }\end{array}$} & \multicolumn{2}{|c|}{$\begin{array}{c}2^{\circ} \\
\text { anel }\end{array}$} & \multicolumn{2}{|c|}{$\begin{array}{c}5^{\circ} \\
\text { anel }\end{array}$} & \multicolumn{2}{|l|}{$\begin{array}{c}10^{\circ} \\
\text { anel }\end{array}$} & valor de $\mathrm{p}$ \\
\hline Diâmetro de vasos grandes & - & & - & & - & & - & & - \\
\hline Diâmetro de vasos médios & - & & 115 & a & 109 & a & 110 & a & $p=0,2533 n s$ \\
\hline Diâmetro de vasos pequenos & 64 & a & 67 & $\mathrm{a}$ & 68 & a & 63 & a & $\mathrm{p}=0,3779 \mathrm{~ns}$ \\
\hline Diâmetro de vasos muito pequenos & 40 & a & 41 & $\mathrm{a}$ & 45 & a & 43 & a & $\mathrm{p}=0,0705 \mathrm{~ns}$ \\
\hline Comprimento de vasos maiores & - & & - & & - & & - & & - \\
\hline Comprimento de vasos médios & - & & 380 & $\mathrm{a}$ & 414 & $\mathrm{a}$ & 318 & $\mathrm{~b}$ & $\mathrm{p}=0,00809 *$ \\
\hline Comprimento de vasos pequenos & 307 & $a$ & 283 & $\mathrm{a}$ & 393 & $\mathrm{~b}$ & 305 & $a$ & $\mathrm{p}=0,00021 *$ \\
\hline Comprimento de vasos muito pequenos & 272 & a & 392 & $\mathrm{~b}$ & 404 & $\mathrm{~b}$ & 269 & a & $\mathrm{p}=0,0000 \star$ \\
\hline Diâmetro das fibrotraqueídes & 21 & $\mathrm{a}$ & 22 & a & 22 & a & 22 & $\mathrm{a}$ & $\mathrm{P}=0,1078 \mathrm{~ns}$ \\
\hline Comprimento das fibrotraqueídes & 1119 & a & 1541 & $\mathrm{~b}$ & 1475 & $\mathrm{~b}$ & 1617 & $\mathrm{C}$ & $\mathrm{p}=0,0000 *$ \\
\hline
\end{tabular}


Gráfico 1. Comparação do diâmetro do elemento de vaso, incluindo todas as categorias de tamanho (grande, médio, pequeno e muito pequeno) em anéis sucessivos de Abuta convexa.

工 Mín-Máx

$25 \%-75 \%$

$\square$ Mediana

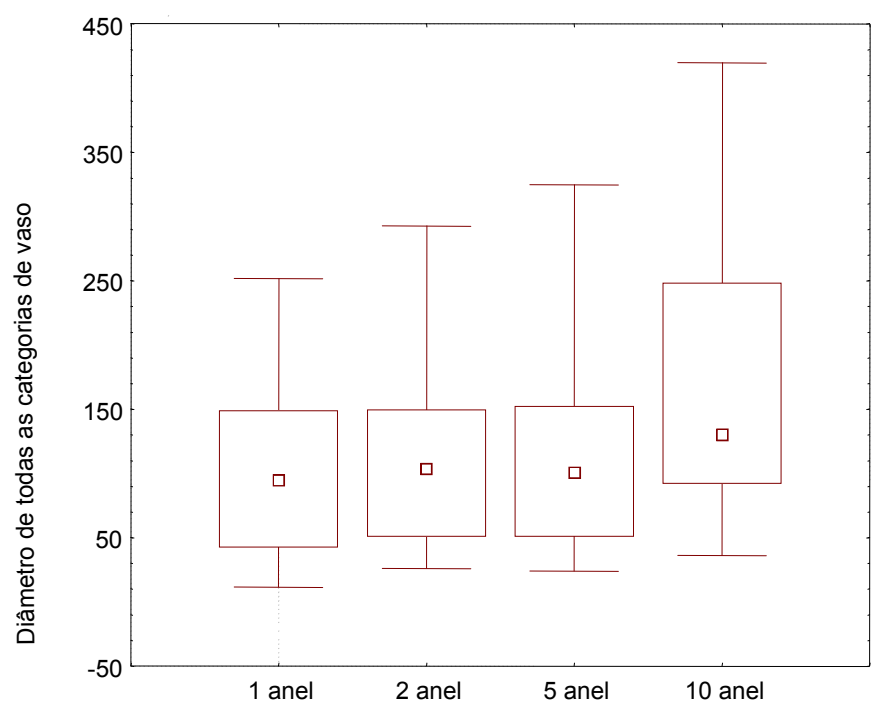

Gráfico 2. Comparação do comprimento de todos os elementos de vasos, incluindo todas as categorias de diâmetro de vaso (grande, médio, pequeno e muito pequeno) em anéis sucessivos de Abuta convexa.

I Mín-Máx $\square$ 25\%-75\% $\square$ Mediana

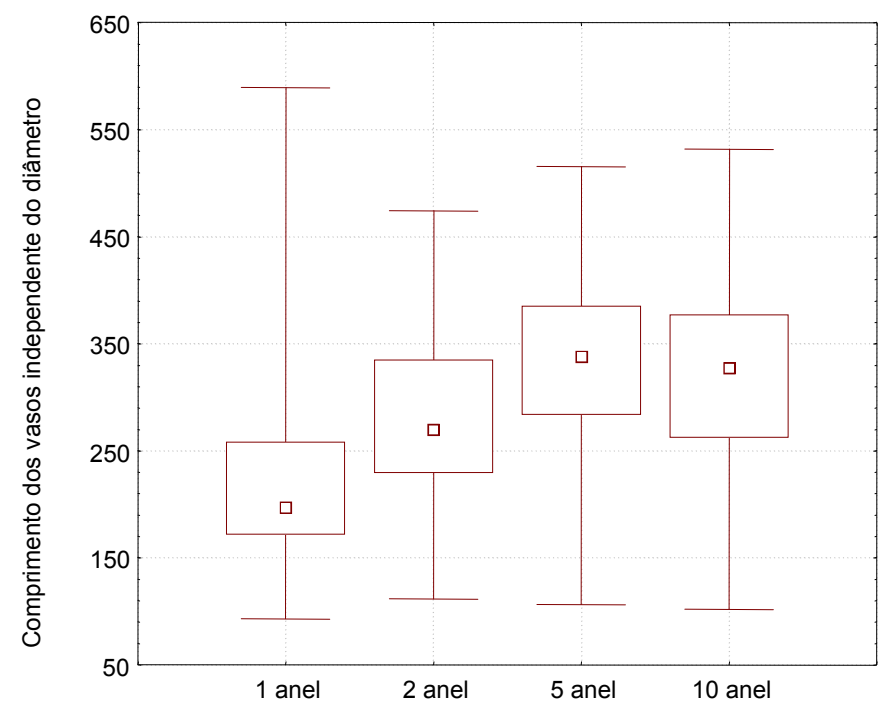


Gráfico 3. Comparação do diâmetro do elemento de vaso, incluindo todas as categorias de tamanho de vaso (grande, médio, pequeno e muito pequeno) em anéis sucessivos de Abuta selloana.

工 Mín-Máx $\square$ 25\%-75\% $\square$ Mediana

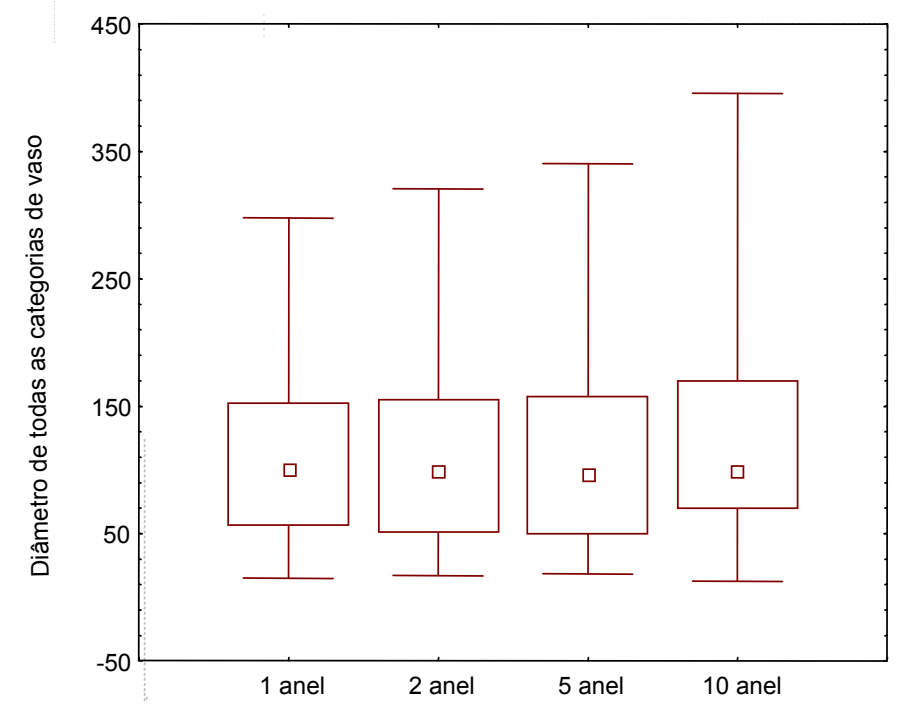

Gráfico 4. Comparação do comprimento de todos os vasos, incluindo todas as categorias de diâmetro de vaso (grande, médio, pequeno e muito pequenol em anéis sucessivos de Abuta selloana.

I Mín-Máx $\square$ 25\%-75\% $\square$ Mediana

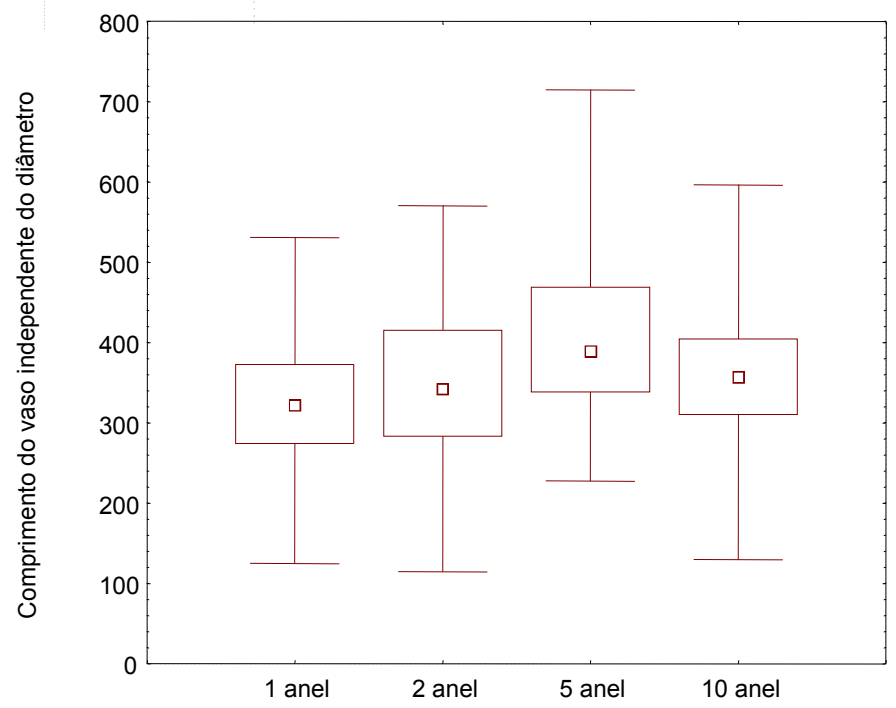


Gráfico 5. Comparação do diâmetro do elemento de vaso, incluindo todas as categorias de tamanho (grande, médio, pequeno e muito pequeno) em anéis sucessivos de Hyperbaena domingensis.
I Mín-Máx
$25 \div-75 \%$
ㅁ Mediana

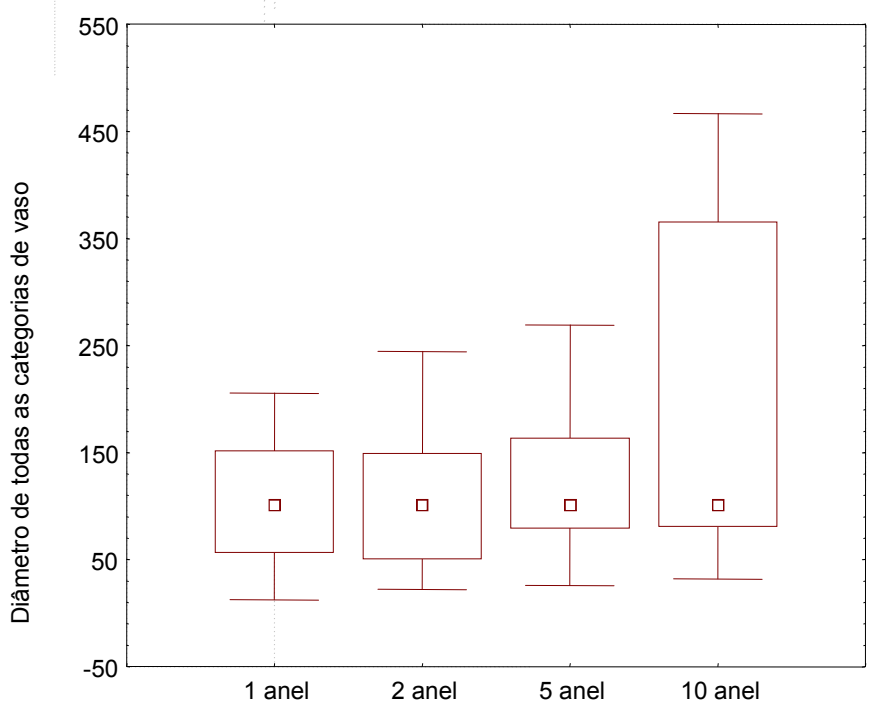

Gráfico 6. Comparação do comprimento de todos os vasos, incluindo todas as categorias de diâmetro de vasos (grand, médio, pequeno e muito pequeno) em anéis sucessivos de Hyperbaena domingensis.

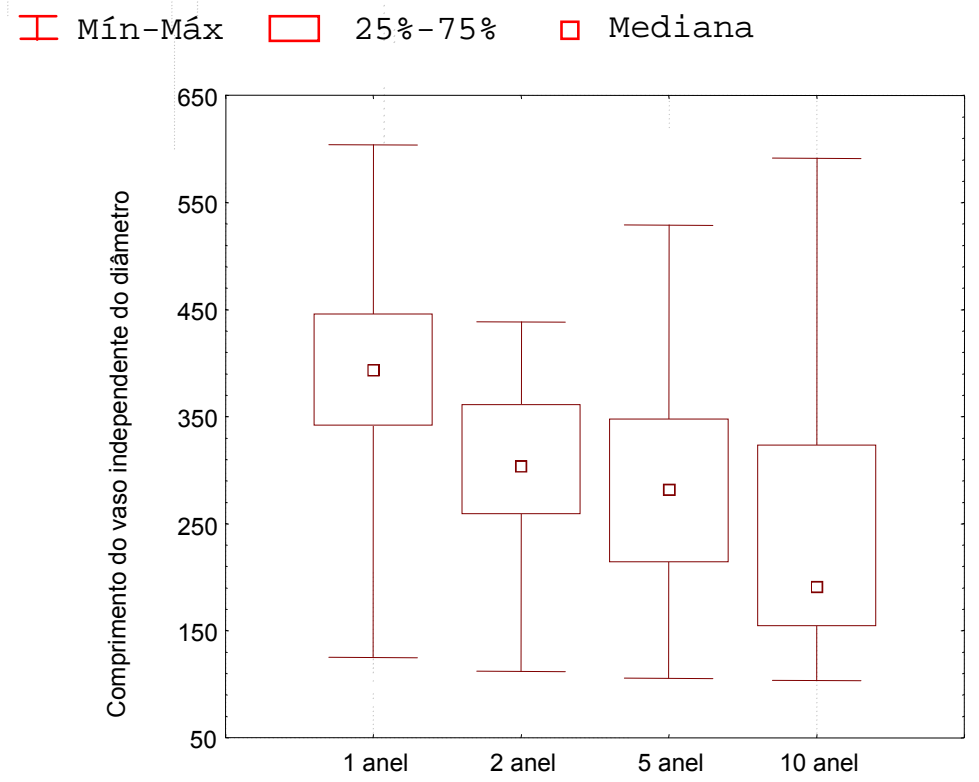




\subsection{2 - Hábito arbustivo e liana de Abuta grandifolia}

Os dados morfométricos das variáveis de três lianas e três espécies arbustivas de Abuta grandifolia encontram-se na Tabela 8. O Gráfico 9 e a Tabela 9 apresenta os resultados da análise de Variância (ANOVA) e o teste de Tuckey-Kramer .

Tabela 9. Análise estatística pelo teste de Mann-Whitney $(\mathrm{p}<0,05)$, para os hábitos arbustivos $e$ lianas de Abuta grandifolia, através do primeiro anel. DV=diâmetro de todas as categorias de vaso. CV=comprimento de todas as categorias de diâmetro de vaso. $\mathrm{DF}=$ Diâmetro de fibras. $\mathrm{CF}=$ Comprimento de fibras. Categoria de diâmetro do elemento de vaso: grande (>150 $\mu \mathrm{m})$; médio $(101-150 \mu \mathrm{m})$; pequeno $(50-100 \mu \mathrm{m})$; muito pequeno $(\leq 50$ $\mu \mathrm{m})$.

\begin{tabular}{|c|c|c|c|c|c|c|c|c|c|}
\hline \multicolumn{3}{|c|}{ Espécie } & DV & \multicolumn{2}{|l|}{$\mathrm{CV}$} & \multicolumn{2}{|c|}{$\mathrm{DF}$} & \multicolumn{2}{|l|}{$\mathrm{CF}$} \\
\hline Liana & $1-$ & - UW 22804 & $103 \mathrm{a}$ & 358 & $\mathrm{a}$ & 20 & $a$ & 1067 & $\mathrm{a}$ \\
\hline Liana & $2-$ & - Uw 23258 & $111 \mathrm{a}$ & 362 & $\mathrm{a}$ & 18 & a & 893 & $\mathrm{~b}$ \\
\hline Liana & $3-$ & - Uw 22771 & $108 \mathrm{a}$ & 363 & $\mathrm{a}$ & 18 & a & 876 & $\mathrm{~b}$ \\
\hline Arbust & 01 & 1 - Uw 3441 & $72 \mathrm{c}$ & 295 & $\mathrm{~b}$ & 21 & a & 1616 & c \\
\hline Arbust & 02 & 2 - RBw 8699 & $57 \mathrm{~b}$ & 269 & $\mathrm{~b}$ & 18 & a & 915 & $\mathrm{~b}$ \\
\hline Arbust & 03 & 3 - Uw 18757 & $47 \mathrm{~b}$ & 270 & $\mathrm{~b}$ & 18 & a & 1089 & $\mathrm{a}$ \\
\hline
\end{tabular}




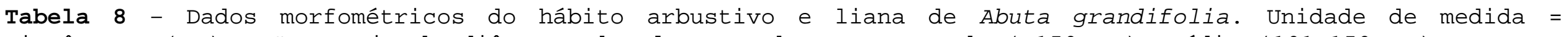

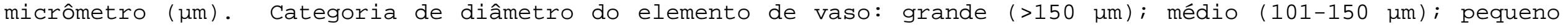
(51-100 $\mu \mathrm{m})$; muito pequeno $(\leq 50 \mu \mathrm{m})$. Dados fornecidos como mínimo-média-máximo.

\begin{tabular}{|c|c|c|c|c|c|c|c|c|c|c|c|}
\hline \multirow[b]{3}{*}{ espécie } & \multirow[b]{3}{*}{ hábito } & \multicolumn{8}{|c|}{ Elementos de vasos } & \multicolumn{2}{|r|}{ Fibras } \\
\hline & & \multicolumn{4}{|c|}{ Diâmetro } & \multicolumn{4}{|c|}{ Comprimento } & & \\
\hline & & grande & médio & pequeno & muito pequeno & grande & médio & pequeno & muito pequeno & diâmetro & comprimento \\
\hline Uw 22804 & Liana & $151-177-236$ & 103-130-150 & $52-74-94$ & $18-32-50$ & 134-309-459 & 164-286-369 & 189-320-382 & 186-319-427 & $14-20-27$ & $881-1067-1248$ \\
\hline $\mathrm{Rb} 23258$ & Liana & $153-217-288$ & $101-125-150$ & $52-68-100$ & $23-38-50$ & $221-351-457$ & 188-363-406 & 227-396-407 & $130-\mathbf{3 3 7}-441$ & $14-18-22$ & 707- 894-1041 \\
\hline Uw 22771 & Liana & 152-205-248 & 104-121-15 & $52-72-18$ & $17-38-70$ & 274-386-533 & 230-352-469 & 201-377-450 & 178-363-437 & $15-18-23$ & 736- 876-1145 \\
\hline Uw 3441 & Arbusto & - & - & 55-64- 84 & $24-40-50$ & - & - & 153-307-412 & $158-272-303$ & 14-21-34 & 823-1119-1511 \\
\hline Rbw 8699 & Arbusto & - & 102-109-118 & $51-62-85$ & $18-37-50$ & - & 226-277-331 & $190-276-342$ & $151-260-324$ & $12-18-24$ & 694- 915-1471 \\
\hline Uw 18757 & Arbusto & - & - & 51-62- 97 & $14-32-44$ & - & - & 91-290-424 & 164-252-407 & $14-18-23$ & $926-1090-1224$ \\
\hline
\end{tabular}


Gráfico 9. Comparação de dados morfométricos entre três lianas e três arbustos de Abuta grandifolia, utilizando o primeiro anel vascular. A - Diâmetro de vaso. B - Comprimento de vaso. C - Diâmetro de fibras. D - Copmprimento de fibra. Liana $1=$ Uw22804 - Liana2 = Rb23258 - Liana3 = Uw22771 - Arbusto1 = Uw3441 - Arbusto2 = Rbw8699 - Arbusto3 = Uw18757.

工 Mín-Máx $\square$ 25\%-75\% $\square$ Mediana
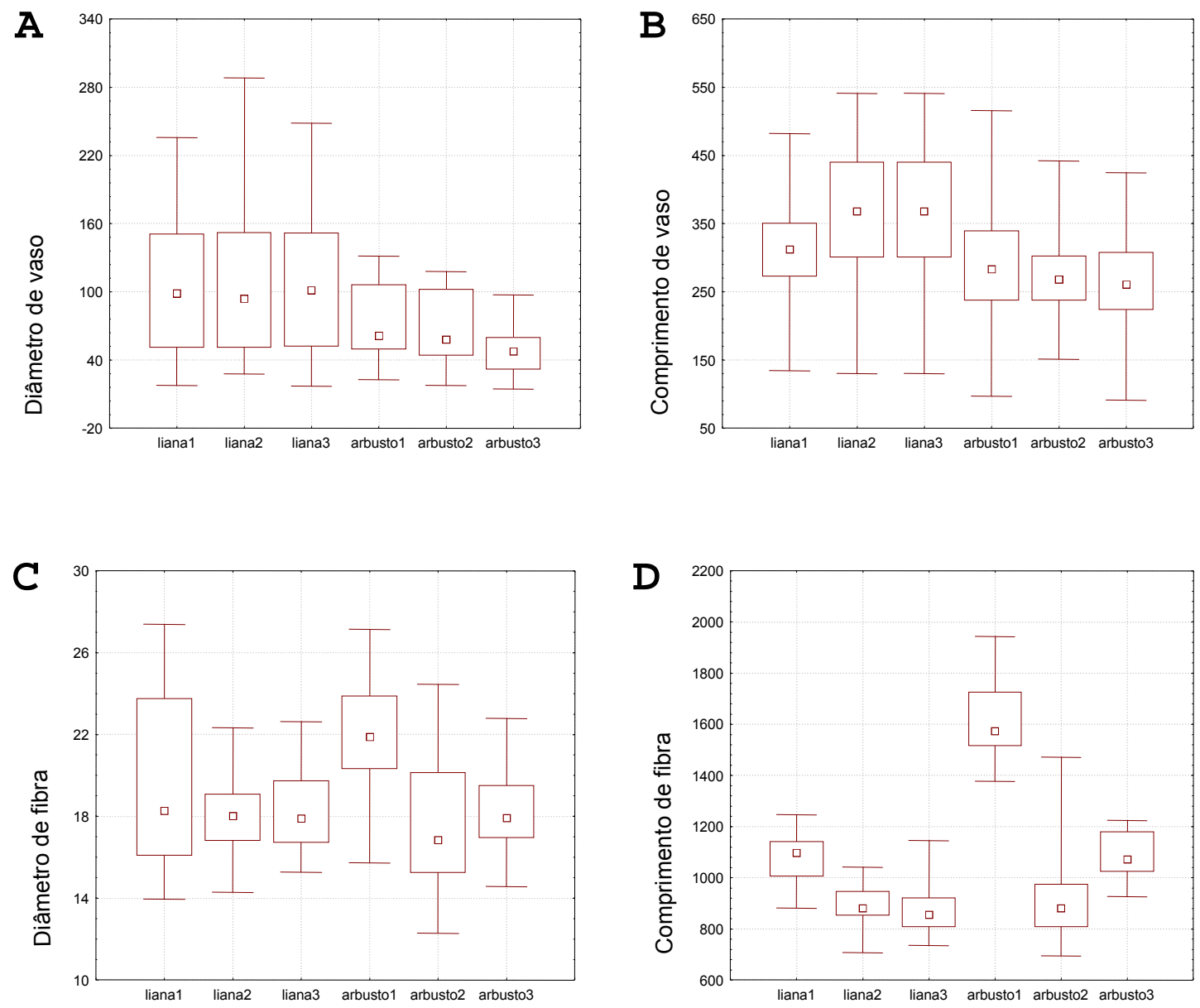


\subsection{3 - Trepadeiras herbáceas, lianas e a espécie herbácea}

Os dados morfométricos das variáveis das lianas, das trepadeiras herbáceas e da espécie herbácea encontram-se nas Tabelas 10 a 13. A Tabela 14 apresenta os resultados da análise de variância (ANOVA) e o teste de Tuckey-Kramer.

Tabela 14. Análise de variância (ANOVA) e teste Tuckey-Kramer para as variáveis do caule em lianas e trepadeiras herbáceas. Médias com a mesma letra não diferem significativamente; médias com letras diferentes diferem significativamente a 5\%; medida = micrômetros $(\mu \mathrm{m}), \quad \mathrm{X}=$ média. Categoria de diâmetro do elemento de vaso: grande $(>150 \mu \mathrm{m})$; médio $(101-150 \mu \mathrm{m})$; pequeno (51-100 $\mu \mathrm{m})$; muito pequeno $(\leq 50 \mu \mathrm{m})$.

\begin{tabular}{|c|c|c|c|c|}
\hline & & & $\mathrm{X}$ & \\
\hline & Parâmetros & liana & $\begin{array}{c}\text { Trepadeira } \\
\text { herbácea }\end{array}$ & $\begin{array}{c}\text { ANOVA } \\
\text { Valor de } \mathrm{p}\end{array}$ \\
\hline Diâmetro de & vasos grandes & 215 a & $184 \mathrm{~b}$ & $0,000063 *$ \\
\hline Diâmetro de & vasos médios & $120 \mathrm{a}$ & 115 a & $0,354635 \mathrm{~ns}$ \\
\hline Diâmetro de & vasos pequenos & $75 \mathrm{a}$ & $78 \mathrm{a}$ & $0,083239 \mathrm{~ns}$ \\
\hline Diâmetro de & vasos muito pequenos & $37 \mathrm{a}$ & $35 \mathrm{~b}$ & $0,040721 *$ \\
\hline Comprimento & de vasos grandes & 373 a & $272 \mathrm{~b}$ & $0,000000 *$ \\
\hline Comprimento & de vasos médios & 340 a & $279 \mathrm{~b}$ & $0,00000 *$ \\
\hline Comprimento & de vasos pequenos & 327 a & $276 \mathrm{~b}$ & $0,000000 *$ \\
\hline Comprimento & de vasos muito pequenos & 334 a & $285 \mathrm{~b}$ & $0,000000 *$ \\
\hline Comprimento & de fibras & 1291 a & $1076 \mathrm{~b}$ & $0,000000 *$ \\
\hline Diâmetro de & fibras & 21 a & $18 \mathrm{~b}$ & $0,000000 *$ \\
\hline Comprimento & de fibrotraqueídes & 1178 a & $865 \mathrm{~b}$ & $0,0000 *$ \\
\hline Diâmetro de & fibrotraqueídes & $22 \mathrm{a}$ & $22 \mathrm{a}$ & $0,681561 \mathrm{~ns}$ \\
\hline
\end{tabular}




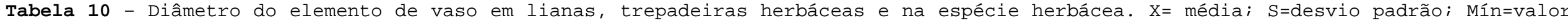

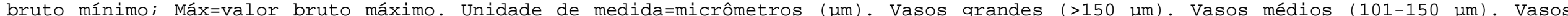

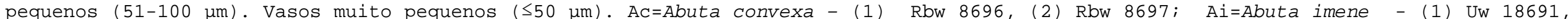

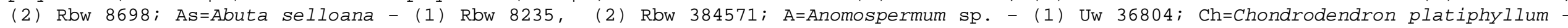

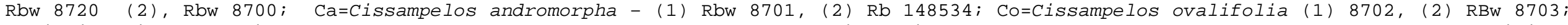

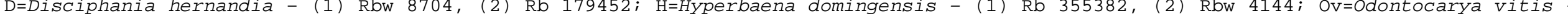

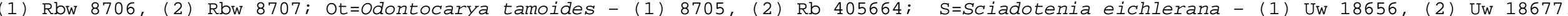
Tg=Telitoxicum multiflorum - (1) Uw18677, (2) Rb 194886; Uf=Ungulipetalum filipendulum - (1) Rbw 8708, (2) Rbw 8709.

\begin{tabular}{|c|c|c|c|c|c|c|c|c|c|c|c|c|c|c|c|c|c|c|c|c|c|c|c|c|c|c|c|}
\hline & \multicolumn{15}{|c|}{ Lianas } & \multicolumn{2}{|c|}{ Ervas } & \multicolumn{10}{|c|}{ Trepadeiras herbáceas } \\
\hline & Ac1 & Ac2 & Ai1 & Ai2 & As1 & As2 & A1 & Ch1 & Ch2 & H1 & H2 & S1 & S2 & $\operatorname{Tg} 1$ & $\operatorname{Tg} 2$ & $\mathrm{Co1}$ & $\mathrm{Co} 2$ & Ca1 & $\mathrm{Ca} 2$ & D1 & D2 & Ov1 & Ov2 & Ot1 & ot2 & Uf1 & $\mathrm{Uf2}$ \\
\hline Parâmetros & \multicolumn{27}{|c|}{ Diâmetro dos elementos de vasos grandes } \\
\hline $\mathrm{X}(\mu \mathrm{m})$ & 203 & 190 & 171 & 223 & 204 & - & 289 & 169 & - & 160 & 172 & 237 & - & - & 202 & - & - & 187 & 182 & 180 & 183 & - & 213 & 189 & - & - & - \\
\hline$S \quad(\mu \mathrm{m})$ & 28 & 24 & 17 & 37 & 38 & - & 86 & 12 & - & 8 & 17 & 54 & - & - & 10 & - & - & 29 & 22 & 16 & 17 & - & 35 & 32 & - & - & - \\
\hline C.V. (\%) & 14 & 13 & 10 & 17 & 19 & - & 30 & 7 & - & 5 & 10 & 17 & - & - & 16 & - & - & 15 & 12 & 9 & 9 & - & 17 & 17 & - & - & - \\
\hline Mín. $(\mu \mathrm{m})$ & 161 & 154 & 152 & 180 & 151 & - & 155 & 156 & - & 151 & 151 & 152 & - & - & 167 & - & - & 154 & 153 & 153 & 157 & - & 207 & 154 & - & - & - \\
\hline Máx. $(\mu \mathrm{m})$ & 266 & 221 & 209 & 339 & 298 & - & 422 & 200 & - & 184 & 205 & 313 & - & - & 257 & - & - & 250 & 248 & 202 & 232 & - & 257 & 279 & - & - & - \\
\hline Parâmetros & \multicolumn{27}{|c|}{ Diâmetro dos elementos de vasos médios } \\
\hline $\mathrm{X}(\mu \mathrm{m})$ & 120 & 131 & 124 & 121 & 128 & 126 & 124 & 128 & 120 & 129 & 120 & 123 & 108 & 116 & 117 & 108 & 110 & 131 & 130 & 122 & 108 & 117 & 135 & 125 & 117 & 113 & 117 \\
\hline$S(\mu \mathrm{m})$ & 12 & 18 & 13 & 16 & 24 & 10 & 14 & 16 & 14 & 13 & 14 & 14 & 9 & 8 & 8 & 6 & 7 & 11 & 14 & 11 & 10 & 11 & 13 & 12 & 12 & 11 & 8 \\
\hline C.V. (\%) & 10 & 14 & 11 & 13 & 19 & 8 & 12 & 12 & 12 & 10 & 12 & 11 & 5 & 7 & 7 & 5 & 6 & 8 & 11 & 9 & 9 & 9 & 10 & 9 & 10 & 9 & 7 \\
\hline Mín. $(\mu \mathrm{m})$ & 102 & 101 & 102 & 102 & 102 & 103 & 102 & 102 & 103 & 109 & 102 & 103 & 100 & 102 & 104 & 101 & 102 & 110 & 103 & 105 & 101 & 102 & 124 & 104 & 104 & 101 & 101 \\
\hline Máx. $(\mu \mathrm{m})$ & 150 & 173 & 143 & 148 & 213 & 140 & 148 & 161 & 149 & 149 & 149 & 150 & 116 & 133 & 133 & 120 & 123 & 148 & 150 & 146 & 125 & 146 & 151 & 149 & 141 & 136 & 130 \\
\hline Parâmetros & \multicolumn{27}{|c|}{ Diâmetro dos elementos de vasos pequenos } \\
\hline $\mathrm{X}(\mu \mathrm{m})$ & 76 & 85 & 84 & 71 & 80 & 82 & 75 & 79 & 67 & 70 & 83 & 78 & 60 & 78 & 64 & 67 & 72 & 83 & 77 & 76 & 84 & 71 & 92 & 74 & 81 & 78 & 73 \\
\hline$S(\mu \mathrm{m})$ & 10 & 6 & 13 & 14 & 8 & 13 & 14 & 16 & 13 & 16 & 15 & 15 & 5 & 13 & 13 & 14 & 12 & 13 & 14 & 13 & 9 & 16 & 7 & 15 & 18 & 15 & 12 \\
\hline C.V. (\%) & 13 & 7 & 16 & 20 & 10 & 16 & 19 & 20 & 20 & 22 & 18 & 20 & 9 & 17 & 20 & 21 & 17 & 16 & 19 & 17 & 11 & 21 & 0 & 20 & 22 & 19 & 17 \\
\hline Mín. $(\mu \mathrm{m})$ & 51 & 77 & 59 & 51 & 64 & 52 & 51 & 67 & 54 & 52 & 51 & 51 & 52 & 58 & 52 & 53 & 54 & 55 & 54 & 53 & 70 & 56 & 76 & 52 & 87 & 52 & 53 \\
\hline Máx. $(\mu \mathrm{m})$ & 88 & 90 & 101 & 98 & 100 & 97 & 100 & 101 & 93 & 99 & 100 & 100 & 72 & 99 & 100 & 99 & 97 & 100 & 100 & 99 & 95 & 97 & 101 & 100 & 100 & 99 & 96 \\
\hline Parâmetros & \multicolumn{27}{|c|}{ Diâmetro dos elementos de vasos muito pequenos } \\
\hline $\mathrm{X}(\mu \mathrm{m})$ & 25 & 38 & 35 & 42 & 34 & 33 & 32 & 40 & 35 & 36 & 37 & 36 & 42 & 39 & 43 & 37 & 34 & 36 & 35 & 33 & - & 38 & 38 & 37 & 39 & 35 & 31 \\
\hline $\mathrm{S}(\mu \mathrm{m})$ & 11 & 10 & 8 & 6 & 11 & 10 & 7 & $a$ & 10 & 10 & 11 & 9 & 5 & 6 & 5 & 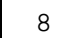 & 8 & 8 & 9 & 9 & - & 9 & 5 & 7 & 8 & 10 & 11 \\
\hline C.V. (\%) & 45 & 26 & 24 & 15 & 34 & 29 & 23 & 22 & 28 & 27 & 30 & 26 & 13 & 15 & 11 & 22 & 25 & 22 & 26 & 28 & - & 24 & 15 & 20 & 20 & 28 & 37 \\
\hline Mín. $(\mu \mathrm{m})$ & 12 & 25 & 18 & 26 & 15 & 16 & 20 & 27 & 19 & 19 & 12 & 12 & 29 & 30 & 34 & 21 & 15 & 15 & 21 & 16 & - & 26 & 25 & 27 & 31 & 14 & 16 \\
\hline Máx. $(\mu \mathrm{m})$ & 50 & 50 & 47 & 51 & 50 & 51 & 49 & 51 & 51 & 51 & 50 & 50 & 50 & 50 & 49 & 49 & 51 & 47 & 50 & 49 & - & 51 & 51 & 49 & 50 & 48 & 50 \\
\hline
\end{tabular}




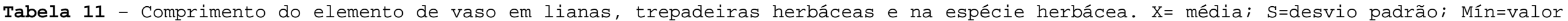

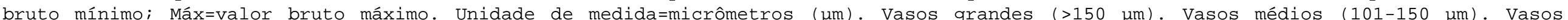

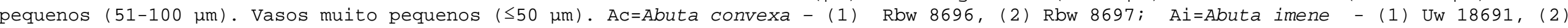

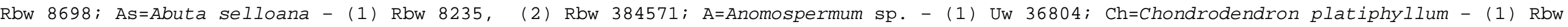

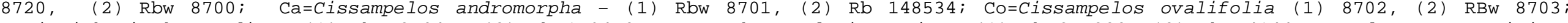

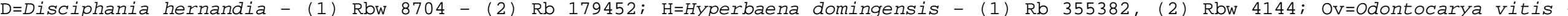

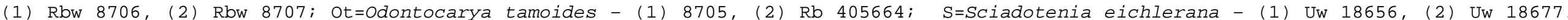
Tg=Telitoxicum multiflorum - (1) Uw18677, (2) Rb 194886; Uf=Ungulipetalum filipendulum - (1) Rbw 8708, (2) Rbw 8709.

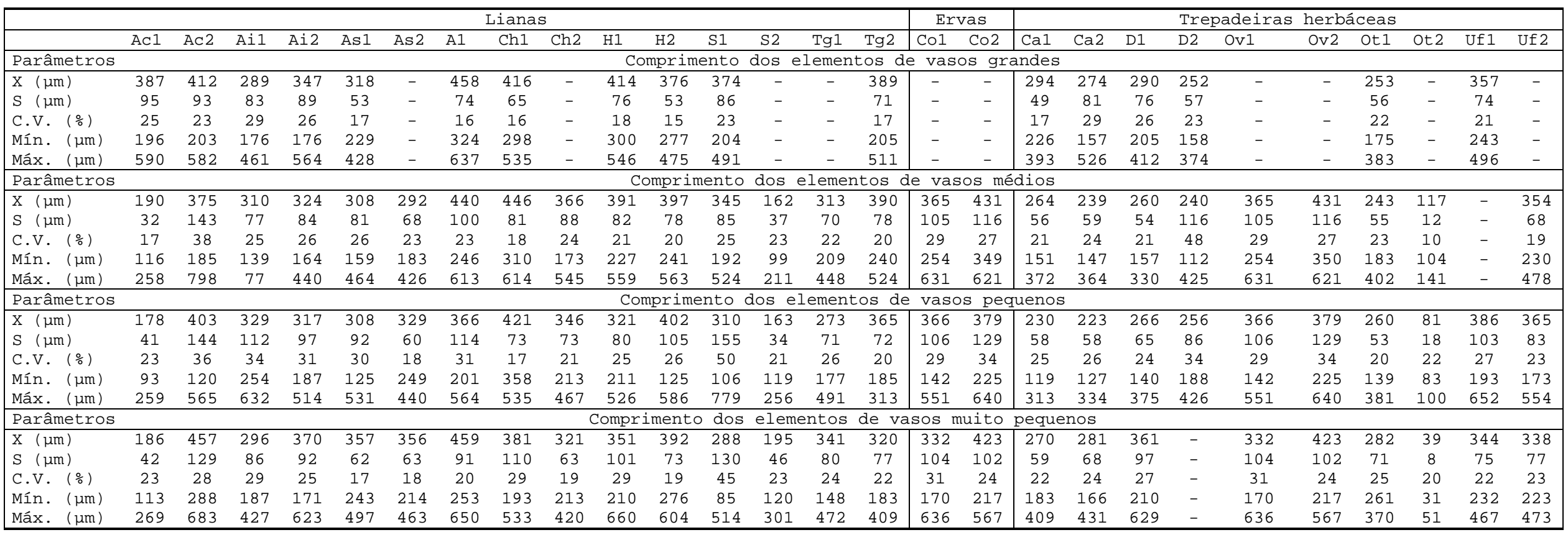


Tabela 12 - Comprimento e diâmetro das fibras e das traqueídes (apenas em S1) em caules de lianas. X= média; S=desvio padrão; Mín=valor bruto mínimo; Máx=valor bruto máximo. Unidade de medida=micrômetros ( $\mu \mathrm{m})$. F=fibra - FT= fibrotraqueíde - $\mathrm{TR}=$ traqueíde. Ac=Abuta convexa - (1)Rbw 8696, (2)Rbw 8697. Ai=Abuta imene - (1) Uw 18691, (2) Rbw 8698; As=Abuta selloana - (1) Rbw 8235, (2) Rbw 384571; $\mathrm{A}=$ Anomospermum sp. - Uw 36804; Ch=Chondrodendron platiphyllum - (1) Rbw 8720, (2)Rbw 8700; H=Hyperbaena domingensis - (1)Rb 355382, (2)Rbw 4144; S=Sciadotenia eichleriana - (1)Uw 18656, (2)Uw 18677; Tg=Telitoxicum multiflorum - (1)Uw18677, (2)Rb 194886. H1=possui apenas fibras - S2=possui apenas fibrotraqueídes.

\begin{tabular}{|c|c|c|c|c|c|c|c|c|c|c|c|c|c|c|c|c|c|c|c|c|c|}
\hline \multirow[b]{3}{*}{ Espécies } & \multicolumn{21}{|c|}{ Lianas } \\
\hline & \multirow{2}{*}{$\begin{array}{c}\text { Ac1 } \\
F\end{array}$} & \multirow{2}{*}{$\begin{array}{c}\text { Ac2 } \\
F\end{array}$} & \multicolumn{2}{|c|}{$\overline{A i 1}$} & \multicolumn{2}{|c|}{ Ai2 } & \multirow{2}{*}{$\begin{array}{c}\text { As1 } \\
F\end{array}$} & \multirow{2}{*}{$\begin{array}{c}\text { As2 } \\
\text { F }\end{array}$} & \multicolumn{2}{|c|}{$\bar{A}$} & \multirow{2}{*}{$\begin{array}{c}\text { Ch1 } \\
\text { FT }\end{array}$} & \multirow{2}{*}{$\begin{array}{c}\text { Ch2 } \\
\text { FT }\end{array}$} & \multirow{2}{*}{$\frac{\mathrm{H} 1}{\mathrm{~F}}$} & \multicolumn{2}{|c|}{ H2 } & \multicolumn{3}{|c|}{ S1 } & \multirow{2}{*}{$\frac{\mathrm{S} 2}{\mathrm{FT}}$} & \multirow{2}{*}{$\begin{array}{l}\mathrm{Tgl} \\
\mathrm{FT}\end{array}$} & \multirow{2}{*}{$\begin{array}{l}\text { Tg2 } \\
\text { FT }\end{array}$} \\
\hline & & & $\mathrm{F}$ & $\mathrm{FT}$ & $\mathrm{F}$ & FT & & & $\mathrm{F}$ & $\mathrm{FT}$ & & & & $\mathrm{F}$ & FT & $\mathrm{F}$ & FT & TR & & & \\
\hline Parâmetros & \multicolumn{21}{|c|}{ Comprimento } \\
\hline $\mathrm{X}(\mu \mathrm{m})$ & 1336 & 2017 & 924 & 870 & 1652 & 997 & 1279 & 906 & 1362 & 1313 & 951 & 994 & 1296 & 944 & 947 & 1249 & 1107 & 772 & 698 & 1110 & 981 \\
\hline$S \quad(\mu \mathrm{m})$ & 214 & 549 & 116 & 102 & 193 & 109 & 138 & 104 & 131 & 159 & 115 & 113 & 217 & 112 & 125 & 176 & 136 & 165 & 68 & 108 & 86 \\
\hline C.V. ( $\left(\frac{\circ}{0}\right)$ & 16 & 27 & 12 & 12 & 12 & 11 & 28 & 11 & 10 & 12 & 12 & 11 & 17 & 12 & 13 & 14 & 12 & 21 & 10 & 10 & 9 \\
\hline Mín. $(\mu \mathrm{m})$ & 975 & 1377 & 688 & 671 & 1159 & 796 & 1116 & 764 & 1193 & 930 & 729 & 789 & 895 & 737 & 754 & 889 & 794 & 539 & 567 & 941 & 762 \\
\hline Máx. $(\mu \mathrm{m})$ & 1880 & 3185 & 1129 & 1109 & 1909 & 1266 & 1679 & 1099 & 1791 & 1664 & 1207 & 1326 & 1612 & 1147 & 1286 & 1644 & 1366 & 1140 & 935 & 1327 & 1133 \\
\hline Parâmetros & \multicolumn{21}{|c|}{ Diâmetro } \\
\hline $\mathrm{X} \quad(\mu \mathrm{m})$ & 18 & 25 & 20 & 23 & 20 & 23 & 22 & 18 & 21 & 25 & 20 & 18 & 18 & 21 & 26 & 19 & 26 & 23 & 23 & 22 & 18 \\
\hline$S \quad(\mu \mathrm{m})$ & 3 & 4 & 3 & 3 & 3 & 3 & 2 & 3 & 3 & 4 & 3 & 3 & 3 & 3 & 3 & 5 & 4 & 4 & 3 & 4 & 3 \\
\hline C.V. ( $\left(\frac{\circ}{0}\right)$ & 19 & 16 & 15 & 14 & 15 & 14 & 11 & 18 & 16 & 17 & 17 & 17 & 15 & 15 & 13 & 26 & 16 & 17 & 11 & 16 & 15 \\
\hline Mín. $(\mu \mathrm{m})$ & 12 & 17 & 13 & 18 & 13 & 18 & 17 & 13 & 12 & 18 & 14 & 13 & 13 & 17 & 18 & 8 & 18 & 16 & 19 & 16 & 14 \\
\hline Máx. $(\mu \mathrm{m})$ & 28 & 34 & 26 & 33 & 26 & 33 & 27 & 28 & 29 & 35 & 27 & 25 & 23 & 29 & 34 & 30 & 36 & 33 & 30 & 29 & 24 \\
\hline
\end{tabular}


Tabela 13 - Comprimento e diâmetro das fibras e fibrotraqueídes em trepadeiras herbáceas e na espécie herbácea. $\mathrm{X}=$ média; $\mathrm{S}=$ desvio padrão; Mín=valor bruto mínimo; Máx=valor bruto máximo. Unidade de medida=micrômetros ( $\mathrm{m})$. F=fibra - FT= fibrotraqueíde. Ca=Cissampelos andromorpha - (1)Rbw 8701, (2)Rb 148534; Co=Cissampelos ovalifolia (1) 8702, (2)RBw 8703; D=Disciphania hernandia - (1)Rbw 8704 - (2)Rb 179452; Ov=Odontocarya vitis - (1)Rbw 8706, (2)Rbw 8707; Ot=Odontocarya tamoides - (1)8705; (2)Rb 405664; Uf=Ungulipetalum filipendulum - (1) Rbw 8708; (2) Rbw 8709.

\begin{tabular}{|c|c|c|c|c|c|c|c|c|c|c|c|c|c|c|c|c|}
\hline \multirow[b]{3}{*}{ Espécies } & \multicolumn{2}{|c|}{ Ervas } & \multicolumn{14}{|c|}{ Trepadeiras herbáceas } \\
\hline & \multirow{2}{*}{$\begin{array}{c}\mathrm{Co1} \\
\mathrm{F}\end{array}$} & \multirow{2}{*}{$\begin{array}{c}\mathrm{C} \circ 2 \\
\mathrm{~F}\end{array}$} & \multirow{2}{*}{$\begin{array}{c}\mathrm{Ca} 1 \\
\mathrm{FT}\end{array}$} & \multirow{2}{*}{$\begin{array}{c}\mathrm{Ca} 2 \\
\mathrm{FT}\end{array}$} & \multicolumn{2}{|c|}{ D1 } & \multicolumn{2}{|c|}{ D2 } & \multirow{2}{*}{$\begin{array}{c}\text { Ov1 } \\
\text { FT }\end{array}$} & \multirow{2}{*}{$\begin{array}{c}\text { Ov2 } \\
\text { FT }\end{array}$} & \multirow{2}{*}{$\begin{array}{c}\text { Ot 1 } \\
\text { F }\end{array}$} & \multirow{2}{*}{$\begin{array}{c}\text { Ot2 } \\
F\end{array}$} & \multicolumn{2}{|c|}{ Uf1 } & \multicolumn{2}{|c|}{ Uf1 } \\
\hline & & & & & $\mathrm{F}$ & FT & $\mathrm{F}$ & $\mathrm{FT}$ & & & & & $\mathrm{F}$ & $\mathrm{FT}$ & $\mathrm{F}$ & FT \\
\hline Parâmetros & \multicolumn{16}{|c|}{ Comprimento } \\
\hline $\mathrm{X}(\mu \mathrm{m})$ & 1063 & 1651 & 593 & 1082 & 870 & 856 & 1362 & 837 & 814 & 1291 & 1286 & 927 & 995 & 904 & 961 & 1000 \\
\hline$S \quad(\mu \mathrm{m})$ & 313 & 176 & 167 & 202 & 156 & 210 & 217 & 88 & 106 & 233 & 295 & 187 & 156 & 120 & 119 & 177 \\
\hline $\mathrm{C} . \mathrm{V} . \quad\left(\frac{\circ}{0}\right)$ & 29 & 11 & 28 & 19 & 18 & 24 & 16 & 10 & 13 & 18 & 23 & 20 & 16 & 24 & 12 & 35 \\
\hline Mín. $(\mu \mathrm{m})$ & 681 & 1242 & 356 & 752 & 695 & 101 & 984 & 668 & 665 & 833 & 735 & 587 & 652 & 688 & 771 & 664 \\
\hline Máx. $(\mu \mathrm{m})$ & 1690 & 1882 & 1062 & 1517 & 1504 & 1223 & 1806 & 992 & 1169 & 1800 & 1897 & 1244 & 1334 & 1148 & 1182 & 1318 \\
\hline Parâmetros & \multicolumn{16}{|c|}{ Diâmetro } \\
\hline $\mathrm{X}(\mu \mathrm{m})$ & 26 & 32 & 20 & 21 & 21 & 20 & 24 & 33 & 20 & 23 & 13 & 18 & 17 & 29 & 18 & 23 \\
\hline$S \quad(\mu \mathrm{m})$ & 6 & 4 & 3 & 5 & 4 & 4 & 6 & 6 & 3 & 4 & 3 & 2 & 2 & 4 & 3 & 4 \\
\hline C.V. ( $\left(\frac{\circ}{0}\right)$ & 23 & 13 & 16 & 23 & 18 & 20 & 23 & 19 & 15 & 19 & 22 & 14 & 14 & 15 & 15 & 16 \\
\hline Mín. (um) & 16 & 24 & 13 & 13 & 15 & 14 & 12 & 24 & 16 & 14 & 7 & 13 & 14 & 20 & 13 & 16 \\
\hline Máx. $(\mu \mathrm{m})$ & 40 & 41 & 26 & 29 & 30 & 29 & 32 & 49 & 30 & 30 & 21 & 23 & 24 & 38 & 22 & 32 \\
\hline
\end{tabular}




\subsection{4 - Fibras e fibrotraqueídes em um mesmo indivíduo}

Os dados morfométricos das variáveis das lianas, das trepadeiras herbáceas e da espécie herbácea encontram-se nas Tabelas 10 a 13. O Gráfico 10 e as Tabela 15 e 16 apresentam os resultados da análise de variância (ANOVA) e o teste de Tuckey-Kramer.

Tabela 15. Análise de Variância (ANOVA) e teste Tuckey-Kramer para as variáveis fibra e fibrotraqueíde em caules da mesma espécie. Médias com a mesma letra não diferem significativamente; médias com letras diferentes diferem significativamente a 5\%; medida $=$ micrômetros $(\mu \mathrm{m}), \quad \mathrm{X}=$ média.

\begin{tabular}{lccc}
\hline Espécie & Fibra & Fibrotraqueide & $\begin{array}{c}\text { ANOVA } \\
\text { Valor de p }\end{array}$ \\
\hline Abuta imene Uw 18691 & $1652 \mathrm{a}$ & $996 \mathrm{~b}$ & $0,00000^{*}$ \\
A. imene Uw 8698 & $965 \mathrm{a}$ & $870 \mathrm{~b}$ & $0,001618 *$ \\
Anomospermum sp. Uw 36804 & $1362 \mathrm{a}$ & $1313 \mathrm{a}$ & $0,443437 \mathrm{~ns}$ \\
Hyperbaena domingensis Rbw4144 & $1313 \mathrm{a}$ & $1361 \mathrm{a}$ & $0,443437 \mathrm{~ns}$ \\
Sciadotenia eichlerana Uw 18656 & $1333 \mathrm{a}$ & $1106 \mathrm{~b}$ & $0,000001^{*}$ \\
Disciphania hernandia Rbw 8704 & $870 \mathrm{a}$ & $856 \mathrm{a}$ & $0,312995 \mathrm{~ns}$ \\
D. hernandia Rb 179452 & $1361 \mathrm{a}$ & $837 \mathrm{~b}$ & $0,00000 *$ \\
Ungulipetalum filipendulum Rbw 8708 & $995 \mathrm{a}$ & $904 \mathrm{a}$ & $0,19391 \mathrm{~ns}$ \\
\hline
\end{tabular}

Tabela 16. Análise de Variância (ANOVA) e teste Tuckey-Kramer para as variáveis fibra, fibrotraqueíde e traqueídes no caule de Sciadotenia eichleriana. Médias com a mesma letra não diferem significativamente; médias com letras diferentes diferem significativamente a 5\%; medida $=$ micrômetros $(\mu \mathrm{m}), \quad \mathrm{X}=$ média.

\begin{tabular}{ccccc}
\hline Espécie & Fibra & Fibrotraqueíde & Traqueíde & $\begin{array}{c}\text { ANOVA } \\
\text { Valor de p }\end{array}$ \\
\hline $\begin{array}{l}\text { Sciadotenia } \\
\text { eichlerana }\end{array}$ & 1333 a & $1107 \mathrm{~b}$ & $772 \mathrm{C}$ & $0,000000^{*}$ \\
\hline
\end{tabular}


Gráfico 10. Comparação do comprimento das fibras, fibrotraqueídes e traqueídes em Sciadotenia eichleriana.

I Mín-Máx $\square$ 25\%-75\% $\square$ Mediana

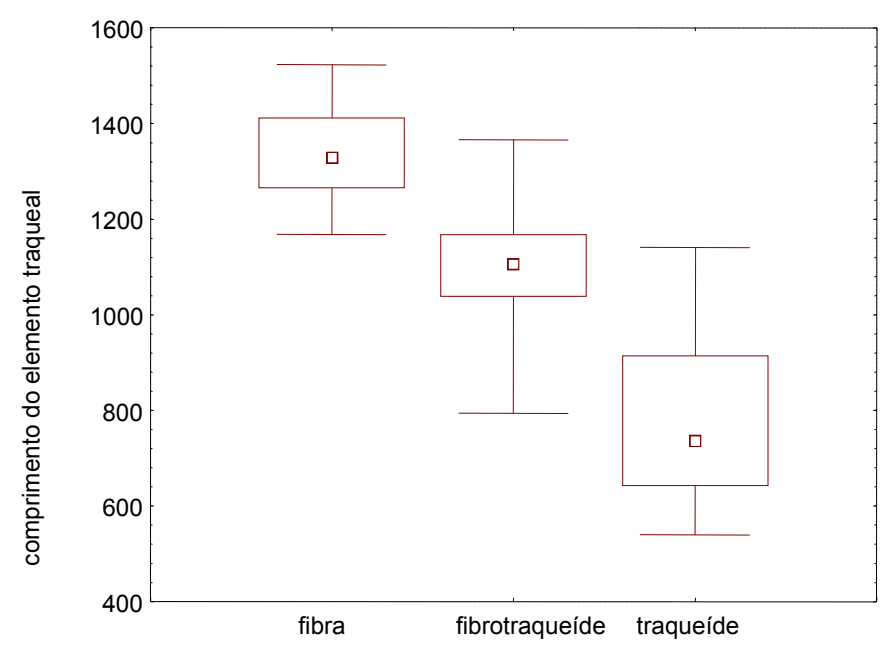




\subsection{5 - Comprimento de elementos de vasos de diâmetro grande e pequeno em todos os hábitos}

Os dados morfométricos das variáveis das lianas e das trepadeiras herbáceas encontram-se nas tabelas 10 a 13. A tabela 17 apresentam os resultados da análise de variância (ANOVA) e o teste de Tuckey-Kramer.

Tabela 17. Análise de variância (ANOVA) e teste Tuckey-Kramer para o comprimento do elemento de vaso de diâmetros grandes e pequenos em todos os hábitos. Médias com a mesma letra não diferem significativamente; médias com letras diferentes diferem significativamente a 5\%; medida = micrômetros ( $\mu \mathrm{m}), \quad \mathrm{X}=$ média. Significado da letra ao lado da espécie: L (liana); A (arbusto); $\mathrm{E}$ (erva), TH (trepadeira herbácea).

\begin{tabular}{|c|c|c|c|}
\hline \multirow[b]{2}{*}{ Espécie } & \multicolumn{2}{|c|}{$\mathrm{X}$} & \multirow{2}{*}{$\begin{array}{c}\text { ANOVA } \\
\text { Valor de p }\end{array}$} \\
\hline & grandes & pequenos & \\
\hline Abuta convexa - Rbw $8696 \mathrm{~L}$ & 331 a & 359 a & $0,129464 \mathrm{~ns}$ \\
\hline A. convexa - Rbw 8697 L & 412 a & 432 a & $0,790700 \mathrm{~ns}$ \\
\hline Abuta grandifolia - Uw 22804 L & 309 a & 319 a & $0,662430 \mathrm{~ns}$ \\
\hline A. grandifolia - Rb 23258 L & 351 a & 337 a & $0,863181 \mathrm{~ns}$ \\
\hline A. grandifolia - Uw 22771 A & 386 a & 363 a & $0,366940 \mathrm{~ns}$ \\
\hline A. grandifolia - Uw 3441 A & 307 a & $272 a$ & $0,39139 \mathrm{~ns}$ \\
\hline A. grandifolia - Rbw 8699 A & 277 a & 260 a & $0,409593 \mathrm{~ns}$ \\
\hline A. grandifolia - Uw 18757 A & 290 a & 252 a & $0,029056 \mathrm{~ns}$ \\
\hline Abuta imene - Uw $86961 \mathrm{~L}$ & 289 a & 296 a & $0,620764 \mathrm{~ns}$ \\
\hline A. imene - Rbw 8698 L & 347 a & 369 a & $0,387909 \mathrm{~ns}$ \\
\hline Abuta selloana - Rbw $8235 \mathrm{~L}$ & 318 a & $357 \mathrm{~b}$ & $0,020421 *$ \\
\hline A. selloana - Rbw 384571 L & 292 a & $356 \mathrm{~b}$ & $0,002395 *$ \\
\hline Anomospermum sp. - Uw 36804 L & 458 a & 459 a & $0,607133 \mathrm{~ns}$ \\
\hline Chondrodendron platiphyllum - Rbw 8700 L & 416 a & 381 a & $0,366940 \mathrm{~ns}$ \\
\hline C. platiphyllum - Rbw 8720 L & 366 a & 321 a & $0,051155 \mathrm{~ns}$ \\
\hline Hyperbaena domingensis - Rbw $4144 \mathrm{~L}$ & 414 a & $351 \mathrm{~b}$ & $0,008007 *$ \\
\hline H. domingensis - Rb $355385 \mathrm{~L}$ & 376 a & 392 a & $0,478828 \mathrm{~ns}$ \\
\hline Sciadotenia eichlerana - Uw 18656 L & 374 a & $288 \mathrm{~b}$ & $0,011344 *$ \\
\hline S. eichlerana - Uw 18677 L & 162 a & 195 a & $0,104767 \mathrm{~ns}$ \\
\hline Telitoxicum minutiflorum - Uw 18052 L & $313 \mathrm{a}$ & $341 \mathrm{~b}$ & $0,002245 *$ \\
\hline T. minutiflorum - Rb $194886 \mathrm{~L}$ & 389 a & 320 a & $0,122956 \mathrm{~ns}$ \\
\hline Cissampelos andromorpha - Rbw $8701 \mathrm{TH}$ & 294 a & 270 a & $0,109445 \mathrm{~ns}$ \\
\hline C. andromorpha - Rb $148534 \mathrm{TH}$ & $274 a$ & 281 a & $0,567066 \mathrm{~ns}$ \\
\hline Cissampelos ovalifolia - Rbw $8702 \mathrm{E}$ & 365 a & 332 a & $0,290312 \mathrm{~ns}$ \\
\hline C. ovalifolia - Rbw $8703 \mathrm{E}$ & 431 a & 423 a & $0,415113 n s$ \\
\hline Disciphania hernandia - Rbw $8704 \mathrm{TH}$ & 290 a & $361 \mathrm{~b}$ & $0,000429 *$ \\
\hline D. hernandia - Rb $179452 \mathrm{TH}$ & 252 a & 256 a & $0,471735 \mathrm{~ns}$ \\
\hline Odontocarya vitis - Rbw $8706 \mathrm{TH}$ & 365 a & 332 a & $0,122947 \mathrm{~ns}$ \\
\hline O. vitis - Rbw $8707 \mathrm{TH}$ & 227 a & 213 a & $0,404094 \mathrm{~ns}$ \\
\hline Ungulipetalum filipendulum - Rbw $8708 \mathrm{TH}$ & 357 a & $344 \quad a$ & $0,478824 \mathrm{~ns}$ \\
\hline U. filipendulum - Rbw $8709 \mathrm{TH}$ & 354 a & 338 a & $0,49053 \mathrm{~ns}$ \\
\hline
\end{tabular}

\subsection{6 - Caule X Raiz}


Os dados morfométricos das variáveis das raízes encontram-se nas tabelas 18 e 19. A tabela 20 a apresentam os resultados da análise de variância (ANOVA) e o teste de Tuckey-Kramer.

Tabela 20. Comparação entre caule e raiz de Cissampelos andromorpha (Rbw 8701) pelo teste Tuckey-Kramer. Médias com a mesma letra não diferem significativamente; médias com letras diferentes diferem significativamente a 5\%; medida = micrômetros $(\mu \mathrm{m}), \quad \mathrm{X}=$ média. Categoria de diâmetro do elemento de vaso: grandes $(>150 \mu \mathrm{m})$; médios $(101-150 \mu \mathrm{m})$; pequenos $(51-100 \mu \mathrm{m})$; muito pequenos $(\leq 50 \mu \mathrm{m})$.

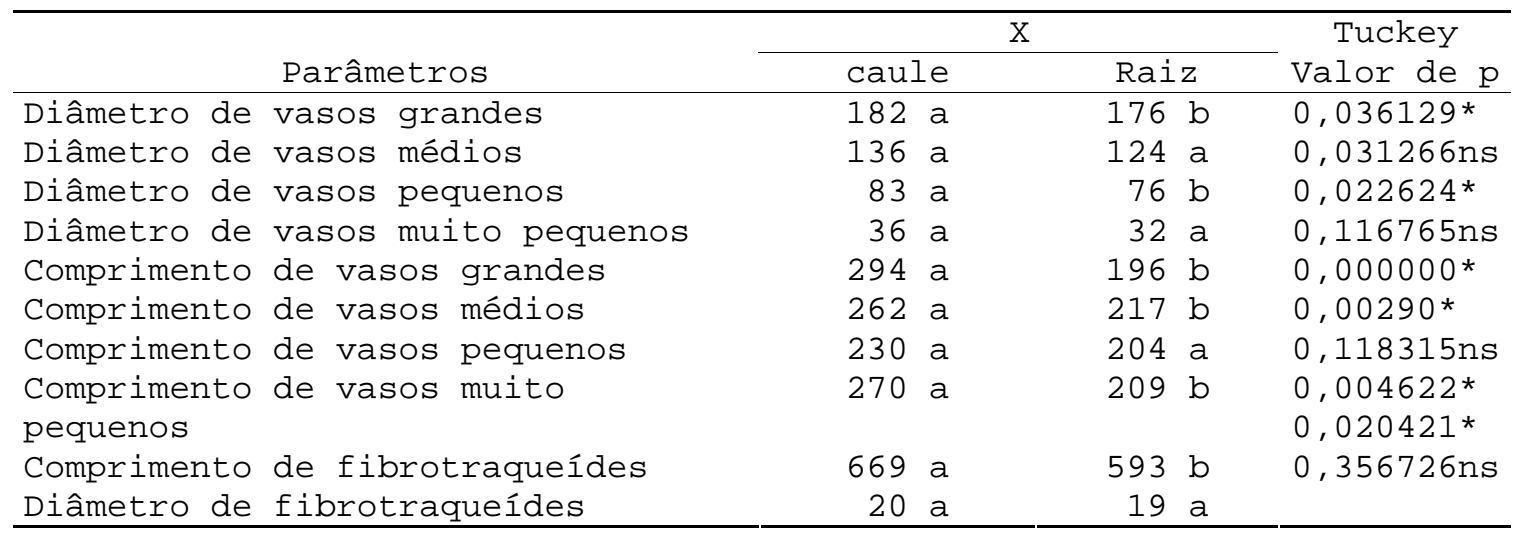


Tabela 18 - Comprimento e diâmetro dos elementos de vasos da raiz. X= média; s=desvio padrão; Mín=valor bruto mínimo; Máx=valor bruto máximo. Unidade de medida=micrômetros $(\mu \mathrm{m})$. Vasos grandes (>150 $\mu \mathrm{m})$. Vasos médios (101-150 $\mu \mathrm{m})$. Vasos pequenos $(50-100 \mu \mathrm{m})$. Vasos muito pequenos $(\leq 50 \mu \mathrm{m})$. CA1 (Cissampelos andromorpha Rbw 8701); CO1 (C. ovalifolia Rbw 8702); CO2 (C. ovalifolia Rbw 8703); DH1 (Disciphania hernandia Rbw 8704); DH2 (D. hernandia - Rb 179452); OV1 (Odontocarya vitis Rbw 8706); OV2 (O. vitis Rbw 8707); UF1 (Ungulipetalum filipendulum Rbw 8708); UF2 (U. filipendulum Rbw 8709) .

\begin{tabular}{|c|c|c|c|c|c|c|c|c|c|c|}
\hline Espécie & CA1 & $\mathrm{CO1}$ & $\mathrm{CO} 2$ & $\mathrm{CP} 1$ & DH1 & $\mathrm{DH} 2$ & OV1 & OV2 & UF 1 & $\mathrm{UF} 2$ \\
\hline parâmetros & \multicolumn{10}{|c|}{ Diâmetro dos vasos grandes } \\
\hline $\mathrm{X}(\mu \mathrm{m})$ & 176 & - & - & - & 175 & - & - & - & - & - \\
\hline$S(\mu \mathrm{m})$ & 31 & - & - & - & 76 & - & - & - & - & - \\
\hline C.V. ( $\left(\frac{\circ}{0}\right)$ & 17 & - & - & - & 43 & - & - & - & - & - \\
\hline Mín. $(\mu \mathrm{m})$ & 153 & - & - & - & 151 & - & - & - & - & - \\
\hline Máx. $(\mu m)$ & 255 & - & - & - & 468 & - & - & - & - & - \\
\hline parâmetros & \multicolumn{10}{|c|}{ Diâmetro dos vasos médios } \\
\hline $\mathrm{X}(\mu \mathrm{m})$ & 124 & 109 & 106 & 119 & 118 & 124 & 107 & - & 114 & 113 \\
\hline$S \quad(\mu \mathrm{m})$ & 10 & 7 & 2 & 14 & 13 & 11 & 6 & - & 11 & 8 \\
\hline C.V. ( $\left(\frac{\circ}{0}\right)$ & 8 & 6 & 2 & ? & 11 & 9 & 6 & - & 10 & 7 \\
\hline Mín. $(\mu \mathrm{m})$ & 106 & 102 & 105 & 101 & 102 & 103 & 101 & - & 102 & 103 \\
\hline Máx. $(\mu m)$ & 147 & 126 & 108 & 146 & 141 & 143 & 122 & - & 134 & 132 \\
\hline parâmetros & \multicolumn{10}{|c|}{ Diâmetro dos vasos pequenos } \\
\hline $\mathrm{X}(\mu \mathrm{m})$ & 76 & 76 & 62 & 75 & 77 & 67 & 69 & 61 & 70 & 62 \\
\hline$S \quad(\mu m)$ & 11 & 16 & 7 & 11 & 14 & 12 & 12 & 6 & 12 & 10 \\
\hline C.V. ( (\%) & 15 & 20 & 11 & 14 & 18 & 18 & 18 & 10 & 17 & 17 \\
\hline Mín. $(\mu \mathrm{m})$ & 52 & 52 & 52 & 60 & 51 & 51 & 55 & 51 & 54 & 51 \\
\hline Máx. $(\mu m)$ & 96 & 99 & 77 & 93 & 95 & 97 & 91 & 76 & 97 & 92 \\
\hline \multicolumn{11}{|c|}{ Diâmetro dos vasos muito pequenos } \\
\hline $\mathrm{X}(\mu \mathrm{m})$ & 33 & 37 & 42 & 35 & 42 & 36 & 38 & 36 & 29 & 39 \\
\hline$S(\mu \mathrm{m})$ & 10 & 8 & 7 & 10 & 6 & 9 & 10 & 9 & 7 & 8 \\
\hline$C \cdot V \cdot\left(\frac{\circ}{0}\right)$ & 30 & 21 & 16 & 29 & 14 & 25 & 27 & 26 & 23 & 21 \\
\hline Mín. ( $(\mu \mathrm{m})$ & 17 & 31 & 26 & 21 & 30 & 20 & 15 & 16 & 17 & 26 \\
\hline Máx. $(\mu \mathrm{m})$ & 49 & 50 & 50 & 51 & 50 & 50 & 50 & 50 & 46 & 50 \\
\hline \multicolumn{11}{|c|}{ Comprimento dos vasos de diâmetros gral } \\
\hline $\mathrm{X}(\mu \mathrm{m})$ & 196 & - & - & - & 300 & - & - & - & - & - \\
\hline$S(\mu m)$ & 31 & - & - & - & 83 & - & - & - & - & - \\
\hline C.V. ( $\left(\frac{\circ}{0}\right)$ & 16 & - & - & - & 28 & - & - & - & - & - \\
\hline Mín. $(\mu m)$ & 138 & - & - & - & 201 & - & - & - & - & - \\
\hline Máx. $(\mu m)$ & 249 & - & - & - & 519 & - & - & - & - & - \\
\hline \multicolumn{11}{|c|}{ Comprimento dos vasos de diâmetros médios } \\
\hline $\mathrm{X}(\mu \mathrm{m})$ & 214 & 319 & 108 & 365 & 299 & 270 & 186 & - & 366 & 323 \\
\hline$S(\mu \mathrm{m})$ & 41 & 68 & 21 & 45 & 97 & 60 & 47 & - & 61 & 92 \\
\hline C.V. ( $\left(\frac{\circ}{0}\right)$ & 19 & 21 & 20 & 12 & 32 & 22 & 25 & - & 17 & 29 \\
\hline Mín. $(\mu \mathrm{m})$ & 153 & 176 & 77 & 294 & 137 & 178 & 106 & - & 277 & 94 \\
\hline Max. $(\mu \mathrm{m})$ & 297 & 481 & 126 & 477 & 590 & 377 & 297 & - & 502 & 548 \\
\hline \multicolumn{11}{|c|}{ Comprimento dos vasos de diâmetros } \\
\hline $\mathrm{X}(\mu \mathrm{m})$ & 205 & 289 & 124 & 344 & 277 & 282 & 189 & 283 & 374 & 269 \\
\hline$S(\mu \mathrm{m})$ & 32 & 69 & 35 & 53 & 82 & 71 & 60 & 75 & 97 & 86 \\
\hline C.V. ( $\left.\frac{\circ}{0}\right)$ & 16 & 24 & 28 & 15 & 30 & 25 & 32 & 27 & 26 & 32 \\
\hline Mín. $(\mu m)$ & 118 & 227 & 92 & 281 & 139 & 169 & 149 & 156 & 177 & 119 \\
\hline Máx. $(\mu m)$ & 262 & 505 & 186 & 463 & 414 & 416 & 330 & 437 & 621 & 381 \\
\hline \multicolumn{11}{|c|}{ Comprimento dos vasos de diâmetros muito pequenos } \\
\hline $\mathrm{X}(\mu \mathrm{m})$ & 209 & 330 & 133 & 337 & 271 & 272 & 229 & 296 & 385 & 287 \\
\hline$S(\mu \mathrm{m})$ & 44 & 69 & 34 & 79 & 87 & 80 & 64 & 96 & 85 & 73 \\
\hline$C \cdot V \cdot\left(\frac{\circ}{0}\right)$ & 21 & 21 & 26 & 23 & 32 & 30 & 28 & 36 & 22 & 25 \\
\hline Mín. ( $(\mu m)$ & 117 & 176 & 97 & 228 & 103 & 127 & 180 & 196 & 190 & 164 \\
\hline Máx. ( $(\mu m)$ & 277 & 456 & 201 & 500 & 434 & 445 & 439 & 507 & 590 & 498 \\
\hline
\end{tabular}


Tabela 19 - Comprimento e diâmetro das fibras e fibrotraqueídes na raiz. $\mathrm{X}=$ média; s=desvio padrão; Mín=valor bruto mínimo; Máx=valor bruto máximo. Unidade de medida=micrômetros ( $\mu \mathrm{m})$. Vasos grandes (>150 $\mu \mathrm{m})$. Vasos médios $(101-150 \mu \mathrm{m})$. Vasos pequenos $(50-100 \mu \mathrm{m})$. Vasos muito pequenos $(\leq 50 \mu \mathrm{m})$. CA1 (Cissampelos andromorpha Rbw 8701); CO1 (C. ovalifolia Rbw 8702); CO2 (C. ovalifolia Rbw 8703); DH1 (Disciphania hernandia Rbw 8704); DH2 (D. hernandia - Rb 179452); OV1 (Odontocarya vitis Rbw 8706); OV2 (O. vitis Rbw 8707); UF1 (Ungulipetalum filipendulum Rbw 8708); UF2 (U. filipendulum Rbw 8709).

\begin{tabular}{|c|c|c|c|c|c|c|c|c|c|c|}
\hline Espécies & $\begin{array}{c}\text { CA1 } \\
\mathrm{FT}\end{array}$ & $\begin{array}{c}\mathrm{CO} 1 \\
\mathrm{~F}\end{array}$ & $\begin{array}{c}\mathrm{CO} 2 \\
\mathrm{~F}\end{array}$ & $\begin{array}{c}\mathrm{CP} 1 \\
\mathrm{FT}\end{array}$ & $\begin{array}{c}\text { DH1 } \\
\text { F }\end{array}$ & $\begin{array}{c}\text { DH2 } \\
\text { F }\end{array}$ & $\begin{array}{c}\text { OV1 } \\
\text { FT }\end{array}$ & $\begin{array}{c}\text { OV2 } \\
\text { F }\end{array}$ & $\begin{array}{c}\text { UF1 } \\
\text { FT }\end{array}$ & $\begin{array}{c}\text { UF2 } \\
\text { FT }\end{array}$ \\
\hline parâmetros & \multicolumn{10}{|c|}{ Diâmetro } \\
\hline $\mathrm{X}(\mu \mathrm{m})$ & 19 & 20 & 25 & 18 & 23 & 21 & 18 & 15 & 17 & 17 \\
\hline$S \quad(\mu m)$ & 3 & 4 & 3 & 3 & 5 & 4 & 3 & 2 & 2 & 3 \\
\hline C.V. ( $\left(\frac{\circ}{0}\right)$ & 16 & 18 & 12 & 15 & 21 & 20 & 16 & 14 & 12 & 17 \\
\hline Mín. $(\mu m)$ & 15 & 12 & 19 & 14 & 13 & 14 & 11 & 12 & 12 & 12 \\
\hline Máx. $(\mu m)$ & 27 & 26 & 31 & 24 & 34 & 27 & 24 & 20 & 20 & 23 \\
\hline parâmetros & \multicolumn{10}{|c|}{ Comprimento } \\
\hline $\mathrm{X}(\mu \mathrm{m})$ & 669 & 637 & 774 & 962 & 935 & 782 & 677 & 616 & 1003 & 928 \\
\hline$S(\mu m)$ & 103 & 70 & 67 & 103 & 139 & 126 & 88 & 114 & 117 & 164 \\
\hline C.V. ( $\left(\frac{\circ}{0}\right)$ & 15 & 11 & 9 & 11 & 15 & 16 & 13 & 18 & 12 & 18 \\
\hline Mín. $(\mu \mathrm{m})$ & 380 & 508 & 650 & 836 & 750 & 497 & 490 & 461 & 818 & 686 \\
\hline Máx. $(\mu m)$ & 832 & 762 & 890 & 1217 & 1200 & 1083 & 898 & 887 & 1365 & 1411 \\
\hline
\end{tabular}


Tabela 21. Comparação entre caule e raiz de Cissampelos ovalifolia (Rbw 8706) pelo teste Tuckey-Kramer. Médias com a mesma letra não diferem significativamente; médias com letras diferentes diferem significativamente a 5\%; medida = micrômetros $(\mu \mathrm{m}), \quad \mathrm{X}=$ média. Categoria de diâmetro do elemento de vaso: grandes $(>150 \mu \mathrm{m})$; médios $(101-150 \mu \mathrm{m})$; pequenos $(51-100 \mu \mathrm{m})$; muito pequenos $(\leq 50 \mu \mathrm{m})$.

\begin{tabular}{|c|c|c|c|}
\hline \multirow[b]{2}{*}{ Parâmetros } & \multicolumn{2}{|c|}{$\mathrm{X}$} & Tuckey \\
\hline & caule & raiz & Valor de $\mathrm{p}$ \\
\hline Diâmetro de vasos grandes & - & - & - \\
\hline Diâmetro de vasos médios & $107 \mathrm{a}$ & $124 \mathrm{~b}$ & $0,000000 *$ \\
\hline Diâmetro de vasos pequenos & 68 a & 76 a & $0,13010 \mathrm{~ns}$ \\
\hline Diâmetro de vasos muito pequenos & 37 a & $33 a$ & $0,08778 \mathrm{~ns}$ \\
\hline Comprimento de vasos grandes & - & - & - \\
\hline Comprimento de vasos médios & 365 a & $214 \mathrm{~b}$ & $0,000000 *$ \\
\hline Comprimento de vasos pequenos & 366 a & $205 \mathrm{~b}$ & $0,000000 *$ \\
\hline Comprimento de vasos muito pequenos & 332 a & $208 \mathrm{~b}$ & $0,000000 *$ \\
\hline Comprimento de fibrotraqueídes & 1063 a & $637 \mathrm{~b}$ & $0,000000 \star$ \\
\hline Diâmetro de fibrotraqueídes & $26 a$ & $20 \mathrm{~b}$ & $0,008296 *$ \\
\hline
\end{tabular}

Tabela 22. Comparação entre caule e raiz de Cissampelos ovalifolia (Rbw 8707) pelo teste Tuckey-Kramer. Médias com a mesma letra não diferem significativamente; médias com letras diferentes diferem significativamente a 5\%; medida = micrômetros $(\mu \mathrm{m}), \quad \mathrm{X}=$ média. Categoria de diâmetro do elemento de vaso: grandes $(>150 \mu \mathrm{m})$; médios (101-150 $\mu \mathrm{m})$; pequenos $(51-100 \mu \mathrm{m})$; muito pequenos $(\leq 50 \mu \mathrm{m})$.

\begin{tabular}{|c|c|c|c|}
\hline \multirow[b]{2}{*}{ Parâmetros } & \multicolumn{2}{|c|}{$\mathrm{X}$} & \multirow{2}{*}{$\begin{array}{c}\text { Tuckey } \\
\text { Valor de p }\end{array}$} \\
\hline & caule & raiz & \\
\hline Diâmetro de vasos grandes & - & - & - \\
\hline Diâmetro de vasos médios & $110 \mathrm{a}$ & $106 \mathrm{a}$ & $0,469211 \mathrm{~ns}$ \\
\hline Diâmetro de vasos pequenos & $72 \mathrm{a}$ & $62 \mathrm{~b}$ & $0,004086 *$ \\
\hline Diâmetro de vasos muito pequenos & $34 a$ & $42 \mathrm{~b}$ & $0,000685 *$ \\
\hline Comprimento de vasos grandes & - & - & - \\
\hline Comprimento de vasos médios & 430 a & $107 \mathrm{a}$ & $0,000273 \mathrm{~ns}$ \\
\hline Comprimento de vasos pequenos & 379 a & $124 \mathrm{~b}$ & $0,000000 *$ \\
\hline Comprimento de vasos muito pequenos & 422 a & $133 \mathrm{~b}$ & $0,00000 *$ \\
\hline Comprimento de fibras & 1651 a & $774 \mathrm{~b}$ & $0,000000 *$ \\
\hline Diâmetro de fibras & $32 \mathrm{a}$ & $25 \mathrm{~b}$ & $0,000001 *$ \\
\hline
\end{tabular}

Tabela 23. Comparação entre caule e raiz de Chondrodendron platiphyllum (Rbw 8720) pelo Teste Tuckey-Kramer. Médias com a 
mesma letra não diferem significativamente; médias com letras diferentes diferem significativamente a 5\%; medida = micrômetros $(\mu \mathrm{m}), \quad \mathrm{X}=$ média. Categoria de diâmetro do elemento de vaso: grandes $(>150 \mu \mathrm{m})$; médios $(101-150 \mu \mathrm{m})$; pequenos $(51-100 \mu \mathrm{m})$; muito pequenos $(\leq 50 \mu \mathrm{m})$.

\begin{tabular}{|c|c|c|c|c|}
\hline \multirow{2}{*}{\multicolumn{2}{|c|}{ Parâmetros }} & \multicolumn{2}{|c|}{$\mathrm{X}$} & \multirow{2}{*}{$\begin{array}{c}\text { Tuckey } \\
\text { Valor de p }\end{array}$} \\
\hline & & caule & raiz & \\
\hline Diâmetro de & vasos grandes & - & - & - \\
\hline Diâmetro de & vasos médios & $128 \mathrm{a}$ & $119 \mathrm{~b}$ & $0,043600 *$ \\
\hline Diâmetro de & vasos pequenos & 39 a & $35 a$ & $0,135152 \mathrm{~ns}$ \\
\hline Diâmetro de & vasos muito pequenos & 79 a & $75 \mathrm{a}$ & $0,203767 \mathrm{~ns}$ \\
\hline Comprimento & de vasos grandes & - & - & - \\
\hline Comprimento & de vasos médios & $446 a$ & $364 \mathrm{~b}$ & $0,000320 *$ \\
\hline Comprimento & de vasos pequenos & 421 a & $344 \mathrm{~b}$ & $0,000085 *$ \\
\hline $\begin{array}{l}\text { Comprimento } \\
\text { pequenos }\end{array}$ & de vasos muito & 381 a & 337 a & $\begin{array}{l}0,113812 \mathrm{~ns} \\
0,891959 \mathrm{~ns}\end{array}$ \\
\hline Comprimento & de fibrotraqueíde & $950 \mathrm{a}$ & $961 \mathrm{a}$ & \\
\hline Diâmetro de & fibrotraqueíde & $20 \mathrm{a}$ & $18 \mathrm{a}$ & $0,10731 \mathrm{~ns}$ \\
\hline
\end{tabular}

Tabela 24. Comparação entre caule e raiz de Disciphania hernandia (Rbw 8704) pelo teste Tuckey-Kramer. Médias com a mesma letra não diferem significativamente; médias com letras diferentes diferem significativamente a 5\%; medida = micrômetros $(\mu \mathrm{m}), \quad \mathrm{X}=$ média.

Categoria de diâmetro do elemento de vaso: grandes ( $>150 \mu \mathrm{m})$; médios $(101-150 \mu \mathrm{m})$; pequenos $(51-100 \mu \mathrm{m})$; muito pequenos $(\leq 50 \mu \mathrm{m})$.

\begin{tabular}{|c|c|c|c|}
\hline \multirow[b]{2}{*}{ Parâmetros } & \multicolumn{2}{|c|}{$\mathrm{X}$} & \multirow{3}{*}{$\begin{array}{c}\text { Tuckey } \\
\text { Valor de p } \\
0,001854^{*}\end{array}$} \\
\hline & caule & raiz & \\
\hline Diâmetro de vasos grandes & $180 \mathrm{a}$ & $175 \mathrm{~b}$ & \\
\hline Diâmetro de vasos médios & $122 \mathrm{a}$ & $118 \mathrm{a}$ & $0,175442 \mathrm{~ns}$ \\
\hline Diâmetro de vasos pequenos & $76 \mathrm{a}$ & $75 \mathrm{a}$ & $0,662430 \mathrm{~ns}$ \\
\hline Diâmetro de vasos muito pequenos & $33 \mathrm{a}$ & $42 \mathrm{~b}$ & $0,000399 *$ \\
\hline Comprimento de vasos grandes & $290 \mathrm{a}$ & $300 \mathrm{a}$ & $0,580743 n s$ \\
\hline Comprimento de vasos médios & 260 a & 299 a & $0,175442 \mathrm{~ns}$ \\
\hline Comprimento de vasos pequenos & $266 \mathrm{a}$ & $277 \mathrm{a}$ & $0,553997 \mathrm{~ns}$ \\
\hline Comprimento de vasos muito pequenos & 361 a & $271 \mathrm{~b}$ & 0,002554 * \\
\hline Comprimento de fibrotraqueíde & $856 \mathrm{a}$ & $935 \mathrm{a}$ & $0,317683 \mathrm{~ns}$ \\
\hline Diâmetro de fibrotraqueíde & $21 \mathrm{a}$ & $23 \mathrm{a}$ & $0,85954 \mathrm{~ns}$ \\
\hline
\end{tabular}


Tabela 25. Comparação entre caule e raiz de odontocarya vitis (RBw 8706) pelo teste Tuckey-Kramer. Médias com a mesma letra não diferem significativamente; médias com letras diferentes diferem significativamente a $5 \%$; medida $=$ micrômetros $(\mu m), \quad x=$ média.

Categoria de diâmetro do elemento de vaso: grandes (>150 $\mu \mathrm{m})$; médios $(101-150 \mu \mathrm{m})$; pequenos $(51-100 \mu \mathrm{m})$; muito pequenos $(\leq 50 \mu \mathrm{m})$.

\begin{tabular}{|c|c|c|c|c|}
\hline \multirow{2}{*}{\multicolumn{2}{|c|}{ Parâmetros }} & \multicolumn{2}{|c|}{$\mathrm{X}$} & \multirow{2}{*}{$\begin{array}{c}\text { Tuckey } \\
\text { Valor de p }\end{array}$} \\
\hline & & caule & raiz & \\
\hline Diâmetro de & vasos maiores & - & - & - \\
\hline Diâmetro de & vasos médios & 117 a & $107 \mathrm{~b}$ & $0,000109 *$ \\
\hline Diâmetro de & vasos pequenos & 71 a & $69 \mathrm{a}$ & $0,953581 \mathrm{~ns}$ \\
\hline Diâmetro de & vasos muito pequenos & $37 \mathrm{a}$ & $38 \mathrm{a}$ & $0,741499 \mathrm{~ns}$ \\
\hline Comprimento & de vasos maiores & - & - & - \\
\hline Comprimento & de vasos médios & $236 a$ & $186 \mathrm{~b}$ & $0,003089 *$ \\
\hline Comprimento & de vasos pequenos & $234 \mathrm{a}$ & $189 \mathrm{~b}$ & $0,010731 *$ \\
\hline Comprimento & de vasos muito pequenos & $197 \mathrm{a}$ & $229 a$ & $0,272961 \mathrm{~ns}$ \\
\hline Comprimento & de fibras & $814 a$ & $67 \mathrm{~b}$ & $0,000011 *$ \\
\hline Diâmetro de & fibras & $21 \mathrm{a}$ & $18 \mathrm{a}$ & $0,30508 \mathrm{~ns}$ \\
\hline
\end{tabular}

Tabela 26. Comparação entre caule e raiz de Odontocarya vitis (Rbw 8707) pelo teste Tuckey-Kramer. Médias com a mesma letra não diferem significativamente; médias com letras diferentes diferem significativamente a 5\%; medida = micrômetros $(\mu \mathrm{m}), \quad \mathrm{X}=$ média.

Categoria de diâmetro do elemento de vaso: grandes (>150 $\mu \mathrm{m})$; médios $(101-150 \mu \mathrm{m})$; pequenos $(51-100 \mu \mathrm{m})$; muito pequenos $(\leq 50 \mu \mathrm{m})$.

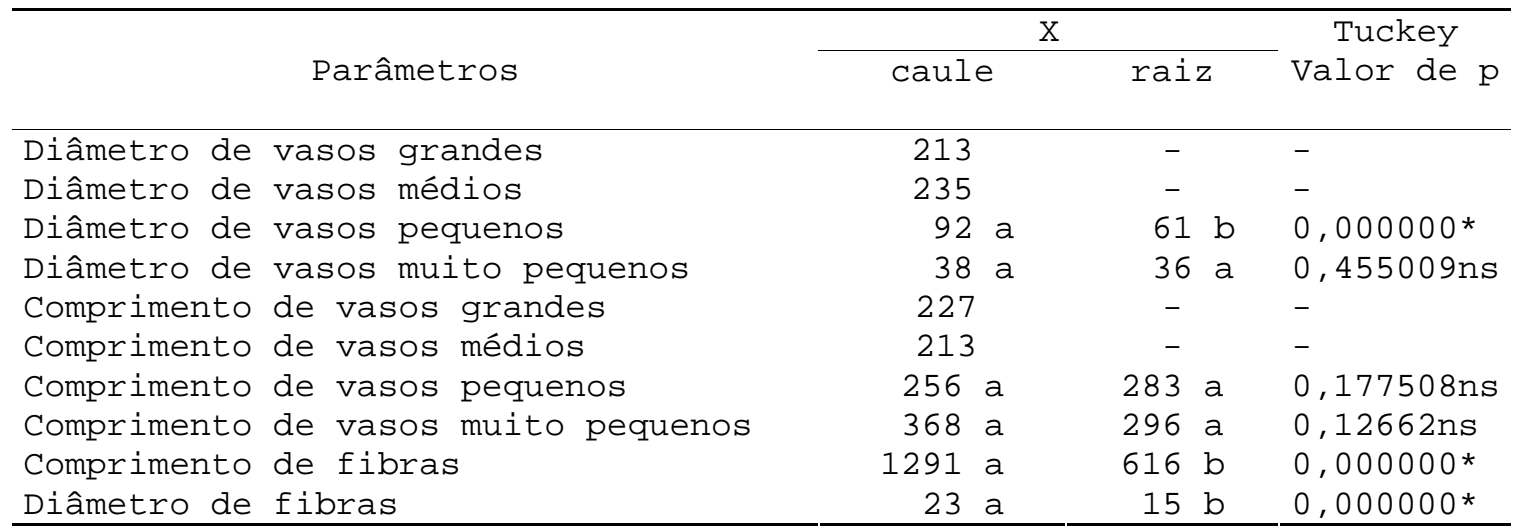


Tabela 27. Comparação entre caule e raiz de Ungulipetalum filipendeulum (Rbw 8708) pelo teste Tuckey-Kramer. Médias com a mesma letra não diferem significativamente; médias com letras diferentes diferem significativamente a 5\%; medida = micrômetros $(\mu \mathrm{m}), \quad \mathrm{X}=$ média. Categoria de diâmetro do elemento de vaso: Vasos grandes $(>150 \mu \mathrm{m})$. Vasos médios $(101-150 \mu \mathrm{m})$. Vasos pequenos $(51-100$ $\mu \mathrm{m})$. Vasos muito pequenos (<50 $\mu \mathrm{m})$.

\begin{tabular}{|c|c|c|c|c|}
\hline \multirow{2}{*}{\multicolumn{2}{|c|}{ Parâmetros }} & \multicolumn{2}{|c|}{$\mathrm{X}$} & \multirow{2}{*}{$\begin{array}{c}\text { Tuckey } \\
\text { Valor de p }\end{array}$} \\
\hline & & caule & raiz & \\
\hline Diâmetro de & vasos grandes & - & - & - \\
\hline Diâmetro de & vasos médios & $117 \mathrm{a}$ & 114 a & $0,142944 \mathrm{~ns}$ \\
\hline Diâmetro de & vasos pequenos & $73 \mathrm{a}$ & $70 \mathrm{a}$ & $0,281552 \mathrm{~ns}$ \\
\hline Diâmetro de & vasos muito pequenos & $31 \mathrm{a}$ & $29 a$ & $0,354822 \mathrm{~ns}$ \\
\hline Comprimento & de vasos grandes & - & - & - \\
\hline Comprimento & de vasos médios & 354 a & $366 \mathrm{a}$ & $0,6622430 \mathrm{~ns}$ \\
\hline Comprimento & de vasos pequenos & 364 a & 374 a & $0,899639 \mathrm{~ns}$ \\
\hline $\begin{array}{l}\text { Comprimento } \\
\text { pequenos }\end{array}$ & de vasos muito & 338 a & $385 \mathrm{~b}$ & $\begin{array}{l}0,057242 * \\
0,734198 \mathrm{~ns}\end{array}$ \\
\hline Comprimento & de fibrotraqueíde & $1000 \mathrm{a}$ & $1001 \mathrm{a}$ & $0,000000 *$ \\
\hline Diâmetro de & fibrotraqueíde & $23 a$ & $17 \mathrm{~b}$ & \\
\hline
\end{tabular}

Tabela 28. Comparação entre caule e raiz de Ungulipetalum filipendeulum (Rbw 8709) pelo teste Tuckey-Kramer. Médias com a mesma letra não diferem significativamente; médias com letras diferentes diferem significativamente a 5\%; medida = micrômetros $(\mu \mathrm{m}), \quad \mathrm{X}=$ média. Categoria de diâmetro do elemento de vaso: grandes $(>150 \mu \mathrm{m})$; médios $(101-150 \mu \mathrm{m})$; pequenos $(51-100 \mu \mathrm{m})$; muito pequenos $(\leq 50 \mu \mathrm{m})$.

\begin{tabular}{|c|c|c|c|}
\hline \multirow[b]{2}{*}{ Parâmetros } & \multicolumn{2}{|c|}{$\mathrm{X}$} & \multirow{3}{*}{$\begin{array}{c}\text { Tuckey } \\
\text { Valor de p }\end{array}$} \\
\hline & caule & Raiz & \\
\hline Diâmetro de vasos grandes & - & - & \\
\hline Diâmetro de vasos médios & $113 \mathrm{a}$ & $113 \mathrm{a}$ & $0,49053 \mathrm{~ns}$ \\
\hline Diâmetro de vasos pequenos & $114 \mathrm{a}$ & $113 \mathrm{a}$ & $0,490953 \mathrm{~ns}$ \\
\hline Diâmetro de vasos muito pequenos & $35 \mathrm{a}$ & 39 a & $0,127719 \mathrm{~ns}$ \\
\hline Comprimento de vasos grandes & - & - & - \\
\hline Comprimento de vasos médios & $357 \mathrm{a}$ & $331 \mathrm{a}$ & $0,264574 \mathrm{~ns}$ \\
\hline Comprimento de vasos pequenos & $386 a$ & $269 \mathrm{~b}$ & $0,000275 *$ \\
\hline Comprimento de vasos muito pequenos & 344 a & $287 \mathrm{~b}$ & $0,014115 *$ \\
\hline Comprimento de fibrotraqueíde & 995 a & 928 a & $0,132663 \mathrm{~ns}$ \\
\hline Diâmetro de fibrotraqueíde & $16 \mathrm{a}$ & $17 \mathrm{a}$ & $0,299253 \mathrm{~ns}$ \\
\hline
\end{tabular}




\section{DISCUSSÃO}

\subsection{Trepadeiras herbáceas $x$ lianas: 0 problema da definição do hábito}

Utilizando o arranjo dos tecidos vasculares, Eames \& MacDaniels (1947) classificam os caules de trepadeiras em dois tipos estruturais: anel de feixes ${ }^{1}$ e cilindro lenhoso. O tipo "anel de feixes" é representado por sistemas vasculares axiais entremeados por parênquima de origem vascular ou não. Os autores não fazem alusão ao conceito de trepadeiras lenhosas e herbáceas, no entanto, admitem que os dois arranjos estruturais supracitados podem ocorrer em caules de trepadeiras herbáceas.

Segundo alguns especialistas, as trepadeiras herbáceas possuem caules delgados e não lenhosos (Udulutsch et al., 2004). Já as trepadeiras lenhosas, ou lianas propriamente ditas (Gentry, 1991), possuem caules quase sempre lenhosos e de grande porte (Richards, 1952). Usualmente, essas duas categorias de trepadeiras ocupam diferentes nichos (Udulutsch et al., 2004). As lianas atingem a copa das árvores e, portanto, estariam quase ou totalmente expostas à luz na sua fase adulta e as herbáceas são restritas à vegetação rasteira de ambientes de sombra ou áreas degradadas como bordas de florestas e clareiras (Richards, 1952; Morellato \& Leitão Filho, 1998; Haber, 2000).

Observamos que os dados morfológicos utilizados para a definição dos termos são subjetivos, pois eles são comparativos (Ex.: caules mais grossos). Não há parâmetros estabelecidos no que se refere ao limite do diâmetro para que a planta seja classificada como liana ou trepadeira herbácea.

\footnotetext{
1 O autor se refere tanto aos feixes vasculares, em estrutura primária, quanto aos "segmentos fasciculares" com estrutura secundária.
} 
Somando-se os problemas, o termo lenhoso também é subjetivo e está sempre ligado a uma lignificação maior (eg: woody fibers), usado como sinônimo de maior diâmetro, ou à idéia da presença de muito xilema secundário. Há um consenso quanto a isso, mas não uma definição clara.

A terminologia consiste em procurar termos funcionais e organizados em um domínio, em criar termos novos no caso das coerências, e em implantá-los no uso (Boulanger, 1995).

O que se busca é o consenso e a clareza na construção dos conceitos terminológicos, caso contrário, estabelece-se uma confusão. Partindo dessa premissa, o termo "trepadeira lenhosa" confere a idéia de um caule lenhoso, mas o seu uso está diretamente associado ao termo "trepadeira herbácea", inferindo a idéia de que esse hábito é destituído de caule lenhoso. Sendo assim, a utilização da palavra "lenhosa" no termo é um agente complicador.

É comum o pesquisador da área ecológica levar mais em conta a posição que elas ocupam na floresta (e.g. Udulutsch et al., 2004) do que sua espessura. No entanto, considerando a experiência de campo adquirida no processo de coleta de material para esta tese, percebe-se que o mesmo hábito tanto pode estar no interior quanto na borda da mata. Também observa-se trepadeiras herbáceas que atingem a copa de árvores, portanto, não ocupando nichos diferentes. Assim, é esperado que estudos morfoanatômicos mais acurados talvez possam ampliar e aprimorar os conceitos.

Carlquist (1996) ressalta que Menispermaceae é pobremente representada em coleções científicas de madeira; a maioria dos trabalhos é baseada em caules finos, sem o conhecimento do diâmetro máximo que a trepadeira pode alcançar. Para essa família, a constatação do hábito dos táxons é bastante deficiente e com muitas lacunas. 
Todas as espécies abordadas neste trabalho possuem cilindros lenhosos, tanto as trepadeiras herbáceas quanto as lianas, as ervas e os arbustos. A natureza do tecido parenquimático que entremeia os sistemas axiais - raio vascular - foi decisiva para tal classificação, pois sendo a grande maioria do tecido de origem vascular logo se constitui em um caule lenhoso.

Neste trabalho, foi possível observar a tendência da presença de câmbios sucessivos nas lianas e arbustos. Como foi estudada apenas uma espécie arbustiva e uma herbácea, não podemos inferir tendências para esses hábitos.

As trepadeiras com hábito escalador e que não desenvolvem câmbios sucessivos em seus caules, neste trabalho, foram classificadas como trepadeiras herbáceas. Já as que desenvolvem camadas concêntricas além do hábito trepador foram classificadas como lianas. É importante ressaltar que os caules adultos das trepadeiras herbáceas permanecem mais finos que o caule das lianas. Essa é uma nova abordagem em Menispermaceae que se deixa em aberto, a qual poderá ser realizada por meio de uma posterior análise com maior número de gêneros.

Solereder (1908) fornece uma lista com espécies sem câmbios sucessivos: Anamirta, Cissampelos, Cocculus, Coscinium, Fateorhiza, Menispermum, Tinospora. Baseado nos dados desta tese, outras espécies foram acrescentadas a essa lista, como Disciphania, Ungulipetalum e Odontocarya, além de confirmar a ausência de câmbios sucessivos em Cissampelos.

\subsection{Caule. Desenvolvimento: raio medular}

Nas plantas herbáceas, as derivadas do câmbio interfascicular são tipicamente parenquimáticas, embora 
freqüentemente lignificadas (Philipson et al., 1971), produzindo raios largos que compartimentalizam os produtos das derivadas do câmbio fascicular (Eames \& MacDaniels, 1947).

O padrão anatômico supracitado foi o mesmo encontrado nas espécies de Menispermaceae estudadas, independentemente do hábito (trepadeira herbácea, liana, erva ou arbusto) .

Segundo Eames \& MacDaniels (1947), no caule não lenhoso, o tecido parenquimático existente entre o sistema axial pode não ser vascular, e, sim, de origem do tecido fundamental.

Esse parênquima é comumente designado como "raio medular". O uso da palavra "medular" refere-se ao fato de que esse tecido fica conectado à medula, portanto, seu limite interno é a própria medula. Já o seu limite externo é citado de diferentes maneiras: estendendo-se até o periciclo (Boureau, 1957) ou até o córtex (Fahn, 1990). O sentido da palavra "raio" no termo "raio medular" é para exprimir um tecido em arranjo de maneira semelhante ao raio vascular.

Concorda-se com Eames \& MacDaniels (1947), que comentam que o uso do termo raio medular não pode ser utilizado como sinônimo de raio vascular, justamente por não serem homólogos .

Pelos resultados aqui obtidos, o raio medular é mais expressivo nas trepadeiras herbáceas, como por exemplo em Cissampelos andromorpha. Nessa planta, ocorre um desnível de posicionamento dos feixes vasculares, favorecendo a diferenciação do raio medular. Nas lianas, apenas Chondrodendron platiphyllum apresenta raios medulares conspícuos. Nessa liana, o raio medular se restringe a acompanhar o xilema primário. Em razão da grande quantidade de parênquima de protoxilema, os raios medulares evidenciam-se por meio do alongamento das células. Porém, 
tão logo se instale o crescimento secundário, o tecido radial produzido conecta-se com o raio medular. Já em outras lianas, que possuem menor quantidade de parênquima de protoxilema, não se configura raio medular, pela inexistência de alongamento celular.

Menispermaceae é uma família reconhecida por possuir raios medulares (e.g. Metcalfe \& Chalk, 1950).

Observa-se uma tendência dos autores em identificarem os raios largos de caules de trepadeiras como raios medulares (e.g. Bhambie, 1972; Mullins et al., 1992), o que pode provocar equívocos.

É importante ressaltar que os resultados aqui obtidos apontam para a presença do raio medular; no entanto, esse se conecta com o raio vascular, não sendo possível, na maioria das vezes, separar os dois raios. Como a participação dos raios medulares é muito ínfima, determinou-se classificar o tecido radial apenas de raio vascular nas espécies de Menispermaceae relatadas nesta tese.

Philipson (1980) cita que os caules de muitas lianas têm regiões interfasciculares bem definidas, como verificamos em Menispermaceae. Por outro lado, o câmbio interfascicular não é detectado com clareza, e fornece como exemplos Aristolochia, Tetrapatheae e Clematis. O autor comenta que um incompleto câmbio interfascicular vestigial é encontrado, e suas células se dividem somente uma ou duas vezes. Na tentativa de agrupar as variações cambiais, Philipson coloca essas espécies na categoria "câmbio interfascicular modificado".

Em um primeiro momento, pensou-se que Menispermaceae fosse destituída de câmbio interfascicular e que o tecido radial era 0 raio medular. Esse tecido freqüentemente atravessa internós, o que não é comum para o raio vascular (Eames \& MacDaniels, 1947). No entanto, por meio do 
desenvolvimento, foi observada a formação do câmbio vascular com iniciais radiais e suas derivadas produzindo, então, raios muito altos.

Philipson et al. (1971) comentam que em plantas herbáceas as derivadas do câmbio interfascicular se estendem aos raios medulares, ou seja, elas têm o mesmo padrão observado nas trepadeiras no presente trabalho. Esses autores afirmam que os raios medulares diferem dos raios vasculares porque se estendem muito no sentido longitudinal, enquanto os raios vasculares são mais limitados. Essa idéia contrapõe os resultados aqui obtidos, pois foi verificado que os raios vasculares, principalmente das lianas, são bem longos, maiores que cinco centímetros e freqüentemente ultrapassando o nó.

É preciso ressaltar que há necessidade de estudos mais acurados naquelas plantas, que são comumente conhecidas por possuírem raios medulares (e.g. Metcalfe \& Chalk, 1950), e - que pode ser interpretado como raio medular pode ser tecido vascular produzido por um câmbio interfascicular de difícil detecção.

\subsection{Caule. Desenvolvimento: câmbios sucessivos, definição, origem e produtos}

Metcalfe \& Chalk (1950) caracterizaram a produção floemática produzida pela atividade cambial de Menispermaceae como floema incluso (ou intraxilemático) do tipo concêntrico. Carlquist (1996) ressaltou que esse termo é inadequado para Menispermaceae, pois o floema não está imerso no xilema secundário, mas dentro de um tecido avascular, o que foi confirmado também pelas diversas etapas do desenvolvimento realizado neste trabalho. 
Esse tecido avascular é o tecido conjuntivo também conhecido como tecido interfascicular ou tecido intermediário (Joshi, 1937; Eames \& MacDaniels, 1947). Além desse aspecto, Carlquist (1999) ressalta que, na variação do tipo floema incluso, um único câmbio está presente, enquanto nos câmbios sucessivos, como o próprio termo infere, vários câmbios vasculares estão envolvidos.

No caule, o tecido conjuntivo pode possuir paredes secundárias e lignificadas ou não, e nesse caso ser facilmente confundido com xilema secundário (Eames \& MacDaniels, 1947; Mikessel \& Popham, 1976); então, à primeira vista, essa variação poderia ser classificada como floema incluso.

O uso do termo "câmbios sucessivos" foi apenas um resgate do termo "sukzessive Zuwachsringe" (anéis de crescimento anuais), adotado pela primeira vez por Pfeiffer (1926). Concorda-se com Carlquist (1996) quando afirma que - termo é uma forma mais acurada de classificar a variação cambial que ocorre em Menispermaceae. O termo "câmbios acessórios" (Eames \& MacDaniels, 1947; Fahn \& Zimmermann, 1982) também é adequado, no entanto, é menos usual na literatura.

Conforme já abordado, observamos neste trabalho que todas as lianas analisadas possuem câmbios sucessivos em seus caules, enquanto as trepadeiras herbáceas são desprovidas dessa variação.

Para Menispermaceae, os únicos trabalhos que abordam alguns aspectos da instalação dos câmbios sucessivos em caules de Menispermaceae são os de Carlquist (1996) e Rajput \& Rao (2003). Esses trabalhos foram baseados somente em caules já maduros, ou seja, após a instalação do crescimento secundário, o que compromete a interpretação dos resultados. 
Depois de acuradas as observações em Abuta imene, baseadas em análise de inúmeras etapas sucessivas do desenvolvimento, observamos que o tecido conjuntivo é originado a partir de células pericíclicas.

A endoderme foi detectada em alguns trechos e observamos que o tecido conjuntivo em diferenciação, a partir do periciclo, a desloca em direção à periferia do órgão, descartando, então, uma possível origem cortical. A origem a partir do periciclo contrapõe os trabalhos de Carlquist (1996) e Rajput \& Rao (2003). Esses autores verificaram a origem a partir da camada cortical mais interna, próxima a um cordão de esclerênquima. Rajput \& Rao (2003) denominam esse cordão de fibras pericíclicas, e Carlquist (1996) não assume um termo, apenas comenta que esse cordão pode conter fibras do protofloema, talvez incutindo a idéia de origem floemática.

Neste trabalho, levanta-se a hipótese de que o tecido gerador da variação cambial aqui relatado, ou seja, uma camada cortical adjacente ao cordão de esclerênquima, é o mesmo tecido relatado pelos autores supracitados. Assume-se neste trabalho posições diferentes das de Carlquist com relação à presença de periciclo no caule.

Nesse aspecto, concordamos com Menezes et al. (2005), que consideram a continuidade dos tecidos através da raiz, caule e folha - sendo assim, no caule, o periciclo permanece ativo durante a vida da planta, como um gerador de tecidos vasculares.

Este trabalho não é pioneiro em admitir a presença de endoderme e periciclo em caules de Menispermaceae. Blottière (1886) nos deixou excelentes registros gráficos que abalizam os resultados aqui apresentados. Por causa das dificuldades de acesso a esse estudo, ilustramos um desses registros (veja as Figuras 198 e 199). 
Observe que nas Figura 198 e 199 o autor reconhece uma porção parenquimática do periciclo e a outra (mais externa) lignificada, assim como se apresenta nas espécies aqui analisadas. Na maioria das espécies, a endoderme não é justaposta, como mostra Blottière (1886), e, sim, entremeada por células pericíclicas parenquimáticas.

Um outro trabalho que cita a presença de periciclo e de uma "bainha amilífera" em caule com câmbios sucessivos é - de Fahn \& Zimmermann (1982), com Atriplex halimus (Chenopodiaceae). Segundo os autores, é o periciclo que dá origem a uma variação cambial.

Carlquist (1996) é o autor com maior número de trabalhos que enfoca a natureza dos câmbios sucessivos em diversas famílias, e, conforme já abordado, ele relata para todos os táxons analisados o surgimento de um meristema no parênquima cortical. Esse meristema forma tecidos secundários, e, portanto, o autor o denomina de "meristema lateral". Apesar de o termo ser vago, como assume o próprio autor, o uso de algo mais preciso (como "meristema lateral capaz de produzir câmbios sucessivos") poderia causar dificuldades e não ser plenamente aceito, de acordo com Carlquist. Os termos "meristema lateral difuso" (Carlquist 1999; Mikessel, 1979) e "meristema confinado" (Carlquist, 2001) também são utilizados.

Conforme supracitado em Abuta imene, o periciclo é o meristema que gera o tecido conjuntivo, que por sua vez, também é em parte meristemático, pois algumas de suas células dão origem aos câmbios sucessivos no material analisado.

Em Abuta imene, o tecido conjuntivo surge como resultado de divisões periclinais do periciclo, formando fileiras radiais de células parenquimáticas, e a parte mais interna, adjacente ao periciclo fibroso do anel original (primeiro anel vascular), permanece meristemática (tecido 
conjuntivo interno), enquanto algumas células medianas se lignificam, formando um cordão de esclereídes de tecido conjuntivo. Para fora desse cordão de esclereídes, as células também permanecem meristemáticas (tecido conjuntivo externo). Essa porção meristemática externa do tecido conjuntivo sofre, agora, novas divisões periclinais repetindo todo o processo descrito.

Esse padrão inicial de desenvolvimento é similar ao descrito por Carlquist (1996), no entanto, o autor relata apenas o surgimento de câmbios que produzem sistema axial. Como o autor não fornece detalhes, pela sua descrição, subentende-se que o tecido existente entre os sistemas axiais é o próprio tecido conjuntivo, sendo então avascular. Nossos resultados apontam para a presença de câmbio que possui somente iniciais radiais, repetindo o mesmo padrão anatômico da primeira camada, inclusive no plano temporal, - ou seja, primeiro surgem os câmbios somente iniciais fusiformes, e posteriormente com iniciais radiais, lado a lado, tornando-se concêntrico.

As famílias Amaranthaceae, Chenopodiaceae e Nyctaginaceae são as mais investigadas com relação à origem dos câmbios sucessivos. Ao analisarmos alguns desses trabalhos, concluímos que os câmbios sucessivos podem ter diversas origens, e algumas vezes controversas, pois há diferentes interpretações para táxons relacionados. Para ilustrar essa situação, trazemos um enfoque dicotômico em Leguminosae.

Chalk \& Chattaway (1937) citam para Machaerium glabrum a origem dos novos câmbios no periciclo ou no córtex, enquanto Nair \& Ram (1990) e Dias-Leme (1999), respectivamente, para Dalbergia paniculata e Machaerium multifoliolatum, demonstraram a formação de novos câmbios no floema secundário. 
Uma idéia muito rebatida é a origem dos câmbios sucessivos por meio do meristema de espessamento primário (MEP) . O termo MEP (= PTM, primary thickening meristem), semelhante ao que ocorre em monocotiledôneas, foi introduzido por Stevenson \& Popham (1973), e usado seqüencialmente por Mikesell \& Popham (1976); Mikessel (1979) e Yarrow \& Popham (1981), para designar a camada geradora da variação cambial em membros de Centrospermae (Aizoaceae, Amaranthaceae, Caryophyllaceae, Chenopodiaceae, Nyctaginaceae e Portulacaceae).

Segundo os autores, o MEP origina o tecido conjuntivo, caracterizado por uma porção interna e uma externa. A porção interna desse tecido originará um câmbio que formará - xilema e o floema secundários, além de novas células de tecido conjuntivo. A porção externa desse tecido conjuntivo dará continuidade na formação dos novos câmbios. Conforme abordado anteriormente, esse padrão de desenvolvimento é do mesmo tipo que encontramos em Menispermaceae produzido pelo periciclo.

DeMason (1983) afirma que o termo não é apropriado para Centrospermae e faz as seguintes ponderações: (1) 0 MEP é um meristema difuso e largo, enquanto o meristema em Centrospermae é estreito e funciona produzindo derivadas centripetamente e centrifugamente; (2) as características histológicas do MEP são diferentes do meristema que ocorre em Centrospermae; (3) o MEP é um espessamento primário, enquanto o meristema de Centrospermae é secundário.

Concordamos com DeMason (1983), especialmente no que consta no item 3, pois o MEP, juntamente com os meristemas apicais, tem a função de formar o corpo primário da planta (Rudall, 1991), e é um equívoco admitir que esse meristema produza tecidos secundários.

Mikessel (1979) admite que $O$ MEP tem origem no periciclo. Menezes et al. (2005) fazem uma nova proposta de 
interpretação para o meristema de espessamento primário, sendo que para as autoras o MEP é o próprio periciclo em fase meristemática, juntamente com a endoderme e suas derivadas (ou apenas o periciclo). Dessa maneira, o MEP reconhecido por Mikessel (1979) nada mais é que o próprio periciclo em fase meristemática.

Nesta tese, levanta-se a hipótese de que a camada citada por diversos autores - camada mais interna do córtex adjacente a um cordão de esclereídes - como sendo a geradora dos câmbios sucessivos, é simplesmente o periciclo.

Para exemplificar essa questão, apresentamos 0 trabalho de Wheat (1977), por possuir figuras muito nítidas e com várias etapas do desenvolvimento, o que é um tanto raro nos trabalhos que abordam a origem dos câmbios sucessivos. O autor cita para a espécie Phytolacca dioica, Phytolaccaceae, que os novos câmbios originam-se no tecido que fica externamente às fibras perivasculares, situadas abaixo da bainha amilífera, e a camada mais externa do floema secundário. Observando as figuras, não fica claro se a região é o periciclo ou o floema.

Não pretendemos aqui esgotar esse assunto, que, por sua relevância, deverá ser analisado de forma mais acurada em estudos de desenvolvimento nas famílias Amaranthaceae, Nyctaginaceae e Phytolaccaceae.

Para Nyctaginaceae, temos uma abordagem recente de Carlquist (2004), em que o autor faz uma reinterpretação do meristema lateral e dos câmbios sucessivos, baseados em raízes e caules. O trabalho é de inquestionável importância no âmbito de abrangência e fornecimento de dados inéditos, mas cabem aqui algumas considerações.

$$
\text { Carlquist afirma que o meristema lateral é }
$$
bidirecional, formando córtex secundário distalmente e 
tecido conjuntivo para o interior (parênquima ou fibra), raios verdadeiros e câmbios vasculares sucessivos.

Metcalfe \& Chalk (1950) já nessa época registraram que algumas espécies de Nyctaginaceae são destituídas de raios que podem ser substituídos por "ray-like radial sheets of conjunctive parenchyma" (faixas radiais de parênquima conjuntivo semelhante a raios). Esse evento foi citado por Carlquist (2004), no entanto, ele afirma que os raios somente são formados pelo meristema lateral em Nyctaginaceae e não por câmbios.

Considerando que o Carlquist (2004) denomina de meristema lateral, é o que chamamos de periciclo, esses raios citados por ele, poderiam estar sendo formados pelo câmbio de origem pericíclica. No entanto, somente estudos de desenvolvimento priorizando todas as etapas de formação do tecido conjuntivo e dos câmbios, que não foram executadas por ele, poderão confirmar ou não nossa hipótese.

Conforme já relatado observamos que o periciclo forma os novos câmbios que originarão os cordões vasculares neoformados e também os câmbios que formarão somente raios. Portanto verifica-se neste trabalho que os raios existentes nos anéis sucessivos são de origem de câmbios formados pelo tecido conjuntivo.

Constata-se, então, também a bidirecionalidade do periciclo, já que produz tecido conjuntivo distalmente e câmbios para o interior. Esses câmbios, por sua vez, também são bidirecionais.

\subsection{Raiz: desenvolvimento}

Carlquist (1996) ressaltou que a anatomia de raízes de Menispermaceae nunca foi estudada, e até este momento não foram localizados trabalhos com esse enfoque. Portanto, os 
dados aqui obtidos acrescentam informações inéditas ao nível de gênero e família.

Neste trabalho, 6 espécies foram analisadas, sendo 4 trepadeiras herbáceas (Ungulipetalum filipendulum, Odontocarya vitis, Disciphania hernandia, Cissampelos andromorpha); 1 liana (Chondrodendron platiphyllum) e 1 herbácea (Cissampelos ovalifolia). Para as duas primeiras espécies, são fornecidos alguns dados do desenvolvimento, e para as demais somente estrutura secundária, pois não se obteve raízes jovens.

Em nenhum indivíduo foram encontradas raízes primárias, apenas raízes laterais.

Há algumas características comuns a todas as espécies analisadas: o sistema de revestimento é uma periderme; ausência de medula e estrutura diarca ou triarca.

De acordo com Esau (1965) e Fahn (1990), na maioria das espécies, o número de pólos de protoxilema, no cilindro central da raiz, pode variar entre plantas diferentes ou em raízes diferentes de uma mesma planta. Algumas etapas do desenvolvimento foram verificadas em três espécies, conforme já abordado. Em Ungulipetalum filipendulum e Cissampelos ovalifolia, observou-se constância no número de pólos protoxilema, diarca e triarca, respectivamente. Já em Disciphania hernandia, um indivíduo apresentou constituição diarca e outro triarca, demonstrando, então, variação em plantas diferentes.

Esau (1977) menciona que o felogênio das raízes se origina mais comumente no periciclo, podendo, entretanto, ser diferenciado na epiderme ou nas camadas subepidérmicas em plantas herbáceas perenes, nas quais o córtex da raiz tem função de reserva de nutrientes.

Nas espécies que foi possível observar, o primeiro felogênio teve origem a partir de células subepidérmicas, e à medida que o caule se desenvolve novos felogênios são 
adicionados em camadas cada vez mais internas; no entanto, não foi possível detectar origem através do periciclo e/ou floema. Neste estudo, o córtex foi praticamente eliminado em todas as espécies, restando poucas células.

Nas raízes, em geral, o periciclo é unisseriado, podendo, em alguns casos, apresentar várias camadas de células (Esau, 1965). O periciclo foi constatado nos três espécimes em que se processaram o desenvolvimento, e apresentaram-se com uma a duas camadas de células nos estágios mais jovens e multisseriados em estágios mais desenvolvidos.

Ungulipetalum filipendulum foi a única trepadeira herbácea que apresentou medula, que só surgiu nos estágios finais de desenvolvimento. A raiz adulta dessa espécie é atípica, pois é constituída por um tecido parenquimático largo, que cruza a região medular. Os raios, tanto os formados pelo câmbio de origem procambial quanto os formados pelo periciclo, estão compostos por células parenquimáticas de parede primárias, assim como a medula recém instalada. Após várias divisões celulares, tanto desses dois raios quanto da medula, a raiz apresenta uma faixa parenquimática, de origem medular e vascular, que cruza o cilindro vascular, separando-o em duas metades. Não foi encontrados resultados similares a esse na bibliografia consultada.

Segundo Esau (1977), os órgãos de reserva apresentam grande quantidade de parênquima de reserva. Pode ocorrer proliferação de parênquima entre os elementos vasculares, como resultado de um crescimento secundário comum, ou, ainda, pelo desenvolvimento de novos sistemas vasculares, externamente ao cilindro vascular - ou seja, crescimento secundário não usual. 
O estudo anatômico do órgão subterrâneo e espessado de Disciphania hernandia evidenciou que a organização do sistema vascular desse órgão é típica de raiz.

Em algumas etapas do desenvolvimento, foi verificado o aumento de espessura da raiz através da proliferação de parênquima, por meio de um crescimento secundário comum, sem a presença de câmbios acessórios. Esse parênquima, pericíclico e vascular acumula amiloplastos, o que caracteriza a raiz como tuberosa ou "raiz de armazenamento", de acordo com Appezzato-da-Glória (2003).

Em inúmeras espécies, a tuberização decorre de um crescimento secundário não usual. O exemplo clássico é a beterraba (Beta vulgaris), que possui camadas concêntricas de câmbios supernumerários externamente ao cilindro vascular normal, produzindo células xilemáticas, floemáticas e parênquima de reserva (Milford, 1973; Rapoport \& Loomis, 1986). Como as lianas de Menispermaceae apresentam câmbios sucessivos no caule, questionava-se a presença também dessa estrutura na raiz.

Houve dificuldades de coletas de raízes de lianas, em razão da localização quase sempre laboriosa e complexa, onde a raiz se encontrava há dezenas de metros de distância da parte caulinar arbórea. Apesar das dificuldades de coleta, obteve-se amostras da raiz de Chondrodendron platiphyllum. Por meio dessa espécie, pela primeira vez, foi possível documentar anatomicamente, mesmo com a ausência de várias etapas, uma raiz de Menispermaceae com câmbios sucessivos.

A raiz, assim como o caule, possui um cordão de esclerênquima, de origem pericíclica no primeiro anel e do tecido conjuntivo no segundo. A camada parenquimática mais interna, adjacente a esse cordão perivascular, se divide, originando o tecido conjuntivo. Os demais eventos, como a formação do segundo cordão de esclereídes e o surgimento 
dos novos câmbios, são idênticos aos já descritos para o caule. A diferença reside no fato de que o evento ocorreu em lados opostos da raiz, causando um aspecto achatado.

A raiz mostra raios mais largos, tanto no primeiro quanto no segundo anel vascular, em relação ao caule. Apesar da ausência de etapas importantes para 0 entendimento da formação do tecido conjuntivo, esse tecido se expande muito em direção às células radiais vasculares, tornando difícil a distinção entre os dois tecidos. Assim como no caule os raios armazenam grande quantidade de amido.

Em raízes mais amadurecidas, como a de Cissampelos andromorpha, foram verificados novos cordões vasculares produzidos pela conversão de iniciais radiais em iniciais fusiformes. Dessa forma constata-se, novos cordões vasculares formados por xilema e floema secundários imersos em raios largos (veja a Figura 140), evento comum em caules de trepadeiras herbáceas estudadas nesta tese.

\subsection{Qual anel sucessivo utilizar em estudos anatômicos?} Uma abordagem com base em dados morfométricos de anéis sucessivos.

\footnotetext{
Segundo Mennega (1982), em Menispermaceae não é possível separar os gêneros com base na anatomia da madeira. No entanto, a autora infere características diagnósticas ao nível de tribo, baseada, principalmente no diâmetro dos vasos. Cabe ressaltar aqui que ela utilizou apenas elementos de vasos com diâmetro tangencial acima de 200 micrômetros, e não utilizou a ferramenta da estatística, além de não especificar qual anel vascular foi utilizado em seu estudo. Mennega (l.c.) encontrou as maiores médias para as tribos Triclisieae, Anomospermae e
} 
Tinosporae, enquanto Hyperbaenae e Menispermae obtiveram as menores médias.

o único trabalho que aborda a morfometria entre anéis sucessivos em Menispermaceae é o de Rao \& Rajput (2003). Esses autores fizeram análises do diâmetro do elemento de vaso em seis anéis sucessivos do arbusto Cocculus hirsutus e encontraram uma diminuição do diâmetro no sentido centroperiferia. Eles também constataram um aumento nas variáveis comprimento de vasos e fibrotraqueídes.

Apesar de os autores não terem tratado os dados estatisticamente, é possível perceber médias bem diferentes entre o primeiro $(193 \pm 10.53 \mu \mathrm{m})$ e o último $(138 \pm 9.24 \mu \mathrm{m})$ anel amostrado.

Após tomar conhecimento do trabalho dos autores supracitados, surgiram as seguintes questões: (1) Se o arbusto Cocculus hirsutus mostrou diferenças significativas no diâmetro do elemento de vaso, que foram menores a cada anel vascular mais externo, como se comportaria uma liana da mesma família?; (2) Se existem indivíduos que apresentam diferenças quantitativas entre os anéis, então, qual é o anel vascular que deverá ser utilizado em análises anatômicas comparativas em Menispermaceae?

Para responder a essas questões, processou-se análises comparativas entre vários anéis sucessivos de um mesmo indivíduo. Foram selecionadas quatro espécies, sendo três lianas e um arbusto, e analisados alguns anéis sucessivos (primeiro, segundo, quinto e décimo anel). Assim, de forma pioneira, fornece-se dados morfométricos dos elementos celulares em anéis sucessivos com o uso da ferramenta estatística.

Dentre as quatro espécies selecionadas, Abuta grandifolia, Abuta convexa, Abuta selloana e Hyperbaena domingensis, a primeira é arbustiva, e não possui vasos maiores que 150 micrômetros (veja a Tabela 3). 
Se os resultados estatísticos indicassem que não havia diferenças consideráveis entre os anéis, então, qualquer anel vascular poderia ser utilizado para estudos comparativos do lenho.

Inicialmente, abordaremos o diâmetro de vaso. Neste trabalho, conforme já relatado, os dados morfométricos dos elementos de vasos foram amostrados com base em quatro categorias de diâmetro: vasos grandes, médios, pequenos e muito pequenos.

Quando o caule apresenta vasos grandes e pequenos, recomenda-se que só os maiores sejam considerados (IAWA Committee, 1989). Cabe ressaltar aqui que as recomendações desse comitê foram criadas visando a identificação madeiras, e esse não foi o objetivo principal desta tese.

Observou-se alguns elementos de vasos, com placa de perfuração simples, mais estreitos que as fibrotraqueídes em material macerado de um mesmo lenho. Esse tipo de situação foi comum em todas as espécies analisadas. No plano transversal, esses vasos poderiam ser facilmente confundidos com fibras ou com traqueídes.

Desse modo, apesar de ser menos usual, o diâmetro dos elementos de vasos, assim como todas as outras estruturas, tais como fibras e traqueídes, foram obtidos a partir de material dissociado. Esse método forneceu maior exatidão no reconhecimento do elemento de vaso.

Dois tipos de procedimentos foram executados com relação aos vasos. Primeiro, foi processada a análise estatística do diâmetro em cada categoria, individualmente, e após com todas as categorias de diâmetros.

Para as três lianas, no geral, apenas o diâmetro dos vasos maiores apresentou padrões consistentes (veja as Tabelas 4, 5 e 6). Para essa variável, as três espécies apresentaram padrões semelhantes, com aumento significativo no sentido centro-periferia, apesar de haver variação em 
qual anel que sofreu aumento. Para esta variável a espécie arbustiva não foi testada, já que não apresentou vasos grandes.

Com relação à análise utilizando todas as categorias de diâmetro de vaso, duas lianas estudadas mostraram padrões semelhantes: Abuta convexa e Hyperbaena domingensis sofreram diferenças significativas no décimo anel (veja as Gráficos 1 e 5). Já Abuta selloana (veja o Gráfico 3) não apresentou diferenças significativas, enquanto que 0 arbusto sofreu um aumento significativo já no segundo anel, e se manteve constante (Gráfico 7).

A seguir, abordaremos o comprimento do elemento de vaso. Para as análises envolvendo cada categoria de diâmetro de vaso de forma independente, observa-se uma tendência não muito consistente para aumento no sentido centro-periferia, pois há muitas oscilações (veja as Tabelas 4, 5, 6 e 7).

Para as análises envolvendo todas as variáveis em conjunto (Gráficos 2, 4, 6 e 8), obteve-se diferenças significativas para todas, mostrando três tendências: (1) aumento do comprimento em Abuta convexa; A. grandifolia, A. selloana (2) diminuição do comprimento em Hyperbaena domingensis.

A primeira tendência está de acordo com o encontrado por Rajput \& Rao (2003), que também observaram um aumento no comprimento do elemento de vaso no sentido centroperiferia.

Outro trabalho, que se tem conhecimento, que enfoca análises morfométricas em anéis sucessivos, aborda a Phytolaccaceae, e foi desenvolvido por Horak (1981). Ele descreve uma diminuição no comprimento do elemento de vaso em cada um dos sete anéis sucessivos de Stegnosperma, a mesma tendência encontrada para Hyperbaena domingensis. É 
importante ressaltar que Horak (l.c.) não fez tratamentos estatísticos das amostras.

Não houve diferenças significantes quanto ao diâmetro das fibras (libriformes e fibrotraqueídes) (veja as Tabelas $4,5, e$ e 7).

Constatou-se uma tendência estatisticamente significada para o aumento do comprimento das fibras no sentido centro-periferia, exceto por Abuta selloana, que não apresentou diferenças consideráveis (veja as Tabelas 4, 5,6 e 7).

Estudos sobre a variação na dimensão dos elementos celulares são mais freqüentes em plantas arbóreas. Dois tipos de análises são investigados: no sentido axial (baseápice) e radial (centro-periferia). Com relação ao sentido radial, os estudos mostram que, no geral, o diâmetro, assim como o comprimento do elemento de vaso e de fibras, é menor próximo à medula, aumentando no sentido à periferia, ocorrendo, posteriormente uma estabilização; esta estabilização das dimensões mostra a formação do lenho adulto (Giroud, 1977; Silva, 1992; Bosman, 1996; Urbinati et al., 2003). Essa diferença está calcada na relação lenho juvenil X lenho adulto, pois, segundo Zobel \& Talbert (1984), as camadas produzidas no lenho juvenil (próximo à medula) têm características muito diferentes daquelas localizadas perto do câmbio (lenho adulto) .

Para as espécies enfocadas nesta tese, no geral, a variável diâmetro do elemento de vaso e o comprimento de das fibras têm o mesmo padrão para arbóreas. Já com relação ao comprimento do elemento de vaso foram encontrados padrões distintos (aumento em três espécies e diminuição em uma).

Apoiando-se nos resultados obtidos, percebeu-se a necessidade de padronização do anel vascular em estudos do lenho para a família Menispermaceae. Considerando que essa 
família é constituída por diversos hábitos, recomenda-se o uso do primeiro anel, pois esse tem origem homóloga com os demais caules de outros hábitos que não formam anéis sucessivos.

A padronização através do primeiro anel poderá contribuir para futuros trabalhos de anatomia de Menispermaceae, pois materiais depositados em herbários poderão ser utilizados. Recomenda-se, no entanto, que sejam utilizados caules com, no mínimo, dois anéis vasculares, pois verificamos que, com a instalação do segundo anel, a diferenciação do primeiro já está completa.

A partir dos dados inéditos obtidos nesta tese, critica-se os dados morfométricos existentes com anatomia do lenho em Menispermaceae (e.g. , 1982; Carlquist, 1996) pela ausência de padronização do anel sucessivo utilizado.

\subsection{Xilema - Considerações gerais para o caule e a raiz}

\subsubsection{Estrutura geral}

A estrutura básica do lenho do caule das espécies abordadas é semelhante ao descrito por alguns autores para a família Menispermaceae (e.g. Metcalfe \& Chalk, 1950; Carlquist, 1996; , 1982; Araque et al., 2000; Solereder, 1908; Détienne \& Jacquet, 1983). As espécies do presente estudo apresentam as seguintes características em comum com os dados desses autores citados: vasos solitários em maioria; presença de variação cambial do tipo câmbios sucessivos em alguns gêneros; elementos de vasos de diâmetros distintos; placa de perfuração simples; parênquima apotraqueal difuso ou em linhas finas; raios largos e altos; fibras com pontoações areoladas; traqueídes; cristais de morfologia variada e tecido conjuntivo entre os anéis sucessivos. 
Não foram observadas diferenças qualitativas entre os anéis sucessivos, exceto para Abuta grandifolia, que apresentou fibras septadas somente no primeiro anel.

A raiz possui o mesmo padrão anatômico caulinar, diferindo apenas quantitativamente. Essa observação está de acordo com os dados de alguns autores que compararam o lenho do caule e a raiz de plantas árboreas (Eames \& MacDaniels, 1947; Morrison, 1954; Cutler, 1976; Dias-Leme, 1994; Esemann-Quadros, 2001).

\subsubsection{Anéis de crescimento}

Estudos dendrocronológicos são aplicados em plantas que têm capacidade de crescimento secundário e produção anual de anéis de crescimento, sendo o hábito arbóreo o mais enfocado por essa ciência (Schweingruber \& Dietz, 2001).

Recentemente, o estado da arte dos estudos dendrocronológicos foi fornecido por schweingruber \& Poschlod (2005). Percebe-se, nessa obra, que as lianas constituem $\circ$ grupo menos estudado sob $\circ$ enfoque da dendrocronologia - até mesmo as monocotiledôneas e pteridófitas são mais abordadas que as lianas.

$\mathrm{Na}$ lista fornecida por Schweingruber \& Poschlod (2005), apenas duas lianas estão incluídas: Clematis vitalba, datada com 41 anos, e Tamus communis, com 20 anos; no entanto os autores não fornecem nenhuma informação adicional.

A ausência de estudos dendrocronológicos pode ser um reflexo do pouco conhecimento sobre a anatomia do lenho em lianas, pois, segundo Schweingruber \& Poschlod (2005), a identificação e a análise dos anéis de crescimento exigem um conhecimento detalhado da anatomia das respectivas espécies. 
No desenvolvimento do estudo para este trabalho, somente as lianas apresentaram anéis de crescimento, anéis esses demarcados pelo achatamento de fibras e células do raio e por porções xilemáticas com ausência de vasos e pouco parênquima. Ressaltamos que o evento não ocorre no primeiro anel, e, sim, nos anéis sucessivos.

Os trabalhos que enfocam anéis de crescimento em plantas com câmbios sucessivos são raros. Schweingruber \& Poschlod (2005) analisaram órgãos com câmbios sucessivos na zona de transição entre caule e raiz em duas espécies de Amaranthaceae e quatro de Chenopodiaceae, e não foram constatados anéis de crescimento. Os autores Kundu \& Guha (1975) ao analisarem um caule de Tiliacora acuminata, espécie arbórea, denominaram os anéis sucessivos como "anomalous growth rings" (= anéis de crescimento anômalos). Os autores Rajput \& Rao (2003) trabalharam com 0 arbusto Cocculus hirsutus - Menispermaceae, e detectaram que a peridiocidade de formação de cada anel vascular foi de dois ou três anos, no entanto, não observaram anéis de crescimento demarcados. Apesar dos anéis vasculares possuirem uma peridiocidade, demonstrada para C. hirsutus, preferimos a utilização do termo anéis de crescimento somente para atividade diferenciada de um único câmbio, portanto discordamos dos autores Kundu \& Guha (1975) que admitem que cada anel vascular representa uma camada de crescimento.

Carlquist (1996) observou anéis de crescimento na liana Pycnarrhena sp. (Menispermaceae). Nessa espécie o autor verificou a presença de vasos estreitos do lenho tardio alternando-se com vasos largos com tilos no lenho inicial. Ressalta-se que esse autor verificou apenas os marcadores de crescimento e não a periodicidade. 


\subsubsection{Elementos de vaso}

\subsubsection{Dimorfismo de vaso}

A presença de vasos de diâmetros distintos no lenho já era uma situação conhecida por diversos anatomistas, quando Carlquist (1981) criou o termo "vessel dimorphism" para designar esse tipo de estrutura. O termo foi traduzido como "vasos dimórficos" por parecer uma linguagem mais adequada do que "vaso dimorfismo" para especificá-lo. Essa característica está presente, principalmente, em plantas com hábito escalador (Carlquist, 1981).

É amplamente conhecido pelos estudiosos que trepadeiras têm caracteristicamente vasos largos (freqüentemente maior que $200 \mu \mathrm{m}$ ) e longos (Carlquist, 1975; Ter Welle, 1985; Ewers \& Fisher, 1989), e alguns autores afirmam que as lianas possuem os vasos mais largos e longos do reino vegetal (e.g. Kramer Kozlowski, 1979; Zimmermann, 1983). (1982) relata o diâmetro de 500 um para a liana Elephantomene, enquanto Carlquist (1996) fornece $437 \mu \mathrm{m}$ para Chasmanthera welwitschii. Dessa maneira, em Menispermaceae, foram encontrados elementos de vasos de diâmetros avantajados.

A vantagem de vasos mais largos, para aumentar a eficiência de condução, é bem conhecida. As desvantagens são mais complexas, mas vasos mais largos são considerados "menos seguros" que vasos estreitos.

O embolismo (formação de bolhas de ar nos vasos) pode ser induzido por estresse de seca (Cochard \& Tyree, 1996) ou congelamento (Sperry, 1995).

O paradigma existente sugere que o embolismo pode ser revertido se houver a dissolução do ar que está na água (e.g. Zimmermann, 1983). A probabilidade de ocorrer embolismo aumenta com o diâmetro do vaso (Sperry \& 
Sullivan, 1992; Hacke \& Sperry, 2001), criando um conflito direto entre eficiência na condução e a necessidade de minimizar a cavitação (Hacke \& Sperry, 2001).

Para exemplificar, trazemos o trabalho de Davis et al. (1999). Os autores encontraram uma forte relação entre cavitação por congelamento e diâmetro médio do elemento condutor para plantas lenhosas de clima temperado. Vasos pequenos $(<30 \mu \mathrm{m})$ não sofreram cavitação, enquanto vasos maiores $(>40 \mu \mathrm{m})$ foram quase completamente cavitados, e os vasos com médias intermediárias (30-40 $\mu \mathrm{m})$ mostraram cavitação parcial.

Em Menispermaceae, os vasos dimórficos estão presentes em todos os gêneros de trepadeiras herbácaeas e lianas, inclusive no arbusto Abuta grandifolia e na erva Cissampelos ovalifolia, sendo comum vasos menores que 30 micrômetros e maiores que 200 micrômeros.

\subsubsection{O diâmetro do elemento de vaso em espécimes de hábitos diferentes}

No presente trabalho, tentamos saber se o primeiro anel seria informativo para análise entre hábitos de uma mesma espécie, escolheu-se, portanto a liana Abuta grandifolia. Segundo (1982), essa espécie é interessante em análises de hábitos por possuir hábito arbóreo, arbustivo e liana. A autora ainda divide o hábito arbóreo em duas categorias: arvoreta e árvore.

Nesta tese, enfatizamos os hábitos arbustivos e lianas. Para isso, foram escolhidos três espécimes de cada hábito (Tabela 8). As três espécies de lianas e as duas arbustivas constituem o mesmo material que (1982) utilizou em seu trabalho. O terceiro espécime da forma arbustiva foi coletado na região Amazônica. 
No presente trabalho, a análise estatistica mostrou que o diâmetro dos elementos de vaso é significativamente menor no hábito arbustivo (veja a Tabela 9 e o Gráfico 9) situação semelhante ao que foi encontrado por (1982). Ressalta-se que a autora não detectou diferenças entre os hábitos arbustivos e arbóreos. Os trabalhos existentes que enfocam as dimensões celulares em um mesmo gênero ou espécie de hábito árboreo e liana, demonstram que as lianas possuem elementos de vasos de diâmetro maior (e.g. Ter Welle, 1985; Iqbal, 1994; Gasson \& Dobbins, 1991; DiasLeme, 1999).

Conforme já abordado, a tendência aqui encontrada, utilizando o primeiro anel vascular está de acordo com o trabalho de (1982) já relatados com anéis sucessivos, ou seja, o primeiro anel é informativo para caules de Menispermaceae.

Também foram encontradas diferenças significativas entre trepadeiras herbáceas e lenhosas (veja a Tabela 14). As lianas tiveram maior média para o diâmetro de elementos de vasos da categoria grande $(215 \mu \mathrm{m})$ do que as trepadeiras herbáceas $(184 \mathrm{\mu m})$. Para as categorias de elementos de vasos médios e pequenos, não houve diferença significativa, no entanto, para a categoria muito pequeno, os elementos de vasos são mais largos nas lianas do que nas trepadeiras herbáceas, ou seja, as trepadeiras herbáceas tem os menores vasos de menor calibre (veja a Tabela 14).

Até o momento, não foi localizado nenhum trabalho enfocando os hábitos trepador herbáceo e liana com relação a dados morfométricos comparativos do xilema.

\subsubsection{Placas de perfuração}

Em relação às placas de perfuração, tanto as do caule quanto as das raízes são simples. Carlquist (1991) sugere 
que a placa simples é comum em lianas e oferece o mínimo de impedimento ao fluxo de água, promovendo uma condução mais eficiente.

Alguns trabalhos fisiológicos que enfocam a relação eficiência versus segurança das placas simples e múltiplas demonstram que nem sempre a afirmação de Carlquist (1991), ou seja, que a placa simples promove uma condução mais eficiente, se aplica. No entanto, dependendo da morfologia (inclinação, número de barras) da placa múltipla, essa placa pode se igualar na resistência com relação à placa simples (Ellerby \& Ennos, 1998).

Schultle et al. (1989), baseados em experimentos fisiológicos e físicos, demonstram que a placa de perfuração simples e a composta (escalariforme) obtiveram igual condução hidráulica em capilares com diâmetro aproximado.

Sperry \& Tyree (1988) sugerem que o tipo de placa pode contribuir para a resistência. No entanto, os autores assumem que o diâmetro da pontoção do vaso se sobressai em importância para o evento - resultado compartilhado com Konrad \& Roth-Nebelsick (2005).

Portanto, como não foram processados experimentos fisiológicos nesta tese, não há evidências suficientes para corroborar ou refutar a suposição de que a placa simples promove uma condução mais eficiente, conforme afirma Carlquist (1991).

\subsubsection{Pontoações dimórficas}

Em todas as espécies analisadas, observa-se que as pontoações do elemento de vaso próximas às suas extremidades são bem maiores que as demais. Carlquist (1996) observou o mesmo evento em dois gêneros de 
Menispermaceae e o autor conclui que se trata de pontoações parênquimo-vasculares. No presente trabalho, compartilha-se da mesma conclusão que esse autor.

Pontoações de tamanhos distintos no mesmo elemento de vaso foram denominadas por Carlquist \& Schneider (2001) como "pits dimorphism", pontoações dimórficas, como se prefere utilizar neste trabalho.

Carlquist (1996) afirma que nunca viu pontoações dimórficas similares às de Menispermaceae em vasos de outras famílias de dicotiledôneas.

Nesta tese, constatamos que as pontoações dimórficas ocorrem também nos elementos de vasos das raízes.

\subsubsection{Comprimento dos elementos de vasos}

Há uma relação consistente e fortemente positiva entre comprimento e largura dos vasos das trepadeiras dicotiledôneas, monocotiledôneas e Gnetum (Zimmermann \& Jeje, 1981; Zimmermann \& Potter, 1982; Ewers \& Fisher, 1989; Ewers et al., 1990; Fisher \& Ewers, 1991; Fisher et al., 2002). Observa-se que essa relação pode ser válida tanto para o elemento de vaso quanto para o vaso. Ewers \& Fisher (1989) ressaltam que há muitas referências de comprimento do elemento de vaso nas plantas, mas relativamente poucos com relação aos vasos.

Os trabalhos com enfoque na anatomia normalmente trabalham com o elemento de vaso, e a grande maioria dos resultados é fornecida por Carlquist (e.g. Carlquist, 1975; 1977). Já os fisiologistas usam o valor do comprimento no vaso, normalmente em experimentos para verificar a condução hidráulica (e.g. Zimmermann \& Jeje, 1981; Zimmerman \& Potter, 1982; Ewers \& Fisher, 1989). 
Nesta tese, um total de 31 indivíduos foi testado, quanto ao comprimento do elemento de vaso de diâmetro grandes e pequenos, isto é, procurou-se verificar a relação positiva. Nesses 31 indivíduos, apenas seis apresentaram diferenças significativas e o restante não mostrou diferenças entre o comprimento de elementos de vasos de diâmetros grandes com relação aos elementos de vasos de diâmetros pequenos (veja a Tabela 17). Portanto, a grande maioria não apresentou diferenças significativas, demonstrando que a relação positiva não é consistente para Menispermaceae, conforme seria o esperado.

Com relação aos hábitos de Abuta grandifolia, as lianas possuem elementos de vasos mais longos que os arbustos (veja a Tabela 9 e o Gráfico 9).

A análise entre trepadeiras herbáceas e lianas também mostrou que essa variável foi maior nas lianas (veja a Tabela 14) - situação descrita para os hábitos liana e arbóreo em comparação (e.g. Ewers et al., 1990; Ewers \& Fisher, 1991; Fisher \& Ewers, 1995; Dias-Leme, 1999).

Mennega (1992) considerou as médias dos comprimentos do elementos de vasos da forma arbustiva, arbórea e liana como iguais. Ressaltamos, mais uma vez, que a autora não fez uso da estatística e nossos dados que foram tratados estatisticamente apontaram que essa variável foi maior nas lianas.

\subsubsection{Fibras, fibrotraqueídes e traqueídes}

Todos os gêneros, indepdendente do hábito, de Menispermaceae estudados possuem em seus caules e raízes fibras libriformes, fibrotraqueídes e traqueídes. A distinção entre fibrotraqueídes e traqueídes nem sempre é tarefa fácil. Nesta tese, classificamos como traqueíde aquele elemento que possuía de duas ou mais fileiras de 
pontoações areoladas e normalmente eram mais curtos e com terminações menos afiladas que as fibrotraqueídes. Esses elementos, por sua vez, possuíam uma fileira e eram mais alongados.

Carlquist (1996) constatou apenas traqueídes e fibras libriformes para Menispermaceae. Já Mennega (1982) constata a presença de fibrotraqueídes e traqueídes vasicêntricas e não faz menção às fibras libriformes. Entretanto, nenhum dos dois autores fornecem figuras para ilustrar as fibras ou as traqueídes.

Metcalfe \& Chalk (1950) mencionam traqueídes largas em Abuta e Tiliacora, mencionando que pode ser possível que sejam traqueídes vasicêntricas.

Os dados morfométricos das fibras foram obtidos do caráter que estava mais bem representado no indivíduo (veja as Tabelas 12 e 13), ou seja, avaliou-se primeiramente a presença ou não de fibras libriformes e fibrotraqueídes no macerado, em seguida estimou-se qual elemento estava em maior freqüência (melhor representado). Quando a espécie apresentava aproximadamente 50\% tanto para fibras quanto para fibrotraqueídes, processou-se as medições de ambos. Quando um elemento estava mais freqüente que o outro, mediu-se aquele que estava melhor representado (maior freqüência).

A freqüência das fibras e fitrotraqueídes variou conforme a espécie. Intentou-se descobrir tendências para os hábitos, mas os resultados obtidos foram similares para lianas e trepadeiras herbáceas - ambos os hábitos apresentam os dois tipos de caráter (Tabelas 12 e 13).

Abordaremos, a seguir, a análise estatística do diâmetro e comprimento das fibras e das fibrotraqueídes entre lianas e trepadeiras herbáceas.

Quanto à significância na comparação das médias do diâmetro das fibras, houve diferença, com maiores médias 
para as lianas. Já para fibrotraqueídes não houve diferenças (veja a Tabela 14). Com relação ao comprimento, as fibras e as fibrotraqueídes são maiores nas lianas (veja a Tabela 14). Procedeu-se os testes comparando a variável comprimento das fibras (fibra libriforme e fibrotraqueídes) em um mesmo caule de oito espécies (Veja a Tabela 15). Para esta análise quatro espécies mostraram tendências significativas às maiores médias para fibra, enquanto para o restante não houve diferenças (veja a Tabela 15).

Em Sciadotenia eichlerana, onde foram realizadas mensurações das fibras, fitrotraqueídes e traqueídes. A análise estatística mostrou que as fibrotraqueídes são maiores que as fibras libriformes e estas por sua vez são menores que as traqueídes (veja a Tabela 16 e o o Gráfico 9) .

Até o momento, não se obteve trabalhos que abordassem análises morfométricas comparativas do xilema entre trepadeiras herbáceas e lianas de Menispermaceae.

Carlquist (1985) verificou a presença de traqueídes em 24 famílias com hábito escalador. Esse autor afirma que em uma análise comparativa entre famílias de plantas escandentes e não escandentes, as escandentes têm tendência a ter traqueídes, enquanto as não escandentes, fibrotraqueídes ou fibras libriformes. Foram verificadas traqueídes, conforme já relatado, na erva Cissampelos ovalifolia e no arbusto Abuta grandifolia, refutando, então, a tendência apontada pelo referido autor.

Autores como Record \& Hess (1943); Fahn \& Leshem (1963) e Mectalfe \& Chalk (1983) citam para raízes a presença de fibras septadas, contendo substâncias de reserva em vários grupos de plantas. Segundo esses autores, algumas substâncias armazenadas nessas fibras, principalmente grãos de amido, podem ser utilizadas em períodos de intenso crescimento. Chondrodendron 
platiphyllum mostrou amiloplastos nas fibras e ausência nas fibrotraqueídes.

Com relação ao diâmetro de fibras em arbustos e lianas de Abuta grandifolia, não houve diferenças significativas para o diâmetro (veja a Tabela 9).

o comprimento das fibras, por sua vez, foi maior nos arbustos (veja a Tabela 9). A mesma tendência foi observada por Mennega (1992) para Menispermaceae e também para Celastraceae (Mennega, 1997).

Uma situação oposta foi encontrada por Dias-Leme (1999) para alguns gêneros de Leguminosae, ou seja, a autora detectou que o comprimento das fibras em lianas é maior que nas arbóreas dessa família.

\subsubsection{Parênquima}

\subsubsection{Parênquima axial}

As observações obtidas com relação ao parênquima axial estão de acordo com o citado por Metcalfe \& Chalk (1950): apotraqueal difuso e em linhas tangenciais finas (de duas a quatro células de largura). Observações checadas também por Carlquist (1986), muito embora esse autor cite também a presença de parênquima vasicêntrico escasso. Já Menega (1982) menciona apenas o parênquima em linhas tangenciais, sinuosas, de uma célula de largura, provavelmente, fazendo alusão ao parênquima difuso tendendo a formar linhas, citado pelos dois autores referenciados.

No presente trabalho, foram verificados os mesmos tipos de parênquima axial citados pelos autores mencionados no parágrafo anterior. No entanto, observamos tendências quanto ao hábito. As trepadeiras herbáceas e a espécie herbácea não apresentaram parênquima em linhas ou 
vasicêntrico, mas somente escasso ou ausente. Já as lianas estão de acordo com a descrição de todos os autores supracitados, especialmente com Carlquist (I.C.).

\subsubsection{Raios vasculares}

\subsection{Raios largos}

Uma das características anatômicas típicas de algumas trepadeiras é a presença de raios largos (Carlquist, 1975, 1991; Fahn et al., 1986; Lev-Yadun \& Aloni, 1995). O armazenamento e o transporte de substâncias são funções dos raios consideradas como uma das mais importantes (Ziegler, 1964; Van Bel, 1990; Lev-Yadun \& Aloni, 1995).

Neste trabalho, observamos a ocorrência de largos raios formados pelo câmbio de origem pericíclica em todas as espécies, independentemente do hábito. Nas que apresentam anéis sucessivos, os raios largos são formados pelo câmbio originado no tecido conjuntivo.

Notamos, ainda, que em algumas espécies ocorrem células envolventes, mas nunca envolvendo completamente o raio. Estas células são originadas de iniciais fusiformes. Esse evento foi registrado também por Rajput \& Rao (2003) para o arbusto Cocculus.

Carlquist (2001, pp. 225) cita uma lista de famílias que possuem raios largos. No entanto, das 88 famílias apresentadas, não consta Menispermaceae. É estranho que Carlquist (1996) tenha publicado um artigo com anatomia da madeira de Menispermaceae (e.g. Carlquist, 1996) e não tenha incorporado essa família à sua lista.

Os raios vasculares interfasciculares da liana Chondrodendron platiphyllum, de todas as trepadeiras 
herbáceas e da erva Cissampelos ovalifolia não são lignificados.

\section{6 .5 .2 .2 . Novos raios}

Além da presença de raios largos e altos, foram observaos raios unisseriados. Eles se originam através da conversão de uma inicial fusiforme em inicial radial (e.g. Carlquist, 2001). No caule e na raiz das trepadeiras herbáceas e da espécie herbácea analisadas, eles se tornam multisseriado, acompanhando o crescimento em espessura do órgão.

Shenck (1893) verificou no caule de várias trepadeiras a expansão dos raios vasculares, e agrupou-as em uma única categoria denominada "tipo Aristolochia". Nesse gênero, o câmbio interfascicular origina somente tecido parenquimático, formando raios largos (Cutter, 1980), assemelhando-se assim aos caules de Menispermaceae. E, mais tarde, surgem raios nos sistemas axiais de Aristolochia, implementando o processo de parenquimatização .

Os termos "clivagem do tecido lenhoso" (Obaton, 1960); "xilema em placas" (Carlquist, 1991; 2001) e "corpo lenhoso fendido" (Shenck, 1893) são termos usados para designar esse tipo de parenquimatização, ou seja, o surgimento de raios largos no sistema axial. Para Obaton (1960), Pfeiffer (1926) e Shenck (1893), o processo é uma categoria em variação cambial, do que discorda Carlquist (2001). Para Carlquist, a parenquimatização é apenas uma característica do hábito escalador. 


\subsection{Ruptura dos raios largos}

No presente trabalho, nota-se que as iniciais radiais podem tornar-se iniciais fusiformes. Esse evento ocorre mais freqüentemente na porção central de um raio multisseriado (Barghoorn, 1940), o que foi confirmado no material analisado nesta tese. Uma inicial radial, ou, mais comumente, várias células contíguas se alongam e assumem, gradualmente, um formato fusiforme. O grupo de células envolvido no processo tende a orientar seus eixos paralelamente, e como resultado do contínuo alongamento provoca a ruptura do raio, formando raios mais curtos.

Isso pode ocorrer tanto no raio floemático quanto no xilemático, portanto, outros elementos podem ser encontrados nos raios: traqueídes (Fahn, 1990), vasos (Carlquist, 1988), dutos de resina (Fahn, 1990), elementos de tubo crivados (Lev-Yadun \& Alone, 1995; Rajput \& Rao, 1997) e fibras (Rajput \& Rao, 2003).

A ruptura do raio pela transformação de iniciais radiais em iniciais fusiformes foi documentada neste trabalho, em etapas seqüenciais, para o xilema e o floema. No xilema, observou-se fibras e elementos de vasos, e no floema, elementos de tubo crivados e células companheiras.

Uma segunda maneira que provoca a ruptura do raio é o alongamento de iniciais fusiformes, que se localizam na margem dos raios (Barghoorn, 1940; Cheadle \& Esau, 1961; Evert, 1961; Esau, 1977; Philipson et. al., 1971).

A intrusão da célula fusiforme pode causar 0 encurtamento ou a redução de largura no raio (Philipson et. al., 1971).

Neste trabalho, observa-se que a intrusão das células envolventes nos raios xilemáticos e floemáticos é um evento bastante comum. No entanto, não se obteve etapas seqüenciais desse processo. 
Carlquist (1996) e Mennega (1982) não fazem menção à interrupção de raios vasculares para Menispermaceae. Já Rajput \& Rao (2003) citam a presença de fibras e elementos de vasos nos raios, e, apesar de os autores não abordarem a interrupção dos raios, uma imagem fornecida no trabalho (veja a Figura 2D, na página 414) parece dar indício da intrusão de células envolventes.

Além dos já supracitados: elementos de vasos, fibras e elementos de tubos crivados, observa-se em Odontocarya tamoides a presença de células esclerificadas no raio.

A presença dessas células, provavelmente, se deve ao aumento de lignificação das células radiais, não estando envolvidas conversão de células radiais em fusiformes.

\subsubsection{Parênquima não lignificado}

Nas lianas (exceto Chondrodendron platiphyllum, que possui também raios lignificados), o parênquima não lignificado está presente, na sua maioria, como tecido conjuntivo. Conforme já foi relatado, esse tecido é potencialmente meristemático e corresponde ao meristema lateral pericíclico, sendo responsável pelo surgimento dos novos câmbios.

O parênquima não lignificado radial presente nas trepadeiras herbáceas, ervas e na liana Chondrodendron platiphyllum possui grande quantidade de amiloplastos demonstrando sua função enquanto reserva.

A presença de parênquima axial não lignificado é considerada como um tipo de "anomalia" por Metcalfe \& Chalk (1950). Carlquist (2001) não considera como variação cambial, e sim como uma característica que ocorre no hábito escalador, sendo restrita a poucas famílias arbóreas (IAWA Committee, 1989). Esse tecido é mencionado para plantas 
suculentas, como Crassulaceae (Metcalfe \& Chalk, 1950), plantas que habitam regiões áridas, como Brassicaceae, Asteraceae e Cactaceae (Metcalfe \& Chalk, 1950; Soffiatti, 2003) e plantas escaladoras (Dias-Leme, 1999; Tamaio, 2001; Ozório-Filho, 2002).

Segundo Fisher \& Ewers (1991) e Carlquist (1991), O parênquima não lignificado constitui um tecido de armazenamento de água, que pode ser utilizado em períodos de estresse sofridos pela planta. O parênquima abundante, independentemente de ser lignificado (com paredes finas) ou não, axial ou radial, oferece vantagens ao hábito escalador, já que compartimentaliza o caule (Fisher \& Ewers, 1991).

Um lenho compartimentalizado oferece flexibilidade ao caule pela justaposição de tecidos rígidos e macios, sem causar injúrias aos vasos (Fisher \& Ewers, 1991; Schenk 1893, Putz \& Holbrook, 1991). Experimentos em trepadeiras sujeitas a torções mostraram que os danos estruturais ficaram confinados nas regiões não lignificadas (Putz \& Holbrook, 1991). Esses autores enfatizam que o parênquima não lignificado colabora com o reparo de injúrias em caules de lianas, pois permite a reposição do tecido injuriado.

\subsection{Cristais}

A diversidade de cristais na família Menispermaceae é muito evidente (Carlquist, 1996). Assim como esse autor, no presente trabalho detectamos, que 0 tecido radial xilemático é o local de maior ocorrência de cristais, além do parênquima axial, medula, faixa esclerenquimática, tecido conjuntivo, córtex e células do parênquima floemático. 
Os cristais podem estar presentes na maioria das células do raio, parcialmente ou mesmo ausentes. Há também uma diversidade de tamanho e de morfologia, cujo padrão segue uma tendência conforme o hábito. Observa-se que cristais prismáticos, tanto grandes quanto pequenos, ocorrem freqüentemente nas lianas. Os cristais cúbicos ocorrem tanto nas lianas quanto nas trepadeiras herbáceas e os aciculares estão mais bem representados nas trepadeiras herbáceas. O mesmo padrão ocorre nas raízes.

Carlquist (1996) não incluiu em sua análise as trepadeiras herbáceas. Mennega (1982) trabalhou com três gêneros e observou tendências similares para os dois hábitos. Ressalta-se que a autora verificou maior abundância dos cristais maiores em Anomospermae.

A ausência de Menispermaceae nas listas de famílias que possuem cristais (e.g. Carlquist, 2001) é notória. Uma família em que os cristais são tão ricamente representados, condição já relatada pelo próprio autor em trabalho anterior (e.g. Carlquist, 1996), poderia constar na referida lista.

\subsection{Tilos}

Tilos foram observados em todas as espécies, independentemente do hábito, no entanto, mais abundantes nas lianas. De acordo com Carlquist (2001), a presença de tilos não parece ter um modelo de distribuição filogenético, mas essencialmente fisiológico.

Abordando a formação de tilos, Zimmermann concluiu que eles são formados em resposta à injúrias. No entanto, a causa imediata para a sua formação não é um trauma, mas a perda de pressão de água nos vasos (Carlquist, 2001). Ainda segundo esse autor, isso 
explicaria a razão de os tilos serem caracteristicamente formadas em vasos largos e não injuriados.

Nesta tese, foram observados tilos em todas as espécies estudadas, principalmente nos elementos de vasos maiores.

$\mathrm{Na}$ maioria dos táxons com tilos, eles ocorrem apenas com parede primária (Carlquist, 2001) e ainda segundo esse autor a presença de tilos com paredes lignificadas e grossas ocorrem em poucas espécies. Nesta tese, foram observados os dois tipos de tilos.

Os tilos podem ter conteúdos: tanino em Cephalotus (Carlquist, 1981); cristais (Gottwald, 1983) e amido (Myers, 1924; Bailey, 1962; Moss, 1936). Segundo Carlquist (2001), essas situações podem simular o que acontece nas células parenquimáticas de um táxon particular.

A presença de amido é bastante rara. Bailey (1962) observou isso em Pereskia aculeata; Moss (1936) em Epilobium angustifolium (Onagraceae) e Myres (1924) em Menispermum (Menispermaceae). Essa autora descreve a situação da seguinte forma: "Some tyloses are receptacules for starch" (alguns tilos são receptáculos de amido) .

Nesta tese, constatamos a presença de amido em tilos na trepadeira herbácea Cissampelos andromorpha, portanto, é a segunda citação para Menispermaceae. Deixamos em aberto se esse fato significa uma tendência para a família, o que pode ser confirmado ou não com estudos específicos em vários gêneros para detecção do amido.

Não foi localizada nenhuma citação a respeito da função do amido dentro do tilo. No entanto, alguns autores fazem suposições para o significado fisiológico do amido existente em parênquima próximo a elementos condutores. Canny (1997), introduziu o conceito de "tensão de tecido". Esse autor propôs que a conversão do amido em açúcar pode causar um entumescimento na célula, e que, 
conseqüentemente, o tecido aplica uma pressão contra a parede das células, o que pode causar uma pressão no diâmetro do vaso, favorecendo o fluxo. No entanto, Tyree et al. (1999), após realizarem experimentos fisiológicos, acreditam que esse processo dura poucos segundos, e concluem que a pressão de tecido não pode ser a causa de um permanente aumento da pressão no xilema.

\subsection{Floema}

O cordão axial de floema secundário é composto por elementos de tubos crivados, células companheiras e parênquima axial e mais raramente raios. Os tubos crivados têm uma tendência à disposição radial em todos os hábitos, sendo mais característico nas trepadeiras herbáceas.

Mennega (1982) cita um padrão diferente do encontrado nesta tese. A autora registra que faixas tangenciais de elemento de tubo crivados se alternam com células parenquimáticas. Esse padrão não está visível nas imagens fornecidas pela autora.

Mennega (I.C.) observou, nas camadas mais externas, elementos celulares colapsados e células parenquimáticas intactas. Esse conjunto característico resulta, segundo essa autora, em uma faixa com aparência de "cap" (gorro). No presente trabalho, encontra-se o mesmo padrão para todos os gêneros trabalhados, exceto para a erva $C$. ovalifolia. Este "gorro", nesta tese é o resultado da composição de floema não condutor, floema primário e células do pericíclico parenquimático no primeiro anel formado, nos restantes é o resultado de floema não condutor e células do periciclo.

Os plastídios permanecem nos elementos de tubos crivados depois que o citoplasma e a maioria das organelas já desapareceram ou degradaram (Esau, 1969; Esau, 1977). 
Segundo a autora, essas organelas podem ter diferentes conteúdos: proteína, cristais ou amido. Este último foi observado no floema de todas as trepadeiras herbáceas estudadas, sendo que não foi verificado nas lianas. O tipo de conteúdo dos plastídios nos elementos de tubos crivados tem importância taxonômica (Esau, 1977; Behnke, 1991).

Cristais aciculares no tecido floemático foram constatados principalmente nas trepadeiras herbáceas. Essa constatação também foi feita por Carlquist (1996).

\subsection{Análise morfométrica em lenho do caule e da raiz}

o diâmetro de vasos em raízes de lianas é raramente citado em literatura (Carlquist, 1991). Fisher \& Ewers (1991) sugerem que eles podem ser tão largos quanto os do caule. Outros autores afirmam que as raízes têm vasos mais largos que os caules (e.g. Greew, 1682, apud Comstock \& Sperry, 2000; Baas, 1982; Ewers et al., 1997), e nos poucos casos testados, isso está associado com os vasos mais longos das raízes (Zimmermann \& Potter, 1982; Kolb \& Sperry, 1999).

Nesta tese realizaram-se análises comparativas do lenho do caule e raiz em 9 espécies, sendo 6 trepadeiras herbáceas, 1 liana e 2 ervas (veja as Tabelas 18 a 28).

Não se observou uma tendência consistente para todas as espécies, mas no geral, o caule apresentou os maiores diâmetros e comprimentos do que a raiz, ou se mantiveram iguais. Apenas em três variáveis a raiz apresentou as maiores médias (diâmetro de vasos médios em C. ovalifolia; diâmetro de vasos muito pequenos em D. hernandia; comprimento de vasos muito pequenos em $U$. filipendulum). Portanto esses resultados aqui obtidos não estão de acordo 
com a tendência supracitada: que os vasos são mais largos e longos nas raízes.

Além das variáveis dos elementos de vasos, processouse também análises estatísticas do diâmetro e comprimento das fibras. Com relação ao diâmetro, quatro espécies apresentam as maiores médias para o caule (veja as Tabelas $21,22,26$ e 27). Já o comprimento das fibras, cinco espécies apresentaram as maiores médias para o caule (veja as Tabelas 20, 21, 22, 25, 26. Verifica-se portanto, uma tendência de igualdade entre os órgãos ou para as maiores médias no caule, a mesma tendência verificada para os elementos de vasos.

\subsection{Identificação do lenho em objetos comercializados}

Os caules de trepadeiras proporcionam beleza à arte de marchetar. A Associação para o desenvolvimento e recuperação do excepcional (ADERE) trabalha com porções do caule de trepadeiras, denominados por eles de cipós, em objetos para fins comerciais e é a grande responsável pelos objetos encontrados comercialmente na região sudeste do Brasil. Essa instituição está, atualmente, se regularizando junto ao IBAMA para autorização de coleta de material. Em excursões aos locais de coleta da ADERE para verificar os métodos de obtenção dos caules, na Serra do Mar em São Paulo, não foi encontrado espécies de Menispermaceae. No entanto, além de coletar, a associação recebe doações de material de diversas parte do Brasil, além de comprar, eventualmente, material que é vendido no "mercado das flores" no CEASA em São Paulo.

Verificou-se vários objetos confeccionados pela Adere nos quais foram utilizados caules de Menispermaceae. Pela análise macroscópica identificou três espécies diferentes e pela análise microscópica, observou-se que uma espécie não 
possui raios lignificados assemelhando-se, portanto, a liana Chondrodendron platiphyllum.

São conhecidas três espécies para o gênero Chondrodendron: C. microphyllum, C. platiphyllum e C. tomentosum. No sudeste brasileiro ocorre apenas $C$. platiphyllum (Barneby, 1996). Como não sabemos a procedência do material e pela subamostragem com relação aos outros gêneros estudados, conclui-se que, a espécie em questão pode ser $C$. platiphyllum. No entanto, somente trabalhos futuros com as três espécies do gênero assim como maior amostragem dos outros gêneros da família poderão confirmar essa suposição. 

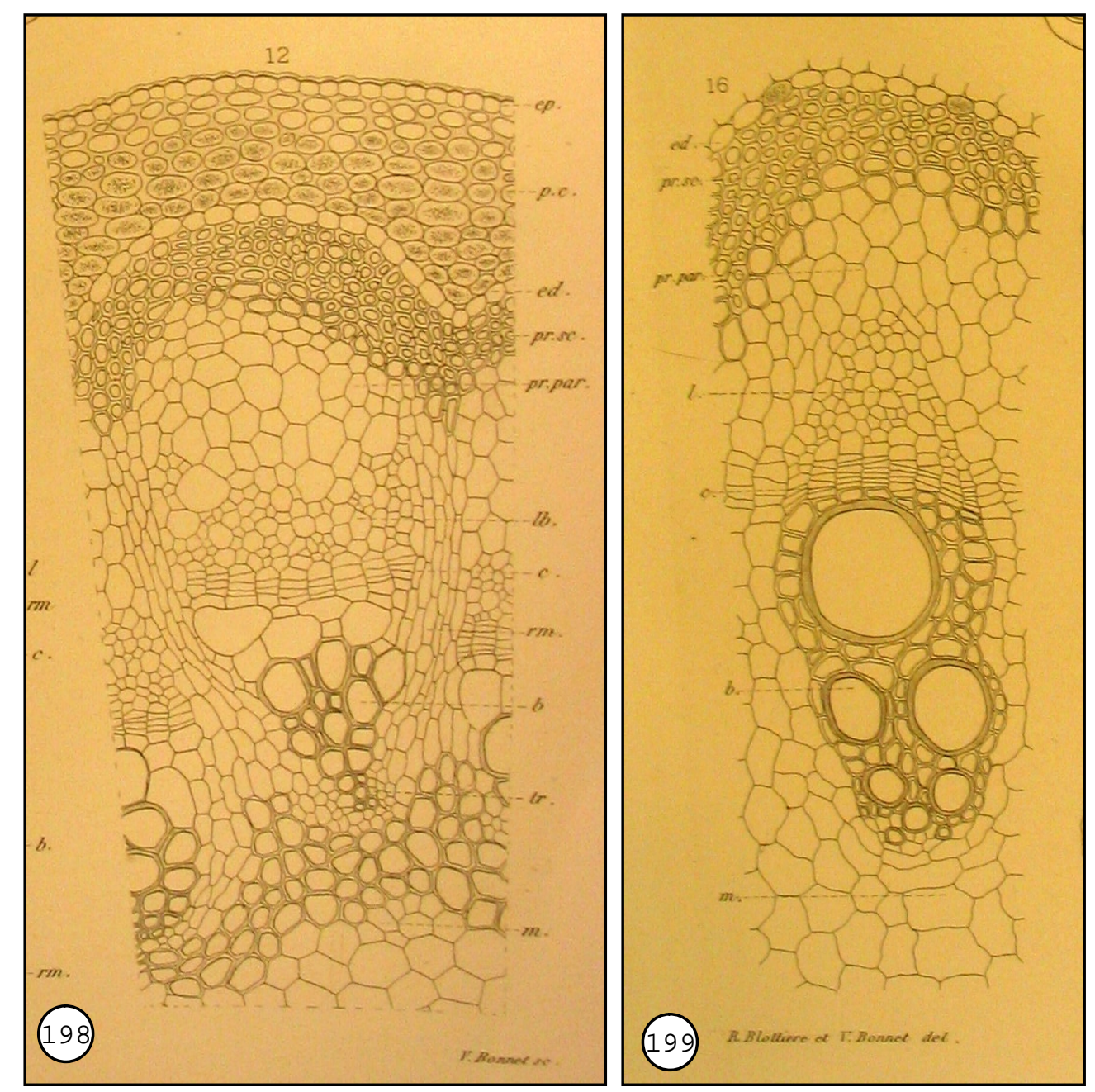

Fig. 12. - Menispermum canadense. - Portion de tige
grossie ; ép.. épiderme; p. c., parenchyme cortical; ed.,
endoderme; pr. sc., péricycle scléreux; pr.par., péricycle
parenchymateux; lb., liber ; c., cambium; $b .$, bois; $t r .$,
trachées; $m$. , moelle; $r m$., rayon médullaire.

Fig. 15-20. - Chasmanthera palmata.

Fig. 15. - Schéma de la tige.

Fig. 16. - Portion grossie du cylindre central : ed., endoderme avec laticifières; $p r$. sc., péricycle scléreux; $p r$. par., péricycle parenchymateux; $l$., liber; c., cambium; b., bois ; $m$., moelle.

Figuras 198-199. Reprodução fotográfica de desenhos esquemáticos e suas respectivas legendas contidos na obra de Blottière (1886). Observe que 0 autor reconhece a presença da endoderme e do periciclo em caules de Menispermaceae. 198. Menispermum canadense. 199. Chasmanthera palmata. 


\section{Conclusões}

Conclusão geral: (1) Há diferenças quanto ao hábito.

\section{Conclusões específicas:}

1. O periciclo forma o tecido conjuntivo, esse, por sua vez, os câmbios sucessivos nas lianas.

2. Sugere-se que o estudo anatômico do caule na família Menispermaceae seja padronizado pelo primeiro anel vascular.

3. O diâmetro do elemento de vaso em estudos com anéis sucessivos tende a aumentar no sentido centroperiferia.

4. As lianas e o arbusto Abuta grandifolia possuem variação cambial do tipo câmbios sucessivos. As trepadeiras herbáceas e a erva Cissampelos ovalifolia não possuem essa variação cambial.

5. Em caules e raízes das trepadeiras herbáceas ocorre a conversão de iniciais radiais em iniciais fusiformes formando novos cordões vasculares constituídos por floema e xilema secundários.

6. Descreve-se algumas etapas do desenvolvimento da raiz de forma inédita. Classifica-se o sistema subterrâneo de Disciphania hernandia como raiz tuberosa.

7. Demonstra-se que o tecido radial existente no primeiro anel vascular é formado pelo câmbio de origem pericíclica e que o raio medular é pouco expressivo em caules maduros. Demonstra-se que os raios existentes nos anéis sucessivos são de origem do câmbio formado pelo tecido conjuntivo. Mostra-se, pela primeira vez, a ruptura do raio na família, por elementos condutores.

8. A raiz da liana Chondrodendron platiphyllum possui a mesma variação cambial encontrada no caule, ou seja, câmbios sucessivos.

9. O xilema secundário da raiz repete o padrão anatômico do caule sob o aspecto qualitativo. Quantitativamente, há diferenças significativas entre caule e raiz, para as seguintes variáveis: diâmetro e comprimento dos vasos e comprimento das fibras (caule>raiz). 
10. Apesar da similaridade quanto à estrutura anatômica geral do xilema caulinar, existem caracteres que separam as trepadeiras herbáceas das lianas: (1) medula mais ampla nas trepadeiras herbáceas; posicionamento desnivelado dos feixes vasculares, favorecendo a presença do raio medular nas trepadeiras herbáceas; (3) conversão de iniciais fusiformes em radiais formando raios largos tanto no floema quanto no xilema; (4) elementos celulares do floema de menor calibre; (5) menor ocorrência de cristais prismáticos, principalmente os grandes; (6) conversão de iniciais radiais em fusiformes formando novos cordões vasculares de floema e xilema secundários; (7) parênquima escasso a ausente em trepadeiras herbáceas, parênquima difuso e difuso em agregados nas lianas; (8) as lianas possuem raios vasculares com células lignificadas, com exceção de Chondrodendron platiphyllum. Já as trepadeiras herbáceas possuem raios não lignificados.

11. No geral, o caule e a raiz de Cissampelos ovalifolia repete o padrão anatômico das trepadeiras herbáceas e o caule do arbusto Abuta grandifolia repete o padrão das lianas.

12. A identificação do caule de Menispermaceae em objetos comercializados somente é possível ao nível de família. 


\section{BIBLIOGRAFIA}

APPEZZATO-DA-GLÓRIA, B. 2003. Morfologia de sistemas subterrâneos: histórico e evolução do conhecimento no Brasil. A.S. Pinto. Ribeiro Preto.

ARAQUE, O.Z., N.E. De PERNÍA \& W.J.H. LEÓN. 2000. Estudio anatómico del leño de seis especies de lianas. Revista Forestal Venezuelana $44(2): 39-48$.

BAAS, P. \& F.H. SCHWEINGRUBER. 1987. Ecological trends in the wood anatomy of trees, shrubs and climbers from Europe. IAWA Bulletin 8(3): 245-274.

BAILEY, I.W. 1962. Comparative anatomy of the leaf-bearing Cactaceae. VI. The xylem of Pereskia saccharosa and Pereskia aculeate. Journal Arnold Arboretum 43: 376-393.

BAILEY, I.W. 1980. Anomalous growth and vegetative anatomy of Simmondsia chinensis. American Journal of Botany 67(2) : 147161 .

BAMBER, R.K. \& B.J.H. TER WELLE. 1994. Adaptative trends in the wood anatomy of lianas. In: IQBAL, M. (ed.). Growth patterns in Vascular Plants. Dioscorides Press, Portland, Oregon.

BARGHOORN, E.S. 1940. The ontogenetic development and phylogenetic specialization of rays in the xylem of dicotyledons. I. The primitive ray structure. American Journal of Botany 27: 918-928.

BARNEBY, B.C. \& B.A. KRUKOFF. 1971. Supplementary notes on american Menispermaceae. VIII. A generic survey of the american Triclisieae and Anomospermeae. Memoirs of the New York Botanical Garden $22(2): 1-84$. 
BARNEBY, B.C. \& KRUKOFF, B.A. 1996. Tidings of Menispermaceae from interior French Guiana and from the Brazilian state of Bahia. Brittonia $48(1): 20-25$.

BAAS, P. 1982. Systematic, phylogenetic and ecological wood anatomy - History and perspectives. Pp. 23-58 In: BAAS, P. (ed.) New perspectives in wood anatomy. The Hangue Martinus Nijhoff Publishers, Leiden.

BEHNKE, H.D. 1991. Distribution and evolution of forms and types of sieve-element plastids in the dicotyledons. ALISO 13(1): $167-182$.

BENNETT, B.C. 1995. Forest Canopies. In: LOWMAN, M. D. \& N. M. NADKARNI (eds). Ethnobotany and Economic Botany of Epiphytes, Lianas, and Other Host-Dependent Plants an Overview. Academic Press.

BERLYN, G.P. \& J.P. MIKSCHE. 1976. Botanical microtechnique and cytochemistry. Ames, The Iowa state Press.

BHAMBIE, S. 1972. Correlation between form, structure and habit in some lianas. Proceedings of the Indian Academy of Sciences 75: 246-256.

BLOTTIĖRE R. 1886. Étude anatomique de la famille des Ménispermées. Thèse, École Supérieure de Pharmacie, Paris.

BOSMAN, M.T.M. 1996. Longitudinal variation in selected wood properties of naturally and plantation grown light red meranti (Shorea leprosula and $S$. parviflora, Dipterocarpaceae). IAWA Journal 17: 5-14.

BOULANGER, J. 1995. Alguns componentes lingüísticos no ensino da terminologia. Ciência da Informação 24 (3) : 313-318.

BOUREAU, E. 1957. Anatomie végétale. L'appareil végétatif des Phanerogames. Vol. 3. Presse Universitaire de France, Paris.

CANNY, M.J. 1997. Vessel contents during transpiration, embolism and refillin. American Journal of Botany 84: 1223-1230. 
CARLQUIST, S. 1975. Ecological Strategies of Xylem Evolution. University of California Press, Berkeley, California.

CARLQUIST, S. 1977. Ecological factors in wood evolution: a floristic approach. American Journal of Botany 64: 887-896.

CARLQUIST, S. 1981. Wood anatomy of Nepenthaceae. Bulletin of the Torrey Botanical club $108(3): 321-330$.

CARIQUIST, S. 1982. Wood anatomy of Onagraceae: further species; root anatomy significance of vestured pits and allied structures in dicotyledons. Annals of Missouri Botanical Garden 69: 755-769.

CARLQUIST, S. 1999. Wood and stem anatomy of Stegnosperma (Caryophyllales); phylogenetic relationships; nature of lateral meristems and successive cambial activity. IAWA Journal $20(2): 149-164$.

CARLQUIST, S. 1985. Observations on functional wood histology of vines and lianas: vessel dimorphism, tracheids, vasicentric tracheids, narrows vessels, and parenchyma. ALISO 11(2):139157 .

CARLQUIST, S. 1988. Comparative wood anatomy. Systematic, ecological and evolutionary aspects of dicotyledon wood. Springer-Verlag, New York.

CARLQUIST, S. 1996. Wood and stem anatomy of Menispermaceae. ALISO 14 (3): 155-170.

CARLQUIST, S. 1991. Anatomy of vine and liana stems: a survey and synthesis. Pp. 53-71 In: PUTZ, F.E. \& H.A. MOONEY (eds.) The Biology of Vines. Cambridge University Press, Cambridge.

CARLQUIST, S. 2001. Comparative wood anatomy. Systematic, ecological and evolutionary aspects of dicotyledon wood. Springer-Verlag, 2nd, completely rev. ed. 
CARLQUIST, S. 2004. Lateral meristems, successive cambia and their products: a reinterpretation base on roots and stems of Nyctaginaceae. Botanical Journal of Linnean Society 146 : 129-143.

CARLQUIST, S. \& E.L. SCHNEIDER 2001. Vessels in ferns: structural, ecological, and evolutionary significance. American Journal of Botany 88: 1-13.

CHALK, L. \& M.M. CHATTAWAY. 1937. Identification of woods with included phloem. Tropical Woods 50:1-31.

CHEADLE, V.I. \& K, ESAU 1961. Loss of cambial initials in Liriodendron tulipifera. American Journal of Botany 48: 532533 .

CHANDURKAR, P.J. 1989. Plant Anatomy. Oxford \& IBH Publishing Co. Pvt. Ltd. Fourth edition.

COMSTOCK, J.P. \& J.S. SPERRY. 2000. Some theoretical considerations of optimal conduit length for water transport in plants. New Phytologist 25: 195-218.

COCHARD, H. \& M. T. TYREE. 1990. Xylem dysfunction in Quercus: vessel sizes, tyloses, cavitation and seasonal changes in embolism. Tree Physiology 6(4): 393-407.

CUTTER, E.G. 1980. Plant anatomy: experiment and interpretation. Edward Arnold (ed.) Organs 2 .

CUTLER, D.F. 1976. Variation in root wood anatomy. Leiden Botanical Series 3: 143-156.

DAVIS, D.S., S.J. SPERRY \& U.G. HACKE. 1999. The relationship between xylem conduit diameter and cavitation caused by freezing. American Journal of Botany 86: 1367-1372.

DEMASON, D.A. 1983. The primary thickening meristem: definition and function in monocotyledons. American Journal of Botany 70: 1195-1204. 
DÉTIENNE, P. \& P. JACQUET. 1983. Atlas d'identification des bois de l'amazonie et dês régions voisines. Centre Technique Forestier Tropical, Noget-sur-Marne.

DIAS-LEME, C.L. 1994. Anatomia comparada do lenho de caule, raiz e ramo de algumas espécies de Euphorbiaceae da Mata Atlântica. Dissertação de Mestrado (não publicado). Instituto de Biociências, USP, São Paulo.

DIAS-LEME, C.L. 1999. Árvores e lianas de Leguminosae Papilionoideae: anatomia do caule. Tese de Doutorado (não publicado). Instituto de Biociências, USP, São Paulo.

EAMES, A.J. \& L.H. MACDANIELS. 1947. An introduction to plant anatomy. McGraw-Hill Book Company. New York. 2 ed.

ELLERBY, D.J. \& A.R. ENNOS. 1998. Resistances to fluid flow or model xylem vessels with simple and scalariform perforation plates. Journal of Experimental Botany 49: 979-985.

ENGEL, V.L., R.C.B. FONSECA \& R. E. OLIVEIRA. 1998. Ecologia de lianas e o manejo de fragmentos florestais. Série Técnica IPEF $12(32): 43-64$.

ESEMANN-QUADROS, K. 2001. Anatomia do lenho de Clusia criuva Camb. (Clusiaceae): órgãos, hábitos e mabientes. Tese de Doutorado (não publicado), Instituto de Biociências, USP, São Paulo.

ESAU, K. 1965. Vascular differentiation in plants. New York, Holt, Rinehart and Winston, 160.

ESAU, K. 1969. The phloem. Encyclopaedia of Plant Anatomy. Gebrüder Borntraeger. Berlim.

ESAU, K. 1977. Anatomy of seed plants. 2a. ed., John Wiley \& Sons. New York. 
EVERT, R.F. 1961. The cambium and seasonal development on the phloem in Pyrus Malus. American Journal of Botany 50 (2): 149-159.

EWERS, F.W. 1985. Xylem structure and water conduction in conifer trees, dicot trees, and lianas. IAWA Bulletin 6(4): $309-317$.

EWERS, F.W., J.B. FISHER \& S.T. CHIU. 1990. A survey of vessel dimensions in stem of tropical lianas and other growth forms. Oecologia 84: 544-552.

EWERS, F.W., J.B. CARLTON, J.B. FISHER, K.J. KOLB \& M.T. TYREE. 1997. Vessel diameters in roots versus stems of tropical lianas and other growth forms. IAWA Journal 18(3): 261-279.

EWERS, F.W. \& J.B. FISHER. 1989. Variation in vessel length and diameter in stems of six tropical and subtropical lianas. American Journal of Botany $76(10): 1452-1459$.

EWERS, F.W. \& J.B. FISHER. 1991. Why vines have narrow stems: histological trends in Bauhinia (Fabaceae). Oecologia 88: $233-237$.

FAHN, A. \& B. LESHEM. 1963. Wood fibres with living protoplasts. New Phytology 62: 91-98.

FAHN, A. \& M.H. ZIMMERMANN. 1982. Development of the successive cambia in Atriplex halimus (Chenopodiaceae). Botanical Gazette 143: 353-357.

FAHN, A. 1990. Plant Anatomy. 4a. ed. Oxford, Pergamon.

FAHN, A., E. WERKER. \& P. BAAS. 1986. Wood anatomy and identification of trees and shrubs from Israel and adjacent regions. Israel Academy of Sciences and Humanities, Jerusalem.

FISHER, J.B. \& F.W. EWERS. 1991. Structural responses to stem injury in vines. In: PUTZ, F.E. \& H.A. MOONEY (eds.) The Biology of vines. Cambridge. University Press. 
FISHER, J.B. \& F.W. EWERS. 1995. Vessel dimension in liana and tree species of Gnetum (Gnetales). American Journal of Botany $82(11): 1350-1357$.

GABRIEL, B.L. 1982. Biological electron microscopy. Nostrand Reinhold Company, New York.

GASSON, P. \& D.R. DOBBINS. 1991. Wood anatomy of the Bignoniaceae, with a comparison of trees and lianas. IAWA Bulletin $12(4): 389-417$.

GOTTWALD, H. 1983. Wood anatomical studies of Boraginaceae (s.1.) I. Cordioideae. IAWA Bull NS 4:161-178.

GENTRY, A.H. 1991. The distribution and evolution of climbing plants. In: PUTZ, F.E., S. BULLOCK \& H.A. MORREY (eds). The Biology of vines. Cambridge University Press.

GERRITS, P.O. \& L. SMID 1983. A new, less toxic polymerization system for the embebdding of soft tissues in glycol methacrylate and subsequent preparing of serial sections. Journal of Microscopy 132: 81-85.

GIROUD, B. 1977. Statistical analysis of wood structure variation as related to distance from the pith in Entandrophragma utile (Meliaceae). IAWA Bulletin 4: 71-75.

HABER, W.A. 2000. Plants and vegetation. In: Monteverde ecology and conservation of a tropical rain forest. Biotropica 19: $149-156$.

HACKE U.G. \& J.S. SPERRY. 2001. Functional and ecological xylem anatomy. Perspectives in Plant Ecology, Evolution and Systematics: $4(2): 97-115$.

HAYWARD, H.E. 1953. Estructura de las plantas utiles. Buenos Aires: Editorial ACME. 
HORAK, K.E. 1981. Anomalous secondary thickening in stegnosperma (Phytolaccaceae). Bulletin of the Torrey Botanical Club 108: 189-197.

IAWA Committee. 1989. IAWA List of microscopic features for hardwood identification. IAWA Bulletin 10: 219-332.

IQBAL, M. 1994. Growth patterns in vascular plants. Dioscorides Press. Portland, Oregon.

JOHANSEN, D. 1940. Plant microtechinic. McGrow Hill book company, Inc. New York.

JOSHI, A.C. 1937. Some salient points in the evolution of the secondary vascular cylinder of Amarantaceae and Chenopodiaceae. American Journal of Botany 24, 3-9.

KRAMER, T. \& T. KOZLOWSKI. 1979. Physiology of woody plants. New York, Academic Press.

KESSLER, P.J.A. 1993. Menispermaceae. In: KUBITZKI, K., J. G. ROHWER \& V. BITTRIH (eds). The families and genera of vascular plants - Dicotyledons 2. Springer-Verlag. Berlin, Germany.

KOLB, K.L. \& J.S. SPERRY. 1999. Transport constraints on water use by the Great Basin shrub, Artemisia tridentate. Plant, Cell and Environment 25: 925-935.

KONRAD, W. \& A. ROTH-NEBELSICK. 2005. The significance of pit shape for hydraulic isolation of embolized conduits of vascular plants during novel refilling. Journal of Biological Physics $31(1): 57-71$.

KRAUS, J.E. \& M. ARDUIN, 1997. Manual básico de métodos em morfologia vegetal. Ed. EDUR, RJ. Brasil.

KRUKOFF, B.A. \& R.C. BARNEBY. 1970. Supplementary notes on American Menispermaceae. VI. Memoirs of the New York Botanical Garden 20 (2) : 1-70. 
KUNDU, B.C. \& S. GUHA 1975. Tiliacora acuminata (Lam.) Miers. Bulletin Botanic Survey of India 17 (1-4): 147-156.

LEV-YADUN, S. \& R. ALONI. 1995. Differentiation of the Ray System in Woody Plants. The Botanical Review 61 (1): 45-84.

MELLO-FILHO, L.E. 1945. O gênero Chondodendron no Brasil suloriental. Bol. Inst. Vital Brasil 5(3): 133-140.

MENNEGA, A.M.W. 1982. Stem structure of the new world Menispermaceae. Journal of the Arnold Arboretum 63: 145-171.

MENNEGA, A.M.W. 1997. Wood anatomy of the Hippocrateoideae (Celastraceae). IAWA Bulletin 18(4): 331-368.

MENEZES, N.L., D.C. SILVA, R.C.O. ARRUDA, G.F. MELO-DE-PINNA, V.A. CARDOSO, N.M. CASTRO, V.L. SCATENA \& E. SCREMIN-DIAS. 2005. Meristematic activity of the endodermis and the pericycle in the primary thickening in monocotyledons. Considerations on the "PTM". Anais da Academia Brasileira de Ciências $77(2): 259-274$.

METCALFE, C.R. \& L. CHALK. 1950. Anatomy of the dicotyledons; leaves, stem and wood in relation to taxonomy with notes one economic uses. Oxford, Clarendon, v.1.

METCALFE, C.R. \& L. CHALK. 1983. Anatomy of the dicotiledons. Oxford, Claredon Press. V.2.

MIKESELL, J.E. 1979. Anomalous secondary thickening in Phitolacca americana L. (Phytoloccaceae). American Journal of Botany 66 (9): 997-1005.

MIKESELL, J.E. \& C.H. POPHAM. 1976. Ontogeny and correlative relationship of the primary thickening meristem in fouro'clock plants (Nyctaginaceae) maintained under long and short photoperiods. American Journal of Botany 63: 427-437.

MILFORD, G.F.J. 1973. The growth and development of the storage root of sugar beet. Annals Applied Biology 75: 427-238. 
MORELLATO, L.P.C. \& H.F. LEITÃO-FILHO. 1998. Levantamento florístico da comunidade de trepadeiras de uma floresta semidecídua no Sudeste do Brasil. Boletim do Museu Nacional, nova série, Botânica 103: 180-191.

MORRISON, T.M. 1954. Comparative histology of secondary xylem in buried and exposed roots of dicotyledonous trees. Phytomorphology 3: 427-430.

MOSS, Z.H. 1936. The ecology of Epilobium augustifolium with particular reference to rings of periderm in the wood. American Journal of Botany 23: 14-20.

MULLINS, M.G., A. BOUQUET \& L.E. WILLIANS. 1992. Developmental physiology: flowering and fruiting. Pp. 112-146. In: MULLINS, M.G. (ed). Biology of the grapevine. Cambrige: University Press.

MYERS, L. 1924. Tyloses in Menispermum. Botanical Gazette 73(4): $453-457$.

NAIR, M.N.B. \& H.Y.M. RAM. 1990. Structure of wood and cambial variant in the stem of Dalbergia paniculata Roxb. IAWA Bulletin 11: $379-391$.

NUNES, O.M. \& N. TAMAIO. Anatomia do caule e raiz de Rhynchosia phaseoloides (SW.) DC Leguminosae. In: Anais do 56을 Congresso Nacional de Botânica.

O'BRIEN, T.P. \& M.E. MCCULLY. 1981. The study of plant structure. Principles an selected methods. Termarcarphi Pty Ltd., Melbourne.

OBATON, M. 1960. Les lianes ligneuses à structure anomale des forêts denses d'Afrique Ocidentale. Annales des Sciences Naturelles Botanic (new series), $12(1): 1-220$.

ORTIZ-GENTRY, R. Del C. 2000. Systematic revision of Curarea Barneby \& Krukoff (Menisperpaceae). Dissertation (não publicado). University of Missouri, Saint Louis. 
OTT, C. 1997. Menispermaceae. Flora of Ecuador 58: 1-81

OZÓRIO-FILHO, H.L. 2002. Variação cambial em Bignoniaceae: padrão anatômico e desenvolvimento do caule. Dissertação de Mestrado (não publicado). Universidade de São Paulo, USP, São Paulo.

PFEIFFER, H. 1926. Das aborne dickenwachstum-handbuch der pflanzenanatomie. Band IX. Verlag von Gebrüder Borntraaeger. Berlin.

PHILIPSON, W.R., J.M. WARD \& B.G. BUTTERFIELD. 1971. The vascular cambium: its development and activity. London: Chapman and Hall.

PHILIPSON, W.R. 1980. Anomalous Cambia. In: IQBAL, M. The Vascular Cambium.

PUTZ, E.F. 1980. Lianas vs trees. Biotropica 12: 224-225.

PUTZ, E.F. \& D.M. WINDSOR 1987. Liana phenology on Barro Colorado Island, Panama. Biotropica 19(4) : 334-341.

PUTZ, E.F. \& N.M. HOLBROOK. 1991. Biomechanical studies of vines. In: Biology of Vines. Cambridge University Press, Cambridge.

RAJPUT, K.S. 2002. Stem anatomy of Amaranthaceae: Rayless nature of xylem. Flora 197: 224-232.

RAJPUT, K.S. \& K.S. RAO. 1997. Occurrence of isolated sieve elements in phloem rays. IAWA Journal 18: 197-201.

RAJPUT, K.S. \& K.S. RAO. 2003. Cambial variant and xylem structure in the stem of Cocculus hirsutus (Menispermaceae). IAWA Journal 24 (4): 411-420.

RAPOPORT, H.F. \& R.S. LOOMIS. 1986. Structural aspects of root thickening in Beta vulgaris L.: Comparative thickening in sugarbeet and chard. Botanical Gazette 147(3): 270-277. 
RECORD, S.J. \& R.W. HESS. 1943. Timbers of New World. Yale University Press, New Haven.

RICHARDS, P.W. 1952. The tropical rain forest, an ecological study. Cambridge University.

ROTH, I. 1981. Structural patterns of tropical barks. Gebrüder Borntraeger. Berlin. Stuttgart.

RUDALL, P. 1991. Lateral meristem and stem thickening growth in monocotyledons. Botanical Review 57: 150-163.

SASS, J.E. 1951. Botanical microtechique, 2. ed. Iowa Press Building, Iowa.

SCHENK, H. 1893. Beitrage zur Biologie Anatomie und Anatomie der Lianen im Besonderon der in Brasilien einheimischen Arten 2. Belträge zur Anatomie der Lianen. Botanische Mittheilungen aus den Tropen 5, ed. A. F. W. Schimper.

SCHWEINGRUBER, F.H. \& H. DIETZ. 2001. Annual rings in the xylem of dwarf shrubs and perennial dicotyledonous herbs. Dendrochronologia 19: 115-126.

SCHWEINGRUBER, F.H. \& P. POSCHLOD. 2005. Growth Rings in herbs and shrubs: life span, age determinatior anatomy. Forest

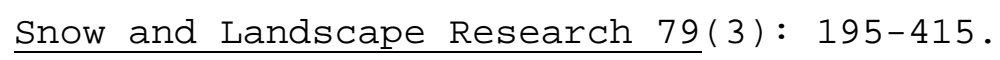

SILVA, C.A. 1992. Variação dimensional dos elementos xilemáticos em duas espécies madeireiras da Amazônia. Acta Amazônica 22: $261-274$.

SOFFIATTI, P. 2003. Estudos anatômicos e filogenéticos na tribo Cereeae, Cactaceae. Tese de Doutorado (não publicado), USP, São Paulo.

SOLEREDER, H. 1908. Systematic anatomy of the Dicotyledons. Vo. 1 e 2, Oxford, Clarendon Press. 
SPERRY, J.S. 1995. Limitations on stem water transport and their consequences. Pp. 105-124. In: GARTNER, B.L. (ed.), Plant sterns. Academic Press, Corvallis, Oregon, U.S.A.

SPERRY, J.S. \& J.E.M. SULLIVAN. 1992. Xylem embolism in response to freeze-thaw cycles and water stress in ring-porous, diffuse-porous, and conifer species. Plant Physiology 100: $605-613$.

SPERRY, J.S. \& M.T. TYREE. 1988. Mechanism of water stressinduced xylem embolism. Plant Physiology 88: 581-587.

STATSOFT, Inc. 1995. Statistica for Windowns version 5.1. Tulsa. STEVENSON, D.W. \& R.A. POPHAM. 1973. Ontogeny of the primary thickening meristem in seedlings of Bougainvillea spectabilis. American Journal of Botany 60: 1-9.

SCHULTLE, P.J., A.C. GIBSON \& P.S. NOBEL. 1989. Water flow in vessels with simple or compound perforation plates. Annals of Botany $64(2): 171-178$.

TAMAIO, N. 2001. Serjania caracasana (Jacq.) Willd. (Sapindaceae): um estudo anatômico do caule e da raiz. Dissertação de Mestrado (não publicado). Instituto de Biociências, USP, São Paulo.

TER WELLE, B.J.H. 1985. Differences in wood anatomy of lianas and trees. IAWA Bulletin 6: 70 .

THORNE, R.T. 1992. Classification and geography of the flowering plants. Botanical Review 58: 225-348.

TYREE, M.T., S. SALLEO, A. NARDINI, M.A. LO GULLO \& R. MOSCA. 1999. Refilling of embolized vessels in young stems of laurel. Do we need a new paradigm?. Plant Physiology 25: 597-599.

UDULUTSCH, R.G., M.A. ASSIS \& D.G. PICCHI. 2004. Florística de trepadeiras numa floresta estacional semidecídua, Rio Claro 
- Araras, Estado de São Paulo, Brasil. Revista Brasileira de Botânica $27(1)$ : 125-134.

URBINATI, C.V., A.A. AZEVEDO, E.A.M. da Silva \& P.L.B. LISBOA. 2003. Variação estrutural quantitativa no lenho de Terminalia ivorensis A. Chev, Combretaceae. Acta Botanica Brasilica $17(3): 421-437$.

VAN BEL, A.J.E. 1990. Medullary bundles in relation to the primary vascular system in Chenopodiaceae and Amaranthaceae. Botanical Gazette 78: 175-199.

WATSON, L. \& M.J. DALLWITZ. 1992. The families of flowering plants: Descriptions, Illustrations, Identification and Information Retrieval. Version: 14 December 2000. Disponível em http://biodiversity.uno.edu/delta/angio/www/menisper.htm Acesso em Dezembro/2004.

WET, H. de, P.M. TILNEY \& B.E. van WYK. 2002. Vegetative morphology and anatomy of Cissampelos in South Africa. South African Journal of Botany 68:181-190.

WHEAT, D. 1977. Successive cambia in the stem of Phytolacca dioica. American Journal of Botany 64 (10): 1209-1217.

WHEELER, E.A., P. BAAS \& P.E. GASSON (eds). 1989. IAWA list of microscopic features for hardwood identification. IAWA Bulletin 10: 219-332.

YARROW, G.L. \& R.A. POPHAM. 1981. The ontogeny of the primary thickening meristem of Atriplex hortensis L. (Chenopodiaceae) - American Journal of Botany 68(8): 10421049 .

ZOBEL, B. \& J. TALBERT. 1984. Applied forest tree improvement. John Wiley \& Sons, New York.

ZIEGLER, H. 1964. Storage, mobilization and distribution of reserve material in trees. Pp. 303-320. In: ZIMMERMANN, M.H. (ed.) The formation of wood in forest trees. Academic Press, New York.. 
ZIMMERMANN, M.H. 1983. Xylem structure and ascent sap. SpringerVerlag, New York.

ZIMMERMANN, M.H. \& A.A. JEJE. 1981. Vessel length distribution of some American woody plants. Canadian Journal of Botany 59: $1882-1892$.

ZIMMERMANN, M.H. \& D. POTTER. 1982. Vessel-length distribution in branches, stem, and roots of Acer rubrum. IAWA Bulletin 3: $103-109$. 